Standardization Activities OF

NATIONAT, TECHNICAL AND

MRADE OROANIZATIONS 


\section{NATIONAL BUREAU OF STANDARDS DiVISIU, 9 SECTION 4}


9,4

DATE DUE

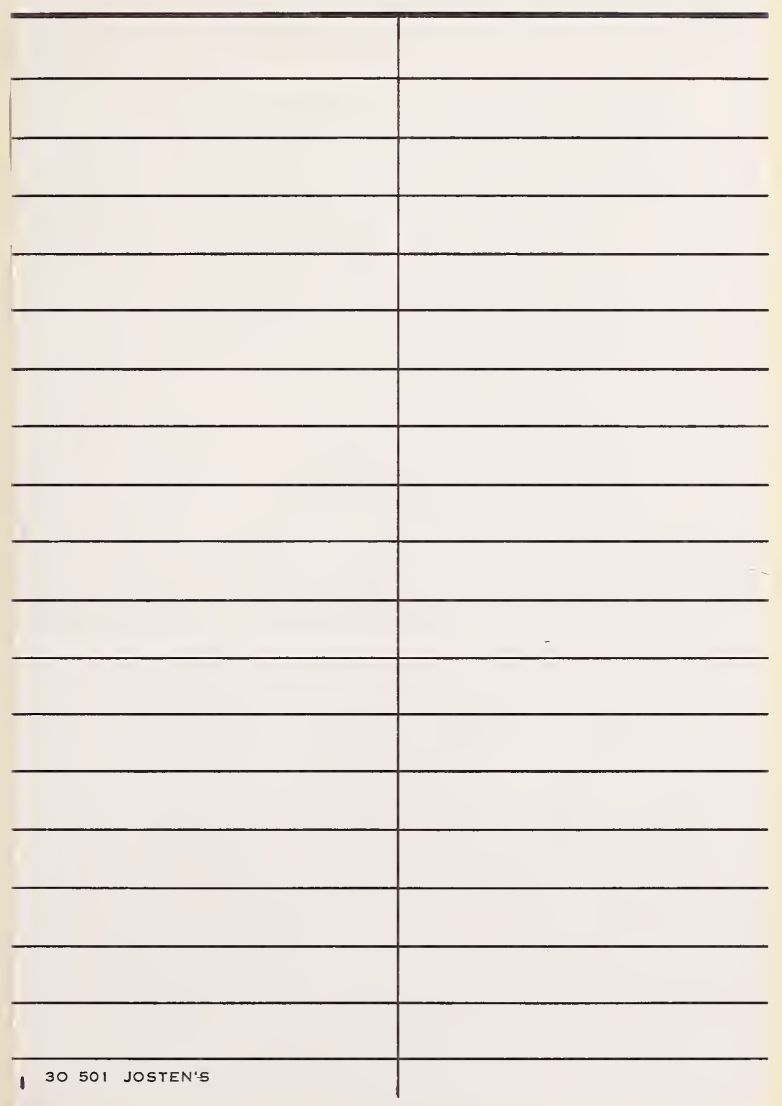


National Bureau of Standards Library

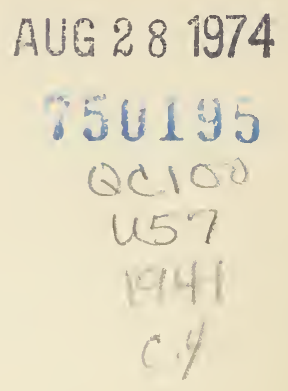


U. S. DEPARTMENT OF COMMERCE

JESSE H. JONES, Secretary

NATIONAL BUREAU OF STANDARDS

LYMAN J. BRIGGS, Director

U.S. NATIONAL BUREAU OF STANDARDS MISCELLANEOUS PUBLICATION M169

\title{
STANDARDIZATION ACTIVITIES OF NATIONAL TECHNICAL AND TRADE ORGANIZATIONS
}

\author{
by \\ ROBERT A. MARTINO
}

Issued November 28, 1941

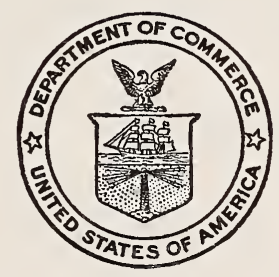

UNITED STATES

GOVERNMENT PRINTING OFFICE

WASHINGTON : 1941

For sale by the Superintendent of Documents, Washington, D. C. - Price 75 cents (Buckram) 


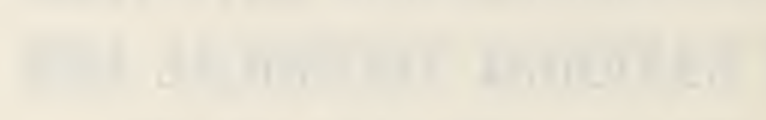

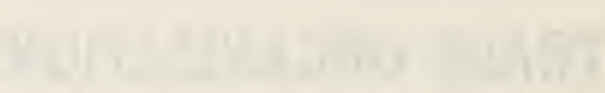




\section{PREFACE}

This volume represents an effort to present an adequate picture of the standardization and simplification movement being carried on by national technical and trade organizations in the United States. It contains outlines of the activities and accomplishments of 450 American societies and associations in which standardization is a major or an important activity. Special attention has been given to the cooperation of these organizations with the leading technical bodies whose principal activities are in the field of standardization or work directly related thereto.

It is believed that this volume will be helpful to officers and agencies concerned with standardization. It will provide the answers to many urgent inquiries now being received by the National Bureau of Standards from manufacturers, industrial experts, engineers, and purchasing agents. It is hoped that the information contained will be helpful also to agencies who are engaged in carrying forward the program for national defense.

Lyman J. Briggs, Director. 


\section{CONTENTS}

Preface

I. Introduction

II. General standardizing agencies

American Standards Association _._.

American Society for Testing Materials

Central Committee on Lumber Standards

National Aircraft Standards Committee

III. Standardization activities of technical societies and trade associations_- 13

IV. Services of the National Bureau of Standards and the Procurement

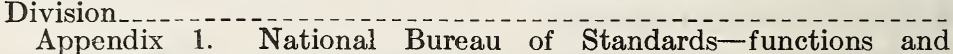
Appendix 1. 1 - Nativities activities $2 . \quad$ Procurement Division, United States Treasury Department-preparation of Federal and Procurement Division specifications

V. Bibliography on standardization

Index 


\title{
STANDARDIZATION ACTIVITIES OF NATIONAL TECH- NICAL AND TRADE ORGANIZATIONS
}

\author{
by Robert A. Martino
}

\section{INTRODUCTION}

The past quarter century has seen among other things the significant rise of standardization and simplification as methods of human progress. Out of these activities have come the framework and basis for mass production of the things we need and use. Standardization is the modern way of making permanent each advance that we make in our civilization.

Standardization embraces many subjects. Its ramifications are extended to include standardization of basic tools of thought and expression, that is, words or terms, abbreviations, symbols, definitions, and the interpretations and conditions governing their use. It includes standardization or simplification of dimensions, size, form, and the magnitude of pertinent characteristics. It includes also standardization of correlated dimensional interrelations such as preferred numbers, staple series of sizes or grades, allowances and tolerances, and other factors which constitute standard practice or process.

The coordination of the machine process calls for standard size, design, and material, and sets time, place, and quantities to be delivcred. These insure the smooth functioning and economy of production and distribution.

Modern standardization provides that after a standard has been established it shall be revised to keep pace with progress in science and industry, and in the user's ideals of satisfying service. Thus there is minimized the lag in experimenting with new discoveries-a real problem of human progress.

Following the experiences of the last World War, the need for simplification and standardization as means for avoiding waste in production and distribution of commodities was clearly recognized. In the early twenties, technical societies and trade associations representing various branches of industry made standardization one of the important activities in their services to their members. This work has been an essential factor in the development of mass production as now employed in many of the principal industries in this country.

A publication* issued by the Bureau of Foreign and Domestic Commerce, U. S. Department of Commerce, shows that there are approximately 3,000 national and interstate organizations represent-

*Trade and Professional Associations of the United States (1941 edition) by C. J. Judkins, chief, Trade Association Section, Bureau of Foreign and Domestic Commerce. 
ing various industries in this country. Of these 450 national technical societies and trade associations carry on standardization and simplification activities in one form or another.

The work of these organizations in the field of simplification and standardization is usually performed by technical committees appointed for the purpose. A particular industry desirous of standardizing a product or a line of products refers the matter to its representative organization (if one is in existence) for consideration. Assuming the project to be one which can easily lend itself to standardization or simplification and is productive of results beneficial to the industry as a whole, a technical committee is appointed to study the various phases of the problems involved. This committee proceeds to formulate the standard or specification, either on its own responsibility, or in cooperation with similar committees of other organizations which may have an interest in the proposed standard or specification. The standard, when finally approved, becomes the official document of the organization issuing it.

The principles of simplification and standardization are not limited to industry only but extend to government as well. The Federal Government is interested in simplification and standardization in several ways. Being perhaps the largest single purchaser of commodities in this country, it is interested in developing a wide range of specifications for materials, equipment, and supplies. Through its great service and research bureaus, whose functions are to serve industry and commerce, it is also interested in many questions relating to simplification and standardization of manufactured products. It cooperates with technical societies and trade organizations through representation on their technical committees in furthering the movement in simplification and standardization, and at the same time utilizes for its own purposes the benefits accruing from these activities.

From the knowledge and experience gained over a period of years technical and trade organizations can serve a useful function during the period of national emergency. By cooperative effort with national defense agencies, these organizations can do much to aid in the work of national defense, especially in matters relating to simplification, standardization, and conservation of strategic, critical, and other industrial materials necessary for defense purposes. 


\section{GENERAL STANDARDIZING AGENCIES}

Among the many technical societies and trade associations in the United States which conduct standardization and simplification work along with their other activities, there are four organizations which make standardization or work closely related thereto, the major feature of their activities, namely, the American Standards Association, the American Society for 'Testing Materials, the Central Committee on Lumber Standards, and the National Aircraft Standards Committee (which deals with matters relating to airframes). These four agencies are actively engaged in the formulation of standards, specifications, codes, and methods of test, and they cooperate with many technical and trade organizations and governmental bodies.

Outlines of the standardization activities of these organizations are given in the present section.

\section{AMERICAN STANDARDS ASSOCIATION}

The American Standards Association (ASA) is a federation of national organizations-trade associations, technical societies, and branches of the Federal Government. Organized in 1918, as a result of the country's experience during the World War with the need for industrial standards and a uniform gaging practice, it has for the past 20 years provided the machinery through which industrial, technical, consumer, and governmental groups work together to develop mutually satisfactory national standards. It serves as the national clearing house for standards. It also acts as the channel for international cooperation in standardization work.

More than 400 American standards developed and approved to date in the building, mining, traffic, mechanical, electrical, and other fields are widely used throughout industry and by municipal, State, and Federal governments.

Through the cooperation of manufacturer and user groups American standards have been developed for taps, milling cutters, forming tools, and the machine tool elements most essential to production. Other standards provide for interchangeability of supplies, or secure the interworking of parts. They cover the purchase of materials-metals, chemicals, cement, or designate tests for the finished product-insulated wire, fire hose, motors, switchgear. There are American standards for drawing and drafting room practice, for graphical symbols, and for abbreviations. The work has recently been extended to the field of specifications for consumer goods sold in retail trade.

Some 50 safety codes form the backbone of State and Federal industrial regulations. Fully 90 percent of the gas appliances now manufactured and sold meet American standards. Every piece of safety glass in many of the new cars is etched to show compliance with American standard specifications. These standards make pos- 
sible uniform requirements in safety devices for machines and other equipment in the fields of both public and industrial safety. They are becoming increasingly important factors in such fields as industrial health, in building, and in traffic safety work.

More than 600 organizations are taking part in this work through 2,987 accredited representatives serving on technical committees.

Administration.-The administration of ASA affairs is vested in a board of directors of nationally known industrial executives. The final approval of standards rests with the Standards Council, which is made up of representatives of all member bodies, all of which are organizations or groups of organizations having an important interest in standardization. The council, therefore, acts as a court of review in which the work of technical committees is either accepted or rejected with reasons. The approval of a standard by the ASA means that everyone concerned has had an opportunity to participate in the work, that the work has been carried out under a procedure that has been regular, and that the standard represents a real national agreement on what is best in American engineering and industrial practice at the time of approval.

The association's offices are at 29 West Thirty-ninth Street, New York, N. Y. P. G. Agnew is the secretary, and a technical staff, including engineers who have had practical experience, assists in carrying on the work. The actual setting up of standards is dons by technical committees representing the producing, distributing, and consuming groups concerned with the projects. It is a basic requirement of ASA procedure that no standards shall be approved unless all important interests have been represented in developing them, thus avoiding the domination of any one interest except when the consent of other groups has been granted.

Procedure.-A national standard implies a concensus of those substantially concerned with its scope and provisions. An important function of the American Standards Association is the judicial one of determining whether a national consensus has been reached. To provide flexibility in meeting the variety of conditions which obtain in standardization work, several methods are provided. The basic test to be applied in all cases is the fact of the assent, affirmatively expressed, of the groups having substantial concern with the standard.

Standards and revision of standards may come before the American Standards Association for approval by any method that provides compliance with the requirements stated above. The following methods are recognized: Sectional committee; existing standards; general acceptance; and proprietary.

The sectional committee method consists in the formation, at the beginning of a project, of a committee to develop one or more standards under an assigned scope. The committee is composed of representatives accredited for the purpose by the various organized groups concerned with the project, and in addition, specially qualified individuals as members-at-large when desirable. Membership in a sectional committee may also be in the name of the organization as such, no individual being designated as representative or alternate. The special utility of the sectional committee method consists in the provision, in advance, of such representation that a consensus will be assured and self-evident when the members have approved their completed assignment. 
The existing standards method provides that a standard of another organization may be submitted for approval by any responsible body, and may be approved by the ASA without having gone through any of the other recognized channels for developing standards, provided it is shown that the proposed standard is supported by the necessary concensus of those substantially concerned with its scope and provisions.

The general acceptance method is recognized as a suitable method for producing national standards by the sole means of a conference of those substantially concerned, supplemented by a sufficiently large number of written acceptances of the conference recommendation from those substantially concerned with the scope and provisions of the recommendation. It is intended for simple projects and for cases in which the organization of a sectional committee is judged by the Association to be unnecessary.

After a standard has been approved by the American Standards Association, any responsible body having a position of preeminent importance in the field of the standard may be designated for the development of revisions of the standard within its own organization, such revisions to be submitted to the ASA for approval. This method of operation is termed the proprietary method, and is applicable only for the revision of standards. The body undertaking the responsibility for such revisions is termed a proprietary sponsor.

International cooperation.-The American Standards Association is a member of the International Standards Association at Basle, Switzerland, through which the national standardizing bodies of the world carry on their general cooperative activities. Through these and other means the ASA makes available to American industry direct and authoritative contact with standardization developments in other lands.

Publications.-The association maintains an information service and a reference library where an up-to-date file of foreign standards and specifications is kept, as well as many pamphlets and books on standardization matters. The library's collection of material, both foreign and domestic, is the only one of its kind in the United States, and consequently the association is able to provide certain types of technical information not to be found elsewhere.

A complete list of American standards may be obtained free of charge by writing to the office of the American Standards Association.

The association also publishes a Yearbook, Industrial Standardization and Commercial Standards Monthly (a monthly magazine), and other material on standardization. The magazine carries information about standardization activities in this country and abroad and the practical use of standards in industry. This magazine is published primarly for members but may also be obtained on a subscription basis by engineers without company affiliation.

\section{AMERICAN SOCIETY FOR TESTING MATERIALS}

The American Society for Testing Materials, a national technical society of over 4,400 members, was formally incorporated in 1902 for the purpose of "the promotion of knowledge of the materials of engineering and the standardization of specifications and the methods of testing." From 1898 there had been an American Section of the International Association for Testing Materials, but it was soon realized 
that an independent American organization was desirable, particularly to effect needed standardization work.

The society's work, then, concerns specifically standardization and research in materials. It is, and has been for 40 years, specifically interested in the quality and tests of materials and only indirectly does it become involved in design problems, dimensional standards, and related matters.

As of January 1941, 952 standard specifications, methods of tests, and definitions were in effect and more than 115 formal research projects were under way involving the work of hundreds of the country's leading technical engineers and scientists. All of this work is of tremendous import to American industry, municipal, State, and the Federal governments, and other bodies and nations.

Membership.-Of the 4,420 regular members of the society, about 1,200 are corporate memberships and the balance are individual members or Federal, State, and municipal departments, universities and technical schools, or technical societies and libraries. Not included in this field are upward of 400 student members at leading technical schools. Some 140 companies support the society through sustaining memberships by contributing dues which are higher than for the regular type of company membership.

In addition to members of the society, there are 1,200 other individuals who are active in the society's committee work, representing various companies which are members of the society. Thus, all told, there are about 6,000 members, committee members and students. The society's headquarters are at 260 South Broad Street, Philadelphia, Pa.; C. L. Warwick is secretary-treasurer.

Purpose and work.-In both phases of the work, standardization and research, the ASTM standing technical committees occupy a most important position. It has been rightly said that these committees are the heart of ASTM. An understanding of their organization and how they function in relation to the parent society is essential.

At the outset it should be stated that the work is of a cooperative nature, and all members of the committees serve voluntarily. The committees function under definite regulations, governing the personnel and methods of procedure. Each committee is made up of three main classes of membership-producers, consumers, and general interests. This latter class comprises independent authorities who have expert knowledge of the materials to be studied, but who are not concerned directly with either their production or use. The "producer" group may not predominate in any committee. It is recognized that no specification covering the quality and methods of testing a material or product will come into wide usage unless it is satisfactory to both the consumer and producer. The ASTM set-up is thus fundamental in its standardization procedure, whereby the producers and consumers of material are brought together on an equal footing.

Standardization procedure.-Proposed standards or revisions of existing standards originate in the committee having jurisdiction in that particular field. After detailed study and work involving methods of determining properties of materials, nomenclature, etc., a proposed standard is evolved which is submitted at a meeting of 
the committee. Actions affecting the proposed standard are subject to a two-thirds vote at the meeting which must be subsequently confirmed by a two-thirds letter ballot vote of the entire committee. Most of the proposed standards are published in the committee reports which are presented at the next annual meeting of the society. If accepted at this meeting, the specification or test method is published as tentative for a year or more to elicit criticism and comments of which due cognizance is taken before the committee recommends that the tentative document be adopted by the society as standard. Each standard before adoption is submitted to letter ballot vote of the entire society membership and a two-thirds favorable vote of those voting is necessary before adoption.

New tentative standards may also be submitted in the interval between annual meetings. Tentative standards so submitted are reviewed by a committee, E-10, on. standards and if that committee is satisfied that a consensus has been reached in the standing committee concerned in respect to the standard and that it has been developed according to the regulations governing the adoption of standards, the tentative standard may be accepted for publication. This committee can also accept revisions in tentative standards and approve revisions of standards for publication as tentative.

Each standard is kept up to date by constant surveillance on the part of the respective committees responsible.

Statistics on standards.-Some idea of the intensive growth in ASTM standardization work is given below showing the number of standards and tentative standards in effect for 5-year intervals beginning in 1905 :

Number of
Year:
1905 -

The following is a classification by the general grouping of the society's committees, showing, respectively, the number of standards in these fields:

Number of standards

A. Ferrous Metals-Steel, Cast Iron, Wrought Iron, Alloys, etc_-_-_-_-_ 177

B. Non-Ferrous Metals-Copper, Zinc, Lead, Aluminum, Alloys, etc_-_-_- 126

C. Cement, Lime, Gypsum, Concrete, and Clay Products

D. Paints, Petroleum Products, Paper, Textiles, Rubber, Soap, etc_-_.--- 466

E. Miscellaneous Subjects, Testing, etc-_- 32

Total 952

Research, knowledge of materials.-Obviously, research and standardization go hand in hand. C. B. Dudley, the society's first president, and a pioneer in the development of specifications, after enumerating certain requirements of a workable specification for material, states that "above all it should embody within itself the results of the latest and best studies of the properties of the materials which it covers." 
Early recognition of this fact and its continued recognition through the years undoubtedly has contributed more basically than any other factor to the wide use and established authority of the society's standards.

Painstaking investigation and study of experience accumulated over years of service are often required before an adequate specification can be prepared. Agreement must be reached on the properties of materials to be specified and methods of testing them. Due cognizance of manufacturing details, methods of inspection, and marking, should be given.

The society sponsors research work in different ways but primarily through the extensive activities of its many standing and research committees. These are correlated by a Committee on Research. This group also has charge of the Research Fund from which contributions are made as the need arises to further worthy research projects. At the present time there are about 115 distinct projects under way, with large numbers of engineers and organizations cooperating.

An important factor also is the opportunity afforded technical and research investigators to give results of their work in papers at ASTM meetings. Each year many such contributions containing important data and information on the properties of materials and their testing are published.

Cooperation with other groups and the Federal Government.-The society recognizes the value and importance of cooperating with other organizations both in standardization work and in research activities wherever a common interest exists. Accordingly, the society has joined with other national bodies in a great many investigative movements. These frequently take the form of joint committees. A phase of cooperative work which the ASTM believes is most important in advancing the knowledge of engineering materials is the joint sponsorship with other groups of symposiums held on important engineering topics. The society has cooperated with such bodies as the American Society of Mechanical Engineers, American Foundrymen's Association, branches of the American Welding Society, Society of Automotive Engineers, and others in this important work.

Among other societies and activities in which the society is officially represented are the following: National Research Council (Division of Engineering and Industrial Research); Alloys of Iron Research, Engineering Foundation; American Society of Civil Engineers; Structural Division, American Society for Metals; American Ceramic Society; Inter-Society Color Council, and others.

The society, one of the five originators of the American Standards Association, a clearing house for standardization activities, is the sole or joint sponsor of many ASA projects and more than a third of the standards approved by the ASA were developed and published by the Society.

Numerous divisions of the Federal Government cooperate closely with the society and its technical committees, and the assistance rendered by the Federal Government and by various branches of the State governments, in particular, highway departments, is invaluable. Particular mention should be made of the cooperation of the National Bureau of Standards and its personnel. The latter is a relatively large group of scientists and engineers of broad training and experi- 
ence concerned especially with developing factual information on many problems related to materials, and as such bring to the large number of ASTM technical committees on which they are active, an invaluable background. The Bureau personnel is the largest "general interest" group in the society.

The Bureau has undertaken much important research work for ASTM and the reports and technical papers from the Bureau, which have been published by the society are no inconsiderable portion of this great mass of technical data.

The Bureau of Mines, Public Roads Administration, Forest Products Laboratory, branches of the U. S. Department of Agriculture, Bureau of Reclamation, and other Federal departments have rendered much service. All of these groups, of course, receive benefits from this work-many ASTM standards are used by the Federal Government; the society by publishing various technical contributions from the Federal Government helps disseminate knowledge.

Service branches of the Federal Government are active in ASTM work, the Army, Navy, and others being represented on committees; they help with various research projects and are vitally concerned with the requirements in ASTM specifications and tests.

It is of interest to note that three of the ASTM past-presidents have been associated with the Federal Government, a former director of the National Bureau of Standards; the chief of the Technologic Branch, U. S. Bureau of Mines; and a brigadier-general, U. S. Army Engineers Corps. The present president of the society is the chief of the Chemistry Division, National Bureau of Standards.

Marking requirements in ASTM standards.-Many of the ASTM specifications require that the products covered shall be marked or identified as to name or brand of the manufacturer, kind of material (in case of different grades or classes), certain testing information (hydrostatic test pressure, in case of pipe), and the ASTM serial designation identifying the specific standard.

Apparatus.-In a number of instances where committees of the society have developed specifications for testing apparatus, requirements have been included that the apparatus be marked in a manner identifying it with the society's standard. In such cases it is also required that the name or trade-mark of the manufacturers of such apparatus be marked thereon as a means of identifying the origin of the apparatus and placing the name of the manufacturer back of the statement implied by the appearance of the "ASTM" mark that the apparatus conforms to the society's standards.

Means of encouraging and facilitating the use of standards.-Obviously, with all the work and time and money expended in developing standards for materials, some thought has to be devoted to the application and use of the material. To an ever-increasing extent, particularly notable in the past decade, the ASTM specifications are applied in industry. In the steel, cement, brick, petroleum and many other fields, the quality of a high percentage of the products is covered by the society's standards-usually incorporated in a purchase order merely by the number of the serial designation, such as A7-39, which covers structural steel for bridges and buildings, the standard having been adopted in its latest form in 1939. 
It should be kept in mind that the over 5,600 men who are affiliated with the society as members or committee members form a great bloc of influence in promoting the use of standards of quality. Also the tremendously increased interest in the whole standards movement has accelerated this use.

Publications.-The methods of publishing standards and the very widespread distribution of these publications aid greatly in facilitating their use. For ease of reference the standards are published in collective form and each is also issued in separate pamphlet form. Of predominant interest is the Book of Standards published triennially with Supplements in the two intervening years. The 1939 Book of Standards and its 1940 Supplement (the 1941 Supplement will be issued in November of this year) gives all of the society's specifications and tests, the book includes tentative standards as well as those formally adopted. It is issued in three parts, as follows: Part I, metals; part II, nonmetallic materials-constructional; and part III, nonmetallic materials-general. Each part has a separate supplement; also each publication has a subject index with a list of the specifications and tests in the order of their serial designations.

All told, 21,800 copies of the 1939 Book of Standards were printed, as follows: Part I, 8,600; part II, 6,700; and part III, 6,500.

Special compilations of standards are also issued providing, respectively, all ASTM specifications and tests in the following fields: Petroleum; textiles; coal and coke; electrical insulating materials; cement; rubber products; paint, varnish, lacquer, and related materials; refractories; and chemical analysis of metals. Many thousands of copies of these compilations are distributed and a great many industries look on them with favor because of their compactness in giving in a somewhat more convenient form than the Book of Standards the specifications and tests with which the industry is primarily concerned.

The availability of each of the 952 ASTM standards in separate pamphlet form provides a ready means of use and many thousands of copies of these are distributed annually.

A yearly index to ASTM standards, including tentative standards, is published and distributed without charge. This publication covering some 172 pages gives under appropriate key words the titles of the standards together with the page and full reference to the ASTM publications in which they appear. Sixteen thousand five hundred copies of the index were published as of December 1940 .

A great many of the society's standards are reprinted by industrial companies and are used in text books and reference publications. While formerly permission to reprint was very freely given, the society has recently, for various reasons, set up a scale of charges for the right to reprint the standards when the published material is used for commercial purposes.

Especially notable has been the widespread use of ASTM standards in various building codes such as those recommeded by the U. S. Department of Commerce, National Board of Fire Underwriters, Pacific Coast Building Officials Conference, the codes issued by New York City, Chicago, Boston, and others. The Materials Section of the Boiler Code Committee of the American Society of Mechanical Engineers is based on ASTM specifications. There are numerous other related ways in which ASTM specifications are used. 
The society's bimonthly Bulletin is effective in promoting the knowledge of the society's work and stimulating the use of its specifications and tests. Through numerous meetings, the annual and spring meetings of the society and various local meetings, the importance of standardization work is stressed. Mention should be made of the close cooperation of a great many technical and business journals who with knowledge of the essential nature of the society's work include technical articles and news accounts of the progress in the field of engineering materials where ASTM functions.

\section{CENTRAL COMMITTEE ON LUMBER STANDARDS}

The Central Committee on Lumber Standards consists of 12 representatives of groups of lumber manufacturers, wholesalers, retailers, and consumers. The chairman is John Foley, forester, Pennsylvania Railroad Co., Philadelphia, Pa.

These representatives of all elements of the softwood lumber industry have in charge the maintenance of Simplified Practice Recommendation R16, Lumber, and its revision when necessary. The committee's suggestions and proposed amendments, following general industry approval, appear in succeeding editions of these basic standards, as published by the National Bureau of Standards.

This Simplified Practice Recommendation sets forth the classifications, nomenclature, grading provisions, sizes, workings, description, measurement, tally, shipping, grade marking, and inspection provisions adopted voluntarily by the softwood lumber industry as the basis for individual grading rules covering the various species of softwood lumber as found in different areas of the United States.

The recommendation was published initially in the year 1924 as a result of four general conferences of the industry, held in 1922, 1923, and 1924. In 1925, 1926, and 1928, the simplification program was revised, and amplified. In 1932 the shingles and mouldings sections, only, were revised. This revision was published in 1933, as a separate booklet, supplementing Simplified Practice Recommendation R16-29.

In 1939 a new edition of this recommendation was issued, with all information appearing in a single illustrated publication containing 99 pages, and designated as "Simplified Practice Recommendation R16-39, Lumber,-American Lumber Standards for Softwood Lumber."

This latest edition shows that the basic provisions have been strengthened and clarified, generally. The provisions governing the selection and inspection of softwood-lumber stress-grades are shown as having been thoroughly revised, in accordance with up-to-date information bearing on the effect of quality on the strength of lumber. The sections on shingles and mouldings were added in their proper places, and a brief history of the project included.

Future work includes the consideration of technical questions arising in connection with the practical use of these standards, and, notably important, the stimulation of all branches of the industry to put into daily practice the principles set forth in the existing standards.

Actual steps in the direction of the latter objective are accomplished facts. They include promulgation, publication and distribution of the booklet itself; information concerning it disseminated through the columns of trade papers, direct correspondence with producers, dis- 
tributors, and users of softwood lumber; and through trade associations and organizations that represent the several branches of the industry; and by means of a cross-reference, in Federal Specification MM-L-751b, Softwood Lumber and Timber.

\section{NATIONAL AIRCRAFT STANDARDS COMMITTEE}

The National Aircraft Standards Committee (NASC), composed of the standards engineers of the airplane manufacturers, is the body officially delegated by those manufacturers to represent them on matters of standardization. William M. Smith is the national chairman whose address is, in care of Bell Aircraft Corporation, Buffalo, N. Y.

The subject matter of primary interest to this group includes all parts manufactured in the airplane manufacturers' plants and all design specifications directly affecting the airframe.

In addition to that part of the airplane manufactured by them, the airplane manufacturers are also directly concerned with certain phases of standardization of the accessories and equipment. Although this work is carried on by the Accessory and Equipment Subdivision of the Society of Automotive Engineers, very close coordination is maintained with the airplane manufacturers through the NASC. Several items in the accessories and equipment field such as electrical systems, hydraulic systems, etc., have also been allocated to the NASC for handling, while concurrent problems in the equipment concerned are being handled by the Society of Automotive Engineers.

The subcommittees of the Society of Automotive Engineers are composed in general of representatives of manufacturers and users of the equipment concerned. In order to coordinate their work with the needs of airplane manufacturers, the NASC supply a list of technical specialists from which representatives are selected to serve on the various technical committees. These representatives act as full-voting members of the committee and are delegated to present the viewpoint of the airplane manufacturers.

In cooperation with the airplane, engine, and accessory manufacturers and the Society of Automotive Engineers, the National Aircraft Standards Committee has organized a committee for the purpose of developing standards in connection with the project on power plant installation. 


\section{STANDARDIZING ACTIVITIES OF TECHNICAL SOCIETIES AND TRADE ASSOCIATIONS}

In this section there is presented a picture of the simplification and standardization movement in various fields of industry conducted by trade associations, scientific and technical agencies, and other organizations which make standardization one of the important features of their services to their members.

In the following outlines relating to the simplification and standardization activities of these organizations, special attention has been paid to the current standardization programs, accomplishments to date, methods of appointing standards or technical committees, authority bestowed upon these committees, and their functions and procedure.

A special effort has been made to include in the following sketches the methods employed by various organizations for making their standards and specifications effective throughout the industry and to determine whether or not their requirements are being complied with.

Simplified Practice Recommendations and Commercial Standards referred to in the text are those which have been established by the interested industries under the auspices of the Divisions of Simplified Practice and Trade Standards of the National Bureau of Standards.

Where the term "sectional committee" is employed, the reference is to a regularly organized sectional committee functioning under the rules of procedure of the American Standards Association, unless otherwise indicated.

\section{OUTLINES OF STANDARDIZING ACTIVITIES}

Abrasive Grain Association, Harry B. Lindsay, secretary, 27 Elm Street, Worcester, Mass. Standardization and simplification activities of this association are carried on by a committee known as the Technical Committee. One phase of the committee's work has been crystallized in the Simplified Practice Recommendation R-118, Abrasive Grain Sizes, which was developed under the auspices of and promulgated by the National Bureau of Standards. The Technical Committee has developed a standard procedure for the measurement of capillarity of electrically fused aluminum oxide abrasives for polishing use. Current activity of this committee is directed toward more uniform application of the Simplified Practice Recommendation throughout the industry.

Abrasive Paper and Cloth Manufacturers' Association, 17 John Street, New York, N. Y. Revised standard specifications for glue bond abrasive-coated products were adopted by this organization in 1929 . The standardization committee for waterproof sandpaper has defined fine flour grades through the adoption of what is known as the sedimentation method of analysis. This method has given a means of $201072^{\circ}-41-2$ 
checking fine sands (finer than screen grades) which previously were not subject to accurate laboratory control. This association initiated the movement which resulted in the establishment and acceptance by the producing and consuming industry of standard sizes and grades for the abrasive products enumerated above, as promulgated in a Simplified Practice Recommendation issued by the National Bureau of Standards.

Acoustical Society of America, Wallace Waterfall, secretary, 919 North Michigan Boulevard, Chicago, Ill. One of the important activities of this organization in standardization is the preparation of standards of terminology, units, scales, and methods of measurement in the field of acoustics. In carrying forward this work the society cooperates with other technical bodies under the procedure of the American Standards Association.

The society is sponsor for the ASA sectional committee on acoustical measurements and terminology under the auspices of which it has already issued American standards covering noise measurement, sound level meters for measurement of noise and other sounds, calibration of microphones, and acoustical terminology. This sectional committee is also considering the development of specifications for audiometers for general diagnostic purposes, and standards for measuring sound transmission.

The society is also represented on three additional ASA sectional committees dealing with standards for motion pictures, letter symbols and abbreviations for science and engineering, and ventilation code.

Aeronautical Chamber of Commerce of America, Inc., Shoreham Building, Washington, D. C. This organization has a committee called the Engine Technical Committee. This group is composed of the administrative heads of the engineering departments of all of the aircraft engine manufacturers. The object in forming this committee is to have a technical group representing the engine manufacturers to study problems of the manufacturers not of a competitive nature; to work toward the goal of obtaining a coordinated viewpoint of the manufacturers; and to prepare and submit to pertinent governmental agencies suitable recommendations when deemed advisable.

In 1938 and 1939 the rapid increase in production, the development of higher powered aircraft and the use of lighter quality materials made a reduction desirable in the variety of specifications for materials used by manufacturers and governmental air services. The Engine Technical Committee of the chamber appointed a Materials Committee to draft a series of specifications that would be used uniformly by the aircraft industry and associated materials suppliers. The committee later recommended that the project be centralized in a recognized standardizing agency of the aircraft and associated materials industries.

Accordingly, the Aeronautical Chamber of Commerce of America proposed that this work be undertaken by the Society of Automotive Engineers, and in response the SAE Council established the Aircraft Materials Division of the SAE Standards Committee in 1939, which took over the specifications drafted by the ACCA committee up to then, and has since prepared additional ones.

The Technical Department of the chamber also acts as National Aircraft Standards Committee liaison with the Aeronautical Board, 
the Bureau of Aeronautics of the U. S. Navy Department, and the Air Corps, as well as outside agencies and other standards organizations. Personnel of the Technical Department have assumed secretarial duties on the NASC Executive Board and on the NASC Power Plant Installation Standards Committee.

Agricultural Insecticide \& Fungicide Association, L. S. Hitchner, executive secretary, 285 Madison Avenue, New York, N. Y. This association has developed, over a period of years, numerous standards for insecticides and fungicides which have been incorporated in Federal and State laws.

With reference to simplification, the association sponsored the movement for the adoption of a schedule of stock sizes for insecticides and fungicides, which resulted in the establishment of Simplified Practice Recommendation R-41, promulgated and published by the National Bureau of Standards.

The association developed standards for the metallic copper content of commercial Bordeaux mixture and for lime-sulfur solutions, which have received general acceptance by industry.

Air Conditioning and Refrigerating Machinery Association, William B. Henderson, executive vice president, Southern Building, Washington, D. C. This association has formulated equipment standards for enclosed ammonia compressors, vertical open shell and tube ammonia condensers, horizontal closed shell and tube ammonia condensers, horizontal closed ammonia shell and tube brine coolers (flooded), submerged open ammonia brine coolers, ammonia liquid receivers, ammonia mains, steel and wrought-iron pipe, cold storage room insulation, low pressure condensing units, Freon-12 condensers (terminal difference), and Freon-12 water coolers (mean temperature difference). During the past year the association completed additional standards covering self-contained summer air conditioning units, Freon-12 evaporative condenser units, Freon-12 condensers of the horizontal closed shell-and-tube type; Freon-12 liquid receivers, and location and inspection of data plate on insulated vessels.

It has also formulated base specifications for self-contained ammonia units, ammonia brine cooler ratings, Freon-12 mains, and standard nomenclature for reciprocating compressors. This association has also formulated a code of application engineering standards for air conditioning for comfort. This code covers minimum standards and is limited to standards and practices for determining the conditions and loads in the design of air-conditioning systems for installation within the United States. The association maintains representation on six sectional committees functioning under the procedure of the American Standards Association dealing with the following subjects: safety code for mechanical refrigeration; pipe flanges and fittings; code for pressure piping; standardization of dimensions and materials of wrought-iron and wrought-steel pipe and tubing; specifications for pressure and vacuum gages, and classification and designation of surface qualities.

Aluminum Research Institute, R. D. T. Hollowell, secretary, 308 West Washington Street, Chicago, Ill. This organization's technical work in matters relating to standardization is carried on by its Chemists' Committee, consisting of the chief chemists of the secondary aluminum manufacturers that compose the institute's membership. 
This committee's activities include cooperation with similar committees of technical bodies.

One of the projects developed by the committee which has been adopted by the institute and is being widely used in the industry concerns the standardization of methods of sampling and analyzing aluminum and certain aluminum alloys.

Amateur Athletic Union of the United States, Daniel J. Ferris, secretary, 233 Broadway, New York, N. Y. Among the several objects of this organization are the establishment and maintenance throughout the United States of a uniform test of amateur standing, and uniform rules for the government of all athletic sports within its jurisdiction; the institution, regulation, and awarding of the amateur athletic championships of the United States; and the institution of a bureau of records covering all branches of amateur sport in the United States.

This union recognizes all amateur sports and claims jurisdiction over basket ball, boxing, gymnastics, handball; running, including hurdle, obstacle racing, and steeplechasing; walking, jumping, pole vaulting; putting shot and throwing hammer, weights, javelin, and discus; swimming, tug-of-war, catch-as-catch-can wrestling, Greco-Roman wrestling, weight lifting, volley ball, indoor baseball, squash ball, code ball, field handball, bobsleighing and coasting, and ice hockey. The union conducts the championships of the United States in all these sports, and its 41 district associations covering the entire United States, annually hold the district championships.

The establishment of standard definitions of rules for the government of athletic sports are formulated by the Board of Governors, which is elected each year and is representative of the active and allied member associations of the union. Besides the adoption of standard contest rules for the various sports under its jurisdiction the union also fixes standards on dimensions, weights, material, and shapes of the various implements, balls, etc., entering into athletic contests.

American Association for the Advancement of Science, Otis W. Caldwell, general secretary; F. R. Moulton, permanent secretary, Smithsonian Institution Building, Washington, D. C. This association is cooperating with other organizations, under the procedure of the American Standards Association, in the preparation of standard definitions of electrical terms. It is also acting as joint sponsor under the same procedure for the standardization of scientific and engineering symbols and abbreviations. The latter activity has already resulted in the American standard symbols for photometry and illumination, mathematical symbols, and letter symbols for electrical quantities, and in tentative American standards for symbols for hydraulics, heat, and thermodynamics, aeronautical symbols, and graphical symbols for telephone and telegraph use, and navigational and topographical symbols. It is also officially represented on the ASA Sectional Committee on Electric and Magnetic Magnitudes and Units.

American Association of Cereal Chemists, Claude F. Davis, president, $\%$ Michigan Bakeries, Inc., Grand Rapids, Mich. Among the stated objects of this association are the encouragement and advancement of scientific and technical research in cereals and their products, particularly in milling and baking; the study of analytical methods 
used in cereal chemistry; and the development and adoption of uniform or standard methods of examination and analysis. A number of technical committees are appointed by the association to carry on the collaborative studies and to organize work around definite cereal problems of interest and usefulness. These committees are engaged in subjects dealing with methods of analysis, standardization of laboratory baking, testing methods for cake flours, testing self-rising and phosphated flours, testing biscuit and cracker flours, definition of technical terms, and standardization of malt analysis.

In addition, the association maintains a Cooperative Research Committee, which is collaborating with a similar committee of the American Society of Bakery Engineers in the study of baking problems.

The association has issued a revised edition of its book, Cereal Laboratory Methods, which is devoted to a description of methods for the chemical analysis of wheat and flour, including chapters on baking, shortening materials, leavening agents, and yeast foods.

American Association of Medical Milk Commissions (Inc.), S. W. Shoemaker, assistant secretary, 1265 Broadway, New York, N. Y. The association has adopted and promulgated a pamphlet, Methods and Standards for the Production of Certified Milk, containing regulations on the organization of local medical milk commissions, dairy buildings and equipment, herd management and stable practice, veterinary supervision, milking, handling and transportation of milk, and hygiene of employees, as well as specifications for certified milk. Any dairyman who agrees to undertake the production of milk meeting its standards is permitted by the association to use its seals, bearing the term "certified milk" on milk bottles. Continued use of these seals is based on weekly examination and inspection of sample milk by local medical milk commissions.

American Association of Nurserymen, Richard P. White, executive secretary, 636 Southern Building, Washington, D. C. Through its Standardization Committee, this association has adopted uniform grading standards covering height measurements and tolerance of deciduous trees and shrubs; standard types of vines; commercial grades of evergreens; grades of various roses; grades of large and small fruit trees; designation of lining-out stock, and trees for forest planting. It has also issued recommended specifications for balling and burlapping, giving minimum sizes of balls, ball depths, and weight equivalent to ball sizes.

American Association of Port Authorities, Tiley S. McChesney, secretary, 2223 Short Street, New Orleans, La. One of the objects of this association is the standardization and establishment of uniformity in the operation, construction, and management of port facilities, and to recommend to the various ports represented in the association the adoption thereof.

The Committee on Standardization and Special Research deals with all matters relating to the standardization of Federal and local port statistics, the standardization of equipment common to operators in different ports, as well as designs, common practice and terminology. This committee has issued a dictionary of port terms.

The Committee on Fire Prevention cooperates with the National Fire Protection Association, of which this association is a member, in developing standard practices in fire resistance, safe operating prac- 
tices, oil pollution, fireboats, standpipe systems, alarm and sign systems, and related subjects.

The association also cooperates with the United States Maritime Commission and National Rivers and Harbors Association in standardization activities. This association is represented on sectional committees on specifications for zinc coating of iron and steel, and on work in compressed air, functioning under the procedure of the American Standards Association.

American Association of State Highway Officials, W. C. Markham, secretary, National Press Building, Washington, D. C. Major activities in the field of standardization being caried on by this association include the study of various materials, methods of construction and maintenance of highways; and the development of technical administration and highway operation standards and policies.

The association's Committee on Standards, together with such subcommittees as may be necessary, is constantly engaged in the formulation of standards and specifications to include road and bridge construction, tests and investigation of materials, maintenance, and all phases of highway research.

This association has prepared and published a book on "Specifications for Highway Bridges" of all kinds constructed by or under the supervision of Federal and State highway departments. In it are included specifications relating to design and construction, and materials used covering cement, aggregates, structural steels, wrought iron, steel forgings and castings, gray-iron, and malleable castings, brick, timber, bituminous materials, etc. It has also issued a publication on "Standard Specifications for Highway Materials and Methods of Sampling and Testing." This book serves as a standard and guide for all those who furnish and use road building materials required by Federal and State highway authorities. Many of the specifications and methods of test are identical with those of the American Society for Testing Materials which the association has adopted.

This association cooperates with other bodies, under the procedure of the American Standards Association, on work which has resulted in the development of American standard specifications for Portland cement; specifications for drain tile; and methods of testing bituminous road and paving materials. In addition, it is represented on ASA sectional committees dealing with standards for the inspection of motor vehicles, and specifications for sieves for testing purposes. It cooperates also, by official representation, with committees of the American Society for Testing Materials on projects relating to steel, and copper and copper alloys.

American Association of Textile Chemists and Colorists, Harold C. Chapin, secretary, care of Lowell Textile Institute, Lowell, Mass. This association was organized in 1921 for the purpose of promoting the increase of knowledge of the application of dyes and chemicals in the textile industry, and of encouraging in any practical way research work on chemical processes and materials of importance to the textile industry.

The membership of the association of approximately 2,700 includes most of the leading textile chemists and colorists of the country as well as members from Canada and 13 different foreign countries.

Since the inception of the association the work of the Research Committee has been one of its most important activities. This committee 
meets frequently and has been so organized as to include about 60 of the more prominent textile chemists and colorists of the country. Working under the general supervision of this Research Committee are 30 subcommittees, each engaged in some specific phase of the work. These subcommittees have been so organized as to represent as far as possible not only the diversified interests of the textile and color application industries, but also distributing and consuming groups.

In the early years of the association the Research Committee concentrated its efforts upon the establishment of fastness standards for dyed textile materials; developing laboratory methods for elassifying degrees of fastness and then selecting certain dyes, which, when properly applied, would represent each class.

Standards and test methods were thus established for fastness of dyed cotton, rayon, wool and silk to light, mill washing or laundering, fulling, bleaching and stoving; also fastness to rubbing or crocking, perspiration, acids, alkalies, carbonization and sea water. Standard dyeings on cotton, wool, and silk have been prepared representing the various degrees of fastness to light, to mill washing and laundering and to rubbing or crocking.

During the period 1931-39, through grants from the Textile Foundation, the Chemical Foundation and corporate members, the association was enabled to extend its activities into the field of fundamental textile chemical research, which was carried on at the National Bureau of Standards, Brown University, Lowell Textile Institute, and the University of Chattanooga.

In 1939 the work supported by the Textile Foundation having grown in scope beyond the original purposes of the association, was centralized under the direct supervision of the foundation at the National Bureau of Standards. The association, however, is continuing its applied research and work on standards.

The growing interest of consumers in merchandise quality has emphasized the importance of the work on standard test methods in which the association has been engaged since its very beginning. Many of the standard test methods worked out by this association are being adopted by the Federal Government and such groups as the American Society for Testing Materials, American Standards Association, National Bureau of Standards, and manufacturers of dyestuffs.

Standard methods for determining the fastness of dyestuffs on the fiber have been devised by the association through its Research Committee in order to make possible the specification of the fastness of colored textiles or dyestuff's as they are used on textiles, to the various color destroying agencies. These methods are classified into several groups and include fastness tests, as follows: Group C, dyed or printed rayons; group $\mathrm{R}$, dyed or printed rayons; group $\mathrm{S}$, dyed or printed silks; and group W, dyed wool. In addition, the association has developed standard methods applicable to all fibers for fastness to perspiration, light, acids and alkalies, carbonizing, sea water, and rubbing (crocking); identification of sizing and finishing in textiles; and determination of sizing and finishing, copper and iron, and manganese in textiles; also determination of waterproofness.

It has also developed standard methods applicable to specific fibers for determination of shrinkage in washable woven cotton fabrics, methods of fiber identification and quantitative separation, tests for 
transference of color, method of testing for moth proofing, fastness to atmospheric gases of dyes on cellulose acetate rayon, determination of degree of mercerization of cotton, and determination of weighting in silk.

The association is represented on the Advisory Committee on Ultimate Consumer Goods, functioning under the auspices of the American Standards Association, in work relating to standardization of consumer goods. It is also represented on technical committees of the American Society for Testing Materials dealing with the preparation of standards and test methods for soaps and other detergents and for water for industrial uses.

American Association of University Women, Esther Cole Franklin, associate in social studies, 1634 Eye Street NW., Washington, D. C. This association was among the pioneering groups in preparing study outlines for adult groups on testing, standardization, and informative labeling of foods, drugs, household equipment, and clothing. Owing to its widespread interest, the association has since 1937 become nationally known as a consumer organization and has undertaken a number of national activities in the consumer interest. Through its subcommittee on consumer interests of the National Committee on Social Studies, the association is represented on the Advisory Committee on Ultimate Consumer Goods of the American Standards Association, functioning under the value and use of adequate standards for consumer goods, and to promote the use of informative labeling of commodities. The association is affiliated also with the National Consumer-Retailer Council and is active in the council's committees on labeling and standards. Under the direction of the association's representative on the council, the labeling committee has developed model labels for a wide number of commodities.

In the interest of consumers generally, the association has adopted recommended procedures for the development and use of standard specifications for consumer goods. The association's legislation program includes an item on the development of standards of quality and performance for consumer goods.

American Automobile Association, Russell E. Singer, general manager, Pennsylvania Avenue at Seventeenth Street, Washington, D. C. The association has developed by itself or in cooperation with other organizations, numerous standards and models for motor vehicle legislation in the States and in cities, designed to promote the safe and efficient movement of traffic. It developed a Model Safety Responsibility Bill and cooperated actively in the development of the Uniform Vehicle Code and the Model Traffic Ordinances.

It developed a guide as to standards for state legislation on roadside development and control.

The association participated in the development of standards for traffic signs, signals, markings, and islands set forth in a Manual on Uniform Traffic Control Devices.

Through a Committee on Parking and Terminal Facilities, the association formulated plans and set up guiding principles and standards for improving parking conditions in central business districts. Proposals relate to both on- and off-street parking.

The association has developed proposed standards of various types relating to increasing the safety and convenience of pedestrians in traffic. 
It has developed detailed methods and various proposed standards for training new drivers. For several years it has been studying methods of examination of applicants for drivers' licenses with the idea of improving standards therefor.

The association cooperates from time to time with the National $\mathrm{Bu}$ reau of Standards, in connection with brake testing and headlight testing, and has prepared charts for the standardization of testing headlight adjustment without special machinery.

The AAA is represented with other organizations on sectional committees of the American Standards Association dealing with standards for proper maintenance of motor vehicles and specifications and methods of test for safety glass.

The association has developed in cooperation with other organizations standards for the operation of school safety patrols.

It is cooperating with other organizations in the National Committee on Traffic Law Enforcement which is developing statements of guiding principles, recommended techniques and standards for improvement of traffic law enforcement.

The association is a member of the National Conference on Uniform Traffic Accident Statistics, the object of which is to develop, improve, and promote standard forms, definitions, and practices for the collection and summarization of traffic accident information and to promote increased use of such information.

The AAA Contest Board prepares detailed specifications and standards which must be met by automobiles competing in various races conducted under its sanction and supervision. Out of the stress and strain of these races have come many improvements and refinements to the automobile, tires, and to other important equipment. Tests of automotive and accessory products under accepted standard rules have become one of the major functions of the AAA Contest Board in offering a medium for the automotive industry to have its wares certified to the car-owning public.

American Bakers Association, Tom Smith, secretary, 1135 Fullerton Avenue, Chicago, Ill. Two committees of this association carry on the standardization and simplification work required by the industry. The Committee on Public Affairs cooperates with the Food Standards Committee of the Food and Drug Administration in the development of standards of identity under the Federal Food, Drug and Cosmetic Act.

This association's Committee on Pan Sizes sponsored the research work at the American Institute of Baking for the purpose of gathering information and data on pan sizes. In this connection, the board of governors of this association, with a desire to benefit the consumer and the baking industry through further improved bread quality, has adopted a resolution setting forth recommended standard pan lengths for bread loaves weighing 12,16, 20, and 24 ounces, baked.

American Bleached Shellac Manufacturers Association, Inc., Paul W. Fisher, executive secretary, 70 Pine Street, New York, N. Y. In cooperation with the United States Shellac Importers Association, Inc., this association has issued a booklet covering official methods of analysis, specifications, and general information on shellac and bleached shellac, which has been approved and adopted by both organizations. This booklet contains detailed specifications relating to 
properties and tests for orange shellac, seedlac, dry bleached shellac, and shellac varnish. It includes also methods of sampling and testing shellac and shellac varnish.

It has issued two publications entitled "How to Use Shellac for Best Results" and "Standard Specifications for the Reference of Architects on the Use and Applications of Shellac." The latter publication contains specifications with respect to guarding against excessive dampness, drying, thinning and mixing, specifications on floor finishing, and finishing of interior woodwork, and for primary (sizing) walls.

American Boiler Manufacturers Association and Affiliated Industries, A. C. Baker, secretary, 264 Rockefeller Building, Cleveland, Ohio; ABMA Fair Practice Committee, H. E. Aldrich, manager, 15 Park Row, New York, N. Y. This association, established in 1888, represents the boiler manufacturing industry engaged in the production of all types of steel steam boilers for stationary and marine use (except steel heating boilers as defined in section IV of the ASME Boiler Construction Code, Scotch-type boilers for stationary use, vertical fire-tube boilers, horizontal fire-box boilers, tubeless boilers, oil country boilers, miniature boilers, and boilers for locomotives); mechanical stokers of 36 square feet of grate area and over; pulverized fuel equipment; superheaters; air heaters and economizers.

Practically all standardization work of this association is carried on by its Fair Practice Committee, which has functioning under its jurisdiction numerous technical committees, the titles of which are indicated by the duties performed by them.

The Contract Forms Committee prepares contract forms which are recommended to manufacturers and purchasers, and makes revisions or additions to them as experience or changed conditions make it desirable.

The Performance Forms Committee prepares standard performance forms which are recommended to manufacturers, engineers who write specifications for the various products, and to purchasers. These forms give the proper method of stating predicted or guaranteed performance and the conditions on which such performance should be based. This committee also studies and reports on various technical problems, definitions, engineering data, etc. The Stoker Technical Committee has a similar purpose, but works specifically on technical problems for stokers; for example, definition of the term "continuous rating," coal sizing for stokers, study of the problems resulting from various city smoke ordinances, etc. This committee also developed data giving engineers and purchasers information needed in specifications for stokers. It is planned that such information will be developed for other products.

The Pulverizer Test Code Committee developed a test code for pulverizers which has been recommended to the Power Test Code Committee of the American Society of Mechanical Engineers for adoption as one of its standards.

The Feed Water Conditions Committee was authorized to employ a nationally known consultant on feed water problems, in cooperation with whom standard water conditions were developed. Such standards 
are recommended for use in connection with guarantees of steam quality or purity.

The Mechanical Draft Fan Equipment Committee is cooperating with a committee of the National Fan Manufacturers Association on problems of distribution which are burdensome to both industries. It is working on a form on which manufacturers can furnish needed fan data to the fan companies, engineers, and purchasers. Simplification studies are also being made.

The Traffic Committee studies and reports proposed changes in freight rates or classifications presenting data and views to the Official Classification Committee of the railroads. A joint committee of boiler manufacturers and tube manufacturers prepared standard tolerances for tube bends based on commercial practice and to provide for proper tube cleaning.

Several years ago this association prepared a manual covering industry standards and engineering information. This manual contains standard contract and performance forms which are being used by the industry, a statement relative to mechanical draft fan equipment, form outlining data required for fan selection, form outlining data required in stoker specifications, standard tolerances on tube bends, outline of method for determining required design pressure for boilers in a specific installation, typical analyses of bituminous coals in various districts, and grindability values for coals in various districts.

This association cooperates with the American Uniform Boiler Law Society and the National Board of Boiler and Pressure Vessel Inspectors in connection with the promotion of uniform boiler laws and regulations and the uniform enforcement thereof. It is officially represented on sectional committees functioning under the procedure of the American Standards Association dealing with the following projects: standardization of bolts, nuts and rivet proportions; standardization of iron and steel pipe and tubing; and standardization of pipe flanges and fittings. This association is also represented on the Joint Research Committee on Boiler Feed Water Studies under the auspices of the American Society for Testing Materials.

American Bottlers of Carbonated Beverages, John J. Riley, secretary, 224 Southern Building, Washington, D. C. In order to eliminate many of the difficulties arising in connection with the use of specialized equipment, including pipe lines and threads, conveyor devices, bottles, and bottle cases, the association has recognized certain standard types and sizes in its publications. Definite material thicknesses are recognized for: the sides and partitions of wooden bottle cases, supply lines, fittings and flow velocities for carbonated water equipment, straight and taper pipe threads, conveyor chains, and crown finish for beverage bottles. A standard is recommended concerning the composition of solutions used for washing beverage bottles. Standard methods of control covering sugar and carbon dioxide content of beverages are suggested.

Basic beverage bottle dimensions have been prepared in cooperation with the Division of Simplified Practice of the National Bureau of Standards. Standard sugar tables and syrup-making computations are published, calculated from the recognized basic tables of the $\mathrm{Na}$ tional Bureau of Standards. Special service for checking these items 
is given through the activities of the laboratory maintained by the association at its headquarters.

American Brush Manufacturers Association, George A. Fernley, secretary, 505 Arch Street, Philadelphia, Pa. Simplification and the establishment of standard sizes of various types of brushes have been carried on very actively by this association. Under the auspices of the National Bureau of Standards, it initiated movements which resulted in the establishment of Simplified Practice Recommendations: R43-28 for paint and varnish brushes, R88-37 for sweeps, R121-31 for block sizes for calcimine brushes, and R167-37 for counter, window, and radiator brushes. These Recommendations have been promulgated and published by the National Bureau of Standards.

American Bureau of Shipping, J. W. Cantillion, secretary, 47 Beaver Street, New York, N. Y. The principal work of this Bureau may be briefly summarized as follows: (1) The publication in the Record of the essential particulars of the hulls and machinery classed with the bureau, the classification assigned to each particular vessel, and the dates when the various surveys were made. Particulars of Amercan vessels not classed with the bureau and also the larger foreign vessels which regularly visit United States ports are also given in the Record for the information of the subscribers; $(2)$ the issuance of certificates of character for merchant ships, their machinery and equipment, i. e., classification certificates, seaworthy certificates, etc., based on surveyors' reports; (3) the carrying out of load line surveys in accordance with the Department of Commerce regulations, and the granting of load line certificates after the freeboard markings on the vessel's sides have been duly verified and found to be in accordance with the freeboard; $(4)$ the preparation of rules for the construction of hulls and machinery, including material specifications and detail regulations for periodic surveys, etc. These rules are modified from time to time in order to keep pace with developments in shipbuilding and marine engineering; they are the standards by which the eligibility of vessels submitted for classification is determined; (5) the carrying out, when specifically requested by owners and builders, of such other work as relates to structural design, construction, and maintenance of merchant ships, and also such important matters as relate to subdivision, etc.; and, $(6)$ the investigation by the technical staff of details in connection with the preparation of new rules and the analysis of the Surveyors' reports of surveys made on vessels in operation with a view to determining what amendments in the existing rules experience has shown to be desirable.

In accordance with the provisions of Appendix A of Regulations of the National Fire Protection Association governing marine fire hazards adopted in 1930, all chemists who test ships' compartments, tanks, etc., as to gas content are required to be certified as to qualifications by the American Bureau of Shipping. In order to obtain such certification each chemist must submit his qualifications as to education, experience and character through the American Bureau of Shipping for approval by the technologist of the American Petroleum Institute; each such certification of the chemist is valid for a period of five years. In conformity wth this procedure the American $\mathrm{Bu}-$ 
reau of Shipping has certified chemists in most of the maritime States of the United States and in Canada and the West Indies, all of whom are required to report regularly to the Bureau regarding all activities related to gas-free certification carried out under their jurisdiction.

The Bureau cooperates to the fullest extent with other organizations associated with merchant marine activities. Members of its staff are represented on committees dealing with a wide variety of subjects, such as standing committees of the American Society for Testing Materials, American Welding Society, American Standards Association, American Institute of Electrical Engineers, National Fire Protection, National Safety Council (Marine Section), and technical committees of the American Merchant Marine Institute and the National Council of American Shipbuilders. The technical staff carried out considerable investigation work in preparation for the International Conference for the Safety of Life at Sea held in 1929 , and for the International Load Line Convention held in London in 1930; the Bureau was directly represented on the United States delegation attending these international conventions.

American Ceramic Society, Inc., Ross C. Purdy, general secretary, 2525 North High Street, Columbus, Ohio. This society carries on a considerable amount of cooperative work in the development of standards and specifications, through representation on committees of the American Standards Association and the American Society for Testing Materials.

The society is officially represented on committees functioning under the procedure of the American Standards Association dealing with the following projects: minimum requirements for plumbing and standardization of plumbing equipment; building code requirements and good practice recommendations for masonry : insulators for electric power lines; classification of coals; letter symbols and abbreviations for science and engineering; specifications for sieves for testing purposes; and specifications and methods of test for safety glass.

It maintains representation also on the following technical committees of the American Society for Testing Materials: steel, refractories, glass and glass products, manufactured masonry units, gaseous fuels, and electrical insulating materials. The society cooperated with the American Foundrymen's Association under the auspices of the National Bureau of Standards in the development of Simplified Practice Recommendation R154-38 covering sizes of cupola refractories, tap-out, and slug-hole blocks.

American Chemical Society, Charles L. Parsons, secretary, Mills Building, Washington, D. C. This society's work in developing standards and specifications is carried on by several committees handling certain specific subjects. Through studies and tests made by its members, the committee on analytical reagents has prepared more than 150 recommended specifications for analytical reagent chemicals which have been adopted and published by the society. This committee has cooperated during the past year with the subcommittee of the committee on revision of the U. S. Pharmacopoeia in the preparation of specifications for reagents for the revision of the Pharmacopoeia.

The committee in charge of analysis of commercial fats and oils has been engaged in developing standard methods relative to moisture, unsaponifiable matter, quantitative and qualitative methods for pea- 
nut oil, and detection of vegetable oils in animal fats. The committee on soap and soap products has prepared a revision of the standard methods for the sampling and analysis of commercial soaps and soap products.

In cooperation with the Scientific Apparatus Makers of America, the society's committee on standard apparatus has prepared and published a publication entitled, Standard Sizes and Shapes of Apparatus. This publication gives recommendations for items of certain types of apparatus to be kept in stock by dealers and in laboratory storerooms for ordinary laboratory work.

Another committee of the society cooperates with committees of the American Public Health Association and the American Water Works Association in the revision of standard methods of examination of water and sewage. Additional standardization work of the society is carried on in cooperation with other technical bodies.

Through representation on a sectional committee the society assisted in the preparation of the safety code for mechanical refrigeration which was approved by the American Standards Association, and is now officially represented on three committees of the latter association dealing with classification of coals, specifications for sieves for testing purposes, and letter symbols and abbreviations for science and engineering. It is also represented on the coordinating committee on corrosion functioning under the auspices of the American Society for Testing Materials.

American College of Surgeons, 40 East Erie Street, Chicago, Ill.; Irvin Abell, M. D., chairman, Board of Regents; Malcolm T. MacEachern, associate director and director of hospital activities; Bowman C. Crowell, associate director and director of clinical research. The standardization of hospitals, hospital organization, management and procedure, and clinical and physical standards, are important features of the activities of this organization. The minimum standards for hospitals adopted by the college cover, in particular, the organization and duties of the medical staff, the providing of accurate and complete case records on all patients treated, and the furnishing of adequate diagnostic and therapeutic facilities. Names of hospitals of the United States and Canada conforming to the minimum standard of the college are published annually in a list of approved hospitals.

This organization has issued a manual containing complete information regarding a standard classification and nomenclature for surgical dressings, and standard specifications for sponges, abdominal packs, sterile gauze dressings, and pads. It prepared and adopted a minimum standard for the organization of clinics for the diagnosis and treatment of cancer; also a minimum standard for industrial medicine and traumatic surgery.

It initiated the program for the development of a standard for steel bone-plates under the procedure of the National Bureau of Standards, which resulted in the establishment of Commercial Standard CS37, covering the physical and metallurgical requirements, design, dimensions, and finish of steel bone-plates and screws available for use in the reduction of bone fractures; also requirements as to packaging, identification, and certification of quality to buyers. 
The college also cooperated with the National Bureau of Standards in the preparation and revision of Simplified Practice Recommendation R133 for stock sizes of surgical dressings.

American Concrete Institute, Harvey Whipple, secretary, 7400 Second Boulevard, Detroit, Mich. Since its organization in 1905, this institute has been devoted to the solution of technical problems arising from the use of cement in concrete and reinforced concrete, and to the dissemination of information in this field of interest. This work is summed up as an effort toward raising the standards of the field which the institute represents.

The work of the institute is concerned primarily with the improvement of practice in design, construction and manufacture in relation to concrete and reinforced concrete; and in the furtherance of this work it cooperates with numerous organizations. The approach to standardization is by stages found on increased knowledge of the properties of Portland cement concrete and of allied and auxiliary materials.

Many committees are assigned to special problems; as a first stagethe correlation of existing knowledge for the purpose of application to concrete design, construction, and manufacturing practice. A second stage of committee effort is in the outline and inauguration of research to fill the gaps in knowledge; then, successively, recorrelation and the promulgation of "recommended practice."

In the stages of the work toward standardization an important factor of institute accomplishment is in individual papers and committee reports recording field and laboratory experience.

Some of the older standards of the institute relate to Portland cement stucco, mixing and placing concrete in buildings, fabricating and setting reinforcing steel, concrete masonry units, cast stone, concrete staves, plain and reinforced concrete serrer pipe, drain tile, concrete pavement, concrete sidewalks, concrete floors, monolithic concrete sewers and recommended rules for sewer design, concrete work on ordinary buildings, Portland cement stucco finishes, supplying, fabricating, and setting reinforcing steel, and recommended practices in the use of cast stone.

Recent work of the institute includes the completion of new building regulations for reinforced concrete and preliminary drafts (for periods of use and discussion) on recommended practice in measuring, mixing and placing concrete; A. C. I. Manual of Concrete Inspection; specifications for plain and reinforced concrete arches; reinforced concrete design handbook; recommended practice for the design of metal supports for reinforcement; and recommended practice for the design of concrete mixes.

Work is in progress on new recommended practices for: Curing concrete, the application of paint to concrete surfaces, manufacture of concrete masonry units, construction of concrete silos, high pressure steam curing, and a specification for cast stone.

Through representation on the Joint Committee on Standard Specifications for Concrete and Reinforced Concrete, consisting of affiliated committees of the American Institute of Architects, American Railway Engineering Association, American Society of Civil Engi- 
neers, American Society for Testing Materials, Portland Cement Association, the institute cooperated in the preparation and publication of a report on Recommended Practice and Standard Specifications for Concrete and Reinforced Concrete which was issued in 1940.

The institute, in collaboration with the Portland Cement Association and the Concrete Masonry Association, initiated the movement for the establishment of standard sizes for concrete building units which are set forth in Simplified Practice Recommendaton R32-38, promulgated and published by the National Bureau of Standards.

In its cooperative work with other organizations the institute is officially represented on a number of sectional committees of the American Standards Association in developing specifications for Portland cement, fire tests of building construction and materials, plastering, sieves for testing purposes, and building code requirements for excavations and foundations. It is also represented on the joint research project on durability of concrete, cooperating with the Highway Research Board of the National Research Council and the American Society for Testing Materials; and on a committee on cement of the American Society for Testing Materials.

American Concrete Pipe Association, M. W. Loving, secretary, 33 West Grand Avenue, Chicago, Ill. All specifications for concrete pipe adopted by this association are those which have been prepared by the Committee on Concrete Pipe of the American Society for Testing Materials and on which the association is officially represented. These specifications include concrete sewer pipe, reinforced concrete sewer pipe, reinforced concrete culvert pipe, and concrete irrigation pipe.

The association is also represented on the ASTM committee dealing with the development of standard specifications for drain tile. This association cooperated with the American Standards Association in the development of specifications for drain tile which were approved as American standard (A6-1925) by that organization.

It has cooperated and continues to collaborate with the Federal Specifications Executive Committee in the formulation of Federal specifications covering pipe for sewers, drains, etc.

American Cranberry Exchange, Inc., C. M. Chaney, secretary, 90 West Broadway, New York, N. Y. This exchange has been in existence since 1907. It is a nonprofit selling organization, owned and controlled by cranberry growers. The primary function of the exchange is to market cranberries grown and produced by its members, and to perform such other duties as are directly or indirectly connected therewith. In order to market cranberries properly, this organization has developed standards for the various varieties and grades of cranberries grown in the various parts of the country, and designates such grades by brands.

American Dental Association, Harry B. Pinney, secretary, 212 East Superior Street, Chicago, Ill. The standardization work of this association is conducted by research associates maintained at the National Bureau of Standards, who carry on research on dental materials such as cements, alloy and denture materials; chemical analysis; and testing certified products. It has formulated standards for dental amalgam alloys, inlay casting investment, inlay casting waxes, impression compounds, inlay casting golds, dental mercury, wrought gold alloys, zinc phosphate and silicate cements, denture rubber, hydrocolloidal impres- 
sion materials, and acrylic denture resin used in prothesis and orthodontia.

Manufacturers of dental materials are advertising the fact that their products comply with the requirements of the specification, and are issuing certificates to the Research Commission of the association guaranteeing such compliance. In addition to the certificate, satisfactory evidence of physical tests must be submitted by the manufacturer to show that he has tested his material and that its properties meet the specifications' requirements. A list of products so certified is published from time to time in the ADA Journal.

The Bureau of Chemistry maintained by this association examines new proprietary products (drugs and pharmaceuticals) with the view to preparing chemical specifications. The Council on Dental Therapeutics of the association, operating in conjunction with this Bureau, was organized as a permanently functioning body to advise the dental profession and the public concerning dental proprietary and nonofficial remedies and materials, with regard to their composition and therapeutic usefulness.

It lists materials as "accepted nonofficial dental remedies" when the articles are found to comply with 10 published rules. In essence these rules state that the composition of the article must be published; tests for determining its composition must be furnished; it must not be advertised to the public (except that disinfectants, dentifrices, and medicinal foods may be advertised within certain limits) ; there must be no false or misleading statements as to its origin, preparation, or therapeutic value; its name must not be misleading; and it must be useful. Articles acceptable to the council are eligible to bear the seal of acceptance, and firms may make use of the seal of acceptance in general advertising within limits imposed by the council's rules governing the use of the seal.

American Dental Trade Association, George A. Lilly, managing director, 1010 Vermont Avenue NW., Washington, D. C. One of the outstanding standardization activities of this organization has been the adoption of a uniform catalog for the use of the dental supply dealer. Standardization and simplification have been carried out on the subjects of finishes for equipment, lathe-shaft ends, crown and bridge cement, baseplate wax, gold shell lengths, felt wheels and cones, chamois wheels, mechanical saws, gold files, vulcanite files, and electrical receptacles. Similar work is going forward on numerous other items used in the dental trade.

Under the auspices of the National Bureau of Standards, this association sponsored the projects for simplification of sizes and varieties for dental hypodermic needles; dental brush wheels; packaging of dental plaster, investment, and artificial stones; dental lathe grinding wheels; dental cone-socket mirrors; and dental rubber (base and veneering). These resulted in the establishment of Simplified Practice Recommendations for each item, which were promulgated and published by the National Bureau of Standards.

American Drug Manufacturers Association, Carson P. Frailey, executive vice president and secretary, 506 Albee Building, Washington, D. C. The work of standardizing drugs is carried on by this association through the activities of several committees organized for this purpose. Many members of these committees serve as asso-

$201072^{\circ}-41-3$ 
ciate members on various revision committees engaged in the revision of the United States Pharmacopoeia and the National Formulary.

One of the principal committees of this association is the Pharmaceutical Contact Committee, a joint committee composed of representatives of the American Pharmaceutical Manufacturers' Association and this organization. This committee deals with problems regarding drug standardization and cooperates closely with governmental and other standardizing agencies.

The Drugs Resources Committee was organized to cooperate with the War and Navy Departments on standards and other problems arising in connection with the national defense program.

The association's Committee on Chemical Tests and Standards was engaged during the past year in investigating several problems concerned with physical constants purity tests, and assay procedures for several USP chemicals. The Biological Section has organized two committees, one to study standardization of bacterial vaccines, and the other to investigate laboratory animals used in biological standardization.

The Committee on Transportation of this association cooperated with the Interstate Commerce Commission in revising the standard rules and regulations for the transportation of hazardous articles by rails and with the U.S. Maritime Commission in connection with proposed regulations regarding coastwise, intercoastal, and export shipments.

In addition, other committees of the association have been active in the development of work on the following projects: Alkaloid and drug standards; analytical assay methods; chemical tests and standards; standardization of vaccines; and standardization of bacterial suspensions by electrophotometric methods.

American Dry Milk Institute, Inc., Roud McCann, director, 221 North La Salle Street, Chicago, Ill. All methods of analysis and work relating to standards for the product of the dry milk industry are carried on by the Standards Committee of this institute. This committee also functions as the Packaging Committee, supervising the general types of packages adaptable for use in packing the industry's products. It is also continuously engaged in matters pertaining to the improvement in analysis, and the improvement and adaptation of standard packages for use in the industry, together with other matters affecting quality improvement and related standardization.

Some of the activities of the Standards Committee have resulted in the development of standards which have been approved by the institute. For example, the institute has adopted and published feed grades for dry skim milk, which cover standards for choice, standard, and sample feed grade. It also adopted a standard grade of dry milk solids (not over $11 / 2$ percent of fat), including method of analysis.

The institute devotes considerable time and attention to projects which are designed to improve standard methods of use among the various industries which it serves, and the development of standard qualities adaptable to the particular field in which sales are made.

American Electro-Platers' Society, W. J. R. Kennedy, executive secretary, 93 Oak Grove Avenue, Springfield Mass. This society cooperates with the American Society for Testing Materials and the National Bureau of Standards in a study of the protective value of 
plated coating on steel. It maintains two research associates at the National Bureau of Standards on research on effects of methods of preparing metals upon protective value of coatings.

The society is represented on the Sectional Committee for Specifications for Zinc Coating of Iron and Steel, functioning under the procedure of the American Standards Association. The work of this committee has already resulted in the development of American standards for zinc-coated sheets; coatings on structural steel shapes, plates, and bars; zinc-coated iron or steel wire; specifications for zinccoated iron or steel chain link fence fabric galvanized weaving; zinccoated iron or steel wire (cable); zinc-coated wrought-iron sheets; and zinc-coated welded and seamless steel pipe for ordinary purposes.

It is also represented on committees for the American Society for Testing Materials dealing with corrosion of iron and steel, and exposure tests of plating on the nonferrous metals.

American Feed Manufacturers' Association, Inc., Ralph M. Field, president, 53 West Jackson Boulevard, Chicago, Ill. This association cooperates very closely with the Association of American Feed Control Officials, both of which have been in existence for more than 30 years. The work of this organization has to do in bringing about uniformity as far as possible in all State laws regulating the manufacture, distribution, and sale of commercial feeding stuff. Every State in the Union except one has at the present time enacted legislation concerning regulations and specifications of commercial feeds sold in the States.

This association cooperates also with the Food and Drug Administration, Federal Security Agency, in its enforcement of the Federal Food, Drug, and Cosmetic Act.

American Foundrymen's Association (Inc.), R. E. Kennedy, secretary, 222 West Adams Street, Chicago, Ill. Practically all standardization work of this organization is carried on in cooperation with the American Society for Testing Materials and the American Standards Association, although through the appointment of several committees, it has developed standards and codes which have been approved and adopted by the association.

The board of directors of this association, realizing the need of having industry develop foundry process codes in order to have uniform practical information available for the industry, authorized the formation of an Industrial Hygiene Codes Committee. The functions of this committee are to assist in the standardization of dust-eliminating equipment and improvement of shop operation conditions in the foundry industry; and to promote standards therefor in cooperation with manufacturers of such equipment. This committee has already developed recommended good practice codes relating to fundamentals of design, construction, operation, and maintenance of exhaust systems; metal cleaning sanitation; grinding, polishing, and buffing equipment sanitation; testing and measuring air flow in exhaust systems; and protection of workers in foundries. This association's Committee on Foundry Sand Research prepared and issued a publication which contains standards and tentative standards covering testing and grading foundry sands and clays.

Through the Joint Committee on Pattern Equipment Standardization, this association sponsored the project on standard pattern 
colors, which resulted in the establishment of Commercial Standard CS19-32, promulgated and published by the National Bureau of Standards, U. S. Department of Commerce. The association maintains representation on 15 technical committees of the American Society for Testing Materials dealing with metallic and nonmetallic materials. It is a cosponsor with the Plumbago Crucible Association for outside dimensions of plumbago crucibles for nontilting furnaces in nonferrous foundry practice (H13-1925), functioning under the procedure of the American Standards Association.

In addition, it is represented on 11 ASA sectional committees on specifications for cast-iron pipe and special castings; manhole frames and covers; safety code for compressed air machinery and equipment; safety code for conveyors and conveying machinery; safety code for cranes, derricks, and hoists; safety code for the protection of heads, eyes, and respiratory organs of industrial workers; safety code for exhaust systems; specifications for sieves for testing purpose; standards for drawings and drafting room practice; and classification and designation of surface qualities.

American Gage Design Committee, H. W. Bearce, secretary, in care of National Bureau of Standards, U. S. Department of Commerce, Washington, D. C. This committee was formed in 1926 for the purpose of consolidating for the benefit of industry at large the independent efforts which were already in progress on the part of a number of large industrial concerns, representatives of the United States Government departments, and several of the leading gage manufacturers to simplify gage construction through the adoption of standard designs for gage blanks and component parts. The designs developed by this committee are now available to everyone and will minimize the necessity for the manufacture of special gages of the simpler types.

The work of this committee has been given full support and recognition by engineering societies, the American Standards Association, the National Bureau of Standards, the War and Navy Departments, and the National Screw Thread Commission.

The activities of the committee in standardizing the design of limit gages for plain plug and ring, and thread plug and ring gages of all sizes above 0.059 to and including $4 \frac{1}{2}$ inches in diameters were adopted in 1929. These standards were published in 1930 as Miscellaneous Publication M100 of the National Bureau of Standards, and subsequently promulgated by the United States Department of Commerce as Commercial Standard CS8-30, Gage Blanks.

The widespread adoption of these standards by gage manufacturers and industry led to a demand that the work be extended to include in the then present Commercial Standard gages of larger sizes and of other types commonly in use. Upon completion of this work the Commercial Standard was revised in 1933 and published and promulgated as Commercial Standard CS8-33.

In 1940, on recommendation of the American Gage Design Committee and with the approval of the Standing Committee of the industry, the Commercial Standard was again revised and issued as Commercial Standard CS8-41, Gage Blanks. As compared with the 1933 edition, it contains new standards for thread setting plug gages, taper thread ring gages, dial indicators, and master disks. 
In promulgating these standards, the committee has not intended to render obsolete existing stocks of gages in the hands of manufacturers and users; rather, it has been its intention to provide a standard which could be gradually adopted through replacement of existing stocks.

American Gas Association, Alexander Forward, managing director, 420 Lexington Avenue, New York, N. Y.; R. M. Conner, director, AGA Testing Laboratories, 1032 East Sixty-second Street, Cleveland, Ohio. This organization conducts many research and standardization activities relating to problems affecting the production, distribution, sale, and utilization of gas.

Problems connected with the development of national standards for gas appliances are entrusted to the association's Approval Requirements Committee. This committee has general supervision over the preparation of all approval requirements for gas-burning appliances, listing requirements for gas appliance accessories, and installation requirements for house piping, appliances, and accessories. It is responsible directly to the Executive Board of the American Gas Association. Being a sectional committee of the American Standards Association it is also responsible to the Board of Directors and Standards Council of that association when requirements are submitted and approved as American Standard or as American Recommended Practice. This group is a standing committee and has operating under it, at the present time, some 33 requirements subcommittees. It makes assignments to these subgroups, has general supervision of their work, and passes on all requirements developed by them. It authorizes the appointment of additional subcommittees from time to time for the development of requirements for additional types of equipment or for other purposes as the necessity arises. The chairman appoints members of all standing and special subcommittees. New or revised requirements which have been developed by a subcommittee, after publication and distribution for criticism, are completed by this committee and submitted to the Executive Board and to the American Standards Association for approval as American Standard.

The chairman, secretary, and others of this group are appointed by the president of the American Gas Association. Manufacturer member appointments are made from nominations by the Association of Gas Appliance and Equipment Manufacturers. Two of the gas company representatives on this committee must also be members of the Laboratories Managing Committee. Members representing government bureaus and trade associations are selected by the organizations they represent on request of the committee chairman. The director of the laboratories is a member of this group and acts as its secretary.

Subcommittees of the ASA Sectional Committee, Project Z21, AGA Approval Requirements Committee receive assignments from and are responsible to the Approval Requirements Committee. Each subcommittee is usually charged with the detailed development of requirements for one particular class of gas appliance, or gas appliance accessory. When a subcommittee has completed a set of requirements it is submitted to the Approval Requirements Committee for further consideration. The subcommittee's work continues from year to year in the revision of and addition to the requirements. These committees also serve another purpose as they are often called upon by the Ameri- 
can Gas Association testing laboratories to interpret certain requirements when a need for clarification arises.

There are four classifications of subcommittees, namely, those instructed to prepare requirements for (1) approval, (2) listing, (3) installation, and (4) standardization.

Approval requirements are prepared for complete self-contained gas-burning appliances or those which consist not only of equipment for burning the gas but also for utilizing the heat or products of combustion therefrom, such as gas ranges or boilers. Listing requirements are drawn up for accessories, such as valves, thermostats and others which are incorporated as a part of a gas appliance. Requirements for installation of gas appliances are prepared for the guidance of the industry in making correct installations of gas equipment. The function of the Standardization Subcommittee is to assist in standardization of form and phraseology of all requirements.

Approval, listing and installation requirements have been developed by the American Gas Association and approved as American Standards by the American Standards Association covering practically all types of domestic gas appliances, many commercial appliances, and gas appliance accessories.

The approval requirements include domestic gas ranges; hotel and restaurant deep fat fryers; portable gas baking and roasting ovens; gas counter appliances; space heaters (including radiant heaters; circulator heaters; wall heaters; gas steam, hot water and warm air radiators; gas logs and imitation coal baskets) ; water heaters (including storage, circulating tank, instantaneous, etc.); central heating gas appliances (including steam and hot water boilers, basement furnaces, and floor furnaces); gas unit heaters; hot plates and laundry stoves; clothes dryers; incinerators; industrial gas boilers; private garage heaters; hotel and restaurant ranges; gas heated ironers; refrigerators using gas fuel; and gas hair dryers.

Listing requirements have been published for the following types of accessories: Gas-burner valves; gas conversion burners; draft lioods; domestic gas appliance pressure regulators; relief and automatic gas shut-off valves for use on water-heating systems (including pressure relief valves, temperature relief valves, vacuum relief valves, and automatic gas shut-off valves); water heater, gas range, and space heater thermostats; automatic devices designed to prevent escape of unburned gas; automatic main gas-control valves (including electric gas valves and diaphragm valves); semirigid gas appliance tubing and fittings; attachable gas water heating units without watercarrying parts; flexible gas tubing; furnace temperature limiting controls and fan controls.

In addition to the above requirements which involve laboratory testing, the committees have developed the following standards of general interest to the industry which include: Installation of conversion burners in house heating and water-heating appliances; and house piping and appliance installation.

The approval seals and listing symbol of the American Gas Association are copyrighted and may be used on appliances, accessories, in advertising or otherwise, only with the consent of the association's Iaboratories. The approval seal and listing symbol are intended to indicate that the equipment to which they are attached has been 
tested and approved or listed by the American Gas Association testing laboratories as complying in detail with all requirements in effect at the time approval or listing was granted. When approval or listing has been granted it is mandatory that the official insignia in exact accordance with the association's requirements be prominently displayed on the appliance or accessory. The approval seals or listing symbol may be shown on, or advertised in conjunction with, only such appliances, appurtenances, or accessories currently approved or listed at the time shown or advertised.

The laboratory seal of approval must be permanently attached to all approved gas appliances. As this permanent seal is usually attached to the manufacturer's name plate and located in a concealed position, an auxiliary approval seal in the form of a gummed paper label or cardboard tag of approved design should be affixed, in a conspicuous position, to the front of every approved appliance. Name-plate manufacturers supply the permanent seals while the laboratories supply the gummed labels or tags at cost.

After approval or listing has been granted on an appliance or accessory, a record of same will be included in the Directory of Approved Gas Appliances and Listed Accessories. This publication is issued in complete form quarterly. Supplements are published as of the first of each intervening month including all devices approved during that month. This is the official record of approved or listed equipment and all appliances entitled to bear the approval seals or listing symbol are included therein.

Approval of appliances and listing of accessories are granted for the ensuing calendar year. Approval and listing may be renewed, however, from year to year for a period not to exceed a total of 5 years by means of an annual factory-inspection service. At the expiration of this period the appliance or accessory is required to be resubmitted to the laboratories and subjected to the requirements then in effect, if further certification is desired. If there has been no change in the requirements or the appliance since it was last tested, no actual tests may be needed and extension may be granted by inspection.

The association cooperates with the American Society for Testing Materials by representation on the technical committee on water for industrial uses, and on the Coordinating Committee on Corrosion.

American Gear Manufacturers Association, J. C. McQuiston, manager-secretary, 602 Shields Building, Wilkinsburg, Pa. This association has in its membership representatives of practically all of the gear manufacturers in the United States. Recognizing a great need for the development of technical standards in the industry, it has for more than 25 years carried on a continuing program for the development of technical standards dealing with all kinds of gearing, as well as in the materials used in their manufacture. More than 25 fundamental technical standards have been formulated by this association through the efforts and cooperation of its technical committees. These standards have been adopted and are applied by the diversified industries the world over.

In its handbook on practices there are included recommended practices for computing allowable tooth loads and stresses in spiral bevel and straight bevel gears for industrial applications; data sheets on 
comparative sizes of gear teeth; standards for electric railway gearing; recommended practice for gearing nomenclature, terms, and definition; rating of helical and herring-bone gear speed reducers used for oil field pumping units; holes in gears; standards for nonmetallic spur gear formulae covering the manufacture of phenolic laminated and rawhide spur gears; gear materials and blanks; standards for transmission roller chains, sprockets, and cutters; recommended practice for computing the load carrying ability of metal spur gears; standard for spur gear tooth forms; recommended practice for formulae and specifications for the design and rating of heavy duty worm gear speed reducers. In addition, the association has also issued a publication relating to a recommended practice for uniform cost accounting.

In its work in standardization, the association cooperates actively with the American Standards Association. It is joint sponsor for ASA sectional committees on standardization of gears, and on transmission chains and sprockets. It is also officially represented on sectional committees dealing with projects relating to standardization of shafting; classification and designation of surface qualities; petroleum products and lubricants; and graphical symbols and abbreviations for use in drawings.

The association is at the present time engaged in developing recommended practices for the following projects: Industrial gear lubrication, inspection tolerances for gears, rating of planetary type and spur gear type speed reducers, concentric and parallel shaft gear motors, gear geometry, standard keyways for holes in gears, and backlash for general-purpose spur gears.

American Gem Society, Robert M. Shipley, executive director, 541 South Alexandria Avenue, Los Angeles, Calif.' This society has among its committees one known as Nomenclature Committee, the personnel of which consists principally of retail jewelers throughout the United States and Canada, and of advisory groups of diamond importers and jewelry manufacturers. This committee considers recommendations from its members in the various branches of the trade, and makes recommendations regarding definitions, standards, and practices for consideration and adoption by the entire membership of the society at its annual meetings. In carrying forward its work, this committee cooperates with the Jewelers' Vigilance Committee, the National Association of Better Business Bureaus and its affiliated bodies, and the Federal Trade Commission.

American Glassware Association, 19 West Forty-fourth Street, New York, N. Y. This association has developed standards in regard to illuminating glassware. These standards were later accepted by the Illuminating Engineering Society for the piece of white glass which is around the incandescent bulbs in IES lamps. This association has developed a labeling plan whereby stamped glass reflectors are labeled by means of identification indicating that the reflector is certified by the Electrical Testing Laboratories. Each reflector so stamped carries with it the name of the manufacturer.

American Gum Importers Association, Inc., George T. Hawxhurst, secretary, 360 Furman Street, Brooklyn, N. Y. Although this association has not issued standards or specifications for imported natural resins, it does, however, issue a National Resins Handbook, which con- 
tains much data on the properties and application of natural resins. Much of the data so compiled is the result of the research and development program being carried out by the association's laboratory.

American Home Economics Association, Edna M. Van Horn, executive secretary, 620 Mills Building, Washington, D. C. In the development of more enlightened purchasing practices on the part of the household buyers, this association has been conducting an extensive educational program through its various affiliated associations and through its publications, particularly the Journal of Home Economics and the Consumer Education Service. The association considers that it can serve in the standardization movement in two important ways : (1) to represent the consumer's point of view to those who are concerned with the production and distribution of consumer's goods; and (2) to disseminate information about the need for and progress in standardization in the consumer-goods field.

The association is a member body of the American Standards Association and is represented on its Standards Council. It is also officially represented on sectional committees functioning under ASA procedure in the development of standards for minimum requirements for plumbing and standardization of plumbing equipment, standards and specifications for refrigerators, ventilation code, approval and installation requirements for gas-burning appliances, and electrical standards.

The association is also a member of the Advisory Committee on Ultimate Consumer Goods and subcommittees thereof, functioning under the auspices of the American Standards Association. As such, the American Home Economics Association takes an active part in developing consumer standards for bedding and upholstery, boys' clothing, sheets, shoe shanks, hosiery, silver-plated tableware, household refrigerators, gas and electric appliances, waterproof materials, definitions of terms used in retailing, and pattern sizes. It is also serving as sponsor for the ASA sectional committee on standardization of sizes of children's garments. The committee has voted to recommend the establishment of a standard system of children's body measurements based upon the height and hip measure which could be used as a basis for garment and pattern sizes. The committee's recommendations are based on the study of body measurements initiated by the Bureau of Home Economics, U. S. Department of Agriculture.

The association has cooperated from time to time with units of industry and with the National Bureau of Standards in the establishment of commerical standards for dress patterns, men's pajamas, wallpaper, plate glass mirrors, colored sanitary ware, knit underwear, and other items of consumer use.

Articles on standardization and its benefits to the consumer appear in the association's Journal of Home Economics on such subjects as textiles, tests, and specifications for the household, food products, labeling of commodities, and purchasing problems of the household buyer.

American Hospital Association, Bert W. Caldwell, M. D., executive secretary, 18 East Division Street, Chicago, Ill. For more than 20 years this association has concerned itself with simplification and standardization of hospital equipment and supplies. Through its 
Committee on Simplification and Standardization of Hospital Furnishings, Supplies and Equipment, there was prepared the Manual of Specifications for the Purchase of Hospital Supplies and Equipment which was published by the association during the past year. This manual is largely a compilation of specifications for hospital equipment, materials, and supplies in use, having been developed by various Federal agencies, including the National Bureau of Standards, Federal Specifications Executive Committee, War Department, Navy Department, and Veterans' Administration. Pertinent standards and specifications formulated by nongovernmental agencies are also included.

In cooperation with the Rubber Manufacturers Association, this organization initiated the programs which resulted in the establishment of Commercial Standards CS38-32 for rubber sheeting; CS40-32 for surgeons' rubber gloves; and CS41-32 covering surgeons' latex gloves. It also sponsored the movement for the establishment of Commercial Standards CS54-35 and CS55-35 covering mattresses for hospitals and institutions, respectively. All of the above-mentioned Commercial Standards were developed under the auspices of the National Bureau of Standards and promulgated and published by that agency.

This association has also taken an active part in simplification work. It cooperated with the National Bureau of Standards in programs for the elimination of unnecessary sizes and varieties, and the establishment of schedules of stock sizes for hospital beds, hospital chinaware, hospital and institutional cotton textiles, and hospital plumbing fixtures, which are set forth in the various Simplified Practice Recommendations covering these items.

During the present year, in cooperation with the American Society of Anesthetists and the National Bureau of Standards, this association assisted in the establishment of Simplified Practice Recommendation R176-41 relating to color marking for anesthetic-gas cylinders. This association is officially represented on three sectional committees, functioning under the procedure of the American Standards Association, on the following projects:minimum requirements for plumbing and standardization of plumbing equipment; standards and specifications for refrigerators; and ventilation code.

American Hot Dip Galvanizers Association, Inc., Stuart J. Swensson, secretary, 903 American Bank Building, Pittsburgh, Pa. Matters relating to standardization, simplification, technical research and development are some of the principal activities of this organization. Practically all of this work is carried on through its Technical Advisory Committee, which is in charge of all such work, including consultants on metal coatings whose services are retained by this organization.

This association has prepared and issued tentative standard specifications for hot-dipped zinc-coated (galvanized) products; malleable and cast iron castings and fittings; bolts and nuts, lag screws, washers, pole-line hardware; turnbuckles; range boilers and tanks; chain-link fence, wire fabric, and wire products; light steel boxes and containers, and cans made out of light sheet iron; pipe; refrigerator coils and refrigerator parts; gratings, grills, and like articles; hoops and bands made of strip steel; chain; large smokestacks and like articles; very small articles-rivets, nails and tacks; wiped articles and awning iron; 
cans, metal ware, hollow ware and like articles; hot-dipped zinccoated (galvanized) steel window sash; hot-dip zinc-coated (galvanized) steel highway sign posts; and tentative method of test for uniformity of coating by the copper sulfate dip test (Preece test) on zinc-coated (hot-dip galvanized) steel castings and forgings, grayiron and malleable iron castings.

This association has adopted an official insignia in the form of tags and stickers. The use of this insignia is controlled by the association, and its members are permitted to use it so long as they continue to be members of the association and the quality of their products conforms to the specifications adopted by the association.

American Hotel Association of the United States and Canada, Thomas D. Green, executive director, 221 West Fifty-seventh Street, New York, N. Y. Activities of this association in the field of standardization are carried on in cooperation with other organizations.

In collaboration with the Vitrified China Manufacturers Association, this organization sponsored the movement which led to the establishment of standard sizes of hotel chinaware as set forth in Simplified Practice Recommendation R5, promulgated and published by the National Bureau of Standards. It also cooperated in the formulation of Simplified Practice Recommendation R113 relative to standard sizes of restaurant guest checks. Under the procedure of the American Standards Association, it cooperated through representation on sectional committees, in the development of American standard safety code for elevators, dumbwaiters, and escalators; and American recommended practice for the inspection of elevators. It is also represented on ASA sectional committees on standards and specifications for refrigerators; and on minimum requirements for plumbing and standardization of plumbing equipment.

The association is cooperating with the Food Service Equipment Industry in the establishment of simplified practice recommendations for standardized sizes, dimensions, and details of construction of numerous food service articles under the auspices of the National Bureau of Standards. It is also cooperating with the American Hospital Association in developing specifications for bedsheets under the procedure of the American Standards Association.

American Institute of Architects, Department of Technical Services, Theodore Irving Coe, technical secretary, 1741 New York Avenue NW., Washington, D. C.

Representatives of the institute not only reflect the opinion of the profession but, by reason of their professional relationship to the building public, represent the interests of the consumer on a considerable number of the committees dealing with the standardization and simplification of building materials, appliances and construction techniques.

The institute serves as cosponsor with several organizations, under the procedure of the American Standards Association, in the development of American standards for the following: Specifications for plastering; safety code for walkway surfaces; safety in the construc- 
tion industry; safety code for elevators, dumbwaiters, and escalators; and recommended practice of school lighting. It is also represented on 17 additional ASA sectional committees on projects dealing with building materials and construction and household appliances. The institute is a member of the Building Code Correlating Committee functioning also under the auspices of the American Standards Association.

The institute takes an active part in the standardization activities of the American Society for Testing Materials and participates in committee activities of the society dealing with development of standards and test methods covering nonferrous metals and alloys, cement, fire tests of building materials and construction, lime, gypsum, mortars for unit masonry, glass and glass products, manufactured masonry units, natural building stone, and bituminous waterproofing and roofing materials.

It was also officially represented on the Joint Committee on Standard Specifications for Concrete and Reinforced Concrete.

In connection with the establishment of simplified practice recommendations and commercial standards for various items relating to building materials, the institute cooperates with the National Bureau of Standards and with industry in the development of these standards. Through its technical secretary, it is represented on standing committees for 17 Simplified Practice Recommendations and 11 Commercial Standards.

The institute has issued several standard contract forms and has been instrumental in the formulation of recommendations as to size and character of advertising matter intended for architects, and the development of a standard filing system for trade literature.

American Institute of Baking, Tom Smith, secretary, 1135 Fullerton Avenue, Chicago, Ill. Conducted for scientific research and education, this institute operates laboratories for the analysis of ingredients, for teaching the value of laboratory control for bakery operation, and for standardizing raw materials. This institute sponsored the gathering of data and information on pan sizes and research with respect to standard pan sizes for white round-top, plain and twisted bread. It cooperates with the United States Department of Agriculture in furnishing technical reports which are prepared by the research department of the institute for use by that agency in the formulation of official rules and regulations.

American Institute of Bolt, Nut, and Rivet Manufacturers, Herman H. Lind, president, 1550 Hanna Building, Cleveland, Ohio. Through its Committee on Standards and Technical Practices and subcommittees thereof, this institute carries on considerable work relating to standardization and simplification of bolts, nuts, and rivets. In carrying forward this work, the institute cooperates with various Departments of the Federal Government, including the War and Navy Departments, the National Bureau of Standards, and the Government Interdepartmental Screw Thread Committee; also with the American Society of Mechanical Engineers, the American Society for Testing Materials, the American Standards Association, the Society of Automotive Engineers, and the technical bodies associated with other industries. 
Through its Committee on Standards and Technical Practices, the institute has published the Standards Book, in which are assembled the current adopted standard practices of the industry. The purpose of this book is to provide a means whereby further unification might be carried on progressively so that as far as practicable all commercial practices of the industry may be eventually standardized.

The institute initiated the movements under the auspices of the National Bureau of Standards for simplification of packaging of machine carriage and lag bolts; and stock production sizes of machine carriage and lag bolts (steel). These activities have resulted in the establishment of Simplified Practice Recommendations R60-30 and R169-37, respectively, both of which have been promulgated and published by the National Bureau of Standards.

The institute is officially represented on six sectional committees functioning under the procedure of the American Standards Association on the following projects: building code requirements for iron and steel; standardization and unification of screw thread; allowance and tolerances for cylindrical parts and limit gages; bolt, nut, and rivet proportions; classification and designation of surface qualities; and graphical symbols and abbreviations for use on drawings. It is also represented on committees of the American Society for Testing Materials engaged in standardization problems relating to wrought iron and steel.

American Institute of Chemical Engineers, S. L. Tyler, executive secretary, Chemists Building, 50 East Forty-first Street, New York, N. Y.

Through committee representation, this institute cooperates with other organizations in standardization work carried on under the auspices of the American Standards Association. The institute maintained representation on the sectional committee for the safety code for mechanical refrigeration, which was approved as American standard B9-1933 by the American Standards Association. It is now officially represented on four sectional committees functioning under the procedure of the American Standards Association, dealing with the following projects: Allowable concentrations of toxic dusts and gases; letter symbols and abbreviations for use on drawings.

The Institute is represented on the coordinating committee on corrosion of the American Society for Testing Materials. It also cooperates with the Process Industries Division of the American Society of Mechanical Engineers in the preparation of test codes of interest to the members of the institute.

American Institute of Consulting Engineers, Philip W. Henry, secretary, 75 West Street, New York, N. Y. This organization takes an active interest in matters relating to standardization. It cooperates with other organizations under the procedure of the American Standards Association on sectional committees in the following standardization projects: Building exits codes; rating of rivers; building code requirements for excavations and foundations; code for pressure piping; definitions of electrical terms; rotating of electrical machinery; and standards for drawings and drafting room practice.

American Institute of Electrical Engineers, H. H. Henline, national secretary, 33 West Thirty-ninth Street, New York, N. Y. All standardization work of the institute is carried on under the direction 
of the standards committee the members of which are appointed by the president. This committee is directly responsible to the institute's board of directors. The committee consists of 12 appointed members, the chairman of the AIEE delegations on other standardizing bodies, the chairmen of working committees, and the president of the United States National Committee of the International Electrotechnical Commission.

The standards of the institute at the present time comprise about 50 sections on electrical machinery and apparatus. These standards are chiefly devoted to defining terms, conditions, and limits which characterize behavior, with special reference to accepted tests. Many of them are recognized officially as American standards by the American Standards Association.

The institute is a member body of the American Standards Association and is represented on the latter's Electrical Standards Committee and its Standards Council. It is sponsor or joint sponsor for the following sectional committees, functioning under the procedure of the American Standards Association, on projects relating to: Code for protection against lightning; hard drawn aluminum conductors; industrial control apparatus; mercury arc rectifiers; railway motors and other rotating electrical machinery on rail cars and locomotives; storage batteries; definitions of electrical terms; standards for electric railway control apparatus; standards for capacitors; standards for lightning arresters; locomotives for coal mines; letter symbols and abbreviations for science and engineering; and graphical symbols and abbreviations for use on drawings. It is also officially represented on many additional ASA sectional committees covering problems in the electrical field.

The institute cooperates with other leading technical bodies, notably the National Electrical Manufacturers Association, the Edison Electric Institute, the American Society for Testing Materials, and the National Bureau of Standards, in matters relating to electrical machinery, apparatus, and materials.

American Institute of Homeopathy, T. H. Carmichael, M. D., chairman, Pharmacopoeia Committee, in care of President's House, Tufts College, Tufts College, Mass. The Pharmacopoeia Committee of this institute prepared the Homeopathic Pharmacopoeia of the United States, first issued in 1897. This publication lists, describes, and gives standard strengths of tinctures, dilutions, medications, and triturations for all drugs which have a recognized use in the preparation of homeopathic remedies. A revised edition of this publication was issued in 1941.

American Institute of Laundering, George H. Johnson, general manager, Joliet, Ill. This institute has consolidated within its organization the Laundryowners National Association of the United States and Canada.

The institute represents a service industry and as such does not develop specifications for commodities. It does, however, maintain research laboratories for the development of better laundering methods, for analysis of the cause of damage to damaged articles, and for studying and testing qualities of textiles before they are placed on the market. 
Through its Department of Research and Textiles, the institute prepared and published the Manual of Standard Practice for the Power Laundry Washroom and a Service Bulletin on Washing Formulas. This bulletin describes typical family and commercial flatwork washing formulas, determination of the proper number of suds, and the causes of linting and graying.

The institute was joint sponsor, with the International Association of Government Labor Officials and the National Association of Mutual Casualty Companies, in the development of the safety code for laundry machinery and operations which was approved as an American standard by the American Standards Association.

American Institute of Mining \& Metallurgical Engineers, A. B. Parsons, secretary, 29 West Thirty-ninth Street, New York, N. Y. Many of the standards, specifications, and codes that have engaged the attention of this institute were developed in cooperation with national technical bodies, principally the American Standards Association and the American Society for Testing Materials.

The institute served as sponsor for American recommended practice for methods for screen testing of ores (M5-1932) and American recommended practice for rock dusting coal mines to prevent coal dust explosions (M13-1925), both of which were approved by the American Standards Association. It is also serving as sponsor under the procedure of the American Standards Association for the project on specifications for clean bituminous coal. In addition, the institute is officially represented on several ASA sectional committees including those dealing with the following subjects: safety code for cranes, derricks and hoists; code for pressure piping; electric and magnetic magnitudes and units; specifications for zinc coating of iron and steel; classification of coals; petroleum products and lubricants; and specifications for sieves for testing purposes; and graphical symbols and abbreviations for use on drawings.

With reference to its cooperation with the American Society for Testing Materials, this institute is represented on the Coordinating Committee on Corrosion, Committee on Coal and Coke, and Committee on Metallography. The institute also took an active part in the establishment of Simplified Practice Recommendation R79-28 for malleable foundry practices, which was promulgated and published by the National Bureau of Standards.

American Institute of Refrigeration, J. F. Nickerson, general secretary, 433 North Waller Street, Chicago, Ill. This organization, over a period of many years has taken an active part in cooperating with technical organizations in the development of standards and codes of interest to the refrigeration industries. Under the sponsorship of the National Bureau of Standards, this organization cooperated in carrying out investigations leading to the establishment of units and standards of refrigeration, and the determination of the physical constants of materials used in refrigerating industries. This investigation led to the formulation of the report by the Bureau on the determination of latent heat of fusion of ice, which was presented to the Third International Congress of Refrigeration. This resulted in the establishment of an international agreement based on the findings of the National Bureau of Standards. 
In connection with the development of standards, the institute, in cooperation with the National Association of Ice Industries and the National Refrigerator Manufacturers Association, initiated the movements for the simplification of sizes of ice cakes and the refrigerator ice compartments, which led to the formulation of Simplified Practice Recommendations R96-28 and R109-29, respectively. These recommendations were promulgated and published by the National Bureau of Standards.

Through its Committee on Standards, the institute maintains official representation on sectional committees of the American Standards Association dealing with the following subjects: pipe flanges and fittings; standardization of dimensions and materials of wrought iron and wrought steel pipe and tubing; standards and specifications for refrigerators; specifications for pressure and vacuum gages; and letter symbols and abbreviations for science and engineering. The institute collaborated in the development of the safety code for mechanical refrigeration which was approved as American standard B9-1933 by the American Standards Association. Recently the American Institute of Refrigeration sponsored a movement to standardize the temperature and relative humidity conditions of cold-storage vaults for the protection of furs and fabrics during the summer season.

American Institute of Steel Construction, V. G. Iden, secretary, 101 Park Avenue, New York, N. Y. This institute was founded in 1921 to further the interests of structural steel in its fabrication, erection and use, through a constructive cooperative program. Its membership is made up of manufacturers engaged in the fabrication and erection of structural steel. Activities of the institute are indicated in the names of its active committees, which include aesthetic design of steel bridges, bonding legislation, code on standard practice, cost accounting, elevated highways, specifications, statistics, and uniform contracts. In addition, the institute carries on technical research programs in regard to the fabrication and erection of structural steel at the National Bureau of Standards, Lehigh University, Columbia University, and New York University.

This institute has prepared and issued tentative minimum requirements and tentative standard welded connections for tier buildings, and also standard specification for fusion weIding of building steel. It also prepared and revised its Manual of Steel Construction in which are included, among other things, the institute's specification for the design, fabrication, and erection of structural steel for buildings, code of standard practice, and specification for fire-proofing structural steel buildings; also specifications of the American Society for Testing Materials covering steel for bridges, steel for buildings, and structural rivet steel; extracts from code for fusion welding and gas cutting in building construction; and minimum live loads allowable for use in the design of buildings, as recommended by the National Bureau of Standards.

The institute takes an active part in the work of technical committees of the American Society for Testing Materials, the American Society of Civil Engineers, and the American Welding Society. It participated in the development of the American standard specifications for fire tests of building construction and materials. 
This institute has recently joined the American Standards Association as a member-body. It is cosponsor with the American Society of Civil Engineers for the project on building code requirements for iron and steel, functioning under the American Standards Association procedure. It is officially represented on five additional ASA sectional committees dealing with building code requirements for excavations and foundations; electric welding apparatus; classification and designation of surface qualities; safety code for grandstands; and graphic symbols and abbreviations for use on drawings.

American Iron and Steel Institute, Walter S. Tower, president, 350 Fifth Avenue, New York, N. Y. One of the major activities of this institute is in connection with a project involving the selection and standardization of a group of steels to be known as standard steels. This work is being carried on under the auspices of the institute by technical committees, the titles of which are indicated by the following subjects with which they deal: Alloy steel, axles, carbon steel bars, cold-rolled strip steel, hot-rolled strip steel, pig iron and ferroalloys, plates, rails, semifinished steel, sheet steel, structural shapes, tin plate, terneplate, and black plate, track accessories, tubular products, wire rods and wire, wrought-steel wheels, and specifications and publications.

Each of these individual technical committees is doing considerable work in classifying and defining the products, and in collecting and compiling manufacturing tolerances, and methods relative to standard methods of inspection for the respective products, and in reviewing existing specifications with a view toward standardizing those which are found to be most common. The work of the respective committees is presented in a series of sections of a Steel Products Manual. All these committees have and still do, from time to time, cooperate with agencies of the Federal Government, including War, Navy, and Commerce Departments, as well as with technical and trade organizations, in matters relating to technical problems and specifications.

This institute is officially represented on sectional committees on mechanical standards and standardization of Methods of Recording and Compiling Accident Statistics, and all standards and specifications for petroleum products and lubricants, and fire tests of materials and construction functioning under the procedure of the American Standards Association.

American Leather Belting Association, E. R. Rath, executive manager, 53 Park Row, New York, N. Y. All matters concerning standardization and simplification of leather belting are handled by the Engineering Committee of this association. Through the work of this committee, the association has adopted horsepower rating table for oak-tanned flat leather belting, has compiled engineering data for a book entitled Short Center Pivoted Motor Leather Belt Drives, and cooperated in the formulation of Federal specifications for vegetable-tanned flat leather belting. It also assisted in the preparation of Federal specifications for flat leather belting and round leather belting.

The Engineering Committee carries on work with the American Society of Mechanical Engineers in the issuance of a standard com$201072^{\circ}-41-4$ 
bining the essential features of the Federal specification for vegetabletanned flat leather belting and this association's horsepower rating table.

American Leather Chemists Association, B. M. Blair, executive secretary, 143 West Twentieth Street, New York, N. Y. This association has recently organized a Technical-Industrial Coordinating Committee for the purpose of establishing cooperation between the 'Tanners' Council of America and this association, together with committees of governmental agencies on technical and standardization problems which may confront the industry from time to time. Other committees of this organization, in cooperation with the National Bureau of Standards and other technical bodies, are carrying on work on various problems relating to the leather industry, including the development of physical tests of leather. Through the efforts of these committees, the association has adopted the following provisional methods: Measuring tearing strength of leather; measuring the susceptibility of leather to cracking and piping; determining the $\mathrm{pH}$ values of vegetable materials containing tannin; cloud and pour points of oils; measuring leather; preparation of samples of leather for analysis; and measuring the bursting strength of leather.

The committees are continuing their studies in establishing methods for conditioning leather for testing; sampling leather for physical tests; analysis of sulfated oils; and method of $\mathrm{pH}$ value of vegetabletanned leather.

American Lighting Equipment Association, H. L. Dillingham, secretary, 19 West Forty-fourth Street, New York, N. Y. This association was organized during the past year by a number of manufacturers of residence lighting fixtures. It is a trade organization which has for its purpose the promotion of certified residential luminaires, the stimulation of national consumer acceptance of luminaires generally, and to expand the present residential fixture market.

Through its Board of Design, the association plans to issue suggestions for the improvement and raising of design standards. Upon certification of sample luminaires, tested by the Electrical Testing Laboratories under the association's specifications incorporating Illuminating Engineering Society's recommended practice, tags will be issued to create an Association promotional fund. On one side of the tag will be the ETL certification of compliance with the specifications, and on the reverse side the ALEA testimonial giving assurance of good design.

American Match Manufacturers' Association, Emil Kekich, secretary, 60 East Forty-second Street, New York, N. Y. Although this association has no special committees dealing directly in standardization work, it does, through its members, take an active part in this work by cooperating with agencies whose interests are allied or related with those of the match industry. It cooperated with the Federal Specifications Executive Committee in the development of the Federal Specification for Safety Matches and in the revision thereof; and with the Interstate Commerce Commission in the revision of regulations relative to shipping containers for transportation by common carriers. This industry has established volume standards for a number of sizes of woodstick match boxes, and the method of packing and the form of wrapped packages of each box have been quite generally standardized through practice. 
American Meat Institute, 59 East Van Buren Street, Chicago, Ill. This institute maintains a Committee on Standardization for the purpose of preparing and recommending to its members standards for packages and supplies and for packs. It has developed standards for packinghouse supplies, packs, and equipment covering lard cans ; sausage, lard, and sliced bacon cartons; cheesecloth and muslin; paper (including standard sizes for wrapping of smoked meats); general specifications for nailed wooden boxes and crates; detailed specifications for boxes and crates; woodenware and cooperage; brushes; and ropes and twines; and packs for lard, sausage, and sliced bacon; and equipment for hand trucks; and beef and pork trolleys.

The institute is represented on the sectional Committee on Safety Code for American Refrigeration functioning under the procedure of the American Standards Association.

American Medical Association, Chemical Laboratory, Albert E. Sidwell, Jr., director, 535 North Dearborn Street, Chicago, Ill. The activities of the Chemical Laboratory are largely concerned with the examination of the constantly growing number of new products submitted to the Council on Pharmacy and Chemistry, with the establishment of standards for these products and with the reexamination of previously accepted products. Much attention is now being devoted to the various derivatives of sulfanilamide, and standards for a number have been established.

Other current investigations are concerned with vaso-constrictors, mercury and bismuth preparations, parenteral solutions, vitamin preparations, estrogenic substances, and other medicinal products.

The michrochemical and spectrographic divisions are constantly in operation and have contributed greatly to the efficiency, accuracy, and facilitation of the work of the laboratory.

American Medical Association, Council on Foods, F. C. Bing, secretary, 535 North Dearborn Street, Chicago, Ill. This council was created primarily for the purpose of preventing or discouraging unwarranted, incorrect, or false advertising claims in the promotion and mechandising of food products. To this end the council considers foods and food advertising in the light of established knowledge or of the best authoritative opinion concerning food and nutritional values; and according to rules adopted from time to time by the council in the interest and for the protection of public health and public welfare. Foods that appear to conform to the requirements thus formulated are accepted by the council.

The council grants the privilege for display of its Seal of Acceptance on the packages of accepted foods and in related advertising, or in accepted general educational advertising of trade associations or members of the food trade for classes of foods but independent of specific brands.

In general, foods merchandised under a label and their promotional advertising, and general or so-called educational advertising for classes or types of foods, come within the purview of the council.

The council does not attempt to consider individual food products of all kinds. Some natural foods of well known nutritive value such as milk, butter, eggs, fresh fruits, and vegetables are not examined, although nutritional claims made in general or educational advertising are examined on request. Some processed foods, especially those 
for which standards or definitions have been established likewise are not considered for description in the book "Accepted Foods." With the various processed foods, as with the natural foods which are not examined, the council reviews nutritional claims made for the products and reports on them when it is considered in the interests of the public to do so. When new representations are made for the nutritional value of foods, which go beyond those that are well recognized for such products, the council considers the claims and reports on them when such action is considered desirable.

Educational food advertising is a term often used to designate a type of informative advertising which deals with foods as a class, usually without reference to specific brands. Educational food advertising presenting reliable information on the nutritional or physiologic values of foods is examined by the council and, when such material complies with the rules, it may be declared accepted.

The Seal of Acceptance may be used on the container label or in connection with any form of advertising effort or display related to the product, after official notification of acceptance by the secretary of the council. In all cases the seal shall appear only on label or advertising pieces which prominently identify the accepted article and the responsible manufacturer or distributor.

The seal displayed on a label or advertisement featuring in any manner both accepted and unaccepted foods must be used or associated with the accepted products only in such manner that there can be no implication that the seal applies to the unaccepted foods also. Neither the seal nor any statement regarding acceptance may be used if there is any possibility of confusion or incorrect inferences.

The seal shall appear without comment on its significance unless such comment has been previously approved by the council. A statement proposed for such use follows: "The Seal of Acceptance denotes that (product name) and nutritional claims made for it are acceptable to the Council on Foods of the American Medical Association."

During the year the Council on Foods continued to give consideration to individual food products, but its attention is being directed more and more to broad nutritional questions. The council attempts to encourage the application of scientific knowledge in the manufacture of food products and research in the field of nutrition while it tries to discourage unwarranted claims for advertising and promotions of manufactured foods.

The recently published book, Accepted Foods and Their Nutritional Significance, which constitutes the official compendium of the work of the Council on Foods, presents a summary of the decisions of the council, the rules under which the council operates and the products accepted by the council for inclusion in its official lists.

American Medical Association, Council on Industrial Health, Car] M. Peterson, M. D., secretary, 535 North Dearborn Street, Chicago, Ill. Shortly after its establishment in 1937 the Council on Industrial Health developed a program of activities, mainly educational in character. Specifically, this educational program has included an Annual Congress on Industrial Health attended by physicians and others, a publications program covering essential details of medical organization in industry and occupational diseases, and the preparation of an outline or syllabus for industrial medical training useful 
in both undergraduate and graduate teaching. In a similar way, a clearing house of information, mainly for the benefit of the practicing medical profession, has been organized and maintained. The council also intends regularly to provide information concerning the scope, objectives, and methods involved in the industrial health movement, to investigate activities in the field of industrial health engaged in by lay and professional organizations, and to study medical nomenclature and other problems relating to the classification, indexing, and recording of causes of lost-time disability in industry.

At the request of the council, constituent State medical associations have organized committees on industrial health or have indicated existing agencies through which the council can act in efforts to elevate medical standards in industry. In much the same way, cooperating committees have been developed in the clinical specialty organizations, especially dermatology, ophthalmology, neuropsychiatry, radiology and pathology. Bulletins have been developed to facilitate interchange of information between the council and these committees.

The council has continued to investigate and has attempted to interpret for the general medical profession the activities and objectives of industrial nurses, engineers, and others, and intends to be of as much assistance as possible in improving the professional status of these allied groups. Studies of terminology in industrial health are being carried on with a view toward the preparation of a bibliography which, it is hoped, will aid in improving the standards of occupational diseases reporting by physicians. Subcommittees in the council are also engaged in the investigation of medical problems relating to standards of industrial medical practice, physical examinations, and workmen's compensation.

American Medical Association, Council on Pharmacy and Chemistry, Theodore G. Klumpp, M. D., secretary, 535 North Dearborn Street, Chicago, Ill. The Council on Pharmacy and Chemistry was created in $1905^{\circ}$ for the purpose primarily of protecting the public and the medical profession against fraud, undesirable secrecy and objectionable advertising in connection with proprietary medicinal articles. The council is composed of seventeen outstanding scientists, and an Executive Secretary.

The council judges products-for which claims of therapeutic virtue are made-based upon the composition of the substance, the pharmacologic, bacteriologic, or biologic data, and in the light of a vailable evidence presented under controlled clinical conditions. It is the belief of the council that in conducting work of this type the names of the members of the council and their professional connections should be known; that the products considered should be judged in accordance with certain rules that are published and may be obtained on request from the council.

A three-fourths affirmative vote is required for the acceptance of a product for inclusion in the book entitled New and Nonofficial Remedies, which is revised and published annually.

If a product is accepted for inclusion in New and Nonofficial Remedies, a statement of acceptance together with a complete description of the product is published in The Journal of the American Medical Association in the column conducted by the council. If a product is rejected, the council publishes a statement about the re- 
jection and the reasons therefor. In some cases where a manufacturer or distributor decides not to promote the product actively and wishes to obtain further data, the council will withhhold publication of the report during a limited period, provided such withholding will not suppress information of value to the public and the medical profession. If the concern decides to discontinue the product after council consideration, the council may decide that the report will not be published but the report is always available to those who inquire.

The work of the Council on Pharmacy and Chemistry is also enhanced by the aid it receives from the AMA Chemical Laboratory, which is equipped for a fine type of drug work. Besides the facilities for the regular type of investigative chemical work, it has a laboratory for microchemical analysis, and also a laboratory for spectrographic and other physical chemical measurements.

In addition to issuing the foregoing reports, the council in its endeavor to advance rational materia medica issues under its auspices a book entitled Useful Drugs, edited every other year.

The Council on Pharmacy and Chemistry also issues the book, The Epitome of the U. S. Pharmacopeia and National Formulary, which is revised whenever the Revision Committee of The U. S. Pharmacopeia issues new supplements. The aim of this book has been to include a concise report on the material in the Pharmacopeia and National Formulary which is likely to be of interest to physicians. This consists of the official titles and their abbreviations; synonyms; brief definitions; concise descriptions of the physical properties, when necessary; actions and uses, when necessary; and dosage.

For articles which are accepted for inclusion in New and Nonofficial Remedies or in the List of Articles and Brands Accepted by the Council But Not Described in NNR the council permits the use of its official seal of acceptance with the following stipulations: (1) The seal may be used on the packages of an article and in the advertising for it. (2) The seal, if used, must be the only seal of such character to appear. No objection is made, however, to any statement or device required or permitted by the government indicating compliance with regulations of a government bureau or department. (3) If the seal is used in price lists and catalogs which also feature unaccepted articles, it must be used for accepted articles in such manner that there can be no implication that the seal applies to the unaccepted articles. (4) The following statement in reference to the significance of the seal may be used in connection with the seal: "The 'accepted' seal denotes that (name of article) has been accepted for New and Nonofficial Remedies by the Council on Pharmacy and Chemistry of the American Medical Association." Further statements in regard to the seal must be submitted to and found acceptable by the council before they may be used. (5) The size of the seal on the package shall not be greater than one inch in height or diameter, and in advertising it shall be in proportion to the dimensions of the advertisement so as to afford ready recognition; but undue size, giving greater prominence to the seal than to other important features of the advertisement or detracting from the dignity of the seal in the opinion of the council, will not be permitted. 
When for any reason the acceptance of an article is rescinded, the seal must not appear on new labels or in new advertising for such article; and old labels and advertising which feature the seal must not be in circulation, in evidence, or before the public longer than six months subsequent to notification of the revocation.

Unless otherwise determined at the time of acceptance, articles admitted to New and Nonofficial Remedies will be retained for a period of three years, provided that during that period they comply with the rules and regulations which were in force at the time of their acceptance. New evidence indicating that the compliance with the rules no longer exists, for instance, with regard to unwarranted therapeutic claims, will be considered the basis for reconsidering the acceptance before the end of a period of three years. At the end of this period, all articles will be carefully reexamined for compliance with existing rules.

The council cooperates with the Food and Drug Administration and with other agencies of the Federal Government. Under certain provisions of the new Federal Food, Drug, and Cosmetic Act, therapeutic products sold for prescription purposes must bear on their labels the statement, "To be used only by or on the prescription of" a physician.

American Medical Association, Council on Physical Therapy, Howard A. Carter, secretary, 535 North Dearborn Street, Chicago, Ill. The Council on Physical Therapy was created in 1925. Its duty is to investigate and report on the merits of various nonmedicinal apparatus and devices offered for sale to physicians, hospitals, and the public. The Council on Physical Therapy operates in general along the same lines as those described under the Council on Pharmacy and Chemistry and its reports are published in The Journal of the American Medical Association under the column Council on Physical Therapy.

The council gives consideration to apparatus and devices offered to the profession for which diagnostic and therapeutic claims are made, and also reports on physical methods for the treatment of disease. Illustrative of the type of products on which this council gives consideration is the following classification: Air filters; audiometers; atomizers and assorted sprayers; diathermy; fever therapy equipment; hearing aids; heat applicators ; infra-red generators; inhalators and resuscitators; metabolism testers; oxygen therapy apparatus (humidifiers, tents, regulators); passive vascular exercise machines; respirators; radium and radon; special supports, abdominal belts and corsets; stethoscopes (electrical); and ultraviolet radiation equipment (sun lamps, therapeutic lamps, ultraviolet meters, ultraviolet transmitting glass).

The Council on Physical Therapy has recently decided to consider portable roentgen ray equipment and electrocardiographs. Products which are found acceptable according to the rules of the council are listed in a booklet entitled "Apparatus Accepted."

The Council on Physical Therapy continues to perform its function of investigating and issuing reports on physical therapy apparatus and methods, of recommending sound physical therapeutic measures, and of encouraging research. 
Minimum requirements for acceptable audiometers have been published, and the council has considered several new vacuum tube hearing aids.

The consideration of apparatus and the publication of reports have been the major activities of the council.

The problem of securing the most desirable means for eliminating radio interference caused by electromedical equipment has been one of the major issues commanding the attention of the council. Two methods, one the screening of the treatment room and the other the reservation of a definite frequency band in the electromagnetic spectrum, have been suggested.

The minimum requirements for the acceptance of sun lamps have been revised, adopted and published.

The council cooperates with the National Bureau of Standards in the investigation of large installations of roentgen ray apparatus. Two articles, one on the dangers of roentgen rays and another on minimum standards for fluoroscopes, have been prepared.

American Mining Congress, Julian D. Conover, secretary, Munsey Building, Washington, D. C. Standardization activities of this organization are carried on by its National Standardization Division, composed of two branches, coal and metal, and consisting of coal producing companies and manufacturers of mining equipment and machinery. The congress, through its standardization division, has developed and approved a number of standards under the procedure of the American Standards Association with which it cooperates with other technical bodies with reference to standardization matters relating directly or indirectly to the mining industry.

The congress served as sponsor for the development of the following standards which were approved by the American Standards Association as American standards: Safety rules for installing and using electrical equipment in coal mines; drainage of coal mines; coal mine tracks, signals, and switches; miscellaneous outside coal handling equipment; wire rope for mines; construction and maintenance of ladders and stairs for mines; safety code for coal mine transportation; underground transportation in metal mines; mechanical loading underground in metal mines; specifications for coal mine cars; and safety rules for installing and using electrical equipment in metal mines. It served as joint sponsor with the National Fire Protection Association in the establishment of the American recommended practice for fire fighting equipment in metal mines. It is joint sponsor with the American Institute of Electrical Engineers and the National Electrical Manufacturers Association in the development of specifications for trolley, storage battery, and combination type locomotives for coal mines, and sponsor for the ASA sectional committee on specifications for mine timbering. It is also officially represented on the ASA sectional committee dealing with classification of coals.

American Oil Chemists' Society, J. C. P. Helm, secretary, 509 Poydras Street, New Orleans, La. This organization is strictly a scientific society devoted to developing methods of chemical analysis of vegetables and animal oils, fats, waxes and soaps and their byproducts. In carrying forward this work, the society maintains 20 committees which are engaged in carrying on from time to time special investigations on various subjects. It has prepared and published 
official and tentative methods of analysis with respect to the following: Cottonseed, soybeans, crude cottonseed oil refining-lye tables, refined oils, fats and oils, soap and soap products, sulfonated oils, soap wrapper tests, crude glycerine, and olive oil.

The society is represented on the technical committee of the American Society for Testing Materials dealing with the development of standard specifications and methods of test for soaps and other detergents.

American Optometric Association, Inc., Edwin H. Silver, associate director, Farragut Medical Building, Seventeenth and Eye Streets, NW., Washington, D. C. A National Advisory Commission on Vision for Motor Drivers, appointed by this association at the instance of the National Conference on Street and Highway Safety, has prepared standards of visual acuity for motor-vehicle operators. The motor Vision Commission of this association has prepared and issued a report in the interest of standard State licensing requirements for automobile drivers. In cooperation with the National Research Council, this association is conducting research work on motor vision and highway safety.

American Paper and Pulp Association, E. W. Tinker, executive secretary, 122 East Forty-second Street, New York, N. Y. Seventeen trade associations representing divisions of the paper industry constitute the membership of this association.

Because of the numerous paper grades designed for many different uses, the problem of standardization in the paper industry is very complex. However, over a period of years, physical standards, as distinguished from quality standards, have been developed in the case of many paper grades. Through representation on the standing committee for Simplified Practice Recommendation R22 on paper, the association assisted in the revision of a standard schedule of basic paper sheet sizes for bond and writing papers, ledgers, looseleaf ledgers, machine posting ledgers, book paper (coated and uncoated), index bristol, and cover paper. This activity is being carried on under the auspices of the National Bureau of Standards.

In cooperation with the Institute of Paper Chemistry, the association has conducted a series of technical studies relative to the evaluation of existing instruments and the development of new ones for the measurement and testing of paper qualities. This instrumentation program constitutes the initial groundwork leading to the grading or standardization of the products of the paper industry.

Although not directly related to standardization proper, the association during the past year published the Dictionary of Paper which contains more than 3,500 definitions of pulps, other raw materials, papers, paperboards, paper properties, and papermaking terms. The contents of this publication afford considerable guidance in the consideration of problems of paper grades, specifications, or standards.

American Petroleum Institute, R. P. Anderson, secretary, Division of Refining, 50 West Fiftieth Street, New York, N. Y.; C. A. Young, secretary, Division of Production, 1508 Gulf States Building, Dallas, Texas. One of the principal activities of this organization, which represents the petroleum industry, is its effort to simplify, standardize, and improve oil country drilling equipment and methods. The 
fundamental purpose of this work is to bring about the adoption of such specifications and methods as meet with the practically unanimous approval of the producers of crude oil and the manufacturers of equipment.

In order to carry on its standardization work the institute adopted a plan or organization in 1929 which divided the work into three main divisions.

The Board of Directors is the governing body of the institute, and as such has authority to direct the work, and to adopt, modify, or reject proposed API specifications and standards. It acts on all matters relating to the standardization of oil field equipment through its Central Committee on Standardization of the Division of Production, and no specifications or standard are considered final except when approved by the Central Committee.

Under the auspices of the Division of Production function various committees on standardization of oil field equipment, development of codes of recommended practice, and codes of measuring, sampling, and testing crude oil and natural gas. These committees have prepared approximately 45 standards and codes covering subjects relating to belting, oil field boilers, cable drilling tools, standard rigs and derricks, oil country tubular goods, rotary drilling equipment, wire rope and manila cordage, pumping equipment and engines, and steel tanks for oil storage, which have been adopted by the institute.

In the Division of Refining functions the Committee on Standardization of Refinery Equipment which has prepared valve specifications (flanged steel outside-screw-and-yoke wedge gate valves and flanged steel plug valves).

In carrying forward its standardization work the institute cooperates with committees of certain national technical bodies on which it maintains representation. It is officially represented on 13 sectional committees, functioning under the procedure of the American Standards Association, on problems relating to standardization of pipe threads, pipe flanges and fittings, and shafting, code for pressure piping, wrought iron and wrought steel pipe and tubing, leather belting, electric motor frame dimensions, zinc coatings of iron and steel, wire rope for mines, transmission chains and sprockets, wire and sheet metal gages, specifications for pressure and vacuum gages, and petroleum products and lubricants. It also cooperates with the American Society for Testing Materials sectional committees on water for industrial uses and rubber belting.

In cooperation with a joint committee composed of representatives of the American Society of Mechanical Engineers and the institute, it developed a code for unfired pressure vessels for petroleum liquids and gases.

In the field of methods of tests and specifications for petroleum products, it cooperates actively with Committee D-2 on petroleum products and lubricants of the American Society for Testing Materials.

This institute, together with the Automobile Manufacturers Association and the Society of Automotive Engineers, maintains research associates at the National Bureau of Standards carrying on cooperative fuel research, which includes motor fuel knock rating and fuel requirements of cars; and flow characteristics of aircraft fuel systems. 
In promoting the use of its standards and specifications throughout the industry, the institute grants to manufacturers the right to place its official monogram on certain standardized equipment, certifying that the material so marked complied with all of the conditions and standards contained in the official publications relating thereto. The institute reserves the right to revoke the use of its monogram for any reason satisfactory to the Board of Directors.

American Pharmaceutical Association, Justin L. Powers, chairman, National Formulary Committee, 2215 Constitution Avenue, Washington, D. C. One of the primary functions of this association is the publication of the National Formulary, which includes standards for widely used drugs and preparations of them. The standards for drugs are established by a committee known as the National Formulary Committee, which consists of a full-time chairman and 10 members. Each member of the committee serves as chairman of a subcommittee consisting of four or five members in addition to the chairman. These subcommittees are divided to consider the following subjects: Pharmacology, chemicals, solution preparations, extractive preparations, solid preparations for internal use, external preparations, bacteriological and biological preparations, miscellaneous preparations, pharmacology and posology, and nomenclature.

The standards developed by this association are recognized as official within the meaning of the Federal Food, Drug, and Cosmetic Act.

Work of a chemical and pharmaceutical nature necessary in connection with establishing standards is carried out in the association's laboratory, which is maintained for that purpose.

Its cooperative work with other organizations includes representation on the technical committee of the American Society for Testing Materials relative to the preparation of standards and test methods for glass and glass products. It participates in the activities of the Inter-Society Color Council with respect to development of uniform definitions and standards for colors.

The association maintains a research associate at the National Bureau of Standards carrying on research relative to the scientific determination of the color names of drugs and chemicals.

American Pharmaceutical Manufacturers' Association, Charles Wesley Dunn, counsel, 608 Fifth Avenue, New York, N. Y. This association is collaborating with the Federal Government through its appropriate committees on matters arising under the Federal Food, Drug, and Cosmetic Act, and is also represented on the special Drug Resources Committee, which was created for the purpose of cooperating with the Federal Government in the program for national defense.

American Public Health Association, Reginald M. Atwater, M. D.. Executive Secretary, 1790 Broadway, New York, N. Y. This association's work in the field of standardization is conducted under the auspices of the Committee on Research and Standards, which has been appointed for that purpose. Under this main committee function a number of subcommittees, the names of which indicate the activities in which each is engaged, as follows: Standard methods for the examination of dishwashing devices, communicable disease control, 
hygiene of housing, standard methods of diagnostic procedures and reagents, standard methods on examination of water and sewage, standard methods on examination of dairy products, standard methods on analyzing frozen desserts, standard methods for the examination of shellfish, standard methods on biological products, bathing places, disinfection of dishes and utensils, plumbing, ventilation and atmospheric pollution, standard methods for the examination of air, lead poisoning, water pollution, sewage disposal, water supply, laboratory animals, industrial anthrax, volatile solvents, pneumoconiosis.

Projects which have been completed by these committees relating to standards and published by the association include standard methods for the examination of water and sewage, standard methods for the examination of dairy products, report on the control of communicable diseases, essential features in the design of sanitary drinking fountains, report on bathing places and diagnostic procedures and reagents, and standard methods for the examination of frozen desserts.

The association cooperates with the American Standards Association by representation on sectional committees on recommended practice of school lighting, building code requirements for light and ventilation, safety code for exhaust systems, letter symbols and abbreviations for science and engineering, allowable concentrations of dusts and gases, sterilization of bedding and upholstery, safety code for industrial sanitation in manufacturing establishments, and ventilation code.

American Public Works Association, Frank W. Herring, executive director, 1313 East Sixtieth Street, Chicago, Ill. In 1937, the American Society of Municipal Engineers and the International Association of Public Works Officials were merged to form this association. Standardization and simplification activities of this organization are carried on by various committees dealing with bituminous, brick, stone block, and concrete pavements, sewers, sidewalks and curbs, and subgrades and foundations. These committees are responsible for the preparation of standard specifications covering materials and construction methods which are adopted and published by the association. Committees of this association cooperate with similar committees of other technical organizations in the development of standards and specifications.

This association maintains representation on sectional committees of the American Standards Association on the following projects: building code requirements, signs and outdoor display structures, and good practice recommendations for masonry; road materials; administrative requirements for building codes; specifications for wood poles; letter symbols and abbreviations for science and engineering, and safety code for grandstands. It is also represented on committees of the American Society for Testing Materials covering specifications for portland cement, concrete pipe, concrete and concrete aggregates, drain tile, manufactured masonry units, and road and paving materials. In addition, it also cooperates with the National Bureau of Standards of the United States Department of Commerce on simplification matters, and with the Highway Research Board on highway construction.

American Railway Bridge and Building Association, F. O. Whiteman, secretary, 332 Dearborn Station, Chicago, Ill. Although this organization does not deal directly in standardization matters, its 
members are concerned with the execution of work covered by standard plans and specifications as a part of their duties as employees of railways. As association members, they study and investigate standard practices of other organizations, and endeavor to summarize the experience gained by others concerning the application of theoretical matter to actual field problems.

American Railway Engineering Association, W. S. Lacher, secreretary, 59 East Van Buren Street, Chicago, Ill. For administrative reasons, this organization functions as the Construction and Maintenance Section of the Association of American Railroads. Through its numerous committees, it maintains and keeps up to date the Manual of Recommended Practices for Railway Engineering and Maintenance of Way. These committees are constantly engaged in developing standards, specifications, test methods and recommended practices on the following main subjects which comprise the several sections of the Manual: Definition of terms; roadway; ballast; ties; rail; track; buildings; wood bridges and trestles; masonry; highways ; signals and interlocking; records and accounts; water service, fire protection and sanitation; yards and terminals; iron and steel structures; economics of railway location; wood preservation; electricity; uniform general contract forms; economics of railway operation; shops and locomotive terminals; waterways and harbors; maintenance of way work equipment; clearances, and waterproofing of railway structures. In addition, it has issued separate specifications for steel railway and movable railway bridges.

The association maintains also a Standardization Committee, whose function it is to determine what recommended practices of the association should be advocated for general use on railways, and which ones should be sponsored as subjects for national standardization. This committee maintains contact with standardization bodies and keeps the association informed on important matters developed by such contact. This association maintains representation on section committees functioning under the procedure of the American Standards Association dealing with the following projects: Specifications for portland cement; specifications for cast iron pipe and special casting; manhole frames and covers; standardization and unification of screw threads; pipe flanges and fittings; bolt, nut, and rivet proportions; safety code for conveyors and conveying machinery; plain and lock washers; safety code for cranes, derricks, and hoists; standardization of dimensions and materials of wrought iron and wrought steel pipe and tubing; hard drawn aluminum conductors; railway motors and other rotating electrical machinery on rail cars and locomotives; specifications for zinc coating of iron and steel; ventilation code; petroleum products and lubricants; standards for drawings and drafting room practice; standards for graphic presentation; specifications for sieves for testing purposes; specifications and methods of test for safety glass; work in compressed air; and graphical symbols and abbreviations for use on drawings.

It is also represented on technical committees of the American Society for Testing Materials engaged in the development of standard specifications and methods of test covering the following subjects: Steel; corrosion of iron and steel; nonferrous metals and 
alloys; copper and copper alloys, cast and wrought; cement; clay pipe; concrete and concrete aggregates; mortars for unit masonry; concrete pipe; timber; bituminous waterproofing and roofing materials; and water for industrial uses. It is also represented on the ASTM Joint Research Committee on Boiler Feed Water Studies, and on the Joint Committee on Standard Specifications for Concrete and Reinforced Concrete.

American Refractories Institute, Martha Buerkle, secretary, Oliver Building, Pittsburgh, $\mathrm{Pa}$. This institute is a national organization, whose object is to promote the interests of manufacturers and carry on research and tests on refractory materials. Its standardization work is carried on by two committees, one dealing with classification and the other with technical matters. Specifications for fireclay brick for malleable furnaces with removable bungs and for annealing ovens were formulated by this organization in 1926, and approved by the joint committee of the American Foundrymen's Association and the American Ceramic Society. These specifications were adopted as standard by the American Society for Testing Materials. Specifications for fireclay brick for stationary boiler service, fireclay brick for marine boiler service, and fireclay brick for incinerators, adopted by the ASTM, were also developed by the institute.

The organization cooperated with other units of industry in the establishment and acceptance by industry of standard sizes and varieties of malleable foundry refractories, and for cupola refractories which are set forth in Simplified Practice Recommendations R79-28 and R154-38, promulgated by the National Bureau of Standards. The institute has adopted and published a very complete list of standard sizes and shapes for fireclay refractories. The institute is represented on the Sectional Committee on Specifications for Sieves for Testing Purposes functioning under the procedure of the American Standards Association and on the Technical Committee for Refractory Materials of the American Society for Testing Materials.

American Road Builders' Association, Charles M. Upham, engineer-director, National Press Building, Washington, D. C. The association functions as clearing house to acquire and disseminate educational and scientific information concerning highway activity in the United States, Canada, Mexico, Central and South America, and many European countries. Its membership includes Federal, State, city, and county highway officials, honorary representatives of foreign countries, highway contractors, highway transport operators, producers of highway materials, and manufacturers of highway equipment. Group and general committees study problems relating to highway legislation, finance, design, construction, maintenance, equipment, and operation. Their efforts are directed toward development of improved standards for the elimination of waste and in bringing about economy in highway administration.

To avoid unnecessary duplication in its research activities, the association cooperates through joint cooperating committees with other organizations having in part similar aims. The results of investigations on the various technical and general problems are presented in report form and discussed at the annual conventions of the association. The final reports are summarized for publication in the 
convention proceedings covering operation and maintenance of roadbuilding equipment, and the selection and utilization of road-building materials.

This association cooperated with the American Association of State Highway Officials on standardization of blades and truck scrapers. It has published several bulletins dealing with standardization studies covering weighing devices for concrete aggregates, steel side forms for concrete pavements, and methods for purchasing equipment.

American Society of Agricultural Engineers, Raymond Olney, secretary, St. Joseph, Mich. This society has adopted a tractor testing and rating code which has become the standard of the farmequipment industry. It also adopted standards for design, dimensions, speed, location, etc., of spline shafts and spline hubs for power take-off for agricultural tractors and machines; standards for positions and endings of tractor drawbars; and standard dimensions and concavity for a limited number of standard sizes of disk blades for disk plows, harrows, drills, listers, and cultivators. The society also adopted recommended practice covering a method for determining and expressing the modulus of fineness and uniformity index of ground (livestock) feed.

It cooperated with other organizations, under the procedure of the American Standards Association, in the formulation of the American standard specifications for drain tile and standard specifications for dimensions of plow bolts. The society also maintains representation on committees of the American Society for Testing Materials in work on drain tile and corrosion of iron and steel.

American Society of Bakery Engineers, Victor E. Marx, secretary, 1541 Birchwood Avenue, Chicago, Ill. Standards adopted by this society for bakery equipment are the result of the work of its Standardization Committee. The society has adopted standards for high-speed dough mixers, flour handling units, sifters, bolting reels and flour hoppers, which were approved by the Bakery Equipment Manufacturers Association. Its Standardization Committee made specific recommendations on the standardizing of live or active belt capacities of belt proofers for various loaf sizes which were concurred in by equipment manufacturers. It also made certain recommendations on heights of cake depositor hoppers and the standard rating of cake mixers by weight of dough, rather than by gallon capacity, which have been approved by the equipment manufacturers.

The Standardization Committee, working in cooperation with manufacturers of air-conditioning equipment, formulated certain standards relating to humidifier practice in baking plants. It also formulated and adopted a standardization of sponge trough sizes which has been accepted and adopted by manufacturers of dough troughs and the society. A research committee of this society is cooperating with a similar committee of the American Association of Cereal Chemists in the study of baking problems.

American Society of Civil Engineers, George T. Seabury, secretary, 33 West Thirty-ninth Street, New York, N. Y. Standardization work of the society is conducted through the appointment of committees to deal with certain projects and through representation on committees of other organizations. 
The society is officially represented on 33 sectional committees, functioning under the procedure of the American Standards Association, in matters relating to building and safety code requirements for various projects; in the development of specifications for cast iron pipe and fittings, cross and switch ties, drain tile, cement, and sieves for testing purposes; in the standardization of graphical symbols and abbreviations, manhole frames and covers, methods of testing wood, and stock sizes and shapes of iron and steel bars; and standards for safety in the construction industry.

It cooperates with the Central Committee on Lumber Standards in the establishment of American lumber standards for softwood lumber and with the standing committee of the Simplified Practice Recommendation for sizes of paving brick, under the auspices of the National Bureau of Standards. It also collaborates with the American Road Builders' Association in developing standards relating to safe highways, and maintains representation on the Research Committee on Yield Point of Structural Steel of the American Society for Testing Materials.

Through representation on the Joint Committee on Standard Specifications for Concrete and Reinforced Concrete, consisting of affiliated committees of the American Concrete Institute, American Institute of Architects, American Railway Engineering Association, American Society for Testing Materials, and Portland Cement Association, the society cooperated in the preparation and publication of a report on recommended practice and standard specifications for concrete and reinforced concrete.

American Society of Heating and Ventilating Engineers, A. V. Hutchinson, secretary, 51 Madison Avenue, New York, N. Y. One of the most important functions of this society for the past 20 years has been the development of heating and ventilating codes and standards. In this connection, it has adopted the following codes and standards relating to the design, installation, testing, rating, and maintenance of materials and equipment used for the heating, ventilation and air conditioning of buildings: standard code for testing and rating aircleaning devices used in general ventilation work; code of minimum requirements for comfort air-conditioning; standard and short form heat balance codes for testing low-pressure steam-heating solid fuel boilers; performance test code for steam-heating solid fuel boilers; standard code for testing steam-heating boilers burning fuel oil; standard code for testing stoker-fired steam-heating boilers; standard code for rating steam-heating solid fuel hand-fired boilers; standard code for testing and rating concealed gravity type radiation (hot water section); standard code for testing and rating concealed gravity type radiation (steam code); standard test code for centrifugal and axial fans; code for heating and ventilating garages; standard test code for heat transmission through walls; code of minimum requirements for heating and ventilation of buildings; code for testing radiators; standard code for testing and rating steam unit heaters; standard code for testing and rating steam unit ventilators; standard code for testing and rating return line low vacuum heating pumps, and report of Committee on Ventilation Standards.

In addition to its own codes, the society has cooperated with other organizations in the development of the following standards and 
codes which it has either endorsed or approved; standard method of rating and testing air conditioning equipment; standard ordinance for chimney construction; standard method of rating and testing mechanical condensing units; and identification of piping systems.

The society is represented on sectional committees functioning under the procedure of the American Standards Association for the following projects : building code requirements for light and ventilation; code for mechanical refrigeration; pipe flanges and fittings; specifications for pressure and vacuum gages; code for testing and rating air cleaning devices used in general ventilation work; safety code for exhaust systems; letter symbols and abbreviations for science and engineering; standards for drawings and drafting room practice; acoustical measurements and terminology; work in compressed air, and graphical symbols and abbreviations for use in drawings.

American Society of Mechanical Engineers, C. E. Davies, secretary, 29 West Thirty-ninth Street, New York, N. Y. The ASME is a professional society organized to promote the art and science of mechanical engineering and the allied arts and sciences; to encourage original research; to foster engineering education; to advance the standards of engineering; to promote the intercourse of engineers among themselves and with allied technologists; and in cooperation with other engineering and technical societies to broaden the usefulness of the engineering profession.

The society has 17 professional divisions the titles of which are indicated by the following subjects covered by them: Aeronautic, applied mechanics, fuels, graphic arts, heat transfer, hydraulic, iron and steel, machine-shop practice, management, materials handling, oil and gas power, petroleum, power, process industries, railroad, textile, and wood industries. There is also a professional division group on ammunition. The applied-mechanics division has a section of the society's transactions, "The Journal of Applied Mechanics," in which are published quarterly for reference purposes worth-while technical papers on this subject with discussions.

The technical committee activities of the society have grown very rapidly during the past 20 years, until now about 2,100 engineers and others are serving on more than 500 committees for which the society is sponsor or joint sponsor. In this work approximately 250 organizations cooperate.

The dimensional standardization and safety activities of the society are carried forward under the procedure of the American Standards Association. The society is sponsor or joint sponsor for 31 sectional committees on standards for screw threads and screw-thread gaging; ball bearings; machine tool elements; small tools; pipe and pipe fittings; bolt, nut, and rivet proportions; and letter and graphical symbols and charts. In addition, it is also serving as sponsor or cosponsor for six sectional committees dealing with the establishment of safety codes for conveyors and conveying machinery; cranes, derricks, and hoists; elevators, dumbwaiters, and escalators; mechanical power transmission apparatus; compressed-air machinery; and pressure piping. It also maintains representation on a number of other sectional committees engaged in work on mechanical engineering and construction projects.

$201072 \circ-41-5$ 
One of the society's most notable technical committee accomplishments is the development of the ASME Boiler Construction Code, the last edition of which was issued in 1940. This code, which is divided into eight sections, contains rules for the construction of power boilers to be used in stationary service, boilers of locomotives, miniature boilers, heating boilers, and unfired pressure vessels, as well as the care of power boilers in service and rules for inspection. One section contains the specifications for the materials to be used in code constructions. The society also issues interpretations of these rules.

The detailed specifications, formulas, tables of dimensions, diagrams and sketches in the code cover plates, tubes, piping, riveted and welded joints, domes, dished and flat heads, braced and stayed surfaces, stays, headers, access and nozzle openings, safety valves, gages, fittings and appliances, welding, and welding qualification procedure.

Other recommendations apply to efficiency of joints, method of checking safety-valve capacity, fusible plugs, standard practice for making hydrostatic tests on a boiler pressure part, rules for existing installations, and for the approval of new materials under the code. Sample manufacturers' data report forms, and tables of standard dimensions are also included.

The society has also issued a code for unfired pressure vessels for petroleum liquids and gases. This was prepared by a joint committee composed of representatives of the American Petroleum Institute and the American Society of Mechanical Engineers. These rules cover the design and construction of fusion-welded vessels, riveted vessels, and integrally forged vessels, and their periodic inspection and repair. The appendix contains suggestions regarding internal structures, corrosion allowances, and protective linings, as well as several examples of computations.

There have also been prepared and issued by the society 19 power test codes, 2 supplementary codes, and 30 auxiliary sections of information on instruments and apparatus. These codes give standard directions for conducting acceptance tests, and for determining the performance of power generating and using equipment.

The society publishes the Mechanical Engineering, a monthly publication, which features technical articles on current practice and developments in the mechanical engineering field.

The ASME Transactions are issued also in monthly installments and contain the many papers read at the national-meetings of the society.

American Society for Metals, W. H. Eisenman, secretary, 7301 Euclid Avenue, Cleveland, Ohio. This society publishes the ASM Metals Handbook, which contains over 300 articles or reports on the application, manufacture, fabrication, treatment, and testing of metals and alloys, both ferrous and nonferrous. These articles and reports have been prepared by individual authors and technical committees. The society maintains representation on the Coordinating Committee on Corrosion and on the Joint Committee on Definitions of Heat-Treatment Terms, and also on the Cast-Iron Committee of the American Society for Testing Materials. 
American Society of Refrigerating Engineers, David L. Fiske, secretary, 37 West Thirty-ninth Street, New York, N. Y. Standardization forms a major part of the work of this society. Through its Standards Committee it has developed the following standards and codes: test code for steam-driven ice-manufacturing plants; standard refrigeration; specifications for synchronous motors for direct-connected ammonia compressors; specifications for pipe and pipe threads; test code for refrigerating systems; corrosion in refrigerating plants; thermodynamic properties of dichlorodifluoromethane (Freon-12); standard methods of rating and testing air-conditioning equipment, mechanical condensing units, self-contained air-conditioning units for comfort cooling, refrigerant expansion valves, and self-contained mechanically refrigerated drinking water coolers; and mechanical refrigeration safety code.

Through its industry committees the society is carrying forward standardization projects dealing with drinking water coolers, unfired refrigerant containing vessels, fruit and vegetable precooling, milk coolers, moisture in refrigerating system parts, natural convection air coolers, refrigerant expansion valves, and refrigerated locker plants.

The society is sponsor for the projects on standards and specifications for refrigerators and safety code for mechanical refrigeration, both being conducted under the auspices of the American Standards Association. In addition, it is officially represented on 11 ASA sectional committees on identification of piping systems, pipe threads, pipe flanges and fittings, compressed air safety code, code for pressure piping, pressure and vacuum gages, zinc coating of iron and steel, ventilation code, symbols and abbreviations, drafting room practice, and preferred numbers.

In cooperation with the National Association of Ice Industries and the American Institute of Refrigeration, the society initiated the program for simplification of ice cake sizes which resulted in the formulation of Simplified Practice Recommendation R96-28, promulgated and published by the National Bureau of Standards.

The society maintains joint committee representation with the American Society of Heating and Ventilating Engineers on air conditioning standards, revision of psychrometric chart, and rating of commercial refrigerating equipment; with the National Research Council on industrial and engineering research; with the Society of Automotive Engineers on refrigerated trucks and buses; with the American Society of Mechanical Engineers on refrigeration plant test code; and with the American Society for Testing Materials on thermal conductivity of all forms of insulation, and on corrosion.

At the present time this association is cooperating with the Air Conditioning and Refrigeration Manufacturers' Association on additional standardization projects. Work is going forward in developing compressor tests, and the rating of shell and tube condensors.

American Society of Sanitary Engineering, James R. Walker, secretary, City Hall, Waterbury, Conn. Standardization is carried on by this society mainly through cooperation with other bodies engaged in similar type of work. This organization, as early as 1906, initiated the movement for development of a plumbing code which was finally adopted under the auspices of the United States Depart- 
ment of Commerce. It carries on cooperative work with the National Bureau of Standards in conducting tests of plumbing equipment for use in high buildings.

The society cooperated with other organizations, under the procedure of the American Standards Association, in the establishment of American standard for pipe threads. It is also officially represented on sectional committees dealing with projects relating to the development of a ventilation code, safety code for mechanical refrigeration, and graphical symbols and abbreviations for use on drawings.

American Society for Testing Materials. (See page 5.)

American Specification Institute, Gerald L. Palmer, executive secretary, 134 North La Salle Street, Chicago, Ill. The prime purpose of this organization, whose members comprise writers of engineering and architectural specifications, is the collection of specifications, information, and ideas from other organizations and sources; the study, discussion, and arrangement of these in standard form; and the distribution of these specifications and information to the members in the form of bulletins and the institute's Specification Record. This latter publication contains specifications, in full or in outline form, from which the specification writer may construct a specification for a particular structure or equipment. Some of the more important subjects covered by these specifications include structural iron and steel, clay and clay products, masonry, electrical devices, heating systems, kitchen and bakery equipment, plumbing fixtures, and other items entering into building construction.

American Spice Trade Association, N. W. Ericson, secretary, 82 Wall Street, New York, N. Y. This association maintains a Standards Committee whose function is to adopt standards of qualities of whole spices, seeds, and herbs imported at American ports of entry. Through the Spice Grinders' Section, the association sponsored the movement for a simplified schedule of stock sizes of tin and silver spice containers which led to the establishment of the Simplified Practice Recommendation R170-38, promulgated and published by the National Bureau of Standards.

American Standards Association. (See page 3.)

American Sugar Cane League, Mercel J. Voorhies, general manager, 407 Carondelet Street, New Orleans, La. Several committees of this organization carry on work leading to the development of methods and standards for products coming within its jurisdiction. The Molasses Committee undertakes to safeguard the standards of molasses in the case of Federal Classification to avoid conflicts with the industry. The Contact Committee cooperates with the United States Department of Agriculture for the purpose of furthering research and other scientific work, both in the field and factory spheres. 'This work embraces the whole matter of plant disease control, development of standards for various cane varieties, and cultivation methods.

American Transit Engineering Association, G. C. Hecker, general secretary, 292 Madison Avenue, New York, N. Y. Standardization work of this association is carried on by numerous technical committees whose function it is to collect, analyze, and disseminate information and data on engineering matters of general interest to the transit industry; to prepare and revise specifications, designs, and practices for adoption by the association; and to cooperate with other 
national organizations in the joint consideration of technical and semitechnical subjects. All assignments of subjects are made by the association's Executive Committee to the Power, Rolling Stock, or Way and Structures Divisions, which divisions comprise the principal phases of the association's work.

The association publishes and keeps under constant revision the Engineering Manual in which are included more than 160 standards and recommendations which have been adopted by the association. These standards and recommendations cover items and equipment coming within the scope of activities of the several divisions.

In connection with its work in standardization the association cooperates, through representation, with committees of other organizations, including American Public Works Association, American Railway Engineering Association, American Road Builders Association, Association of American Railroads, National Fire Protection Association, and the National Safety Council.

The association takes an active part in the work of the American Standards Association. It is a member body of that organization and is officially represented on 29 sectional committees engaged in the development of standards for various projects and on the following ASA Advisory Committees: Electrical Standards; Mechanical Standards; Highway Traffic Standards; and Safety Code Correlating Committee. It is also represented on technical committees of the American Society for Testing Materials dealing with subjects relating to road and paving materials, corrosion of iron and steel, copper and copper-alloy wires for electrical conductors, and steel.

In the field of simplification, the association initiated projects under the auspices of the National Bureau of Standards which resulted in the establishment of Simplified Practice Recommendations covering standard packaging of overhead electric railway material, electric railway motor and controller parts, automatic engine parts, and air brake (electric railway) parts.

American Trucking Associations, Inc., J. V. Lawrence, general manager, 1424 Sixteenth Street, NW., Washington, D. C. The work of this organization in the field of standardization is carried on actively by the Operations Division and the Traffic Department. To these divisions are entrusted practically all phases of standards work which affect the entire industry all over the United States.

The Operations Division is collaborating closely with the Bureau of Motor Carriers, Interstate Commerce Commission, in the movement to standardize and make uniform regulations throughout States, similar to regulations adopted by the Interstate Commerce Commission for the safety of operation of motor carriers subject to their jurisdiction. It cooperated with the National Bureau of Standards in the establishment of Commercial Standards for certain after-market accessories, including lights of various kinds and emergency flares and electric lanterns. 'Under the associations' sponsorship, this division has what is known as the Safety and Operations Section, the membership of which is composed of safety, personnel, maintenance, and similar executives of motor carrier operations throughout the country. Included in this section are a number of research committees the activities of which will ultimately lead to the formulation of standard practices. The Operations Division is engaged at the present time in draft- 
ing a standard code for use in the trucking industry. It is also working in developing standard forms for use by the members of the industry. The associations, through this division, is sponsor for the Sectional Committee on Standard Loading Platforms at Freight Terminals and Warehouses, functioning under the procedure of the American Standards Association. This project when completed is expected to recommend standards for the height and other dimensions of loading platforms for both rail and truck use. It is also officially represented on the ASA Sectional Committee on Standards for the Inspection of Motor Vehicles.

The activities of the Traffic Department in standardization matters are guided by policies established by a National Traffic Committee, which is composed of 74 representatives of motor carriers from all sections of the country. The Traffic Department published the $\mathrm{Na}$ tional Motor Freight Classification. This publication contains type of containers provided for in the classification and publishing in an issue of national scope descriptions of the thousands of articles found in transportation tends to establish standards of transportation of various commodities. It also sets up, in general, standard classification rules and provision with respect to motor carrier transportation. Standardization of practice throughout the trucking industry furthered through development of uniform motor carrier bills of lading forms which are established and maintained in the national classification.

The Motor Carriers Explosives and Dangerous Articles Tariff is also published by this association through the Traffic Department and under the guidance of the National Traffic Committee. This publication contains the rules of the Interstate Commerce Commission with respect to the handling, labeling, billing, and transportation of approximately 500 articles considered to be dangerous, explosive, inflammable, corrosive, or poisonous. It gives also specifications to be observed relative to packing and containers and restrictions as to contents permitted to be transported with other merchandise.

Another activity of the Traffic Department relates to the associations' freight claim section, the general aspects of which are being carried on through a national committee for the purpose of establishing standards of practice among carriers with respect to procedure to be followed in the handling and settlement of freight claims. In this connection, standard rules and forms have been adopted tending toward uniformity of use by motor carriers throughout the country.

Further standardization fostered by the Traffic Department is found in the standard docket proposal form which is used in presenting proposals for changes in motor carrier tariff ratings, rates, rules and regulations.

American Veneer Package Association, Robert W. Davis, executive officer, 804 Seventeenth Street NW., Washington, D. C. This association cooperates with transportation companies, shipping associations, and other interested parties in the formulation of standards and strength requirements for shipping boxes and baskets made from rotary cut veneer. It maintains committees for the study of container problems.

The association cooperates also with all the various agencies of the Federal Government, including the United States Department of 
Agriculture, Interstate Commerce Commission, Department of Commerce, and the Federal Trade Commission concerning matters relating to standardization of containers.

American Veterinary Medical Association, J. G. Hardenbergh, executive secretary, 600 South Michigan Avenue, Chicago, Ill. This association maintains two committees whose work is devoted in the interest of standardization. The Committee on Proprietary Pharmaceuticals is engaged in the standardization of veterinary medical remedies of the proprietary class. The Committee on Biological Products cooperates very closely with the Bureau of Animal Industry, United States Department of Agriculture, in the standardization of biological products.

American Vitrified China Manufacturers Association, A. M. Walker, president, care of Bailey-Walker China Co., Bedford, Ohio; James K. Love, secretary, care of Shenango Pottery Co., New Castle, $\mathrm{Pa}$. In cooperation with other units of industry, this association has been active in the establishment of standard sizes and varieties of hotel chinaware, cafeteria and restaurant chinaware, dinìng car chinaware, and hospital chinaware, which resulted in the publication and promulgation of Simplified Practice Recommendations by the National Bureau of Standards of the United States Department of Commerce. This association also cooperates with the Federal Specifications Executive Committee in the formulation and revision of Federal Specification M-C-301 for vitrified china.

American Walnut Manufacturers Association, Burdett Green, secretary-manager, 616 South Michigan Boulevard, Chicago, Ill. 'This association sponsored the rules for grading American black-walnut lumber, which were published by the National Hardwood Lumber Association in its rules for the measurement and inspection of hardwood lumber, cypress, veneers, thin lumber, and plywood. These grading rules are in general use, not only in the United States but also in foreign countries. It has adopted rules for grading American (black) walnut logs. It has also prepared minimum specifications and grading rules for walnut stumps fresh cut from live timber.

Working in cooperation with the National Bureau of Standards, this association initiated the movement which led to the establishment of Commercial Standard CS64-37 for walnut veneers, and assisted in the preparation of a Commercial Standard for solid hardwood wall paneling which resulted in the formulation of Commercial Standard CS74-39 providing two classes of wall paneling.

This association has adopted a certification mark "American walnut certified veneers", and maintains an inspection service. It issues a certificate of inspection on each shipment, which states that the walnut veneers have been rigidly graded and inspected by an independent inspector whose name appears on the certificate. It further states that the veneers are certified to comply with the requirements of Commercial Standard CS64-37 for quality, workmanship, thickness, full measurement, and the true representation of the flitch by the samples.

American Warehousemen's Association, Wilson V. Little, general secretary, 222 West Adams Street, Chicago, Ill. This organization sponsored the movement that resulted in the establishment by the industry of standard warehouse forms promulgated in Simplified Practice Recommendation R34, issued by the National Bureau of 
Standards. As a supplement to that project and with the cooperation of the Department of Commerce and other interested parties, the association formulated the standard contract terms and conditions for general merchandise and refrigerated warehouses.

The Association of Refrigerated Warehouses Division of this association cooperated with the American Standards Association in the development of the standard safety code for mechanical refrigeration, which was approved as American standard B9-1933 by the ASA. The association is participating in the ASA project for the standardization of height of loading platforms.

The American Warehousemen's Association, Merchandise Division, and the Association of Refrigerated Warehouses-the two Divisions constituting the Association-have evolved cost formulae and other standard accounting practices relating to the branches of the warehousing business for which they respectively function.

American Washer and Ironer Manufacturers' Association, J. R. Bohnen, executive secretary, 80 East Jackson Boulevard, Chicago, Ill. Although this organization has not as yet set up standards for household washers and ironers, it does maintain a committee which collaborates with the Underwriters' Laboratories in formulating certain safety standards or specifications covering fire hazards.

American Water Works Association, Harry E. Jordan, secretary, 22 East Fortieth Street, New York, N. Y. The Committee on Water Works Practice is in responsible charge and control of all technical activities of the association. This committee appoints such subcommittees as it may deem necessary to properly carry on its work, including the development of standards and specifications. Fully organized committees are at the present time engaged in projects relating to development of standard specifications for the construction and testing of deep wells, as well as the purchase requirements for, and method of, testing deep well pumps; methods of safe handling of chemicals used in water purification; preparation of specifications for steel plate pipe and coatings; specifications for the laying of cast-iron pipe; specifications for valves, sluice gates, and fire hydrants; and other miscellaneous items in the water works field.

Other committees in the Water Purification Division of the Association are actively engaged in the preparation of specifications and tests for water purification chemicals; activated carbon research; specifications for and methods of testing zeolites; methods of determining fluorides; methods of water treatment and laboratory control; standards for purification plant operation; and specifications for filtering material.

Through its Committee on Water Works Practice, the association has published the Water Works Practice Manual which contains, among other things, standard methods for the mechanical analysis of sand and gravel, standard specifications for cast-iron pipe and special castings, hydrants and valves, and disc meters; also specifications for chemicals used in water purification, specifications for pressure water filters, and standard agreement for engineering construction.

In carrying forward its work in the field of simplification and standardization, the association maintains representation on numerous committees of certain technical organizationș. It is officially 
represented on sectional committees functioning under the procedure of the American Standards Association in the development of standards for the following projects: Specifications for cast-iron pipe and special castings, manhole frames and covers, standardization of plumbing equipment, pipe threads, pipe flanges and fittings, code for pressure piping, standardization of dimensions and materials of wrought-iron and wrought-steel pipe and tubing, national electrical code, specifications for zinc coating of iron and steel, specifications for sieves for testing purposes, and standardization of graphical symbols for use on drawings.

It cooperates with committees of the National Fire Protection Association on electrical code; hydrants, valves, and pipe fittings; public water supplies for private fire protection, including the uniform marking of fire hydrants; and on tanks.

The association maintains representation on the American Society for Testing Materials' Joint Research Committee on Boiler Feedwater Studies, and on the Coordinating Committee on Corrosion. In addition, it maintains a representative on the standing committee of Simplified Practice Recommendation R57 covering standard sizes of wrought-iron and wrought-steel pipe, valves, and fittings, which was promulgated by the National Bureau of Standards.

In cooperation with a committee of the American Public Health Association, a committee of this association assists in the preparation and revision of the publication, Standard Methods for Examination of Water and Sewage, which is now in its ninth edition.

The association has cooperated with the Municipal Finance Officers Association in the production of a Manual of Water Works Accounting. A standing committee of the two associations is charged with the duty of revising the text whenever changes in accounting practices indicate the advisability.

The association also gives cooperation to the National Association of Railroad and Utilities Commissioners. At the present time a Committee on Survival and Retirement Experience with Water Works Facilities is engaged in developing information concerning the actual life history and retirement experience with certain basic water supply capital units. This information is intended to clarify the understanding of the probable useful life of such materials.

American Waxed Paper Association, George J. Lincoln, Jr., executive secretary, Lincoln-Liberty Building, Philadelphia, Pa. Through the appointment of temporary committees to handle specific questions as they arise from time to time, this association has done much work in simplification and in formulating standards for the industry.

It sponsored the movement which led to the establishment of a list of simplified sizes for waxed tissue paper, which was promulgated and published as Simplified Practice Recommendation R125-31 by the National Bureau of Standards. The larger part of this industry's production is used for wrapping bread. The industry, through the association, has adopted a 10-inch diameter roll with a 3 -inch core as its standard. It has also adopted 23 -pound waxed to 36-pound finished weight as its standard for opaque bread wrappers. It has standardized as much as is practical in the use of opaque paper for bread wrappers, which is a full bleached sulfite stock 
with a special treatment for opacity. When the baker wishes to give additional protection to his product, full bleached sulfite is used for an inner wrapping of bread.

In this connection, the association has developed standards on three weights of inner wrap, namely: 15 -pound waxed to 20 pounds; 18 pound waxed to 25 pounds; and 20 -pound waxed to 30 pounds.

In collaboration with biscuit and cracker manufacturers, this association is endeavoring to establish proper standards for the best wrapping of cartons.

American Welding Society, William Spraragen, technical secretary, 33 West Thirty-ninth Street, New York, N. Y. Standardization work arising within the welding industry is conducted through technical committees appointed by the society, which cooperate with similar committees of other technical bodies.

For more than 10 years, the Committee on Building Codes has been assisting municipal and State code committees and building departments in preparation of suitable regulatory specifications for fusion welding in fabrication of structural steel, piping and tankage in building construction. This committee prepared the code for fusion welding and gas cutting in building construction, which was revised on three separate occasions in order to keep it in harmony with the advancement of the welding art. The provisions of the building code have now been adopted by more than 200 municipalities, including the great metropolitan centers of New York, Chicago, and Baltimore. The Building Code Committee cooperated with the Board of Standards and Appeals of New York City in formulating rules for fusion welding under the new city building code.

Upon completion of its work in the preparation of the specifications for the design, construction, alteration, and repair of highway and railway bridges by fusion welding, issued in 1936, the original committee on welding bridges was discharged. A new committee called the Conference Committee on Welded Bridges was authorized by the executive committee of the society. This committee is devoting its activities to clarifying points in the specifications which may be questioned as a result of practical application, and securing the adoption of the society's bridge specifications by professional bodies throughout the country. The bridge specifications referred to above have been approved by the American Railway Engineering Association and also by the American Association of State Highway Officials. During the past two years the committee has been active in preparing revisions to these specifications. The Filler Metal Specifications Committee developed specifications for iron and steel filler metal which has been adopted and published jointly by the American Society for Testing Materials and this society. One of the objectives of this committee is to issue separate specifications for arc welding electrodes and gas welding rods. The first of these covering tentative specifications for iron and steel arc welding was completed and approved by both societies. A parallel specification for iron and steel gas welding rods is now in the course of completion by a special committee appointed for the purpose. Subcommittees have been appointed during the past year to prepare filler metal specifications for high alloy steels, nickel and nickel alloys, aluminum and aluminum alloys, and copper and copper alloys. 
Functioning under the auspices of the Committee on Welding in Marine Construction are two subcommittees, one dealing with boilers and the other on hulls. These and other subcommittees act as conference committees to the Bureau of Navigation and Steamboat Inspection of the United States Department of Commerce in assisting that body in preparing specifications for boilers, unfired pressure vessels, piping, hull structures, and on other matters coming under the cognizance of the various subcommittees. Considerable progress has been made in developing a code on welding in marine construction rules for the fusion welding of drums and shells of marine boilers, and pressure vessels have been completed and approved by the society. These rules are based on rules prepared by the Boiler Code Committee of the American Society of Mechanical Engineers in cooperation with this society's Committee on Welded Pressure Vessels. The Boiler Subcommittee is undertaking the preparation of rules for the repair of marine boilers and pressure vessels. In addition, this subcommittee has formulated tentative rules for fusion welding steam, oil, or air piping in marine construction. These rules apply to piping for working pressures in excess of 100 pounds per square inch. Rules for the fusion welding of hulls and hull parts have also been completed and published by the society. The new rules of the American Bureau of Shipping relating to hull construction are based on these rules.

The Hull Subcommittee is at the present time engaged in revising the rules for the fusion welding of hull and hull parts, and the preparation of rules for the repair of hulls by fusion welding.

The Committee on Symbols has prepared revised welding symbols and instructions for their use which were approved by the society. These symbols have been submitted to the American Standards Association for approval as an American standard.

The Committee on Large Welded Pipe for Hydraulic Purposes has prepared a tentative code which comprises the general ground covered by the existing codes for unfired pressure vessels with the exception of rules for special fittings.

The Committee on Standard Qualification Procedure worked toward the elimination of confusion by correlating varying qualification test requirements by merging them into one tuniform code. The purpose of these qualification tests is to adequately determine the quality of a fusion welded joint by the specific process used, and to test the ability of the welding operator to apply that process. This work resulted in the establishment of rules giving them the title, Standard Qualification Procedure, which was approved and published by the society. The committee has recently completed its work on a revised edition of the Standard Qualification Procedure. The principles of this new revision are now being incorporated in a number of revised codes and specifications, including the ASME Boiler Code and Unfired Pressure Vessel Code, the ASA Code for Pressure Piping. the American Petroleum Institute's specifications on all-welded oil storage tanks, and the society's specifications for welded highway and railway bridges.

The proposed Standard Methods for Mechanical Testing of Welds prepared by the Committee on Standard Tests for Welds have been approved by the Executive Committee of the society as a tentative standard. 
The Committee on Pressure Piping prepared a code for all applications of pressure piping, including some hydraulic, gas, air, oil, and refrigeration, which was approved by the society and by the American Standards Association as an American standard.

Another committee of this society has prepared specifications covering the development of inspection method used in manufacturing of U-69 and U-70 pressure vessels. The society maintains a conference committee which cooperates with the ASME boiler code committee dealing with questions involving the application of fusion welding to boilers and pressure vessels.

The Machinery Code Committee was appointed two years ago for the purpose of revising the tentative code for fusion welding and flame cutting in machinery construction, and also in reviewing the draft of the new tentative code for arc and gas welding and gas cutting in machinery construction.

The Committee on Rules for Field Welding of Storage Tanks has formulated a standard entitled "Tentative Rules for Field Welding of Storage Tanks" which was approved by the society's Executive Committee last year. These rules have been incorporated in the tentative specifications for elevated steel water tanks, standpipes, and reservoirs prepared by the American Water Works Association. By a recent action of the Executive Committe, all of the society's other committees dealing with storage tanks have been consolidated into the one Committee on Rules for Field Welding of Storage Tanks.

This society maintains extensive representation in other technical bodies in connection with matters of mutual interest. It is officially represented on sectional committees of the American Standards Association dealing with the following projects: Safety code for construction work; building code requirements for iron and steel; code for pressure piping; definitions of electrical terms; electric welding apparatus; preferred voltages-100 volts and under; code for the protection of heads, eyes, and respiratory organs of industrial workers; ventilation code; drawings and drafting-room practice; work in compressed air; and graphical symbols and abbreviations for use on drawings. It is also represented on committees of the American Society for Testing Materials engaged in the preparation of specifications for joint filler metal; on iron-chromium, ironchromium-nickel and related alloys; and on copper and copper alloys. It also cooperates with the American Institute of Electrical Engineers on power supply for welding operations; with the National Board of Boiler and Pressure Vessel Inspectors relative to questions connected with boiler and pressure vessel legislation in the various States; with the American Transit Association in the preparation of filler metal specifications; with the Association of American Railroads on specifications for fusion-welded tank-car tanks; and with the American Petroleum Institute on revision of specifications for pipe intended for welded casings.

American Wood-Preservers' Association, Horace L. Dawson, secretary, 1427 Eye Street NW., Washington, D. C. Among the objects of this association are the standardization of specifications for wood preservatives, for their introduction into the materials to be preserved, and for the improvement of materials and methods used in construction with preserved wood. 
Among the numerous standing and special committees engaged in various association activities, several deal directly in the development of standards and research, namely: Committees on Preservatives, and on Pressure Treatment of Oak Ties and Lumber; joint Committee on Douglas Fir Pressure Treatment; Committees on Southern Pine Ties, Piles, Posts, and Poles; and Special Committee on Revision and Coordination of Treatment Standards.

The association publishes and issues the Manual of Recommended Practice, in which are incorporated approximately 50 standards and methods of recommended practice relating to preservative treatment of wood which have been adopted by the association. It maintains representation on the Sectional Committees on Specifications for Wood Poles and on Cross-Ties and Switch-Ties, functioning under the procedure of the American Standards Association. These committees have engaged in standardization which led to the approval of several American standards for various kinds of poles and ties by the American Standards Association.

American Zinc Institute, Ernest V. Gent, secretary, 60 East Fortysecond Street, New York, N. Y. The activities of this institute in the field of standardization are confined to specifications and standards in connection with the finished products of the zinc industry. In this respect, the institute is a member of the American Society for Testing Materials, and cooperates with committees of the latter organization dealing with corrosion of iron and steel, on specifications for nonferrous metals and alloys, and on corrosion of nonferrous metals and alloys. It has cooperated in the preparation of ASTM specifications covering slab zinc (spelter), rolled zinc, and zinc base alloy die castings. In addition, it concerns itself in all ASTM specifications relating to zinc-coated steel and iron articles such as, for example, fencing, wire, sheets, pipe, hardware, etc., as well as methods of test in connection therewith.

The institute maintains representation on Sectional Committees on Standardization of Wire and Sheet Metal Gauges, and Specifications for Zinc Coating of Iron and Steel functioning under the procedure of the American Standards Association. It cooperates also with the Federal Specifications Executive Committee in the preparation and revision of Federal specifications covering slab zinc (spelter); zinc plates, sheets and strip; and zinc dust-zinc oxide primer paint (for galvanized (zinc-coated) or zinc surfaces). In conjunction with the promotion activities of the institute and its efforts to improve the quality of zinc-coated (galvanized) roofing sheets, the institute licenses steel manufacturers without charge to stamp the Zinc Institute's seal of quality mark on all galvanized sheets, which conform to rigid specifications as to quality and which carry a full two-ounce zinc coating.

Anthracite Industries, Inc., Allen J. Johnson, director of laboratory, Primos, Delaware County, Pa. Practically all of the standardization work of this organization in the fuel-burning equipment field is carried on by its laboratory, which cooperates with organizations having similar or allied interests in this field. The laboratory initiated the project for domestic burners for Pennsylvania anthracite (underfeed type) which resulted in the establishment of 
Commercial Standard CS48-34, promulgated by the National Bureau of Standards.

In cooperation with the American Society of Heating and Ventilating Engineers and the Cooking and Heating Appliance Manufacturers, steps have been taken to prepare similar constructional and functional codes covering practically all other types of fuelburning equipment. With reference to cook stoves, the laboratory's work has progressed to the point where a code has been ratified by a special engineering committee appointed by the Cooking and Heating Appliance Manufacturers. This code is being submitted to the American Society of Heating and Ventilating Engineers for adoption. In the boiler field, this laboratory is working closely with the Institute of Boiler and Radiator Manufacturers on new boiler radiator codes for domestic boilers. In this connection, the laboratory is recognized as being one of the official testing stations where a considerable amount of work for boiler manufacturers is done.

The laboratory has developed its own testing codes covering several similar devices and including such items as thermostats, waterheating equipment, warm-air furnaces, magazine boilers, commercial stokers, and space heaters. In addition to the above specific work with equipment, the laboratory is conducting other work designed to improve the utilization of solid fuel. As an example, it is making studies of drafts and draft regulation leading towards a development of a standard code of domestic chimney construction and performance.

Anthracite Institute, Louis C. Maderia III, executive director, offices at 19 Rector Street, New York, N. Y., and 225 South Fifteenth Street, Philadelphia, Pa. The individual anthracite operating companies, comprising the membership of this organization, have adopted a uniform classification of accounts and the standard accounting forms. The institute has established standard anthracite specifications comprising screen-grading limits for broken, egg, stove, nut, pea, buck, rice, and barley sizes of anthracite coal, with permissible impurities in each grade. The industry conducts a laboratory for the approval of coal-using equipment, and issues a list of approved devices, including domestic stokers, thermostatic equipment, vacuum furnace cleaners, service water heaters, and space heaters. Other research activities are conducted by the industry.

The institute is represented on the Sectional Committee on Classification of Coals functioning under the procedure of the American Standards Association.

Anti-Friction Bearing Manufacturers Association, Inc., H. O. Smith, secretary-manager, 60 East Forty-second Street, New York, $\mathrm{N}$. Y. The primary object of this association is the establishment of standards for ball and roller bearings of various types. Its work in standardization is carried on by three engineering committees which collaborate with similar committees of the Society of Automotive Engineers, the American Standards Association, International Standards Association, the National Electrical Manufacturers Association, the National Grease Manufacturers Association, and various interested agencies of the Federal Government.

The Annular Bearing Engineers' Committee has not only developed standards for dimensions and tolerances of various types of 
ball bearings, but they have also established a framework of general bearing boundary dimensions to allow ease of future standardization. The committee has recently developed standards for new bearings required by the aircraft industry, also annular ball bearings with snap rings and a series of extra light bearings to meet modern spacesaving requirements. The dimensions of this latter series have been accepted as an international standard. The committee has also set up standards for mounting practice, including shaft and housing dimensions and tolerances to permit correct applications of bearings, also standards for bearing lock nuts and lock washers. The committee is preparing standardization of exterior dimensions for seal bearings and is actively in contact with the Army, Navy, and aircraft departments in the formulation of specifications, etc., to facilitate procurement.

The Thrust Bearing Engineers' Committee has formulated standards which were approved by the association for metric thrust bearings, inch-type thrust bearings, and a standard definition for parallelism and accompanying tolerances.

The Roller Bearing Engineers' Committee, recently organized, is engaged in preliminary work looking toward standardization of roller bearings. The methods employed by this association in the field of standardization is for the Bearing Engineers' Committee to set up tentative standards, which are submitted for final approval to the management of the participating companies on these committees. The standards, when approved, if they affect standards in existence under the jurisdiction of the Society of Automotive Engineers, are submitted to that agency for approval. They are in turn submitted to the American Standards Association, which finally transmits them to the International Standards Association, if the standardization in question affects that body. The standards involving dimensional data are published yearly in the SAE Handbook.

Appalachian Hardwood Manufacturers, Inc., H. E. Everley, manager, Trade Extension Department, 414 Walnut Street, Cincinnati, Ohio. This organization has a Trade Extension Committee which functions regularly in matters relating to standardization. Under the supervision of this committee, there was designed and placed on the market Appalachian standardized and packaged hardwood paneling, which is being manufactured in accordance with Commercial Standard CS76-39, promulgated by the National Bureal of Standards.

The committee cooperates with the National Hardwood Lumber Association and the various regional hardwood associations in formulating and adopting the national standards covering the manufacture of standardized and packaged hardwood paneling.

Apple Growers Association, J. E. Klahre, general manager, Hood River, Oreg. This association handles fresh fruits, such as apples, pears, cherries, and strawberries, the grades and standards of which are fixed by the State and Federal Departments of Agriculture. It also handles canned pears, apples, cherries, and strawberries, the standards of which are fixed by the National Canners Association and the Northwest Canners Association.

This association cooperated with the National Bureau of Standards and the apple wraps industry in the development of a quality stand- 
ard for dry and oiled paper apple wraps. This resulted in the establishment of Commercial Standard CS44-32, which was promulgated and published by the National Bureau of Standards.

Arkansas Soft Pine Bureau, B. E. Lowry, executive secretary, Little Rock, Ark. This organization has prepared and issued grading rules for Arkansas soft pine lumber, which conform to American lumber standards for yard and factory lumber. It has also issued specifications covering dimensions and small timbers, utility timbers and heavy joists, factory flooring, decking and heavy shiplap structural lumber. All bureau members are subscribers to the Southern Pine Inspection Bureau, at New Orleans, La., which is the grading and inspection authority for administration of the grading rules published by the bureau.

Aromatic Red Cedar Closet Lining Association, A. L. Foster, chairman, care of George C. Brown \& Co., Greensboro, N. C. This organization initiated the movement for the establishment of standard dimensions, quality, and red-heart content for aromatic redcedar closet lining set forth in the Commercial Standard CS26-30, published by the National Bureau of Standards of the United States, Department of Commerce. The association recommends to its members the use of a label guaranteeing that red-cedar closet lining supplied by them conforms to the standard grading rules given in the above-mentioned Commercial Standard.

Asphalt Institute, W. R. Macatee, managing director, 801 Second Avenue, New York, N. Y. The institute has a Technical Committee composed of technical representatives of each member company. The members of the committee cooperate in researches having to do with standardization of asphalt products and in which the institute's own laboratory also participates. So far, the standardization activities of the committee have been devoted mainly to development of specifications for liquid asphaltic road materials which have been classified under four distinct types, namely: rapid-curing, mediumcuring, slow-curing, and emulsified asphalts.

During 1940 it prepared specifications for asphalt enamel protective coatings for steel water pipe. It has also developed and put into effect uniform standards with respect to range of penetration of the several classes of asphalt cement. As standardization is effected, the committee recommends adoption by the institute's board of directors. In preparing specifications, it cooperates with the Public Roads Administration of the Federal Works Agency, through which collaboration is also had with the various State highway departments.

The technical department of the institute cooperates with other technical organizations, notably the National Bureau of Standards of the United States Department of Commerce and the American Society for Testing Materials. It assisted in the establishment of Simplified Practice Recommendation R4 covering asphalt grades; also with ASTM committees dealing with road and paving materials, and bituminous roofing and waterproofing materials. The technical department is also represented on the Committee on Specifications for Bituminous Pavements of the American Public Works Association. 
Asphalt Roofing Industry Bureau, J. S. Bryant, managing director, 2 West Forty-fifth Street, New York, N. Y. The Technical Committee of this bureau cooperates actively in the formulation, and improvement of standards and specifications covering asphalt roofing products, which are formulated by the Federal Specifications Executive Committee, the American Society for Testing Materials, and the Underwriters' Laboratories. Through its simplification committee, this bureau made studies and analyses designed to show the multiplicity of items produced in the industry and their relative importance from a sales volume standpoint. The purpose of these studies was to enable manufacturers to intelligently accomplish such individual simplification and standardization of their own lines as circumstances seemed to warrant. This organization maintains a research associate at the National Bureau of Standards conducting research work on durability of asphalt roofing.

Associated Cooperage Industries of America, Inc., M. T. Rogers, assistant secretary, 408 Olive Street, St. Louis, Mo. This organization carries on its standardization work through several committees appointed especially for that purpose. The Committee on Grade Rules and Specifications for Slack Cooperage Material has developed standard specifications covering slack barrel staves, coiled elm hoops and slack barrel heading.

The Committee on Grade Rules and Specifications for Tight Cooperage Material formulates specifications for tight barrel staves; tight barrel heading, circled and square; and beer staves and heading. These rules and specifications for cooperage material are used throughout the United States as standard.

The Committee on ICC Specifications for Slack Barrels considers and recommends specifications for slack barrels for the transportation of explosives and other dangerous commodities. In carrying forward this work it cooperates with the Interstate Commerce Commission, the Bureau of Explosives of the Association of American Railroads, the Manufacturing Chemists' Association, and other interested bodies. This committee also cooperates with the Freight Container Bureau of the Association of American Railroads in developing standards for slack barrels for fruits and vegetables.

The Committee on ICC Specifications for Tight Barrels cooperates with various organizations in developing proper standards and specifications for tight barrels for the transportation of explosives and other dangerous articles. The association assisted the Board of Trade of the city of Chicago in the development of standard specifications for pork barrels, lard tierces, and tierces for pickled meats. It also assisted in the promulgation of Congressional acts to fix the standard barrel for fruits, vegetables, and other dry commodities, and to standardize lime barrels; also in establishing rules and regulations promulgated under authority of the Federal Standard Barrel Law, which are set forth in Circular C71 issued by the National Bureau of Standards. The members of this association are constantly cooperating with container users in the development of barrels suitable for their products. These barrels are all made from material produced in accordance with the association's standard grades and specifications.

$201072^{\circ}-41$ - 6 
Associated Factory Mutual Fire Insurance Companies, Inspection Department, O. W. Stewart, manager, 184 High Street, Boston, Mass.

The Inspection Department of this association of 26 mutual fireinsurance companies serves large industrial plants in the United States and Canada. It also maintains the Factory Mutual Laboratories for the testing and approval of fire protection devices and devices involving fire hazard. Approved appliances are listed in the pamphlet "Approved Equipment." The manufacturers use the F. M. symbol on devices which have received approval. The Inspection Department formulates specifications for some of the appliances, writes installation rules, and publishes loss prevention bulletins giving information on safeguards for special hazards and suggested building construction features. This association is a member of the fire-protection group of the American Standards Association and is active in the affairs of the 15 sectional committees of that association dealing with safety codes and materials and equipment for fire fighting. Through committee representation, the association also cooperates in the standardization activities of the National Fire Protection Association, the American Society of Mechanical Engineers, the American Society for Testing Materials, and other similar organizations.

Associated General Contractors of America, Inc., Herbert F. Foreman, managing director, Munsey Building, Washington, D. C.

Standardization and simplification constitute important activities in the conduct of affairs of this organization. The work is carried on by various committees and the national staff which, either on their own iniciative or in cooperation with committees of other organizations, have developed standards and specifications approved by the $\mathrm{AGC}$ for the guidance and use of the members of the industry.

Through its Accident Prevention Committee, the association has published and kept under constant revision the Manual of Accident Prevention in Construction.

The Joint Conference on Standard Construction Contracts, composed of representatives of the association and those of the principal public and private associations and societies in the construction industry, formulated standard contract forms for building, engineering, and standard forms for the qualification of bidders on public and private work, which have been adopted by the AGC.

Several special committees of the association have developed miscellaneous standard forms for construction, including pre-qualification of bidders, cost of owning construction equipment, etc.

It is a member of the National Safety Council and is actively engaged in promoting interest in accident prevention in construction as well as considering other matters relating to construction safety under development by the National Safety Council.

The Mixer Manufacturers Bureau, composed of mixer and paver manufacturers in the United States, affiliated with the Associated General Contractors of America, has developed standard sizes and capacities for concrete mixers and pavers. Similarly, the Contractors Pump Bureau, also affiliated with the AGC, has adopted standard sizes and capacities for contractors' pumps. Both of these standards are in full effect and the principal manufacturers representing the great preponderance of production in the industry are guided by them. 
The association cooperates also with the Central Committee on Lumber Standards in the establishment of American lumber standards dealing with lumber sizes and use classifications of commercial softwoods; and with the National Bureau of Standards in the formulation of Simplified Practice Recommendations relating to construction materials and supplies.

The association maintains official representation on 13 sectional committees, functioning under the procedure of the American Standards Association, in developing standards and safety codes covering various projects in the construction and building industries. It is also represented on technical committees of the American Society for Testing Materials engaged in the preparation of standard specifications for cement and for road and paving materials.

Association of American Battery Manufacturers, V. L. Smithers, commissioner, 2706 First-Central Tower, Akron, Ohio. This association is a successor to the National Battery Manufacturers Association. Although it has not set up separate standards for specifications in the field which it represents, this association maintains a technical committee through which it coordinates the activities of the National Bureau of Standards, the Society of Automotive Engineers, and the American Standards Association in all matters pertaining to standards and specifications of storage batteries. This association is represented on the Sectional Committee on Definitions of Electrical Terms, functioning under the procedure of the American Standards Association.

Association of American Feed Control Officials (Inc.), Leslie E. Bopst, secretary-treasurer, College Park, Md. The primary object of this association is to promote uniformity in legislation, definitions, and rulings, and the enforcement of laws relating to the manufacture, sale, and distribution of feeding stuffs and livestock remedies in the continent of North America.

The association has officially adopted definitions and standards of feeding stuffs for the following products: Alfalfa, animal, barley; brewers' and distillers'; corn, cottonseed, lespedeza, linseed and flax, marine, milk, mineral, oat, peanut, rice, rye, screenings, soybean, wheat, yeast, and miscellaneous. It has also given favorable consideration to tentative definitions covering vitamin A and D feeding oil, dried sugar cane pith, feeding molasses (beet, cane, corn sugar), sweet potato pulp, fortified cod liver oil, oat flour, and peanut oil cake. In carrying forward its work the association has adopted the methods of analysis of the Association of Official Agricultural Chemists of North America.

Committees of this association cooperate with committees of the American Feed Manufacturers' Association and the National Cottonseed Products Association in attaining high standards of feed production and merchandising for the betterment and benefit of the feed industry as a whole. The association also collaborates with the United States Food and Drug Administration in the enforcement of regulations under the Federal Food, Drug, and Cosmetic Act.

It has adopted uniform types of labels for all classes of feeds. Manufacturers or jobbers are required to place labels on all packages of feeds, and the registration of brands and guaranties must be filed with each State-control agency. A guaranty and label for a 
brand having been registered may not be subsequently so modified as to permit the lowering of the quality of the feed, unless it can be clearly shown that the modification sought to be made is consistent with the interest of the feeder. The control organization may cancel the registration of any feed when it has been found that the brand name is misleading in any respect, or the feed contains an injurious ingredient, or packages are incorrectly labeled with regard to ingredients, or there is evidence of misbranding or adulteration, or when labels on packages contain any statement, design, or device which tends to deceive the purchaser.

Association of American Railroads, Bureau of Explosives, W. S. Topping, chief inspector, 30 Vesey Street, New York, N. Y. This bureau which functions as an agency for cooperation between the Association of American Railroads and the Interstate Commerce Commission, maintains a chemical laboratory for the study of explosives and other dangerous articles and containers therefor, and a force of traveling inspectors to insure compliance with the requirements of the regulations and specifications of the Interstate Commerce Commission dealing with the transportation of explosives and other dangerous articles.

Association of American Railroads, Engineering Division, Electrical Section, W. S. Lacher, secretary, 59 East Van Buren Street, Chicago, Ill. This section issues a Manual of Recommended Practice which at present includes specifications for trolley wire; friction tape; rubber insulating tape; conduit and fittings; stud terminal bonds; electric light, power supply and trolley lines crossing railways; and the construction of overhead electric supply lines. It also contains rules for the prevention of electric sparks that may cause fire during the transfer of inflammable liquids, rules for flood lighting and third rail clearance diagram. This section maintains representation on a number of sectional committees functioning under the procedure of the American Standards Association in connection with the following projects: rating of rivers; pipe flanges and fittings, electric wiring and apparatus; insulated wires and cables; hard drawn aluminum conductors; insulators for electric power lines; mercury arc rectifiers; railway motors and other rotating electrical machinery on rail cars and locomotives; power switchgear; electrical measuring instruments; definitions of electrical terms; rotating electrical machinery; electric welding apparatus; transformers; electrical insulating materials; standardization of vacuum tubes for industrial purposes, radio-electrical coordination; specifications for soft or annealed copper wire; and specifications for wood poles.

It is also represented on a technical committee of the American Society for Testing Materials engaged in preparing standard specifications and methods of test for rubber products. It cooperates with the Rural Electrification Administration in the development of standard forms of agreement for wire line crossings over railway tracks.

During the past year the section concentrated its attention on the revision and abridging of its Manual on Recommended Practice. Following are subjects on which work is in progress to this end: participation, through representatives, in revision of National Electrical Safety Code, with particular reference to wire line crossings; 
overhead clearance lines for permanent way structures on electrified lines; protection of tracks used in unloading and loading inflammable liquids from danger of fire caused by electric sparks; and specifications for electric wire and cables and other electrical material. A special study is being made of national and other widely used specifications for electrical materials and equipment, with a view to replacement where possible, of material now in the Manual, by title references to acceptance standards of other organizations.

Association of American Railroads, Engineering Division, Signal Section, R. H. C. Balliet, 30 Vesey Street, New York, N. Y.

This section harmonizes and coordinates the principles and practices of American railroads, and revises and keeps up-to-date the drawings and specifications contained in its Manual of Recommended Practice covering design, construction, maintenance, and operation of railway signaling devices. It has also prepared a number of educational chapters on American Railway Signaling Principles and Practices covering subjects in connection with the various types of signaling and block system devices.

During the past year, committees of this section investigated the development of new devices, improvement of existing equipment, and new methods of installation, maintenance, and operation pertinent to the art of signaling and the Manual of Recommended Practice was brought up-to-date by the adoption and in some cases revision of various drawings and the following specifications and recommended practice: Electropneumatic switch operating mechanism; circuit controller for drawbridges; interlocking at drawbridges for the protection of train movements; mechanically locking the levers of interlocking machines; electropneumatic interlocking; car retarder system; fence for the protection of traffic against slides and rock falls; track welding or heat-treating in track circuit territory; alternating-current and direct-current coded signal systems; tantalum rectifiers and valves; tractive armature direct current polarized relay; track circuit rail bonding; channel pins; automatic block signaling circuits; made ground for protection against abnormal potentials; minimizing the effect of foreign current on direct current track circuits; definitions for technical terms used in signaling; instructions ; form of agreement for interlocking; joint signal facilities-construction cost detail; performance report-automatic highway grade crossing protection; signal and interlocking units; signal glasses; railroad highway grade crossing signs; reflector unit; air depolarized carbon caustic soda primary cell; lubricating oil; metal plating; compound for closing wire entrances and openings; sealing compound for protecting wire entrances and openings; sealing compound for protecting wire entrances, outlets, sleeves, potheads, etc., against entrance of moisture; various types of steel ; paint and painting; highway grade crossing signals; flashing light signal lamp unit; wires and cables; interlocking; centralized traffic control, and automatic block signaling systems.

This Section is represented on sectional committees functioning under the procedure of the American Standards Association dealing with the following subjects: Standardization and unification of screw threads; pipe flanges and fittings; wire and sheet metal gages; National Electrical Safety Code; insulated wires and cables; dry 
cells and batteries; insulators for electric power lines; rolled threads for screw shells of electric sockets and lamp bases; electrical insulating materials; letter symbols and abbreviations for science and engineering; and preferred voltages- -100 volts and under.

It is also represented on a technical committee of the American Society for Testing Materials on the subject of insulating tapes.

Association of American Railroads, Freight Claim Division, Lewis Pilcher, Secretary, 59 East Van Buren Street, Chicago, Ill. This Division publishes a so-called Freight Claim Rule Book, or manual of practices, in which are set forth (1) rules and standards prescribed for the investigation, adjustment, and interline apportionment of claims paid; (2) lists of freight claim and prevention officers of carriers; (3) uniform blanks, (4) recommended practices in loss and damage prevention work, and (5) other information for use in the freight claim offices of carriers. There are also published and distributed semiannually, in printed form, interpretations of freight claim rules as handed down by the committees of the Division, as result of arbitration procedure.

Association of American Railroads, Freight Container Bureau, Edward Dahill, chief engineer, 30 Vesey Street, New York, N. Y.

In all of its work leading to the formation and adoption of recommended methods or practices for packing, boxing, and crating, engineers of this bureau cooperated with the officials of the industrial organizations representing manufacturers of these commodities to which attention is being given; and with the container and accessory manufacturers and their associations.

It is the practice of the bureau to submit all recommendations to a special committee appointed by the industry to pass on the recommendations before they are approved for printing and distribution. In several cases the bureau has carried on work leading to the preparation of recommended containers and packing methods at the direct request of a trade association, which has approved and adopted the recommendations as standard for its members. The bureau's engineers make shipping and laboratory tests and spend much time at the shippers' plants, at freight stations, and in consignees' receiving rooms, gathering information as to what are the causes for loss and damage to assist in determining how these causes may be eliminated. A considerable portion of the time of those engineers who are working on fresh fruits and vegetables is spent in the producing territories for the purpose of acquainting the shippers with the recommended containers and standard practices for loading and bracing.

The bureau cooperates very closely with national and local trade and traffic associations and with various Federal and State agencies. Over 200 standards relating to various types of containers for packing and shipping of various commodities have been formulated and covered by illustrated pamphlets which have had a wide distribution. In addition, 561 container specifications and approximately 90 loading rules for fresh fruits and vegetables have been developed and prepared by the bureau for tariffs effective throughout the United States.

Association of American Railroads, Joint Committee on Grade Crossing Protection, L. C. Heilman, secretary, Transportation Building, Washington, D. C. This committee cooperates with State 
regulatory bodies, through conferences with the National Association of Railroad and Utilities Commissioners, and particularly with its committee directly interested in railroad-highway grade crossing protection matters. During the past year specifications and requisites for automatic crossing gates to be used as an adjunct to the crossing signal have been developed by the engineering committees to whom the subject was referred, and these have been accepted by the joint committee. A number of installations calling for this additional protection have been made and others are in progress.

At the present time the joint committee has in preparation a revision in its publication outlining the standards and practices for railroad-highway grade crossing protection. Among other subjects that are receiving consideration by the joint committee are the following: Practicable method to provide uniform operating time for signals at all train speeds; and practicability of, and requisites for, intermittent and continuous floodlighting for railroad-highway grade crossings.

Association of American Railroads, Mechanical Division, V. R. Hawthorne, executive vice chairman; A. C. Browning, secretary, 59 East Van Buren Street, Chicago, Ill. Through the activities of its different committees and the investigations and research carried out under their direction, this division has adopted standards and recommended practices covering materials for cars and locomotives which are incorporated in a manual. This manual, which is revised and supplemented annually, includes material specifications for steel axles, wheels, forgings, tires, steel springs, boilers and fireboxes, iron and steel castings, pipe and pipe fittings, bearings, rubber hose, gaskets, and miscellaneous materials. In addition, it publishes a supplement to the manual which contains drawings for cars and trucks. The division also issues periodic revisions of manuals relating to wheels and axles, and locomotive tires.

The division through its Committee on Loading Rules publishes mandatory rules covering standard methods to govern loading of commodities on open top cars. These methods are formulated in cooperation with the shippers of such commodities, and are carefully tested before adoption. Thousands of test loads are annually followed through to destination. These rules are in the interest of safety to employes, the general public, and lading and equipment. The division is also represented on the Standards Council and Mechanical Standards Committee of the American Standards Association.

The various committees of the division are at present continuing their investigations and research for the purpose of keeping the standards and recommended practices revised and up-to-date, and leading to the adoption of additional practices for the improvement of railroad rolling stock and motive power.

The Committee on Brakes and Brake Equipment, in cooperation with the manufacturers of power brake equipment, is continuing its research in connection with best means for controlling the speed and stopping of trains. During the past year the committee in cooperation with the manufacturers and the Bureau of Safety, Interstate Commerce Commission, completed an investigation of experimental $\mathrm{AB}$ freight brakes that had been in continuous service 
for four years without having received any lubrication or other maintenance work.

The Committee on Couplers and Draft Gears is continuing its investigation of these devices in cooperation with the manufacturers. The committee will continue additional check tests of approved draft gears at the draft gear testing laboratory of the Association located at Purdue University, Lafayette, Indiana, to assure that draft gears, as sold, conform to the gears upon which certificate of approval was granted.

The Committee on Car Construction, in cooperation with the Design Committee of the American Railway Car Institute, continues its work in connection with designs of standard cars. The committee is giving special attention to the matter of light-weight designs of freight cars, including the matter of fusion-welded construction.

The Committee on Specifications for Materials, in cooperation with other committees of the division and manufacturers, is conducting studies and review of the material specifications of the division to insure the specifications shall represent the best materials obtainable. This committee is also cooperating with the Committee on Car Construction in testing new designs of cast steel side frames and bolsters and with the mechanical engineer in tests of axles.

The Committee on Wheels, in cooperation with the technical committees representing the various types of wheels, is carrying on investigation and research in connection with the specifications, designs, and service of the various kinds of wheels.

The Committee on Tank Cars is cooperating with the builders, owners, and users of tank cars in connection with designs and service of tank cars and tank-car appliances and devices. The committee keeps in close touch with the service rendered by the experimental tank cars constructed under authority granted by the Interstate Commerce Commission. Revised specifications of the ICC for tanks to be mounted upon, or form part of a car, have been approved and adopted, the committee has reviewed and revised AAR requirements for tank cars to be consistent therewith. The revised specifications are published by the division.

The Committee on Locomotive Construction, in cooperation with a committee of engineers representing the locomotive builders, is conducting an investigation and research for the purpose of improving the design and service of locomotives, and in increasing the degree of standardization of fundamental parts of locomotive design. The division maintains a laboratory at the plant of the Timken Roller Bearing Co., Canton, Ohio, for fatigue testing of full size car axles. Through research conducted at this laboratory the division has adopted new and improved design for passenger car axles. Research is continuing to develop improved material specifications for passenger car axles for heavy duty service.

Association of American Railroads, Electrical Section, Mechanical Division, J. A. Andreucetti, secretary, 59 East Van Buren Street, Chicago, Ill. Through the activities of its various committees and the investigation and research carried out under their direction, this section has adopted standards and recommended practices in regard to cars and locomotives which are incorporated in a manual. This 
manual, which is revised and supplemented annually, includes electrical equipment on railroad cars, namely, generators, storage batteries, air conditioning and heating auxiliaries, automatic air-brake control, etc.; electrical equipment for diesel locomotives; turbo generators and auxiliaries for steam locomotives; electric welding equipment; radios applied to railway cars; motors and control equipment for shops and power plants. The various committees of the section are at the present time continuing investigation and research in connection with the subjects above enumerated.

Association of American Railroads, Operating-Transportation Division, G. C. Randall, Chairman, General Committee, L. R. Knott, secretary, 59 East Van Buren Street, Chicago, Ill. Through the activities of its different committees, this division deals with rules and regulations governing car service, demurrage and storage, and also with rules and rates governing payment by a railroad for use and detention of cars not owned by that road. It assigns "reporting marks" by which cars and other equipment used in interchange are identified and recorded. The Official Railway Equipment Register, issued quarterly, contains detailed information concerning the nearly $2,000,000$ cars regularly used in interchange service. This division publishes recommended methods, which are now prepared by the Committee on Closed Car Loading Rules of the Freight Station Section, for loading commodities in closed cars.

Pamphlets have been issued covering the loading of many items, including automobiles, trailers, commodities in bags, barrels, drums, kegs, storage batteries, brick and hollow building tile, hot top brick, butter in tubs, cable and similar commodities on reels, car wheels, empty cylinders, commodities in fibreboard containers, rules governing the loading, bracing and blocking of freight, bulk grain, grain and grain products in fibreboard containers and sacks, ink and like commodities, dressed lumber and millwork, livestock, machinery, marble in slabs, newsprint, book and printing paper, paint, paper and similar commodities on skids, plasterboard, wallboard and lath, radiators, mechanical refrigerators, prepared roofing materials, soda ash, steel products, pulp grinder stones, stoves and ranges and tin plate on wooden skid platforms. It has also issued recommended rules for the receipt, stowing, handling and delivery of less-thancarload freight. In addition, this division has prepared circulars on rules governing the location of loading racks, unloading points and storage facilities for any inflammable liquid with flash point below 30 degrees Fahrenheit; procedure to be followed in connection with regulations regarding the unloading of tanks containing chlorine on carrier tracks; rules relating to the unloading of tank cars containing liquefied petroleum gas (butane or propane); and recommended practice for the prevention of electric sparks that may cause fire during the transfer of inflammable liquids to or from rail equipment.

Association of American Railroads, Operating-Transportation Division, Fire Protection and Insurance Section, W. F. Steffens, secretary, 230 Park Avenue, New York, N. Y.

This section, composed of representatives of member lines actively employed in the work of fire protection and its allied subjects, including insurance, was formed in 1939. This group formerly functioned independently as the Railway Fire Protection Association. 
This section has for its objectives the improvement of methods of fire protection and prevention, the establishment of safeguards against loss of property and life by fire, and the standardization of practices through the interchange of ideas and experiences.

Association of American Railroads, Operating-Transportation Division, Medical and Surgical Section, J. C. Caviston, secretary, 30 Vesey Street, New York, N. Y. This section handles matters relating to the health of railroad employees and patrons. It cooperates with State health bodies, and with the United States Department of Public Health, insofar as sanitation and similar matters concern employees and passengers. It has adopted recommended physical standards for railroad employees, by classes, as well as standard forms for conducting such physical examinations, making surgeon's report of injuries, etc.

Association of American Railroads, Operating-Transportation Division, Operating Section, J. C. Caviston, secretary, 30 Vesey Street, New York, N. Y. The functions of this Section have to do with the development of rules and practices with respect to operating phases of railroading. It publishes and keeps up-to-date by periodic revisions (a) the Standard Code of Operating Rules, (b) the Standard Code of Block Signal Rules and Interlocking Rules, (c) and the Standard Form for Detour Agreements. It also issues rules and recommended practices for handling of interline baggage between carriers. The present wording of the Standard Codes was adopted in November 1938.

Association of American Railroads, Operating-Transportation Division, Protective Section, J. C. Caviston, secretary, 30 Vesey Street, New York, N. Y. The functions of this section relate to the police protection of shipments and passengers, and particularly to the prevention of thefts. The section is a clearing house for all railroad police or special service departments throughout the United States and Canada. It prepares and distributes monthly, statistics regarding trespassers and also issues a monthly News Letter containing items of particular interest to railroad and other law enforcing officers. The section has been largely instrumental in effecting very close cooperation with other national law enforcing agencies, as well as with municipal police authorities.

Association of American Railroads, Operating-Transportation Division, Safety Section, J. C. Caviston, secretary, 30 Vesey Street, New York, N. Y. The activities of this section are primarily devoted to the prevention of accidents to employees and the public, through educational channels. It prepares and issues monthly illustrated circulars and posters relative to particular types of accidents. Some of these publications are directed to the prevention of accidents at railroad-highway grade crossings and to trespassers on railroad property, in which the public is more directly concerned. It also prepares monthly statistical reports covering employee casualty ratios and grade crossing accidents.

A code of safety rules covering the three major departments of the railroads is now nearing completion and will be ready for distribution during the current year.

Association of American Railroads, Operating-Transportation Division, Telegraph and Telephone Section, W. A. Fairbanks, secre- 
tary, 30 Vesey Street, New York, N. Y. In its looseleaf manual for use by engineering and field forces are included more than 350 recommended specifications and practices for the advancement of efficiency of the telegraph and telephone departments of the railroad service, and the standardization of plant, equipment, and practices.

The section maintains numerous standing committees which are engaged in the completion and revision of rules, recommendations, and specifications respecting the construction and maintenance of the outside plant (including pole line and underground construction; joint and conflicting construction; preservative treatment; terminal, aerial wire and cable construction; cable splicing; transpositions; maintenance; electrolysis, wire crossing; and material, tools and equipment); construction and maintenance of the inside plant (including apparatus, material, and tools; locations and layouts; telephone and miscellaneous equipment; telegraph equipment; design of circuits; and printer telegraph apparatus); transmission; research and development, protection, radio and wire carrier systems; communication plant operation and inductive interference.

The personnel of the committees include recognized authorities on subjects assigned. Through this membership, recommendations and specifications are developed which are truly representative and which can be safely followed by the communication departments of the member roads throughout the country, thus insuring a high standard of efficiency.

This section maintains representation on sectional committees functioning under the procedure of the American Standards Association dealing with the following subjects: Manhole frames and covers, code for protection against lightning, radio, specifications for dry cells and batteries, electrical insulating materials, radio-electrical coordination, specifications for zinc coating of iron and steel, specifications for soft or annealed copper wire, specifications for wood poles, standards for graphic presentation, miscellaneous pole line material and unification of methods of designating wire and sheet metal gages.

Association of American Railroads, Purchases and Stores Division, W. J. Farrell, secretary, 30 Vesey Street, New York, N. Y. Committees of this division are actively engaged in preparing standards, specifications, and recommended rules and practices, in order to bring about the highest efficiency in economy in the purchasing, handling, and distribution of materials and supplies in the railway industry. It has prepared a Purchasing and Stores Department Manual containing recommended rules and practices; a standard material classification; a standard scrap classification; specifications for tin and sheet metalware; simplified lists of sizes of various items of materials.

During the past year committees of this division have carried on work in connection with the standardization of quality and sizes of paper; standard specifications for various items of stationery, such as envelopes, car cards, shipping tags, baggage checks, etc.; also in simplification and standardization of stores stock covering the following: Suggested unification of specifications for rivet steel and rivets; simplification of electric lamps for signal purposes; simplification of sizes of rolled steel wheels for engine trucks; recommenda- 
tions in connection with standardization of electric hand lanterns for trainmen; suggestions for standard specifications for paint, varnish, and cleaning brushes; simplification of sizes of mechanical steel tubing (revision); suggested unification of specifications for structural steel shapes, plates, and bars for locomotive and car use; simplification of sizes for bridge reamers, standard length and short body; and hand reamers.

The division is continuing its activities with the ultimate aim of making further recommendations for efficient practices in the purchasing, handling, storing, and distribution of materials and supplies, through investigations, studies, and deliberations by its regular subject committees. The division is represented on the Standards Council of the American Standards Association.

Association of American Wood Pulp Importers, Johannes Westergaard, president, 630 Fifth Avenue, New York, N. Y. This association is officially represented, with the American Paper and Pulp Association and the Technical Association of the Pulp and Paper Industry, on a joint committee to approve and govern the actions of commercial chemists engaged in the testing of wood pulp for the paper industry in the United States. Official rules relating to the weighing, sampling, and testing of wood pulp for moisture have been formally approved and adopted by this association. It maintains a Traffic Committee which cooperates with railroads, steamship companies, and storage warehouses in the establishment of a standard set of storage and rail freight rates.

Association of Edison Illuminating Companies, Preston S. Millar, secretary, East End Avenue at Seventy-ninth Street, New York, $\mathrm{N}$. Y. Much of the work in standardization as relates to this association is carried on in cooperation with technical organizations, notably, the American Standards Association. It served as joint sponsor for two sectional committees, functioning under the procedure of the American Standards Association, as follows: Insulated Wires and Cables for Other Than Telephone and Telegraph Use (with nine other organizations); and in the development of the Code of Electricity Meters (with the National Bureau of Standards and the National Electric Light Association, now the Edison Electric Institute). It also participated in the preparation of specifications for dry cells and batteries and the National Electric Safety Code, both of which were approved by the American Standards Association.

It is officially represented on 19 ASA sectional committees dealing with the following projects: Code for pressure piping; code for lighting factories, mills, and other work places; insulated wires and cables; insulators for electric power lines; mercury arc rectifiers; power switchgear; radio, revision of National Electrical Safety Code; code for protection against lightning; rolled threads for screw shells of electric sockets and lamp bases; specifications for wood poles; standards and specifications for domestic refrigerators; pipe flanges and fittings; definitions of electrical terms; standardization of dimensions and materials of wrought iron and wrought steel pipe and tubing; identification of piping systems; revision of code for electricity meters; dry cells and storage batteries; revision of American standard for shaft couplings, integrally forged flanged type, for hydro-electric units. 
In consultation with the Insulated Power Cable Engineers Association, the High Tension Cable Committee of this association prepared specifications for impregnated paper insulated, lead-covered cable, solid and oil-field types, which were printed by the association. Through its Committee on Electric Switching and Switchgear, there were prepared specifications for oil circuit breakers, which were also printed by the association.

Association of Gas Appliance and Equipment Manufacturers, C. W. Berghorn, managing director, 60 East Forty-second Street, New York, N. Y. This organization represents manufacturers of gas appliances and gas plant and distribution equipment.

The association works closely with the American Gas Association and through representation on Sectional Committee on Appioval and Installation Requirements for Gas Burning Appliances, functioning under the auspices of the American Standards Association, cooperates with other organizations in the development of American standards covering gas appliances and equipment.

Association of Iron and Steel Electrical Engineers, Brent Wiley, managing director, Empire Building, Pittsburgh, Pà. Standards, specifications, and codes formulated and adopted by this association include electric overhead traveling cranes, heavy-duty steel mill service; guide forms, steel-mill auxiliary control, alternating-current motors for main roll drives; commutating-pole mill-type motors; engine stops; 40-inch blooming-mill drives; and rules for the safe operation of traveling cranes.

The association has prepared reports covering standard practices in connection with the type of lubrication and method of application to all types of equipment and apparatus used in the iron and steel industry; standardized operation and maintenance of electric overhead traveling cranes; standardized method for the organization and operation of engineering and maintenance departments; uniform methods of measuring fuel efficiencies, both for heating furnaces and boilers; a preliminary report on the standardization of control apparatus for open-hearth furnaces; and a report showing the location, horsepower, and electrical characteristics of every motor 300 horsepower and over installed on main-roll drives in the iron and steel industry in the United States and Canada. It has also prepared reports, charts, and data indicating the developments in the iron and steel industry for 25 years.

The association has also prepared reports relating to the application of antifriction bearings, mill-type motors, cranes, and roll necks; standardized full magnetic direct-current controllers for use in steel mills; safety regulations for the handling of fuels; safety regulations necessary when working on high-tension lines; and the life of wire rope used on ladle cranes in the iron and steel industry.

Association of Lift Truck and Portable Elevator Manufacturers, Howard R. Waterbury, executive secretary \& treasurer, P. O. Box 295, Stamford, Conn. Established in 1920, this association has, as one of its primary objects, the standardization of the products of the industry which it represents. During the past year, this organization revised and brought up to date its specifications covering lift trucks, skid platforms, portable elevators, and storage racks. These standards are now in general use throughout the industry. 
Association of Manufacturers of Chilled Car Wheels, F. H. Hardin, president, 445 North Sacramento Boulevard, Chicago, Ill.; 230 Park Avenue, New York, N. Y. This association, organized in 1908, includes in its membership every commercial manufacturer of chilled car wheels in the United States and Canada.

The functions of this organization are divided into several primary responsibilities, namely, research related to improvements in chemical, phyiscal, and metallurgical properties of material; inspection of the manufactured product and the standardization of specifications and inspection methods; and standardization of wheel design.

The association maintains several standing committees dealing with metallurgical research projects, wheel design and specifications. In carrying out its functions the association cooperates with technical committees of the Association of American Railroads and the American Society for Testing Materials on standardization matters relating to methods of testing, theory and practice of mounting railroad wheels on axles, and wheel design. It maintains also a wellequipped laboratory in Chicago for research purposes.

The association has issued a Manual of Inspection which includes a code of practice covering specifications relative to pouring, annealing, and testing; recommended practices with respect to inspection for the purpose of eliminating any product which has been found to be imperfect or undesirable; instructions covering association standard forms; and specifications of the Association of American Railroads for cast-iron wheels for locomotives, tenders, and cars.

Association of Official Agricultural Chemists (Inc.), W. W. Skinner, secretary-treasurer, Box 540, Benjamin Franklin Station, Washington, D. C. The chief function of this association is the development of methods of chemical analysis for foods, drugs, agricultural products, and other related items, which results in the publication every 5 years of a book entitled Official and Tentative Methods of Analysis. Incident to this work the association advises with other organizations on questions on standardization of these types of commodities.

A committee of this association cooperates with several committees of other organizations on food definitions, and also with the Food Standards Committee of the United States Food and Drug Administration. Other committees of this association carry on work that deals with the quartz-plate standardization and normal weight, and definitions of terms and interpretation of results on fertilizers and liming materials.

The association cooperates with the American Public Health Association in the preparation of standard methods of milk analysis, and with the committee on revision of the United States Pharmacopoeia on methods of testing drugs and medicinal products.

Association of Official Seed Analysts, W. A. Davidson, secretarytreasurer, care of U. S. Department of Agriculture, Beltsville Research Center, Beltsville, Md. The activities of this association in the field of standardization of methods of testing is carried on primarily by the association's Research Committee. This committee, for a number of years, studied the methods by which the germination and purity of seeds are determined, and has endeavored to develop standard means of making such tests that would eliminate, 
insofar as is possible, the human element which tends toward lack of uniformity in results. The committee, in addition to carrying on research into methods of test, endeavors to foster greater uniformity in the results of the present methods used, by circulating among the members of the association, as well as among commercial seed analysts, samples which have been referred to as referee samples. The results of the tests made by the various laboratories are tabulaterl, so that each analyst may determine the extent to which his interpretation complied with those of other analysts.

At a recent meeting of the association, action was taken to further coordinate these activities by appointing three members of its Research Committee to work with a representative of the seed laboratory in the United States Department of Agriculture, for the purpose of developing more standardized methods in the testing of seed. The committee consists of representatives from two States, the United States Department of Agriculture, and the Canadian Department of Agriculture. The association is a member of the International Seed Testing Association, which consists of official laboratories primarily in European countries. The purpose of the International Seed Testing Association is to develop uniform methods of such testing for international trade in seeds.

Association of Refrigerated Warehouses. This organization is a division of the American Warehousemen's Association. See outline of latter association on page 67.

Association of Roller and Silent Chain Manufacturers, Guy A. Wainwright, secretary, 402 Kentucky Avenue, Indianapolis, Ind. This organization is interested in standardization of dimensions of roller and silent chains and sprockets for the purpose of securing interchangeability, and also in standard recommendations for power capacity and speed of these chains. Subcommittees of engineers are appointed from time to time to deal with specified subjects, and their work is reviewed and approved by the entire association. The association, itself, does not publish standards, preferring to sponsor standards for adoption through the procedure of the American Standards Association. It cooperates with the American Society of Mechanical Engineers, Society of Automotive Engineers, American Petroleum Institute, and the American Gear Manufacturers Association in standardization matters of mutual interest.

Automobile Manufacturers Association, William J. Cronin, secretary, Maufacturers Committee, New Center Building, Detroit, Mich. Practically all standarization work arising in the industry represented by this organization is conducted through the Society of Automotive Engineers financed in substantial part by grant from the association. The association cooperated with the National Conference on Street and Highway Safety in the preparation and promulgation of State and city traffic ordinances.

With the American Petroleum Institute and the Society of Automotive Engineers, it maintains 13 research associates at the National Bureau of Standards working on problems dealing with motor-fuel knock rating and fuel requirements of cars, and flow characteristics of aircraft fuel systems.

The association is officially represented on four sectional committees, functioning under the procedure of the American Standards 
Association, in connection with standards for the inspection of motor vehicles, safety code for conveyors and conveying machinery, standards for graphic presentation, and petroleum products and lubricants.

Book Manufacturers' Institute, Inc., J. Raymond Tiffany, general counsel, 25 West Forty-third Street, New York, N. Y. The principal standardization activities of this institute have been in connection with the development of commercial standards for various kinds of materials used in book manufacture. In cooperation with the Employing Bookbinders of America, this organization initiated the establishment of Commercial Standards CS49-34 covering chip board, laminated chip board, and miscellaneous boards for bookbinding purposes; and CS57-40 for book cloths, buckrams, and impregnated fabrics for bookbinding purposes, except library bindings. It also cooperated with the National Bureau of Standards in the establishment of Commercial Standard CS50-34 for binders board. All of these standards which have been promulgated and published by the National Bureau of Standards have been adopted by the industry. The institute has also collaborated with a committee of textbook publishers and representatives of State departments of education in formulating minimum standard specifications for school textbooks. The States having adopted these minimum manufacturing standards and specifications to date are: North and South Carolina, Florida, Tennessee, Georgia, Texas, Louisiana, Mississippi, and Arkansas.

Brake Lining Manufacturers' Association, Inc., C. A. Ekwall, secretary, 370 Lexington Avenue, New York, N. Y. The Technical Committee of this association is responsible for the standardization and simplification of the product of this industry. This committee has cooperated with the National Bureau of Standards in the development of specifications for a brake-lining testing machine which the Bureau has constructed for testing purposes. The committee also collaborated with the Federal Specifications Executive Committee in the formulation and revision of Federal specification covering brake lining.

Buff and Polishing Wheel Manufacturers Association, Inc., H. L. Gaardsmoe, secretary, 110 East Forty-second Street, New York, N. Y. The only program which this organization has developed along standardization or simplification lines has been the development of a standard stock schedule of sizes of buffing wheels. This resulted in the establishment of Simplified Practice Recommendation R115-30, which was promulgated by the National Bureau of Standards.

Building Officials' Conference of America, John W. Oehmann, president, 1253 Lawrence Street NE., Washington, D. C. The primary object of this organization is the discussion of principles and practices underlying the laws and ordinances relating to buildings so far as concerns structural safety, fire hazard, and housing conditions; the methods of administration of such laws and ordinances; and the development and recommendation of regulations and legislation.

It does not offer to set up any standards of materials or construction. Through official committee representation, this organization has cooperated with other bodies, under the procedure of the American Standards Association, in the development of the build- 
ing exits code, specifications for fire tests of building construction and material, and the manual of accident prevention in construction. It is serving as joint sponsor with the American Municipal Association and the Pacific Coast Building Officials Conference for the ASA Sectional Committee on Administrative Requirements for Building Codes. The conference is represented on additional ASA sectional committees dealing with building code requirements and good practice recommendations for masonry, building code requirements for light and ventilation, building code requirements for excavations and foundations, and building code requirements for iron and steel.

Calcium Chloride Association, Ray A. Giddings, secretary, Penobscot Building, Detroit, Mich. The primary object of this association is to conduct research, and to distribute information relative to the uses of calcium chloride. Although it does not of itself prepare standards, this association has adopted for the use of its members the standard specifications for calcium of the American Society for Testing Materials, and the specifications of the American Association of State Highway Officials for the use of calcium chloride in stabilizing soil aggregate mixtures. The Technical Committee of this association assists in the development, revision, and use of these specifications.

The association maintains a research associate at the National Bureau of Standards in connection with volume studies of concrete, and through other current research fellowships at Michigan State College, Purdue University, and West Virginia University School of Mines, seeks to establish standards for recommendation of calcium chloride use in concreting, consolidation of soil aggregate roads, treatment of soils to prevent frost heaving, and for dustproofing and freezeproofing coal.

This association promulgates standards for various uses of the product, such as the properties of calcium chloride solutions for refrigerating brine, freezeproofing water for fire barrels, poster paste, tractor tire ballast, etc. Such standards, adopted by its committee of technical representatives, serve to correlate the data of the member producers.

California Fruit Exchange, F. W. Reed, assistant general manager, P. O. Box 2038, Blue Anchor Building, Sacramento, Calif. This exchange is a growers cooperative marketing organization, which markets the fruit of some 3,000 grower members, who are organized into approximately 50 local associations and large contract shippers. It has developed grade specifications for fruits and grapes, together with approved and recommended methods of packing. Fruits which meet the standard grades of the exchange are permitted to carry the trade-mark label on each individual container.

For approximately 20 years this organization has maintained a Committee on Standardization, which cooperates with the standardization department in the development of grades and standards for marketing fresh deciduous-tree fruits and grapes.

California Olive Association, E. Hevel, assistant secretary, 216 Pine Street, San Francisco, Calif. This organization has developed nine canned olive size grades under which canned ripe olives are $201072^{\circ}-41-7$ 
graded and sold. These grades are based on the California Ripe Olive Standardization Act, revised to 1935, which provides certain standards of quality, fill of container, and requirements for marking of olives packed in tin or glass containers.

California Redwood Association, Kenneth Smith, president and general manager, 405 Montgomery Street, San Francisco, Calif. An important function of this association is the standardization of grades, sizes, patterns, and grade marks for redwood lumber. This work is carried on by the Grading Committee and the Pattern Book Committee, which serve as advisory committees to the association.

This association has adopted standard specifications for grades of California redwood lumber and standard patterns of worked redwood lumber. It has also adopted official grade marks which appear on lumber signifying that it has been graded in accordance with the standard specifications of the association. These marks are applied by graders of member companies or licensees whose grading is supervised and approved by the Department of Inspection and Grades of this association or by association inspectors.

The Grading Committee has worked with the Water Cooling Tower Association toward the standardization of grades of redwood cooling tower lumber.

This association cooperates with other lumber organizations and with the Central Committee on Lumber Standards in keeping current the American Lumber Standards set forth in Simplified Practice Recommendation R16, promulgated and published by the National Bureau of Standards. The association's grading rules for redwood lumber are in accordance with these standards.

The association has also cooperated with regional associations under the auspices of the National Bureau of Standards in the development of Commercial Standards for shingles and for tank stock lumber.

California Walnut Growers Association, A. W. Christie, field manager, 1745 East Seventh Street, Los Angeles, Calif. Following investigation and report by its Standardization Committee, this association, through its Board of Directors, adopted specifications covering all the different packs of walnuts sold both shelled and unshelled. These specifications are closely similar to those established under the Federal Walnut Marketing Agreement in effect under the Agricultural Adjustment Administration, and are also similar to standards for United States grades for both shelled and unshelled walnuts.

Canners League of California, Preston McKinney, vice president and secretary, 64 Pine Street, San Francisco, Calif. The league, a trade association of fruit and vegetable canners, was established in 1905.

It maintains a Standards Committee whose function it is to keep the league's standards current and to cooperate in the formulation and revision of specifications for canned fruits issued by various agencies of the Federal Government.

The league has published the eighth edition of specifications for the grades of California canned fruits which include apricots, cherries, figs, fruit cocktails, fruits for salad, grapes, peaches, pears, plums, prunes, and spiced fruits.

Canning Machinery \& Supplies Association, S. G. Gorsline, secretary, 827 Bedford Road, Battle Creek, Mich. The standardization 
activities of this organization are carried on in cooperation with associations dealing with the establishment of standards for materials used in canning purposes. It has cooperated with the $\mathrm{Na}$ tional Canners Association in the standardization of sizes of tin cans and with the Glass Container Association of America in developing standard sizes of glass containers.

This association is represented on the sectional committees of the American Standards Association dealing with the following projects: Allowance and tolerances for cylindrical parts and limit gages; safety code for conveyors and conveying machinery; specifications for pressure and vacuum gages, and classification and designation of surface qualities.

Cast Iron Pipe Research Association, Thomas F. Wolfe, research engineer, 122 South Michigan Avenue, Chicago, Ill. This organization is cooperating with sectional committees of the American Standards Association in developing standard specifications for castiron pipe and fittings; preparation of a code for pressure piping; and development of flange standards. It also cooperates with the American Gas Association in formulating standards for mechanical joints for gas pipe, and in the preparation of specifications for plain end cast-iron pipe and fittings for use in gas distribution lines.

This association has adopted a symbol-a letter " $Q$ " with a checkwhich is stenciled on each length of pipe produced by the members of the association. Its purpose is to identify the pipe as cast iron pipe. The association states that the reason for the adoption of the symbol is the fact that it desires to advertise cast iron pipe to the public, even though it is not purchased directly by it except through taxes. It is felt that in the absence of an identification mark the public would have no way of knowing whether the pipe being installed in their streets was cast-iron pipe or some other type of pipe.

Cast Iron Pressure Pipe Institute, J. R. Dangler, executive vice chairman, 1006 Earle Building, Washington, D. C. This organization cooperates with technical committees of certain associations who are engaged in standardizing the principal products of this industry. The institute has adopted the following standards and specifications which are being used by the member companies in the manufacture of industry items: Federal specification for cast-iron water pipe; American standard specification for cast-iron pit cast pipe for water or other liquids; American standard specifications for cement mortar lining for cast-iron pipe and fittings; American Water Works Association standard specifications for cast-iron water pipe and special castings; American Gas Association standard specifications for castiron pipe and special castings, and manual for computation of strength and thickness of cast-iron pipe, approved as American recommended practice by the American Standards Association.

Cellulose Plastics Manufacturers' Association, John E. Walker, secretary, 631 Tower Building, Washington, D. C. The Trade Customs Committee of this association has authority to consider all matters relating to standardization of products, codes of ethics, and other trade practices. Standards for pyroxylin sheets, rods, and tubes covering standard sizes, dimensions, and tolerances, prepared and recommended by this committee, have been approved and adopted by the association. 
Central Committee on Lumber Standards. (See page 11.)

Certified Milk Producers Association of America (Inc.), S. W. Shoemaker, secretary, 1265 Broadway, New York, N. Y. Standardized methods for the production and distribution of "certified milk," as formulated by the American Association of Medical Milk Commissions, have been adopted by this organization.

Chain Institute, Inc., W. S. McCann, secretary, 208 South La Salle Street, Chicago, Ill. Simplification and standardization of chains form a major part of the activities of this organization. The Committee on Simplified Specifications of this institute sponsored the movement for the reduction in the number of sizes of chains appearing in the manufacturers' catalogs. This resulted in the formulation of Simplified Practice Recommendation R100, covering standard stock items of welded chains, promulgated and published by the National Bureau of Standards.

Through its Committee on Tire Chain Specifications, the institute has prepared, and keeps constantly under revision, specifications for several types of tire chains relative to material, physical dimensions, tolerances, and other requirements for the various sizes and dimensions of pneumatic tires. The Institute's Committee on Welded and Weldless Chain Specifications is at the present time cooperating with the Federal Specifications Executive Committee in revising the Federal specification covering standard miscellaneous chains and attachments.

Chamber of Commerce of the United States of America, Washington, D. C. One of the main activities of this organization in the field of standardization is the cooperative and educational service it renders through its large membership and its numerous contacts with business in encouraging the elimination of waste in industry. The national chamber also acts as a means for bringing together various groups of industries in an attempt to solve their standardization problems, either alone or through the procedure of the various sections of the United States Department of Commerce created for the specific purpose of aiding this type of work.

The Domestic Distribution Department has given consideration to problems relating to the simplification and standardization of consumer goods.

The Trade Association Department of the chamber has from time to time made studies of trade promotional activities of associations which included references to standards, inspection, certification, and labeling of commodities.

Chlorine Institute, Inc., Robert T. Baldwin, secretary, 50 East Forty-first Street, New York, N. Y. All standardization work of this organization is carried on by its Committee on Container Specifications and Safety. The function of this committee is to develop and to keep under constant revision specifications covering certain items used in the chlorine industry.

The institute has adopted specifications for safety valves, dome cover plate, dome cover lid stop, and standard angle valves for chlorine tank cars. These are recommended standards and have been approved by the Committee on Tank Cars of the Association of American Railroads. 
In addition, the institute has adopted a standard method for the determination of hydrogen in loaded tank cars.

At the present time the institute's Committee on Container Specifications and Safety is engaged in revising specifications for valves and fusible plugs for cylinders and ton containers for liquid chlorine, and in providing standard means of unloading chlorine tank cars.

The institute cooperates actively with the Compressed Gas Manufacturers' Association in matters relating to general interest in the safe transportation of compressed gases.

Clay Products Association, J. D. Cook, secretary, 111 West Washington Street, Chicago, Ill. This association is a member of the American Society for Testing Materials, through which it cooperates with its committees dealing with drain tile, clay pipe, and manufactured masonry units. In this connection, it assisted the society in the formulation of ASTM specifications for clay sewer pipe and the methods to be used in testing. In addition, this association has printed a pamphlet entitled, Tentative Standards for Vitrified Clay Products, which is intended to be used as a guide to manufacturers. These tentative standards cover vitrified salt-glazed clay sewer pipe and fittings; fire-clay flue linings and fittings; flue or chimney pipe and fittings; wall coping and fittings, and specifications for the laying of vitrified salt-glazed clay sewer pipe.

During the past 2 years, through the Armour Research Foundation, the institute has been carrying on a research in connection with a jointing compound for vitrified clay sewer pipe. This research has been completed, and the material known as clay pipe jointing compound 111 is now ready for the market.

Clay Sewer Pipe Association, Inc., 947 Oliver Building, Pittsburgh, Pa. This association represents most of the manufacturers of vitrified clay sewer pipe and allied products, whose plants are located in the northeastern part of the United States including the territory from Indiana to the Atlantic seaboard and from Virginia to Canada. The association is engaged in the preparation and revision of standards of quality and dimensions of heavy clay products including single strength, double strength, and extra strength sewer pipe and sewer pipe fittings; sewer liner plates; flue linings and fittings; stove pipe and fittings; wall copings and fittings; and traps and plumbing fittings.

The association is represented on the Technical Committee of the American Society for Testing Materials in connection with the standardization of specifications for clay sewer pipe. It is in active cooperation with the Federal Specifications Executive Committee in the consideration of Federal vitrified clay sewer pipe specifications; and with the highway departments of the States in its territory, and with municipal and industrial engineers on the same subject.

Collapsible Tube Manufacturers Association, Lester B. Platt, secretary, 19 West Forty-fourth Street, New York, N. Y. Through long time practice and experience in the trade, this industry, prior to the formation of the present association, developed and adopted a standardization schedule of sizes and weights for tin, lead, and aluminum tubes. In addition, it has also standardized the thread dimensions used on the tube necks and caps to conform to the threads 
employed by the manufacturers of molded bakelite caps which are pürchased from the plastic trade.

Commercial Refrigerator Manufacturers Association, Paul H. Sullivan, executive secretary, 111 West Washington Street, Chicago, Ill. Neither this association, nor the industry which it represents, has formulated or adopted any standards covering refrigerator equipment. It has, however, worked very closely with governmental agencies over a period of years in developing approved specifications covering the requirements of various departments of the Federal Government in connection with refrigerators or coolers of all types for the preservation or storage of perishables. These include meat coolers, storage rooms, refrigerated containers for storage and/or transportation of perishables, refrigerators for biological purposes, hospital refrigerators, and mortuary refrigerators.

Commission on Standardization of Biological Stains, H. J. Conn, chairman, Agricultural Experiment Station, Geneva, N. Y. This commission is essentially a coordinating committee, representing several organizations, whose activities deal with the standardization and simplification of biological stains. Much of the work of this commission deals with standardization of the nomenclature, eliminations of brands, and formulation of specifications under the most commonly used biological stains. Cooperation is in effect with the American Pharmaceutical Association, as a result of which specifications of biological dyes have recently been published in the Bulletin of the National Formulary Committee, which have the endorsement of that committee and of the Commission on Standardization of Biological Stains, as well.

Certification labels are issued by the commission to manufacturers of biological stains, the certification label on any bottle of stain meaning that a sample of the particular batch of stain from which the contents of the bottle were taken has been submitted to the commission for testing, and a portion is permanently on file in the chairman's office; that the sample proves true to type as judged by spectrophotometric tests; that its dye content is up to specification and is correctly indicated on the label; that it has been tested by experts in the procedures named on the label and has been found satisfactory; and that no other batch can be sold under the same certification number except by such a breach of confidence on the part of the manufacturer as to risk losing the good will of the commission. Up to the present time 50 stains have been put on a certification basis by the commission.

Compressed Air Institute, C. C. Rohrbach, secretary, 90 West Street, New York, N. Y. The membership of this organization comprises the principal manufacturers of air and gas compressors, pneumatic tools, and rock drills. Standardization work of this institute is carried on through its Technical Committee, to which all projects are referred for final approval.

The institute has developed and prepared the fifth edition of Trade Standards, which includes standards for rating, testing, installation, and care for all types of displacement compressors, and apparatus of various types of compressors operated by compressed air. The standards include also a summary of nomenclature and terminology relating to air compressors. The institute is represented on five 
sectional committees of the American Standards Association dealing with the following subjects : safety code for compressed air machinery and equipment; code for pressure piping; petroleum products and lubricants; work in compressed air; and graphical symbols and abbreviations for use on drawings.

Compressed Gas Manufacturers' Association, Inc., F. R. Fetherston, secretary, 11 West Forty-second Street, New York, N. Y. This association has developed a safety device schedule which represents the minimum requirements recommended for safety devices for cylinders of a capacity not exceeding 1,000 pounds of water. These data may be extended to cover safety devices for larger containers when and if necessity arises.

Through its Sulphur Dioxide Committee, the association has approved a tentative standard method of analysis for refrigeration grade liquid sulfur dioxide.

The Test and Specification Committee of this association takes an active part in the revision of the Interstate Commerce Commission regulations for the transportation of explosives and other dangerous articles by freight and express, and in baggage service, including specifications for shipping containers.

The association cooperates with the American Standards Association through representation on sectional committees dealing with the development of specifications for pressure and vacuum gages, code for pressure piping, safety code for mechanical refrigeration, and safety code for compressed air machinery and equipment. It is also represented on the technical committee on gaseous fuels of the American Society for Testing Materials.

Concrete Reinforcing Steel Institute, H. C. Delzell, executive secretary, Builders Building, Chicago, Ill. The primary objects of this organization are to foster and increase the use of reinforced concrete construction; to carry on research work, publish and disseminate information as to the safe and proper materials to be used in reinforced concrete construction, and the proper methods of their use; to aid and promote the standardization of materials and nomenclature, the standardization of specifications and building codes, and the standardization of engineering practice methods of fabrication, forms of proposal, and contracts.

This institute maintains two committees which deal with work in standardization and simplification, these being the Committee on Engineering Practice, and the Committee on Standards Practice. The former committee, through its Subcommittee on Research and Tests, has conducted, and is still continuing to conduct, studies and tests on steel used for concrete reinforcement. It completed behavior studies of the various types of high-yield-point steels when used as tension reinforcement in concrete beams; and also bond tests using reinforcing bars with varying degrees of rust. These tests were conducted by the Fritz Engineering Laboratory, Lehigh University, under the direction of the institute.

A research program under way at the present time concerns comparative beam tests, to determine relative behavior of twin-twisted and stretched bars, and of deformed bars having equal yield strengths, when used as tension reinforcement in beams under flexure. These tests are being carried on at Columbia University under 
the direction of the institute and supervised by the Structural Engineers' Society of New York.

The Committee on Standards Practice completed a standardization of 11 sizes, weights, and areas for plain and deformed reinforcIng bars, which were developed into Simplified Practice Recommendation R26, promulgated by the National Bureau of Standards, and later adopted by the institute. This committee also formulated a Manual of Standard. Practice covering specifications for and the use of reinforcing materials.

All specifications published in this manual are the current standards of the American Society for Testing Materials, the American Concrete Institute, the Portland Cement Association, the Metal Lath Manufacturers Association, and this institute.

Acting as joint sponsor with the National Bureau of Standards, the institute was responsible for the establishment of American Standard A38-1933 for steel reinforcing spirals, under procedure of the American Standards Association. It initiated the movement under the auspices of the National Bureau of Standards which resulted in the establishment of Simplified Practice Recommendation R87 for forms for concrete joist construction floors.

The institute maintains membership and actively participates in committee work of such national organizations as the American Society for Testing Materials, American Concrete Institute, and other technical bodies. It also cooperates with various agencies of the Federal Government in connection with standardization work affecting the reinforcing steel industry.

The institute has adopted a "Quality Mark" which enables the specifier, or his representative in the field, to determine readily that reinforcing bars bearing this mark are rolled from new billet-steel of American manufacture, in compliance with the standard specifications of the American Society for Testing Materials for new billetsteel concrete reinforcement bars. The mill mark determines at a glance the manufacturer of the bars bearing the mark. The appearance of the "Quality Mark" and mill mark on reinforcing bars is assurance that the material is of the best commercial quality obtainable.

Contracting Plasterers International Association, Edward McDonnell, secretary, 4755 Commonwealth Avenue, Detroit, Mich. Standard specifications for lathing and plastering which may be incorporated into architects' construction specifications, or serve as a guide in writing lathing and plastering specifications, have been formulated and adopted by this association. Included in the specifications are recommended practices for various types of lath, plastering, and stucco, with requirements for materials, or the citing of standard specifications for materials.

The association has also adopted fair-trade practice rules applicable to the construction industry.

It is officially represented on the Sectional Committee on Specifications for plastering, functioning under the procedure of the American Standards Association.

Copper and Brass Research Association, T. E. Veltfort, manager 420 Lexington Avenue, New York, N. Y. Standardization work of this organization is carried on by its Committee on Standards, whose 
function it is to study all phases of standards in the industry and to make whatever recommendation may be necessary.

Standards already developed by the committee and approved by the association cover length and width tolerances for metal in sheets, strips, and coils; diameter tolerances of wire and rod; and gauge or wall thickness tolerances of round seamless tubes. The committee is continuing its work in studying additional standards applicable to this industry.

The association sponsored the movement which led to the establishment of simplified practice recommendation R150 for copper wire nails, under the auspices of the National Bureau of Standards.

The association is a member body of the American Standards Association and has representation on the Standards Council of this organization. It is also officially represented on ASA sectional committees engaged in the development of standards relating to minimum requirements for plumbing and standardization of plumbing equipment, pipe threads, code for pressure piping, wire and sheet metal gages, and classification and designation of surface qualities. It is also represented on technical committees of the American Society for Testing Materials on nonferrous metals and alloys, on corrosion of nonferrous metals and alloys, and on cast and wrought copper and copper alloys.

The association maintains a research associate at the National $\mathrm{Bu}$ reau of Standards investigating the strength of soldered joints for household plumbing systems, and on a general investigation of copper and sheet metal work.

Copper Wire Engineering Association, Stanton Hertz, executive director, 815 Fifteenth Street NW., Washington, D. C. This association maintains an Overhead Construction Practices Committee, which is an engineering advisory committee composed of five electrical engineers who are expert on the technical subject of overhead power and distribution lines. This committee deals with technical subjects and makes recommendations relative to improvements in practices of the use of copper-type conductors on overhead conductor lines. This committee, in cooperation with the management of the association, promulgates and issues bulletins, conductor wire tables, sag and tension charts for copper and copperweld-copper, and other copper-type conductors for the use and guidance of consumers who build overhead electric power lines.

Cordage Institute, J. S. McDaniel, secretary, 350 Madison Avenue, New York, N. Y. Several committees of this organization have cooperated with similar committees of the American Petroleum Institute in the preparation of standards for cordage used in oilwell production, and with the American Society for Testing Materials in the standardization of methods of tensile-strength testing and nomenclature of all hard-fiber products.

This organization cooperated in the formulation and revision of Simplified Practice Recommendation R92 relating to hard-fiber twine and lath yarn (ply and yarn goods), which was established in cooperation with the National Paper Trade Association under the auspices of the National Bureau of Standards. It developed a standard method of testing for hard-fiber wrapping twine, which was approved and adopted during the past year. 
This organization has also cooperated with the State of New York, City of New York, and with numerous other quasi-public or private corporations in the development of specifications for hard-fiber cordage and twine.

Cork Institute of America, Arthur L. Faubel, secretary, 25 West Forty-third Street, New York, N. Y. This institute is an affiliation of the Cork Insulation Manufacturers Association, the Cork Stopper Manufacturers Association, the Cork Composition Manufacturers Association, the Cork Tile Manufacturers Association, and the Cork Marine Goods Manufacturers Association.

Although the institute has done little work in connection with the establishment of standards, it has cooperated with Federal Government agencies in the preparation of Federal specifications covering compressed cork; cork tile; cork composition, gasket, and sheet; cork stoppers; molded cork pipe covering; insulating cork, granulated, and cork sheets for ring life buoys. In addition, it has collaborated with the Bureau of Marine Inspection and Navigation of the United States Department of Commerce in connection with regulations for vital requirements concerning the manufacture of cork life preservers and cork ring buoys.

Corset and Brassiere Association of America, Benn Lewis, secretary, 200 Fifth Avenue, New York, N. Y. This association has recently embarked on a program of standardization of colors which is being carried on by its Committee on Standardization. The functions of this committee are to consider the possibility of adoption of standard shades of colors which are found to be most satisfactory for use on foundation garments. As a result of its work the association has recently adopted a standard nude color in several fabrics. The committee is now engaged in extending nude color standardization to other fabrics. In carrying forward this activity, the association is cooperating with the American Standards Association and the National Bureau of Standards.

Cotton Duck Association, James Edw. Hooper, chairman, Specifications Committee, care of Wm. E. Hooper \& Sons Co., Woodberry, Baltimore, Md. This association has a Committee on Specifications whose function it is to cooperate with the various Departments of the Federal Government in the development of Federal and other specifications covering cotton ducks and fabrics. The committee also works with various State or private agencies along the same lines.

Cotton-Textile Institute (Inc.), Paul B. Halstead, secretary, 320 Broadway, New York, N. Y. The work of the institute in simplification and standardization projects is carried on in cooperation with large cloth and yarn consumer organizations, bureaus of the Federal Government, and other bodies. In its work on specifications it cooperates with the National Bureau of Standards, trade organizations and firms interested in cotton textiles.

This institute initiated the establishment of Commercial Standard CS32-31 covering construction, quality, size, methods of tests, and labeling of cotton cloth for rubber and pyroxylin coating, which was promulgated and published by the National Bureau of Standards. It also cooperated with the National Bureau of Standards in the development of Simplified Practice 
Recommendation R119 relative to standard sizes of fast selvage terry towels. The institute is also cooperating with the American Standards Association and various bureaus of the Federal Government in setting up standards for bedsheets and pillowcases.

Cotton Thread Institute, Inc., David Snyder, executive director, 11 West Forty-second Street, New York, N. Y. All matters relating to standardization and simplification are carried on by three committees appointed by the institute.

One committee, known as the Federal Thread Specifications Committee, has been cooperating for a number of years with the Federal Specifications Executive Committee in the preparation and revision of Federal Specification V-T-276 for cotton thread. The Standardization Committee is engaged in problems relative to a basis for standardization of thread qualities, sizes, and specifications. The third committee, called the Simplification of Products Committee, has for its purpose the study of problems of simplyfying the put-ups and yardages of industry products, and of establishing the types of threads which should be sold on a yardage basis and those which should be sold on a weight basis. This committee has already made several recommendations to the members of the institute with respect to industrial threads and standardization of existing put-ups of twocord, three-cord and four-cord tubes, spools, and cones. The committee now has under consideration several recommendations covering standard put-ups for mercerized threads.

Crayon, Water Color, and Craft Institute, John E. DeMeyer, president, 511 Fifth Avenue, New York, N. Y. To assure the purchasing public of materials of satisfactory quality, and to give the seller a definite set of specifications upon which to base his quotation, the institute has prepared and published a set of recommended minimum quality standards. These standards should protect the public against the purchase of materials of inferior quality. The institute has also established a certified products label, the use of which is dependent upon actual certification, after chemical test, of merchandise which meets the minimum health standards set up by the institute. This test particularly relates to the lead and arsenic content of crayons, chalk, water colors, and tempera colors so as to insure that such products are noninjurious to human health.

Crown Manufacturers Association of America, Louis B. Montfort, executive secretary and general counsel, Munsey building, Washington, D. C. This association, composed of crown or bottle-cap manufacturers, has recommended certain standards for the wording and type of label appearing on crowns or bottle caps for beverage bottles. These standards are made to conform to the Federal and State labeling laws on food products, and cover the size of type and specific information to be supplied on label, with one general type of labeling for synthetic-flavored beverages, one type of labeling for pure-fruit-flavvored beverages, and one type for beverages flavored with the oils of the fruits.

This association cooperated with the Glass Container Association of America, the American Bottlers of Carbonated Beverages, and other units of the industry in the standardization of carbonated beverage bottles, as represented in the Simplified Practice Recommendation on this subject now being circulated for acceptance by industry. 
One of the provisions of this Recommendation is that the contents' clause of all beverage bottles be blown plainly and conspicuously in the side of all bottles in the beverage field. By this provision the contents' clause may be omitted from the cap and the same cap may be used for various sizes of bottles.

Crucible Manufacturers' Association, C. C. Rohrbach, secretary, 90 West Street, New York, N. Y. This organization succeeded the Plumbago Crucible Association in 1933. Its work in standardization is limited to one project, which is conducted under the auspices of the American Standards Association. It is joint sponsor with the American Foundrymen's Association in establishing standard outside dimensions of plumbago crucibles for nontilting furnaces in nonferrous foundry practice.

Dairy Industries Supply Association, Roberts Everett, 232 Madison Avenue, New York, N. Y. The Technical Committee of this association is concerned with the standardization and simplification of requirements and supplies and equipment used in the dairy industry. The Technical Committee has developed sanitary fittings, including gasket and bevel joints, reducers, and fittings for thermometers used in connection with dairy equipment.

At the present time the committee is giving consideration to the following projects presented to it by the Evaporated Milk Association of Chicago: the improvement of design and the standardization of milk filters; the standardization or definition of a sanitary agitator in a tank, along with its location and the construction of the stuffing box; and definite specifications as to bacterial content, moisture, and temperature of the can with reference to the performance of can washers.

Diamond Core Drill Manufacturers Association, Clifford C. Rohrbach, secretary, 90 West Street, New York, N. Y. This association was instrumental in enlisting the services of the National Bureau of Standards in the movement which led to the establishment of Commercial Standard CS17-41 covering diamond core drill fittings. The Technical Committee of this association is now actively engaged in preparing a revised edition of this standard.

Diesel Engine Manufacturers' Association, Otis A. Sibley, secretary, 140 Cedar Street, New York, N. Y. This association has prepared and issued a book on standard practices dealing with stationary installations, definitions, equipment, and performance of Diesel engines. It has also issued another publication on marine Diesel engine standards, which also covers definitions, equipment, installation, and performance. Both of these publications cover in detail the application of Diesel engines, the kind of fuel oil to be used, lubricating oil and cooling-water systems, and other items relating to engine construction and performance.

This association cooperated with the National Electrical Manufacturers Association in standardizing electric generator sizes and speeds. It is at the present time working with several organizations in the development of standards for fuel and lubricating oils. It is represented on the following Sectional Committees functioning under the procedure of the American Standards Association: Specifications for Pressure and Vacuum Gages; Classification and Designation of Surface Qualities; Graphical Symbols and Abbreviations for Use on Drawings; and Petroleum Products and Lubricants. 
Distilled Spirits Institute (Inc.), Howard T. Jones, secretary and general counsel, 1132 National Press Building, Washington, D. C. The development of standards of identity and quality constitutes an important activity of this institute. Under the guidance of the main technical committee which was created a little more than a year ago, the institute has organized several committees which are now actively engaged in developing standard qualities of corn, malt, and rye to be used for distillery purposes. Another committee known as the Committee on Analytical Methods is studying the problem of developing a standard laboratory procedure for determining the fermentable carbohydrates in grain and malt.

Among the problems being considered by the Spent Grains Committee, several lead directly towards standardization. Studies are being made by this committee with reference to the determination of the exact and complete composition of stillage resulting from various types of mash, the determination of the vitamins content of dried grains, and the standardization of analytical procedures; also the establishment of methods and standards for grading of dried grains based upon physical and chemical properties.

In the carrying out of its work in developing standards and analytical methods and tests, committees of the institute cooperate with committees of other organizations, notably the Malt Research Institute and the American Chemical Society, and with various universities, state agricultural experiment stations, and agencies of the Federal Grovernment.

Douglas Fir Plywood Association, W. E. Difford, managing director, Tacoma Building, Tacoma, Wash. Members of this industry requested the cooperation of the National Bureau of Standards to consider the formulation of a standard covering grading rules for Douglas fir plywood.

Following a general conference on this subject, there was established in 1933 Commercial Standard CS45, which set forth definitions and standard sizes of good and sound panel faces, wallboard, concrete form panels, door panels, and export grades. This standard was first revised in 1936 to include definitions of sheathing, automobile and industrial grades, and provided for the widening of concrete form panels.

As a result of suggestions from the Federal Housing Administration, the Commercial Standard was revised a second time in 1938 to provide for two classes of moisture resistance and changes in the sheathing grade. A general demand for the various grades of Douglas fir plywood as manufactured for permanent exterior use led to a third revision of the standard in 1940 to include detail requirements for seven distinct grades of the exterior type. This Commercial Standard, now in use by all Douglas fir plywood mills, including those which are members of the Douglas Fir Plywood Association and those which are not, provides the consumer the assurance of obtaining the exact grade or type of Douglas fir plywood needed for wïdely varying uses.

A corps of inspectors employed directly by the association constantly check manufacturing technique and the finished product, to make certain they are up to the standard. Further checking takes place in the Association laboratory where random plywood samples 
are tested for conformance with the provisions of the Commercial Standard.

Drop Forging Association, Raymond M. Seabury, secretary-treasurer, 605 Hanna Building, Cleveland, Ohio. Although this association has been organized only recently, it has already developed standard tolerances for forgings under 100 pounds each. These tolerances are applicable to thickness, width, draft angle, quantity, and fillets and corners. In addition, it has prepared a draft of a proposed code of standards and practices for the industry.

Edison Electric Institute, 420 Lexington Avenue, New York, N. Y. This institute, successor to the former National Electric Light Association, has taken over all of the activities of the latter organization in the field of standardization. At the present time the institute's Transmission and Distribution Committee, through its subgroup on Standards and Specifications, is revising various suggestions for specifications issued by the National Electric Light Association. These cover bolts and nuts, anchor rods, lag screws, eye bolts, steel cross arm braces, rolled steel washers, insulator and pin threads and gauges, and low and medium voltage pin-type insulators.

Through joint committee cooperation with the National Electrical Manufacturers Association, this institute has prepared and published reports on test specifications for household electric ranges, automatic electric storage water heaters, and domestic flatirons; also methods of measuring radio noise.

The institute served on the industry Committee on Interior Wiring Design with several other organizations, in the publication of a handbook of interior wiring design. This handbook surveys the field of wiring adequacy for buildings. It treats of the electrical needs of the residence, factory, office, or store, and it interprets modern practice in installing wiring. The material presented in this publication conforms with the requirements of the American standard codes for fire prevention and personal safety.

As a member of the Electric Light and Power Group of the American Standards Association, the institute takes an active part in the standardization activities of that organization. It is officially represented on sectional committees, functioning under ASA procedure, in connection with the following projects: rolled threads for screw shells of electric sockets and lamp bases; national electrical safety code; pipe flanges and fittings; manhole frames and covers; standards for drawings and drafting-room practice; and code for pressure piping.

The institute also cooperates actively with the American Society for Testing Materials. It maintains representation on the Society's technical committees dealing with electrical-heating, electrical-resistance, and electric-furnace alloys; boiler feedwater studies; water for industrial uses; thermal insulating materials; and iron-chromium, iron-chromium-nickel, and related alloys.

Electric Fuse Manufacturers Guild, G. P. Byrne, secretary, Dodge Building, New York, N. Y. This organization has not had occasion up to the present time to develop standards and specifications with respect to electric fuses. It does, however, cooperate through its Committee on Circuit Breaker Matters with the Underwriters' Laboratories concerning labels for electric fuses and materials from 
which the cases of cartridge fuses are made. In addition, it cooperates with the National Bureau of Standards and with the Federal Specifications Executive Committee in the preparation and revision of Federal specifications covering standard sizes, materials, and performance of different types of electric fuses.

Electric Hoist Manufacturers Association, E. Donald Tolles, secretary-counsel, 165 Broadway, New York, N. Y. This association has adopted standard specifications for wire rope electric hoists. It is cooperating with the Navy Department in formulating specifications for electric hoists for land and ship duty. This association is represented on the sectional committee of the American Standards Association dealing with the safety code for cranes, derricks, and hoists.

Electric Overhead Crane Institute, Thos. B. Jordan, executive secretary, Trinity Court Building, 74 Trinity Place, New York, N. Y. This organization cooperated with the Bureau of Yards and Docks of the Navy Department in the development of standards in connection with electric overhead cranes. The institute is represented on the American Standards Association's sectional committee dealing with safety code for cranes, derricks, and hoists.

Electrochemical Society, Inc., Colin G. Fink, secretary, 3000 Broadway, New York, N. Y. The standardization work of this organization is carried on largely by committees appointed to deal with primary and secondary batteries, alkali and chlorine, corrosion, power, electrochemistry of gases, and insulating materials.

Through its several committees, the society cooperates with the National Electrical Manufacturers Association and the National Bureau of Standards in the formulation of standard tests for dry cells used in radio receiving sets.

It also cooperated with the American Standards Association in the formulation of American standard specifications for dry cells and batteries, and on the following work which is still in progress: definitions of electrical terms; standard scientific and engineering symbols and abbreviations; and graphical symbols and abbreviations used on drawings. The society's cooperative work is also being carried on with the American Society for Testing Materials in determining the resistances to corrosion of various metals and alloys.

Employing Bookbinders of America, A. G. Watson, executive secretary, 28 West Forty-fourth Street, New York, N. Y. This organization, in cooperation with the Book Manufacturers' Institute, initiated the establishment of Commercial Standard CS49-34 covering chip board, laminated chip board, and miscellaneous boards for bookbinding purposes. Also, in cooperation with the Book Manufacturers' Institute and the Institute of Book Cloth and Impregnated Fabrics Manufacturers, it established Commercial Standard CS57-40 for book cloths, buckrams, and impregnated fabrics for bookbinding purposes. It also assisted in the formulation of Commercial Standard CS50-34 covering binders board for bookbinding and other purposes. All of these standards were promulgated and published under the auspices of the National Bureau of Standards.

In collaboration with the Binders Board Manufacturers Association, this organization undertook a simplification of sizes of binders board which resulted in the establishment of Simplified Practice Recommendation R81-28, promulgated and published by the National Bureau of Standards. 
Engineering Foundation-Welding Research Committee, W. Spraragen, executive secretary, 29 West Thirty-ninth Street, New York, N. Y. During 1935 the Welding Research Committee was organized by the Engineering Foundation and sponsored jointly by the American Welding Society and the American Institute of Electrical Engineers, for the purpose of assembling, digesting and publishing all available information regarding welding research, stimulating and conducting needed research in the welding field; and correlating existing and future programs of welding research.

Its activities are divided into three parts: Literature, fundamental research and industrial research. The purpose of the Literature Division is to make available in convenient condensed form the welding knowledge contained in the literature. This division has already published over 50 digests, some of which include fatigue strength and corrosion of welded joints, bend tests and impact tests of welds, shrinkage stresses due to welding, the heat effect in welding, welding copper and its alloys, oxygen cutting, spot welding of aluminum, arc and gas welding of aluminum, welding of magnesium, and aluminum soldering.

The project in fundamental research is a carry-over from the American Bureau of Welding. The work now comprises more than 40 active research projects in many universities throughout the country. In addition to the direct results of these investigations, they serve as a means of educating professors and students, thus providing a supply of young engineers who are familiar with welding. A considerable number of these researches have developed data, methods of analysis, and information as to the nature of the phenomena involved, which constitute a major contribution to those industries concerned with welding. A total of 110 research reports have already been issued.

The purpose of the Division of Industrial Research is to coordinate industrial research without trespassing upon fields of a temporary confidential nature. Its functions are carried out in three ways: First, stimulation of research on selected phases of welding, and the publication of the results in the form of papers and reports; second, arranging symposia on selected subjects as, for example, impact tests, and weldability of steels; and, third, by conducting large research projects of broad general importance, notably fatigue research, stresses in welds, weldability of steels, resistance welding, and structural steel. The work of this division is carried out through the organization of suitable committees. At the present time this division has functioning under its auspices committees on carbon steel, lowalloy steels, high-alloy steels, aluminum alloys, copper alloys, nickel alloys, methods of test, weld stresses, nondestructive tests, resistance welding, fatigue testing (structural), and structural welding. As a result of the activities of these committees, approximately 50 reports have been prepared and published.

In carrying forward the work of the several divisions, the Welding Research Committee has the full support of its sponsors and maintains close cooperation with the following national technical organizations: American Institute of Steel Construction, American Iron and Steel Institute, American Petroleum Institute, American Society of Mechanical Engineers-Boiler Code Committee, American Society 
for Testing Materials, American Transit Association, American Bureau of Shipping, American Society of Civil Engineers, Resistance Welder Manufacturers Association, War and Navy Departments, and other agencies of the Federal Government interested in welding problems.

Evaporated Milk Association, Frank E. Rice, executive secretary, 307 North Michigan Avenue, Chicago, Ill. Organized for the purpose of conducting research, this association's activities include also the development of standards in connection with the products of the industry.

For many years the association has led the industry in adoption and limitation of container sizes. For more than 25 years, there have never been at one time more than two sizes of household packages of evaporated milk. For 10 years, the two sizes have been $141 / 2$ ounces and 6 ounces (avoirdupois) net weight.

It cooperated with the United States Food and Drug Administration in the development of definitions and standards of identity promulgated by the Administration under the Food, Drug, and Cosmetic Act. The association also cooperated with the Federal Specifications Executive Committee in the formulation of the Federal specifications for evaporated milk which are used by Federal agencies in the purchase of evaporated milk.

The association developed sanitary standards for the evaporated milk industry which cover standards for plant and equipment, plant operation and personnel, tests for quality to be applied at receiving room, and standards relating to composition and physical character of evaporated milk.

Farm Equipment Institute, Robert A. Jones, secretary, 608 South Dearborn Street, Chicago, Ill. Among the standardization activities of this institute is the development, in cooperation with the National Bureau of Standards, of Simplified Practice Recommendation R-23 for plow bolts. This institute maintains representation on the standing committee on revision of this Simplified Practice Recommendation.

Through its Committee on Farm Safety the institute has developer standards for shields having uniform connecting points, so that guards covering the power take-off of tractors may be attached to shields covering the power line of operated machines.

Farmers \& Manufacturers Beet Sugar Association, Arthur A. Schupp, executive secretary, Second National Bank Building, Saginaw, Mich. Although this association does not issue any standards or specifications, it does attempt to improve the quality of sugars which have been found to be below the average of those tested. This association receives a sample of every strike of sugar made by its members. These samples are inspected for grain size, color, and bacteria content. Results are then reported back to the individual members for their determination as to the quality of the sugar.

Fibre Box Association, Elmer J. Koch, executive secretary, 224 South Michigan Avenue, Chicago, Ill. This association publishes a Handbook of Useful Information which contains standard nomenclature, methods of construction, and illustrations of corrugated and $201072^{\circ}-41-8$ 


\section{Miscellaneous Publications, National Bureau of Standards}

solid fibre containers and component parts, together with standard specifications as established and published by the Consolidated Freight Classification Committee for freight shipments; similar specifications as published by the Railway Express Agency for express shipments; parcel-post regulations as published by the general Post Office Department, together with other useful information relating to fibre shipping containers.

The association cooperated actively with the National Bureau of Standards in the development of Simplified Practice Recommendations relating to corrugated and solid fibre boxes for canned fruits and vegetables, corrugated fibre boxes (used by department and specialty stores), and single-faced corrugated-paper rolls. It also cooperated with the Bureau of Explosives in the preparation of specifications and regulations for the shipping of explosives and other dangerous articles by freight, express, and highway, recently published by that Bureau. The association is reprinting in pamphlet form these specifications as they relate to the use of corrugated and solid fibre boxes, to take the place of a previous pamphlet issued by one of the earlier trade associations of this industry.

A special technical consultant, appointed by this association, is conferring with and assisting in the preparation of suitable fibre boxes for use of the Quartermaster Corps of the United States Army for packing of subsistence, equipage and other supplies; with the Ordnance Department, War Department, for the shipping of ordnance, and other supplies; and with the Navy, through the Bureau of Supplies and Accounts, for the shipping of equipage, subsistence, and other supplies. The purpose is to develop packing specifications, which will make available to the several Government departments, suitable corrugated and solid fibre boxes, such specifications to be made part of the Federal specifications as used by those departments.

Fine Wire Manufacturers' Association, Ferry \& Dawson, secretarytreasurer, 1427 Eye Street NW., Washington, D. C. This association is comparatively new, but it maintains a Standardization and Simplification Committee, which devotes considerable time with reference to the establishment of standards that will properly identify the products of the industry which the association represents. The association, through its committee, is cooperating closely with similar committees of the American Society for Testing Materials and the American Iron and Steel Institute in connection with the development of standards for fine wire.

Fir Door Institute, W. E. Difford, managing director, Tacoma Building, Tacoma, Wash. In order to establish a standard to form a basis for a common understanding between manufacturers, distributors, and users of stock fir doors, members of this industry, through its association, requested the cooperation of the National Bureau of Standards to consider the formulation of a standard. Following a general conference on this subject, there was established in 1938 Commercial Standard CS73-38 for old growth Douglas fir standard stock doors. For the purpose of preserving the high standards of quality, and to insure distributors and ultimate consumers that they will receive the proper grade of fir door, this institute recommends that fir doors conforming to the grading rules established 
in Commercial Standard CS73-38 shall be marked or branded with the letters "FDI" and the grade.

This institute also initiated the movement for the establishment of a standard covering standard specifications for factory fitted Douglas fir entrance doors. This resulted in the formulation of Commercial Standard CS91-41, which was approved by the industry and promulgated and published by the National Bureau of Standards.

Folding Paper Box Association of America, A. E. Murphy, 205 West Wacker Drive, Chicago, Ill. Simplification has been one of the major activities of this association. In cooperation with the National Bureau of Standards, it initiated the program for the standardization of sizes and calipers for stock garment and millinery boxes, which resulted in the establishment of Simplified Practice Recommendations R172-38 and R173-38, both of which were promulgated and issued by the National Bureau of Standards. It also cooperated through a joint committee composed of representatives of several associations in the formulation of Simplified Practice Recommendation R44-36 covering a standard schedule of box board thicknesses.

The Stock Box Committee of this association is at the present time working up suggestions for sizes and calipers on stock cake boxes and stock laundry boxes. In this connection, it is cooperating with the National Retail Dry Goods Association in an attempt to have department stores and specialty stores accept the recommended standards.

Formed Steel Tube Institute, N. Myles Brown, secretary, 1621 Euclid Avenue, Cleveland, Ohio. This organization has functioning under its auspices a Standardization and Simplification Committee, whose work is that of developing standards covering welded steel tubing. The efforts of this committee thus far have been directed towards preparation of a handbook of welded steel tubing, which sets forth the physical, chemical, and metallurgical properties of welded steel tubing; also commercial tolerance limits, and extensive engineering data. This handbook when completed will serve as a guide and aid to both engineers and laymen.

This institute cooperates with the American Society for Testing Materials, the American Petroleum Institute, and the American Society of Mechanical Engineers in the development of standards for electric welded steel tubing.

Glass Container Association of America, V. L. Hall, assistant business manager, 19 West Forty-fourth Street, New York, N. Y. Five committees of this organization carry on work leading to standardization and simplification. These committees, known as Standardization Committee, Redesign and Specifications Committee, Beer Bottle Committee, Milk Bottle Committee, and Standard Testing Procedure Committee, cooperate with similar committees of other organizations and the Federal Government in matters relating to standardization of glass containers.

The Standardization Committee has to do with the standard finishes for glass bottles, and the publication of blueprints to glass container manufacturers. These blueprints are available to all manufacturers of glass containers, and of caps and closures in the United States. These standards are in a constant state of revision 
as to glass tolerances and improvement in production methods. The prints, covering all glass finishes, represent some 15 years of effort. Virtually all glass containers are sold on the basis of Glass Container Association specifications.

The Redesign and Specifications Committee deals with the redesign of standard glass containers, usually to secure lighter weights. Private mold items, and items produced by only one or two companies, are not considered by this committee. The object is to redesign standard containers so that all manufacturers may follow the same specifications, and consequently all of these standard containers can be used by packers without interference in their packaging equipment. These prints are available to all manufacturers of glass containers for their voluntary acceptance.

The Beer Bottle Committee carries on work relating to the standardization of beer bottles. This is particularly important because for the re-use feature of practically all of this class of bottle. This committee is now working with two associations of the brewery industry in an attempt to simplify and standardize beer bottles. The work of this joint committee is available to all brewers and glass container manufacturers.

The Milk Bottle Committee has to do with the standardization of milk bottles. This committee also works with manufacturers of milk-bottle equipment and with dairies, and information developed is available to these industries.

The Standard Testing Procedure Committee is engaged in developing a standard method for testing the strength of glass containers. This procedure is not only designed to test the strength of glass containers, but also to control factory operations. The work of the committee is available to all glass container manufacturers. In carrying forward its simplification activities, this association, in cooperation with the International Association of Milk Dealers and the National Association of Milk Bottle Cap Manufacturers, initiated the programs for the establishment of standard sizes of milk and cream bottles and bottle caps, and glass containers for cottage cheese and sour cream.

Under the auspices of the National Bureau of Standards, these have resulted in the establishment of Simplified Practice Recommendations R10 and R148-33, respectively. The association has also cooperated with the National Bureau of Standards in the development of Simplified Practice Recommendation R123-30 for carbonated beverage bottles, and in Simplified Practice Recommendation R156-41 covering containers for extracted honey (glass and tin).

Glass Cutter Manufacturers Association of America, R. C. Barrett, secretary, Bristol, Conn. This association, through the efforts of its members, has effected dimensional standardization of all glass cutter wheels used in the industry. It cooperated with the Navy Department in devising work tests for glass cutters which now serve as practical work test standards for all glass cutters. These work tests standards formed the basis on which there was prepared the Federal specification for glass cutters (wheel type).

Glazed Brick and Tile Institute, Harry C. Plummer, director of engineering and research, $1756 \mathrm{~K}$ Street NW., Washington, D. C. This organization is an affiliate of the Structural Clay Products 
Institute. Through its Standards and Specifications Committee, the Glazed Brick and Tile Institute conducts work in the standardization of shapes and colors. Some of this committee's work has already led to the development of standard specifications and grading rules for glazed brick and tile, which have been adopted and published by the institute.

Representatives of this institute cooperate with technical committees of the American Society for Testing Materials and the Federal Specifications Executive Committee in formulating specifications for glazed ware. In addition to the above, the institute is conducting and sponsoring research at Ohio State University which, while not directed primarily toward standardization, is providing data that will be of material assistance both in the development of specifications and in the standardization of products.

Gray Iron Founders' Society, Inc., W. W. Rose, executive vice president, 1010 Public Square Building, Cleveland, Ohio. The technical activities of this society are carried on largely in cooperation with the American Society for Testing Materials, the American Standards Association, the American Foundrymen's Association, and the American Society of Mechanical Engineers. This organization maintains official representation on two sectional committees of the American Standards Association on projects relating to manhole frames and covers, and classification and designation of surface qualities. It is also represented on the ASTM committees dealing with specifications for cast iron, and coal and coke.

Grinding Wheel Manufacturers Association, Harry B. Lindsay, secretary-treasurer, 27 Elm Street, Worcester, Mass. The standardization and simplification activities of this association are carried on by two committees, namely, Standardization Committee and Safety Committee. The work of the Standardization Committee has been confined to simplification matters. It initiated the programs for simplification of sizes of grinding wheels and uniformity of abrasive grain sizes. These resulted in the establishment of Simplified Practice Recommendations R45-39 and R118-40, respectively, both of which were promulgated and published by the National Bureau of Standards.

This association was joint sponsor with the International Association of Industrial Accident Boards and Commissions in the development of the safety code for the use, care, and protection of abrasive wheels, which was approved as American standard B7-1935 by the American Standards Association. It is also represented on three ASA sectional committees on Safety Code for Exhaust Systems, and on Classification and Designation of Surface Qualities, and, Small Tools and Machine Tool Elements.

Gummed Industries Association, Philip O. Deitsch, managing director, 19 West Forty-fourth Street, New York, N. Y. Standardization of No. $1 \mathrm{kraft}$ sealing tape was initiated by this association and led to the acceptance by industry of Simplified Practice Recommendation R114-30 covering standard weights, sizes, and strength of sealing tape. This Standing Committee is at present cooperating in a further study of the adhesive qualities of tape with a view to establishing minimum standards. The association has made arrangements with a commercial testing laboratory whereby acceptors 


\section{Miscellaneous Publications, National Bureau of Standards}

of the Simplified Practice Recommendation may have available a satisfactory means of testing the tape which they manufacture, distribute, or use. Samples are sent to the association, where they are given identification numbers and sent to the laboratory for test, the test results being reported to the secretary of the association.

Gypsum Association, Henry J. Schweim, general manager, 211 West Wacker Drive, Chicago, Ill. Much of the standardization work of this association is done in conjunction with the American Society for Testing Materials and the American Standards Association. Through representation on technical committees, it assisted in the preparation of standard specifications for gypsum and gypsum products which were adopted and published by the American Society for Testing Materials.

The association cooperated in the work of the American Standards Association sectional committee in the development of specifications for gypsum plastering which was approved as American Standard A42.1-1938. It is also represented on the ASA sectional committee which formulated the American standard fire tests of building construction and materials.

In cooperation with the Building Officials Conference of America, it sponsored the chapter on reinforced gypsum for inclusion in the ASA recommended building code. The association is now cooperating with ASA sectional committees on Specifications for Sieves for Testing Purposes, and on Building Code Requirements for Wood.

Hack Saw Manufacturers Association of America, Inc., 1 Wall Street, New York, N. Y. This association cooperated with the National Bureau of Standards in the establishment of Simplified Practice Recommendation R90-36 relating to standard sizes of tungsten blades and high-speed blades. This association is at the present time accumulating data bearing upon the demand for various sizes by way of testing the sufficiency of the blades set forth in the recommendation, and also in obtaining data for further simplification of unnecessary blades.

Hand Chain Hoist Institute (Inc.), W. S. McCann, secretary, 208 South La Salle Street, Chicago, Ill. The entire membership of this institute cooperates actively with the United States Navy Department in the initiation and revision of the specifications covering chain hoists, fixed and trolley, and trolleys, which are adopted by the Navy Department and several other agencies of the Federal Government on which to base contracts for purchase.

Hardwood Dimension Manufacturers Association, Inc., Louis J. Bosse, managing director, Heyburn Building, Louisville, Ky. Committees of this association cooperate with all branches of the Federal and State Governments, hardwood and wood trade associations, and wood-using industries in bringing about standardization programs on grading rules of hardwood dimension lumber. In this connection, the association requested the cooperation of the National Bureau of Standards in initiating movements which resulted in the establishment of four Commercial Standards covering several types of products. As a result of this effort, the National Bureau of Standards promulgated and published Commercial Standards CS60-36 covering grading rules for hardwood dimension lumber; CS76-39 which provides two classes of solid hardwood interior trim 
and molding; and SC89-40 relating to standard grades, sizes, patterns, and species of hardwood stair treads and risers. In order to assure purchasers that the various types of products covered by these Commercial Standards are in accordance with the quality and grade covered by the standards, the producers of this industry may either individually, or in cooperation with the association, issue guarantee certificates of classification for specific shipments, or grade and trademark, of each piece or bundle as conforming to the particular Commercial Standard.

Heat Exchange Institute, C. C. Rohrbach, secretary, 90 West Street, New York, N. Y. 'The work of this institute is carried on by technical committees which are continuously engaged in developing standards and keeping them up to date. Through the work of these committees, the institute has prepared and issued the following: Condenser section standards; steam jet ejector and vacuum-cooling section standards; and deaerating and deaerator heater section standards.

At the present time the Technical Committee for the Condenser Section has under consideration a research project on heat transfer. The Technical Committee for the Steam Jet Ejector and Vacuum Cooling Section has under consideration the compilation of technical information resulting from the test of a standard ejector.

Heating, Piping \& Air Conditioning Contractors National Association, Joseph C. Fitts, secretary, Suite 1401, Rockefeller Center, 1250 Sixth Avenue, New York, N. Y. Two committees of this association are actively engaged in carrying forward standardization activities of this association. The Committee on Standards has for its objectives the standardization of materials and design for installation of heating, piping, and air-conditioning work in this industry; also the cooperation with other bodies interested in standardization and the representation of the industry on standardization projects developed under the procedure of other organizations.

The Committee on Welding is engaged at the present time in the standardization of welding procedures for pipe welding, both by the electric arc and oxyacetylene welding.

Through its Committee on Standards, this association has developed standard rules for determining the amount of radiation required to properly heat a given space, which are based on the heat required to offset losses due to transfer of heat through walls, windows, floors, ceilings, and roofs; and the initial heat required to bring the air that leaks into that space up to the required temperature. It has also compiled data with reference to the proper types and sizes of boilers recommended for installation to bring about the desired amount of heat.

In the book on engineering standards developed by the committee, there are included rules for determining the amount of radiation required to heat a given space properly; the net square feet radiation loads recommended for low-pressure heating boilers; pipe sizes for steam heating and hot-water systems after being heated in boilers; and dimensions of valves, fittings, and materials; and standards for air conditioning installations.

The Committee on Welding has issued a Standard Manual on Pipe Welding which gives information covering development and process 


\section{Miscellaneous Publications, National Bureau of Standards}

of oxyacetylene pipe welding; apparatus, equipment, materials, and supplies; mechanics of welding and cutting; and material and data on welding construction. It has also prepared specifications covering metallic arc welding of steel pipe, fittings, and flanges; and specifications for metallic arc welding of carbon molybdenum pipe, fittings, and flanges; and metallic arc welding and specifications for oxyacetylene welding of pipe, fittings, and flanges.

The association cooperated with the National Bureau of Standards in the establishment of Commercial Standards CS5-40 for genuine wrought-iron pipe nipples and CS7-29 for standard-weight malleable iron or steel screwed unions; also in the development of Simplified Practice Recommendation R90-36 relating to sizes of hacksaw blades.

This association is joint sponsor with the American Society of Mechanical Engineers and the Manufacturers Standardization Society of the Valve and Fittings Industry for the Sectional Committee on Pipe Flanges and Fittings functioning under the procedure of the American Standards Association. It is also represented on five additional ASA sectional committees which deal with the following subjects: code for pipe threading; code for pressure piping; standardization of dimensions and materials of wrought iron and wrought steel pipe and tubing; standards for drawings and drafting-room practice; approval and installation requirements for gas-burning appliances; and graphical symbols and abbreviations for use on drawings.

In promoting its standardization work, the association has developed a national program for certified heating to replace the purely local programs formerly in use. It has adopted a national insignia, including a certified heating supplementary proposal, to be sent with each bid, the plate to be attached to each boiler, and the certificate to be issued on completion of the work to the house owner, certifying that the heating system was installed in accordance with the certified heating standards adopted by the association.

Hickory Handle Association, Guy E. Basye, secretary, Hope, Ark. This association cooperated with other representatives of the industry in the formulation, revision, and acceptance by industry of standard definitions for various quality grades of hickory handles as promulgated in Simplified Practice Recommendation R77-39, issued by the National Bureau of Standards. These standard grades are the recognized standards of this association. This association also cooperates with the Federal Specifications Executive Committee in the revision of Federal specifications for hickory handles for long and small tools.

Horological Institute of America, Ralph E. Gould, secretary, in care of National Bureau of Standards, Washington, D. C. This institute was organized in 1921 by the National Research Council as an outgrowth of the scarcity of instrument repairmen of high quality during the World War. It is an independent, self-governing, nongovernmental organization whose purposes are the scientific and educational advancement of the watchmaker.

The institute's activities are governed by an Advisory Council of 27 , composed of representatives of the watchmakers, the horological schools, the time-inspection services of the railroads, the American 
watch manufacturers, the National Research Council, and the Federal Government. It recommends standards of instruction for horological schools and advises with officials in the establishment of horological courses in schools and colleges, and grants certificates to horological schools based upon their standards of instruction. It gives examinations both in theory and practice to watch repairers and grants certificates to those who pass the examinations. It prepares and publishes material of educational value to watchmakers. It grants honors for outstanding contributions to the science of horology.

At present, the institute is cooperating with the National Roster of Scientific and Specialized Personnel in the preparation and distribution of a questionnaire and technical check list for circulation to watchmakers as part of the national defense program.

Hydraulic Institute, C. C. Rohrbach, secretary, 90 West Street, New York, N. Y. This organization is a trade institute comprising the principal manufacturers of displacement and centrifugal pumps. Through its several technical committees, it has developed standards covering centrifugal puimps, rotary pumps, reciprocating pumps, deep-well turbine pumps, and a test code for testing centrifugal and rotary pumps for the purpose of determining whether pumps keep the guarantees under which they are sold.

Through its Committee on Materials Specifications, it has prepared specifications for gray-iron castings, nickel-base austenitic cast iron, carbon and alloy steel castings, bronze castings, cast nickel copper alloy (monel), and heavy duty bolting material and nuts. These specifications cover cast materials which are representative of those generally used in the manufacture of pumping equipment for the petroleum industry.

The institute cooperates specifically with the United States Department of Commerce, the Chamber of Commerce of the United States of America, the American Society of Mechanical Engineers, the American Standards Association, the American Mining Congress, and the National Fire Protection Association; also with the technical and trade organizations of other industries with which the pump industry has problems in common.

The institute is represented on four sectional committees functioning under the procedure of the American Standards Association dealing with the following projects: pipe flanges and fittings; code for pressure piping; petroleum products and lubricants; and graphical symbols and abbreviations for use on drawings.

Illuminating Engineering Society, Frank G. Horton, executive secretary, 51 Madison Avenue, New York, N. Y. Standardization work of this society is carried on by a number of technical committees appointed to handle various specific projects. Their titles which are indicated by the subjects with which each one deals are, as follows: Lighting practice, motor vehicle lighting, natural lighting, aviation lighting, rural lighting, painting in relation to lighting, residence lighting, nomenclature and standards, light and safety, characteristics of illuminating materials, street and highway lighting, and lighting service. Standards, specifications, and reports prepared by the various committees are published by the society, some of which relate to recommended practice of industrial lighting, testing 


\section{Miscellaneous Publications, National Bureau of Standards}

specifications for lighting equipment, nomenclature of illuminating glasses, recommended practice of street lighting, code of highway lighting, and American recommended practice of school lighting.

The society cooperates actively with committees of scientific and technical bodies in matters relating to standards and recommended practices. It maintains representation on the United States National Committee of the International Commission on Illumination; on the governing board of the American Association for the Advancement of Science; on a joint committee with the National Electrical Manufacturers Association on specifications for flood-lights; on the Highway Research Board of the National Research Council; on the Inter-Society Color Council; and on committees of the American Society of Safety Engineers. It is officially represented on sectional committees functioning under the procedure of the American Standards Association in the development of the following projects : Motion pictures; standards for graphical symbols and abbreviations for use on drawings; rolled threads for screw shells of electric sockets and lamp bases; industrial and school lighting practices; safety code for the inspection of motor vehicles; letter symbols and abbreviations for science and engineering; and on building code requirements for light and ventilation.

The society has developed specifications for the purpose of providing certain requirements with respect to lamps that will satisfactorily serve for individual desk work or reading, and which will endure over a reasonable period of time with a minimum of casualty and fire hazard. These lamps made by portable lamp manufacturers in conformity with the society's specifications and after examination and approval by the Electrical Testing Laboratories, may have attached to them the IES tag of approval.

Illuminating Glassware Standards Institute, H. L. Dillingham, secretary, 19 West Forty-fourth Street, New York, N. Y. This institute was organized during the past year and includes in its membership manufacturers of illuminating glassware. Its purpose is to suggest standards of design, to supervise tests, and to identify all glassware manufactured by its members with an appropriate insignia. The use of the insignia is to insure the buying public that all illuminating glassware so labeled is of high quality.

Incandescent Lamp Manufacturers' Association, Louis Klein, secretary, 45 East Seventeenth Street, New York, N. Y. This organization has appointed an Engineering Committee which functions under the direction of the association's board of directors. This committee was established for the purpose of setting minimum standards and requirements for materials, equipment, production, life and efficiency used by its members. As a prime effort in this direction, the Engineering Committee is coordinating its activities with manufacturers so as to bring about standardization of some of the items used in the manufacture of electric incandescent lamps.

Indiana Limestone Institute, E. C. Walters, secretary, Bedford, Ind. This organization is composed of quarriers and fabricators of Indiana limestone, and one of its primary objects is to establish and maintain standards of varieties, grades and finishes of limestone, and its fabrication. The institute conducts considerable research and tests on practically every phase of the production and 
practical use of limestone. It has formulated and issued master specifications for Indiana colitic limestone, covering grades and finishes, shop drawings, fabrication, loading and shipment, parging, laying, and cleaning.

Industrial Management Society, P. H. Weber, president, 421 Engineering Building, 205 West Wacker Drive, Chicago, Ill. 'Through the Occupational-Rating Research Group, this society developed an occupational-rating plan for hourly and salaried occupations, which is a standard devised by the society for standardizing and evaluating occupations. This standard is being widely used at the present time throughout the country. During the past year the occupational-rating group made extensive use of this standard for grading a variety of hourly rated occupations. The use and adoption of the plan as set forth in this standard serve to establish more uniform classifications of grading occupations among various manufacturers concerned.

Industrial Safety Equipment Association, W. J. Parker, secretarytreasurer, 366 Madison Avenue, New York, N. Y. Practically all of the work of this association in the field of standardization is carried on in cooperation with the American Standards Association. It is officially represented on four ASA sectional committees on safety code for the use, care, and protection of abrasive wheels; safety code for the protection of the head, eyes, and respiratory organs of industrial workers; performance requirements for protective occupational footwear; and safety code for woodworking machinery.

It is at the present time cooperating with the National Bureau of Standards in the preparation of a Simplified Practice Recommendation on packaging of unit first-aid dressings and treatments, and in the establishment of a Commercial Standard covering materials for safety wearing apparel.

Industrial Truck Statistical Association, W. S. McCann, secretary, 208 South La Salle Street, Chicago, Ill. This association maintains a Committee on Standardization, whose efforts are directed towards the development of standardization and simplification of steering and power controls for electric industrial trucks of various types, as well as tractors. The committee is also working on a set of specifications for various capacities of electric industrial trucks of different types, and tractors designed especially for the convenience of and for the use of governmental agencies. These specifications, when formulated, will cover maximum and minimum ranges of standard dimensions for each capacity and type of truck and tractor. The association adopted revised standard specifications for automatic battery-charging motor-generators and panels.

Industrial Unit Heater Association, L. O. Monroe, secretary, 5-208 General Motors Building, Detroit, Mich. Through its Engineering Committee, this organization has developed standards for propeller unit heaters and a standard code for testing and rating steam unit heaters, this latter code being developed by a joint committee of the American Society of Heating and Ventilating Engineers and this association. In cooperation with the National Electrical Manufacturers Association, it is developing a standardization program for motors in connection with the unit heater industry. 
Institute of American Poultry Industries, E. B. Heaton, managing director, 110 North Franklin Street, Chicago, Ill. Although this institute has not issued standards and specifications, it does, through its Shell Egg Committee; Frozen and Dried Egg Committee; and Dressed Poultry Committee, cooperate with the United States Department of Agriculture and the Food and Drug Administration (Federal Security Agency) in the development of standards and grades for various poultry items.

Institute of Boiler and Radiator Manufacturers, R. E. Ferry, general manager, 60 East Forty-second Street, New York, N. Y. A standard code, known as the I-B-R Testing and Rating Code for Low Pressure Heating Boilers, hand-fired and automatically fired, including solid fuel and oil, has been formulated by the institute. It has initiated a program for simplification of sizes of large tube, cast iron radiators, which resulted in the establishment of Simplified Practice Recommendation R174-40, promulgated by the National Bureau of Standards.

The institute is represented on the American Standards Association sectional committee which formulated American standard for pipe thread. It also maintains representation on the American Society of Mechanical Engineers Subcommittee on Heating Boilers, which is in charge of the development and revision of the ASME Boiler Code.

Institute of Book Cloth and Impregnated Fabrics Manufacturers, C. Stewart Comeaux, secretary, 103 Park Avenue, New York, N. Y. In cooperation with the Employing Bookbinders of America and the Book Manufacturers' Institute, this organization initiated the program which resulted in the establishment of Commercial Standard CS57-40 for book cloths, buckrams, and impregnated fabrics for bookbinding purposes, except library bindings, which was promulgated and published by the National Bureau of Standards. In connection with this standard, the manufacturers of starch-filled and impregnated bookbinding fabrics place on their fabrics a label to indicate that the material is guaranteed to meet the requirements of the Commercial Standard. The recommended wording of the label is as follows: "These goods are manufactured to conform with Commercial Standard CS57-40 issued by the United States Department of Commerce."

Institute of Cooking and Heating Appliance Manufacturers, Samuel Dunckel, managing director, Shoreham Hotel, Washington, D. C. The Technical Committee of the Oil Division of this institute has developed tentative standards for flue-connected oil-burning space heaters which cover the code for oil-heater rating tests, methods for publication of oilheating ratings in manufacturers' and jobbers' cata$\operatorname{logs}$, and method for selecting the proper size oil heater to heat a given space. It is at the present time working on a draft for standards for pot-type oil-burning appliances, which it proposes to submit for approval as a Commercial Standard under the auspices of the National Bureau of Standards.

The Solid Fuel Stove Division is carrying on research work with the Battelle Memorial Institute in Columbus, Ohio, with reference to coal stoves which will include the preparation of a standard rating code for stoves. Oil heaters produced by manufacturers are 
tested in their own laboratories, and the results of their findings are submitted to the central laboratory of the institute for checking.

The institute permits manufacturers to use the rating seal on heaters which have been rated and tested in accordance with the institute's standards. The wording of the label or seal is as follows: "The Manufacturer certifies that catalogue ratings on this heater are in accordance with the standards of the Institute of Cooking and Heating Appliance Manufacturers."

Institute of Leather Cloth and Lacquered Fabrics Manufacturers, C. Stewart Comeaux, secretary, 103 Park Avenue, New York, N. Y. This organization superseded the Association of Pyroxylin Coated Fabric Manufacturers several years ago. This institute carries on standardization work from time to time in connection with commodities over which it has jurisdiction. A committee of this organization is at the present time developing specifications for grey goods. It assists the Federal Specifications Executive Committee in the revision of Federal specifications covering artificial leather (upholstery). Another phase of standardization accomplished by this institute has been the preparation of classification key numbers for use in identifying comparable grades of pyroxylin coated fabrics (artificial leather). The institute has also cooperated with the Bureau of Marine Inspection and Navigation in the preparation of standards for cover material for buoyant cushions.

Institute of Makers of Explosives, C. Stewart Comeaux, secretary, 103 Park Avenue, New York, N. Y. Standardization and simplification activities of this institute are carried on by the Committee on Standardization, the membership of which is composed of technical representatives of the various member companies. This committee has fostered the use of the American standard table of distances, which represents the accepted practice by many States; also the United States Army, Navy, and United States Coast Guard, and complied with by all explosives manufacturers, with respect to the distances between explosive plants, storage magazines for explosives, and inhabited buildings, public railways and public hightways.

There has also been issued an additional table known as the intraplant table of distances. These two tables have been incorporated in the institute's "Suggested State Law" and "Suggested City Ordinance," which law and ordinance have been put into effect by a number of States and municipalities, as also the United States Army, Navy, and Coast Guard, on all new construction. Through its efforts in simplification, the institute has issued a pamphlet on standardization of sizes of cartridges and strengths of high explosives, which represents a reduction in the number of strengths and sizes offered by the explosive manufacturers over a period of years.

The Standardization Committee has cooperated with the Bureau of Explosives, for the safe transportation of explosives and other dangerous articles, in preparing rules governing conditions under which explosives may be most safely transported by rail and water. This is accomplished by continuous contact with that bureau.

Another phase of standardization by the institute is in its cooperation with the various regulatory bodies of the different States, in the preparation of rules and regulations in connection with the safe practices and approved types of explosives for underground blasting. 
Further standardization has resulted from the continuous cooperative activities between the institute and the United States Bureau of Mines, in the matter of preparing regulations for the safe and efficient use and handling of explosives.

The fuse manufacturers, who are associate members of the institute, undertook a program of simplification which resulted in reducing the kinds and types of fuse, and the establishment of a simplified schedule which satisfactorily and economically meets the demands of the trade. The committee is at the present time making a study of standardization of blasting caps and electric blasting caps, in the hope of reducing the number and types of caps and thereby promoting safety through such reduction. The Committee on Standardization has from time to time been responsible for the preparation of rules in connection with the general use and handling of explosives, which has resulted in making the use of explosives safer to the user and the public generally.

Institute of Radio Engineers, Inc., Harold P. Westman, secretary, 330 West Forty-second Street, New York, N. Y. The standardization activities of this institute are carried on by the following technical committees, the names of which are indicative of the fields covered by them: Electroacoustics, electronics, facsimile, frequency modulation, radio receivers, symbols, television, transmitters, and antennas, and radio wave propagation. These committees, which are composed of engineers active in the radio laboratories and manufacturing organizations in this country and, some, in Canada, meet from time to time and prepare reports which deal with the following types of material: definitions of terms, letter symbols, graphical symbols, and methods of testing and rating equipment. Reports issued by these committees are approved by the Standards Committee of the institute, which has the responsibility for the initiation and guidance of such activities. After approval by the board of directors, the reports are published as documents of the institute.

As a result of the work of its technical committees, the institute has issued standards on electroacoustics, electronics, radio receivers, and transmitters and antennas.

The institute is sponsor for the Sectional Committee on Radio functioning under the procedure of the American Standards Association, and is represented on 10 additional ASA sectional committees dealing with the following subjects: specification for dry cells and batteries; electrical measuring instruments; definitions of electrical terms; standardization of vacuum tubes for industrial purposes; electric and magnetic magnitudes and units; radio-electrical coordination; letter symbols and abbreviations for science and engineering; standards for drawings and drafting room practice (exclusive of architectural drawings); acoustical measurements and terminology; and graphical symbols and abbreviations for use on drawings.

Institute of Shortening Manufacturers, Inc., Earl S. Haines, executive secretary, Norris Building, Atlanta, Ga. The principal standardization work carried on by this organization has been in connection with a simplified practice program on packages. The entire industry generally follows the institute's package standards. The standard packages developed and used through this program for standard shortening are: 400-lb tierces, 110-lb drums, 60-lb tubs (Pa- 
cific Coast only), 50, 55-lb butter-tubs (North only), 20-lb wooden pails (New England and New York State only), 48-1b tin, 16-lb pails (Southwest only), 8-lb pails, 4-lb pails, 8-lb cartons, 4-lb cartons, and $1-1 b$ cartons. For hydrogenated shortening the packages are tierces, $100-1 \mathrm{~b}$ or 110 -lb drums, 45 -lb cans, 50 -lb cans, and 60 -lb cans.

The institute has collaborated with the Army and Navy and with the Food and Drug Administration on specifications and standards for shortening and edible oils.

Insulated Power Cable Engineers Association, G. M. Haskell, secretary, care of General Cable Corporation, 420 Lexington Avenue, New York, N. Y. The membership of the association is composed of engineers from the leading manufacturers of wire and cable for electrical purposes in the United States. Many of its members are also members of other technical associations, such as the American Institute of Electrical Engineers, Association of American Railroads, American Standards Association, and the American Society for Testing Materials.

This association functions as a whole in the study, development, and publication of standards for many of the products of the insulated wire industry. It cooperates with other organizations interested in standardization, such as the American Standards Association, the American Society for Testing Materials, with engineering committees on their various activities and with many branches and agencies of the Federal Government concerning their standards for electric wires and cables.

This association has published the following specifications and has others in the course of development: rubber insulated power cables; rubber insulated parkway cables; varnished cambric insulated cables; metallic coverings for insulated electric cables; and ozone resistant type insulation for electric cables. It has for a number of years cooperated with the High Tension Cable Committee of the Association of Edison Illuminating Companies in the preparation and revision of specifications for impregnated paper-insulated, leadcovered cable of the solid and oil-filled types.

Insulation Board Institute, B. J. Westover, manager, 111 West Washington Street, Chicago, Ill. A group of manufacturers of structural insulating board initiated a program for the establishment of Commercial Standard CS42-35 covering specifications for two classes of insulating board designated as "insulating building board" and "roof insulating board." This standard was promulgated by the National Bureau of Standards and adopted by this institute. Several committees of the institute are at the present time carrying on work in the field of standardization. In this connection, standardization committees are engaged in developing standard widths, lengths, and thicknesses of structural insulating boards for recommendation to the National Bureau of Standards of the United States Department of Commerce, and a technical committee is also working on the standardization of the physical properties of structural insulating boards.

The institute cooperates with the Federal Specifications Executive Committee in the development and revision of Federal specifications covering insulating fiber-board. It maintains a research associate at the National Bureau of Standards conducting tests of dry wall 
construction. The institute is officially represented on the Sectional Committee on Specifications for Plastering, functioning under the procedure of the American Standards Association.

Inter-Society Color Council, Deane B. Judd, chairman, in care of National Bureau of Standards, Washington, D. C. This council grew out of a color conference sponsored by the Revision Committee of the United States Pharmacopoeia in 1930. Its membership consists of officially designated representatives of the several national societies and associations interested in the description and specification of color and of individuals interested in color. From its inception, the work of the council in coordinating and giving advice on problems submitted by its member bodies has been accomplished through committee work. The aims and purposes of the council are to stimulate and coordinate the work being done by the various societies and other organizations leading to the standardization, description, and specification of color, and to promote the practical application of these results to the color problems arising in science, art and industry.

The council has developed standard designations of color for the description of drugs and chemicals. These designations are being put into the latest revisions of the National Formulary and the United States Pharmacopoeia, and are finding acceptance in many diverse fields. It has also developed a method of designating theatrical gelatines which is being extended to the designation of dye solutions generally. A movement by the council for standard terminology has resulted in the compilation of a comparative list of 300 color terms. Development of a test for color aptitude is also well under way. The preliminary form of test already developed serves to detect the most common forms of color blindness.

Internal Combustion Engine Institute, E. F. Deacon, secretary, 408 Continental Building, Dallas, Tex. This organization is composed of manufacturers of internal combustion engines sold for automotive, agricultural, industrial, and oil field applications. Through its Sectional Committee it meets periodically to consider the development of standards for the industry. The institute has adopted standards covering testing and rating procedure; warranties and policies; and accessory equipment.

Through its sectional committee, the institute cooperates with the American Petroleum Institute and the American Gas Association in formulating standard formulae for the application of internal combustion engines to oil-well pumping service and stationary power involving the use of natural gas fuel.

International Acetylene Association, H. F. Reinhard, secretary, 30 East Forty-second Street, New York, N. Y. This association has developed and issued specifications for standard hose connections for oxygen, acetylene, and similar fuel gases, which will assure interchangeability of parts made by various manufacturers. It cooperates with the Compressed Gas Manufacturers Association in drafting standards for threading of valves used in cylinders for storing compressed gases. It is officially represented on five sectional committees 'of the American Standards Association dealing with the following projects: safety in the construction industry; safety code for mechanical refrigeration; code for pressure piping; specifications for pressure and vacuum gages; and ventilation code. 
International Apple Association, R. G. Phillips, secretary, 1108 Mercantile Building, Rochester, N. Y. This organization has taken an active part in the promotion of legislation for the standardization of fruit and vegetable containers. These activities, cooperated in by other allied trade bodies, resulted in the enactment by Congress of the standard barrel law and the standard basket and hamper acts.

The association was instrumental in obtaining the passage of the Federal climax basket act, and also the original New York State mandatory standard apple-grading law, which was used as a model for the drafting of legislation by other States in the so-called barrel territory.

It collaborated with other national fruit and vegetable trade organizations, including the National League of Commission Merchants, Western Fruit Jobbers' Association, American Fruit and Vegetable Shippers' Association, and the Fruit and Vegetable Brokers' Association, in drafting and setting up rules and definitions of trade terms for the fruit and vegetable industry, which standards were either approved or adopted by these organizations.

International Association of Electrotypers \& Stereotypers, Inc., A. P. Schloegel, field secretary, 949 Leader Building, Cleveland, Ohio. Through its Standardization Committee, this organization has prepared standards for printing plates. These standards cover thicknesses and tolerances for unmounted and curved electrotypes, bevel of edges of patent base plates, thickness of shell, and standard formula for electrotype backing metal. This association has also prepared and issued two additional pamphlets, one covering standards for lockup, and the other relating to standards on engraving.

International Association of Garment Manufacturers, A. F. Allison, 260 West Broadway, New York, N. Y. This association cooperated with the National Bureau of Standards in the establishment of Commercial Standards relating to dress patterns; men's pajamas; and boys' blouses, shirts, waists, and junior shirts. It has also cooperated with the Federal Specifications Executive Committee in the preparation of Federal specifications relative to measurements for dress and work shirts.

International Association of Government Labor Officials, Isador Lubin, secretary, in care of Bureau of Labor Statistics, United States Department of Labor, Washington, D. C. This organization, composed of labor officials both in the United States and Canada, does not, of itself, develop standards in the fields represented by its members. Practically all of the standardization work coming within the purview of this association is carried on in cooperation with the American Standards Association.

It was joint sponsor with the American Institute of Laundering and the National Association of Mutual Casualty Companies for the safety code for laundry machinery and operations, which was approved as an American standard by the American Standards Association. This association also participated in the development of American standard safety codes covering mechanical refrigeration, safety in the construction industry, building exits, and the national electrical safety code. It is officially represented on 24 additional 
ASA sectional committees dealing with the following projects: safety code for elevators, dumbwaiters, and escalators; building code requirements for light and ventilation; and administrative requirements for building codes; also safety codes for compressed air machinery and equipment; conveyors and conveying machinery; cranes, derricks, and hoists; protection of heads, eyes, and respiratory organs of industrial workers; exhaust systems; prevention of dust explosions; amusement parks; grandstands; ventilation code; and standardization of methods of recording and compiling accident statistics; allowable concentrations of toxic dusts and gases; safety code for forging and hot metal stamping; safety code for industrial sanitation; code of lighting-factories, mills, and other work places; logging and sawmill safety code; protective occupational footwear; quarry operations; safety code for rubber machinery; textile safety code; safety code for walkway surfaces; and safety code for woodworking machinery. It is also represented on the ASA Safety Code Correlating Committee and Building Code Correlating Committee.

The association maintains a Standing Committee whose duty it is to report annually concerning the methods of preparing safety codes in the various States of the Union and in the several provinces of Canada.

International Association of Ice Cream Manufacturers, Robert C. Hibben, executive secretary, Barr Building, Washington, D. C. The Simplified Practice Committee of this association, either of its own initiative or in cooperation with similar committees of other organizations, has carried on a simplification program which resulted in the establishment of three Simplified Practice Recommendations promulgated by the National Bureau of Standards. This association initiated a project for a schedule of standard sizes for ice cream cups and cup caps, as set forth in Simplified Practice Recommendation R132-36.

In cooperation with the Dairy Industries Supply Association, it established the Simplified Practice Recommendation for standard sizes of brick molds and cartons. It also developed, in cooperation with the Milk and Ice Cream Can Institute, a schedule of standard sizes of tinned steel ice cream cans given in Simplified Practice Recommendation R164-36.

This association maintains representation on the Standing Committee for the revision of Simplified Practice Recommendation R175-40 for heavy-duty round-nesting paper containers for foods and beverages. In addition, committees of this association collaborated with the International Association of Milk Dealers in the formulation of standards of the latter association for sanitary pipe fittings.

International Association of Industrial Accident Boards and Commissions, V. A. Zimmer, secretary-treasurer, in care of United States Department of Labor, Washington, D. C. This association, as its name would indicate, is an organization consisting of various State, Territorial, and Provincial agencies, which deals with industrial accidents and workmen's compensation.

Practically all of the standardization work of this association is conducted under the auspices of the American Standards Association. It is sponsor for the project on the safety code for exhaust systems and work in compressed air. It acted as joint sponsor with the 
Grinding Wheel Manufacturers Association, resulting in the formulation of the American standard safety code for the use, care, and protection of abrasive wheels; with the American Society of Mechanical Engineers and the National Conservation Bureau in the formulation of the American standard safety code for mechanical power-transmission apparatus; with the National Safety Council in developing a safety code for rubber machinery; with the National Conservation Bureau in the formulation of the American standard safety code for woodworking plants; and with the National Council on Compensation Insurance and the National Safety Council on standardization of methods of recording and compiling accident statistics.

This association is also represented on 14 additional ASA sectional committees dealing with the following projects: building exits code; safety in the construction industry; safety code for elevators, dumbwaiters and escalators; safety code for mechanical refrigeration; safety code for compressed air machinery and equipment; safety code for conveyors and conveying machinery; safety code for cranes, derricks, and hoists; code for pressure piping; regulations of the $\mathrm{Na}$ tional Board of Fire Underwriters for electric wiring and apparatus; National Electrical Safety Code; safety code for the protection of heads, eyes, and respiratory organs of industrial workers; ventilation code; and safety code for the prevention of dust explosions.

International City Managers' Association, Clarence E. Ridley, executive director, 1313 East Sixtieth Street, Chicago, Ill. For more than 10 years this association has been concerned with the establishment of standards of administration for the various municipal departments.

Beginning in 1930, the association's research staff, with the cooperation of other organizations, developed measurement units for certain public works activities. This system, together with a budgetary accounting system, was installed in a number of cities, and manuals describing these installations were published and distributed to city officials and other interested groups throughout the country. The association also engaged in the development of a police record system designed to aid in improving police administration and published a manual.

In 1936 and 1937 the association, jointly with the University of Chicago and the Committee on Public Administration of the SociaI Science Research Council, made a study of measurement techniques now being used in local governments, and pointed out the next steps that might be taken in the measurement of municipal activities. Results of the study were published by the association in a report in 1938 entitled Measuring Municipal Activities.

Attention has been given in recent years to the development of specifications for the content of annual municipal reports, resulting in the publication in 1930 of a report entitled Specifications for the Annual Municipal Report, and a supplementary report issued in 1940 entitled A Check List of Suggested Items for the Annual Municipal Report. This association is officially represented on several sectional committees of the American Standards Association.

International Municipal Signal Association, Inc., Irvin Shulsinger, secretary, 8 East Forty-first Street, New York, N. Y. The develop- 


\section{Miscellaneous Publications, National Bureau of Standards}

ment of standards and specifications by this association is carried on by five committees, which deal with various phases of signal engineering. The Signal Systems Materials Committee considers standards for materials and equipment, and recommends same for adoption under the proper procedure. The Signal Operating Methods Committee considers standards of signal operating methods and recommends them for adoption. The Signal Committee's duties are to make recommendations for signaling methods to be adopted by the National Fire Protection Association for inclusion in their various codes on municipal fire alarm systems and interior fire alarm systems. The Radio Communications Committee undertakes studies of the art of radio communications in the municipal communication field. The Traffic Control Devices Committee is engaged in making improvements in the art of traffic control.

All of these committees maintain subcommittees which work and advise committees of the International Fire Chiefs Association relative to studies dealing with signal engineering.

The Signal Systems Materials Committee is cooperating with Governmental agencies working on programs on National defense, and in coordinating the work of municipal fire departments and communications systems.

This association has formulated and adopted 18 specifications covering signal wires and cables, and materials used in connection therewith. The association is officially represented on four sectional committees functioning under the procedure of the American Standards Association for the following projects: Regulations of the National Board of Fire Underwriters for electric wiring and apparatus; National Electrical Safety Code; code for protection against lightning; and insulated wires and cables.

Lead Industries Association, Felix Edgar Wormser, secretary, 420 Lexington Avenue, New York, N. Y. This organization has adopted standards for lead pipe and lead pipe sizes, lead fittings, and lead for calking purposes. At the present time the association is engaged in simplifying lead fittings standards. In addition to its own work on standardization and simplification, this organization maintains representatives who serve on committees of the American Standards Association and American Society for Testing Materials, especially in connection with the standardization of plumbing goods. It also cooperates with various agencies of the Federal Government in the development of specifications covering lead products.

Lightning Rod Manufacturers Association of the United States of America, S. D. Kretzer, in care of National Lightning Protection Co., Jefferson and Eugenia Streets, St. Louis, Mo. Standards of this association are incorporated in the Code for Protection Against Lightning published by the National Bureau of Standards. This code was the result of the cooperative work of several organizations, including the Lightning Rod Manufacturers Association, working under the sponsorship of the American Institute of Electrical Engineers and the National Bureau of Standards, and carried out under the procedure of the American Standards Association. The code includes specifications for lightning rods and rules for their installation along with regulations for the protection of buildings, towers, smoke stacks, etc., and for the protection of structures containing inflammable and explosive dusts, liquids and gases. 
Other work of this association includes that done in cooperation with the Farm Fire Protection Committee of the National Fire Protection Association in an effort to keep the standards of the two organizations in harmony.

Linoleum and Felt Base Manufacturers Association, Chester E. Rahr, general manager and treasurer, 500 Fifth Avenue, New York, N. Y. Two committees of this association carry on work in the field of standardization. The Technical Committee cooperates with Federal, State, and municipal governments in establishing standards for products of the industry. Specifically, it has assisted the Federal Specifications Executive Committee in formulating and revising Federal specifications covering battleship linoleum and cork carpet, and is now cooperating in the development of specifications covering other types of linoleum. Its Simplification and Standardization Committee functions as a coordinating unit in obtaining members' views with respect to various gages of linoleum, sizes of rugs, quality, and grade.

Liquid Tight Paper Container Association, George J. Lincoln, Jr., secretary, 1532 Lincoln-Liberty Building, Philadelphia, Pa. For the past 20 years standardization of paper containers has constituted an important function of this association. Through its efforts in this field this association has established standard measures, such as half-pint, pint, quart, two-quart, and gallon capacities. It has also accomplished a standard method of packing, such as 300 halfpint units to a shipping case, 200 pint, 100 quart, 50 half-gallon, and 50 gallon.

The products of this industry, which are straight-sided paper containers with slip cover lid, are recognized by all the States as a measure, and not merely as a container.

Every manufacturer of this product must submit the containers to the bureaus of weights and measures of the several States to see that the containers are of accurate capacity. If approved, a license number is then granted. This license number must be printed or stamped on each and every container that is manufactured. At the present time a committee of this association is conducting a study leading to standardization of certain industrial products, as well as certain types of printing.

Machine Screw Nut Bureau, G. P. Byrne, managing director, 53 Park Place, New York, N. Y. Although this bureau does not publish standards or specifications of its own, its Committee on Standardization and Simplification considers dimensional standards of the products of the industry relating to diameter, length, pitch of thread, type of head, etc. The committee actually does not complete any project; it merely develops standards which are satisfactory and efficient both to consumers and manufacturers. These projects are presented to the Ameriaan Standards Association, who actually complete and promulgate them in the form of recommended American standards.

Mahogany Association, Inc., George N. Lamb, secretary, 75 East Wacker Drive, Chicago, Ill. This association is composed of American firms that import genuine mahogany logs into the United States and manufacture them into lumber and veneer. It cooperates with the National Hardwood Lumber Association in establishing 
grading rules for hardwood lumber. The rules published by the latter association also include rules covering the grading of mahogany lumber.

This association took an active part with other lumber associations in the preparation of a standard for two classes of solid hardwood wall paneling, which resulted in the formulation and promulgation of Commercial Standard CS74-39 by the National Bureau of Standards.

This association has inaugurated a labeling program whereby it licenses manufacturers to use labels issued by them and to affix said labels to furniture made of genuine mahogany. Contracts, with the association, signed by manufacturers, contain penalty clauses in the form of liquidated damages for willful misuse of the labels. Labels are issued in two colors. The red label so placed on a piece of furniture indicates that it is made of solid mahogany lumber, whereas the blue label means that the furniture is made of solid mahogany lumber for frame parts, and of mahogany plywood for larger surfaces. The purpose of labels is to guarantee to the customer that furniture so labeled is made of genuine mahogany, and not of cheaper substitute woods stained to resemble mahogany, frequently described as "combination mahogany" or "mahogany finish." It is also a guaranty that furniture so labeled is not made of Phillippine hardwoods, or other tropical substitutes which are in no way related to genuine mahogany but are sometimes sold as "Philippine mahogany."

Malleable Chain Manufacturers' Institute, C. W. Spalding, chairman, 11 South La Salle Street, Chicago, Ill. A group of seven firms comprises the membership of this organization which has been developing standards for malleable chain and attachments since 1917, at the suggestion and recommendation of the War Industries Board. All standardization and development work is done with the participation of all of the institute's members rather than by specific committees. The results of this work are published in the catalogs of its members.

Malleable Founders' Society, Robert E. Belt, secretary, Union Commerce Building, Cleveland, Ohio. The work of this society deals largely in technical research and advisory services, in assisting its members to maintain standard grades of products, and in the development of new applications and uses for malleable castings. In carrying on this work, it has sponsored the adoption of the present standard specifications of the American Society for Testing Materials for malleable castings, as well as those of other technical organizations and of the Federal Specifications Executive Committee.

The society maintains official representation on a committee of the American Standards Association dealing with the classification and designation of surface qualities, corrosion and other subjects, and is represented on the ASTM Committee on Malleable Iron Castings. It cooperated with the National Bureau of Standards in the establishment of Simplified Practice Recommendation R79 for malleable foundry refractories.

Manganese Track Society, R. E. Einstein, secretary, 301 South Main Street, East St. Louis, Ill. 'The Standardization Committee of this organization meets at frequent intervals with the Track Com- 
mittee of the American Railway Engineering Association for the purpose of discussing design, uses, and materials entering into the construction of the product made by the members of the society. This has resulted in the publication of a book of track-work plans and specifications, which comprises drawings and other details required in the construction of track structures now in use, and practically considered as standards for the American railroads.

Manufacturers Standardization Society of the Valve and Fittings Industry, John J. Harman, general secretary, 420 Lexington Avenue, New York, N. Y. This society, with its predecessor, the Committee of Manufacturers on Standardization of Pipe Fittings and Valves, has been in continuous existence for the past 30 years.

The method of carrying on standardization work by the society is by means of committees selected from the engineering departments of representative manufacturers that are directly engaged in the manufacture of the products in question.

At present the society has about 20 committees carrying on work on subjects covering codes, screw and flange fittings (ferrous and nonferrous), marine valves and fittings, marking and terminology, materials, radiator valves, screw threads, cast- and malleable-iron fittings, brass valves, unions and union fittings, water works, welding, etc.

The society has now in force approximately 20 standard practices which it has developed and adopted. These are for bronze flanges and flanged fittings (150-, 250-, and 300-pound) ; roughing-in dimensions for light radiator valves, union elbows, and return-line vacuum valves; by-pass size standard; finishes for contact faces of connecting-end flanges of ferrous valves and fittings; cast-iron screwed drainage fittings; spot-facing standard; 125-pcund and 250-pound SP bronze screw pipe fittings; pipe bushings; locknuts; steam bronze castings for valves, flanges, and pipe fittings; gray-iron and malleable-iron castings for flanges, pipe fittings, and valve parts; standard marking system for valves, fittings, flanges, and unions; drain tapping standard; screw threads for high pressure and temperature bolting; 300-pound malleable-iron screw fittings; ferrous flanged valve center to face dimensions; and railing fittings.

In addition, the society serves as joint sponsor with the American Society of Mechanical Engineers and the Heating, Piping and Air Conditioning Contractors National Association for the Sectional Committee on Pipe Flanges and Fittings, which resulted in the approval of 11 standards by the American Standards Association. It is also officially represented on 11 additional ASA sectional committees working on the following projects: specifications for castiron pipe and special castings; minimum requirements for plumbing and standardization of plumbing equipment; pipe threads; safety code for mechanical refrigeration; code for pressure piping; standard hose coupling screw threads; standardization of dimensions and materials of wrought-iron and wrought-steel pipe and tubing; classification and designation of surface qualities; specifications for zinc coating of iron and steel; standards for drawings and drafting room practice; work in compressed air; and graphical symbols and abbreviations for use on drawings. It is also represented on committees of the American Society for Testing Materials dealing with 
development of specifications for cast-iron, steel, and copper and copper alloys.

The society initiated the program for the elimination of unnecessary sizes of wrought-iron and wrought-steel pipe, valves, and fittings. This resulted in the establishment of standard stock sizes as set forth in Simplified Practice Recommendation R57-32, promulgated and published by the National Bureau of Standards.

Through its various committees the society cooperates also with the Federal Specifications Executive Committee in formulating and revising numerous Federal specifications on valves and fittings; and also with the Bureau of Marine Inspection and Navigation of the United States Department of Commerce in connection with the development and revision of its general rules and regulations pertaining to the use of valves and fittings. It also cooperates with other organizations on standardization projects coming within the field represented by the society.

Manufacturing Chemists' Association of the United States, Warren N. Watson, secretary, 608 Woodward Building, Washington, D. C. An important activity of this association is in the field of container research and the safe packaging and transportation of explosives and other dangerous articles. This work is handled by technical committees, among which are the following: Tank Car Committee; Carboy Committee, Steel Barrels and Drums Committee, Poisonous Articles and Miscellaneous Packages Committee, and Traffic Committee. These committees work in cooperation with the Bureau of Explosives, the Interstate Commerce Commission, and the Bureau of Marine Inspection and Navigation, United States Department of Commerce, in facilitating the authorization of new and improved containers, and regulations designed to further safeguard and improve the transportation of hazardous commodities. This association has issued a series of manuals in which are included all of the standards and recommended practices formulated by the various committees and adopted by the association.

The standards and recommended practices which now appear in manual form cover carboys for shippers and consignees; glass carboys, boxed; handling and storing and service requirements of steel drums, including warning labels; handling of hydrofiuoric acid and nitrocellulose wet with alcohol or water; bulk shipments in box cars of sodium bisulphate; standard tables for aqua ammonia, hydrofluoric acid, nitric acid, sulphuric acid, and zinc chloride solution; and unloading of steel tank cars when filled with various kinds of corrosive liquids. This association cooperated with a sectional committee of the American Standards Association in the development of the American standard safety code for mechanical refrigeration. It is also represented on ASA Sectional Committees on the development of a ventilation code and safety code for exhaust systems. Through the several technical committees, research work is sponsored in technical colleges and universities on projects relating to the safe handling or transportation of chemicals and related products.

Maple Flooring Manufacturers Association, E. C. Singler, secretary, 332 South Michigan Avenue, Chicago, Ill. One of the prime objects of this association is to establish and enforce uniform grades and standards of products; to constantly improve methods of manu- 
facture; and to make the association trade-mark a symbol of excellence in methods and materials. Through its Grades Committee, this association has established grading rules for northern hard maple, beech, and birch flooring. For the protection of the specifier and consumer, the association requires its members and encourages other hard-wood flooring manufacturers to properly and clearly grade mark and species market their entire flooring product. The letters MFMA on maple, beech, or birch flooring signify that the flooring is standardized and guaranteed by the association to be in accordance with the current established grading rules.

This association has also adopted specifications for heavy duty finishes and for gymnasium-type finishes for maple, beech, and birch floors. A number of years ago it adopted a certification program for approval of heavy duty finishes for such floors. In accordance with this plan (revised 1939 to include gym-type finishes) products meeting required tests are certified to the association on the basis of laboratory examination according to the specifications. For this purpose the association employes the services of a commercial testing laboratory. Products, which have met these specifications and have been so certified to the association, will receive its written approval. Under the present plan, products meeting the laboratory test prior to January 1, 1941, will be certified to the association and by the association to members of the industry as of that date. MFMA approval will be effective from date of certification to January 1, 1944, subject to the condition that prompt notification will be given the association of any change in formula, and of withdrawal of approval on substantial evidence of depreciating the quality of the product.

Mellon Institute of Industrial Research, University of Pittsburgh, E. R. Weidlin, director, 4400 Fifth Avenue, Pittsburgh, Pa. The functions of the institute are fourfold, namely, it is an industrial experiment station, a training school for industrial scientists, a center for investigation in pure as well as applied chemistry, and a clearing house on specific scientific information for the public.

Various fellowships have been active in the field of standardization. Much of this work has involved the development of analytical methods, physical testing procedures, and factual information for use in the preparation of specifications.

The American Refractories Institute, a national organization comprised principally of manufacturers of refractory materials, maintains a multiple fellowship in Mellon Institute for the purpose of conducting studies relating to the manufacture, use, and development of this important commodity. The activities of the fellowship are divided between evaluation studies and research work. Contributions are made from time to time relating to the development of new test methods and specifications, and study of the properties and behavior of refractories in service.

Another phase of the technical work in the American Refractories Institute is that of the Technical Advisory Committee. This group is comprised of technical experts from the industry, and the purpose of the committee is to help direct the fellowship and to offer technical assistance to other organizations, such as the American Foundrymen's Association, the American Ceramic Society, and the 


\section{Miscellaneous Publications, National Bureau of Standards}

American Society for Testing Materials. From time to time, cooperation is extended to the National Bureau of Standards, the Naval Boiler Testing Laboratory at Philadelphia, city and municipal organizations, as well as the large variety of industries which consume refractory materials.

The Mellon Institute along with a number of other organizations is supporting the work of the American Coordinating Committee on Corrosion. This committee was organized in 1938 under the immediate sponsorship of the American Society for Testing Materials. There have long existed in England and Holland and a number of other foreign countries coordinating committees sponsored by the counterparts of the National Bureau of Standards. Frequent requests for information on the status of corrosion investigations in the United States had been received from these foreign committees, and the desirability of having a similar organization in this country became apparent some years ago. The committee as originally constituted consisted of official delegates from 16 national technical societies, from the National Bureau of Standards, from Battelle Memorial Institute, and from Mellon Institute. Since that time a number of additions have been made.

The committee is designed to coordinate research and developmental activities in the entire field of corrosion in this country. It lists in its confidential directory the names of some 275 individuals selected by the committee from a total of 500 or 600 persons who submitted data on their qualifications. The scope of activities covered by these listed individuals varies from academic work on the theory of corrosion to actual application of corrosion principles to the protection of process equipment, pipe lines, household utilities, etc.

The Coordinating Committee whose secretariat is at the Mellon Institute, collaborates to the fullest extent with similar committees and particularly with Federal agencies. The committee is already cooperating with the War Department on a number of confidential projects.

The institute maintains research for the Committee of Revision of the Pharmacopoeia of the United States which is presently engaged in the preparation of the twelfth revision of the Pharmacopoeia of the United States. The committee operates through 15 subcommittees including the one on organic chemicals.

This subcommittee is charged with preparation of standards for organic chemicals, natural and synthetic, including alkaloids, fatty oils, soaps, and purely synthetic chemicals. It is also engaged in preparing standards for surgical dressings, in which it enjoys the cooperation of the offices of the Surgeons General of the Army and Navy and of the National Institute of Health. It also, in its broader program, has the close cooperation of the Food and Drug Administration.

A representative of the institute serves as chairman of the Committee on Laboratory, American Pharmaceutical Association. This laboratory is engaged in the preparation and revision of standards found in the National Formulary, a volume official under the Food, Drug and Cosmetic Act, and devoted to medicinal preparations and diagnostic reagents. 
The institute maintains representation on several committees of the American Society for Testing Materials that are engaged in setting up specifications for the determination of thermal and physical properties of all types of insulating materials. Definite standards have been laid down for compression strength, flexual strength, and linear shrinkage. After specifications for various other physical and thermal properties have been established, work will go forward in establishing definite specifications for insulating materials to meet certain conditions. Representation is also maintained on American Society for Testing Materials' technical committees engaged in problems relating to water for industrial uses and the development of standards and methods of test for glass.

The institute was represented also on a joint committee with representatives of the American Society for Testing Materials, the American Society of Heating and Ventilating Engineers, the American Society of Refrigerating Engineers, and the National Research Council in the development of a test code for the determination of thermal conductivity of all types of insulating materials.

The institute, through its fellowships, cooperates with other organizations in the field of standards. Representation is maintained on the Advisory Committee on Ultimate Consumer Goods, functioning under the auspices of the American Standards Association, on problems relating to consumer standards; and on the Crankcase Oil Stability Research Committee of the Society of Automotive Engineers.

The Industrial Hygiene Foundation of America, which has its headquarters in the institution, operates collaboratively with various national societies and governmental agencies through its medical and preventive engineering committees composed of specialists. Investigations are also sustained at Harvard University and the University of Pennsylvania.

Metal Cutting Tool Institute, Harry C. Hungerford, secretary, 410 Asylum Street, Hartford, Conn. One of the chief activities of this institute is the standardization and simplification of all products coming under its classification, which is metal cutting tools, including taps and dies, milling cutters, drills, reamers, and miscellaneous cutting tools. The institute is divided into three major divisions, namely: Taps and Dies, Milling Cutters, Drills and Reamers; and each division is represented by separate committees on physical standards and standardization and simplification of product. The subjects which these committees consider and the projects completed by them cover the revision of physical dimensions of all tools coming under their classification, so as to keep the standards in line with current manufacturing conditions and practices. This institute cooperates with the National Bureau of Standards, and other Federal agencies, as well as the American Standards Association, in standardization matters. The Tap and Die Division has issued a standard catalogue of sizes of taps and dies, and also a commercial standard pamphlet covering standard dimensions of taps and dies which has been adopted by tap and die manufacturers. These latter standards coincide with the physical dimensions given in American standard B5.4-1939 covering cut and ground thread taps approved by the American Standards Association. 


\section{Miscellaneous Publications, National Bureau of Standards}

The division maintains representation on Sectional Committees of the American Standards Association on Standardization and Unification of Screw Threads, Pipe Threads, and Allowance and Tolerances for Cylindrical Parts and Limit Gages.

The Milling Cutter Division prepared and issued a standard catalogue covering sizes and dimensions of milling cutters. The division is represented on the standing committee of Simplified Practice Recommendation R36-34 for milling cutters which recently prepared a revision of the recommendation. It is also represented on the ASA sectional committee which compiled and issued the American standard B5c-1930 covering standards for milling cutters.

The Drill and Reamer Division has likewise prepared and issued a standard catalogue on sizes and dimensions of drills and reamers. This division is officially represented on the Sectional Committee on Standards for Small Tools and Machine Tool Elements functioning under the auspices of the American Standards Association which has, among other things, completed a revised draft of twist drill standards (ASA B5.12-1940) and a new American standard, B5.101939 for reamers. It is also represented on two additional ASA sectional committees on allowance and tolerances for cylindrical parts and limit gages, and on Classification and designation of surface qualities.

The institute, through its divisions, cooperates very closely with the Federal Specifications Executive Committee in the development and revision of Federal specifications for twist drills.

Metal Lath Manufacturers Association, Arthur Tuscany, commissioner, 208 South La Salle Street, Chicago, Ill. Subjects of primary interest to this association include metal lath, plaster, and stucco construction. This association was instrumental in bringing about a simplification of sizes and varieties of metal lath which resulted in the establishment of Simplified Practice Recommendation R3-39 promulgated and published by the National Bureau of Standards. It cooperated with the Sectional Committee on Standard Specification for Gypsum Plastering, which was approved as American standard A42.1-1938 by the American Standards Association. In addition, it has prepared and issued standard metal lath specifications for better plastering and concrete stucco covering quality of materials and methods of application of all types of metal lath expanded or fabricated from sheets, and primarily designed to be used as a base for plastering.

This association also cooperates with the Federal Specifications Executive Committee in the preparation of Federal specifications for metal bases for plaster and stucco construction.

The Metal Lath Manufacturers Association has developed specifications and details for various types of ceiling and partition construction. This information has been published in the Partition Handbook and in Metal Lath News. It has been done in an attempt to standardize construction practice.

Metal Paper Fastener Institute, Thos. B. Jordan, executive secretary, Trinity Court Building, 74 Trinity Place, New York, N. Y. This institute developed a standardization program which resulted in the adoption of standards covering physical dimensions of brass and steel washers of various sizes. It also formulated physical standards 
for brass and steel paper fasteners of the round and flat types and of various styles of wire paper clips.

Metal Window Institute, Myron J. Jones, technical assistant, 1427 Eye Street NW., Washington, D. C. Three committees of this organization are currently interested in activities relating to standardization and simplification. These committees, known as Executive, Technical, and Coordination Committees, cooperate through the institute with various agencies of the Federal Government in the preparation of specifications relative to metal windows.

Specifically, this institute collaborated with the National Bureau of Standards relative to tests of air infiltration through windows; with the American Iron and Steel Institute in the preparation of the fire protective provisions of a model building code; and with a State agency in the establishment of standards for light penetration through windows and glass block. The institute has prepared and is now revising its own standard covering specifications for public work. It cooperated with the National Bureau of Standards in the preparation of Simplified Practice Recommendation R72 relative to standard stock sizes for solid section steel windows. It is represented on the sectional committee engaged in the development of modular dimensions for building materials and equipment, functioning under the American Standards Association's procedure.

This organization instituted and completed a program of research at the University of Michigan in connection with air-conditioning requirements of glass.

Milk Cap Statistical Bureau, George J. Lincoln, Jr., executive secrecary, Lincoln-Liberty Building, Philadelphia, Pa. This organization, formerly known as the National Association of Bottle Cap Manufacturers, carries on work in simplification and in development of standards for the bottle cap industry, through committees which are appointed from time to time. One of the principal features of its program has been the development of a standard color chart of 16 colors for milk bottle caps. This standardization of colors assists dairies, changing their sources of supply from one manufacturer to another, in being able to continue on the same colors, where formerly different manufacturers all had different shades of the some color.

This bureau has also established a standard with reference to milk bottle caps which is 40-point thick, single white-lined board. It is at the present time engaged in establishing a standard method for closing in the ends of the tubes in which the caps are packed. The object of this method is that the caps will be packed in more sanitary tubes, and customers will be able to obtain standard pack from whatever source they may purchase.

This organization took an active part in the establishment of Simplified Practice Recommendation R148-33 covering standard sizes and dimensions of glass containers for cottage cheese and sour cream, which was promulgated and published by the National Bureau of Standards.

Mine Inspectors' Institute of America, C. A. McDowell, secretary, 427 Park Street, California, Pa. The only standardization activity conducted by this institute up to the present time has been in connection with the suitability of types of explosives for use in mines, including standard methods of handling and transportation. It 


\section{Miscellaneous Publications, National Bureau of Standards}

served as sponsor for the recommended practice for the use of explosives in bituminous coal mines. This was approved as American recommended practice M14-1930 by the American Standards Association.

Mirror Manufacturers Association, Ivan A. Bickelhaupt, secretary, Shoreham Building, Washington, D. C. At the request of this association, a general conference of manufacturers, distributors, and users was held in 1930 for the purpose of establishing standards of quality for plate-glass mirrors. As a result of this conference, conducted at the National Bureau of Standards, there was adopted a specification covering five grades of plate-glass mirrors and promulgated as Commercial Standard CS27-30. At the suggestion of the association, the Standing Committee for the industry recommended revision of this standard to include "shock" or common window-glass mirrors, and to eliminate two grades. The revised standard was approved and a second edition was published as Commercial Standard CS27-36.

For the guidance of the buying public and the protection of the mirror manufacturer, the association recommended to mirror manufacturers that each commercial standard grade mirror may be labeled in the color designated below, with the following statement for each particular grade: red for "A" quality; blue for No. 1 quality; and green for No. 2 quality-we guarantee this mirror to be manufactured of polished plate-glass and to be of --_----quality as specified in Commercial Standard CS27-36, issued by the National Bureau of Standards, United States Department of Commerce.

Monorail Manufacturers Association, E. Donald Tolles, secretarytreasurer, 165 Broadway, New York, N. Y. All the standardization activities carried on by this association to date have been the preparation and adoption of specifications for overhead track systems which were approved in 1938. These specifications cover track, suspension fittings, manually operated trolleys or carriers, switches, cranes and transfer bridges, specifications for wire-rope electric hoists, electric hoist and travel carriers, and wiring.

Motor Fire Apparatus Manufacturers' Association, Inc., W. J. Parker, secretary-treasurer, 366 Madison Avenue, New York, N. Y. Although this association has not developed specifications of its own covering motor fire apparatus, it has, through its technical advisory committee, cooperated with the National Board of Fire Underwriters and the National Fire Protection Association in the development of specifications for fire apparatus for both municipal and rural communities.

Multiple V-Belt Drive Association, Philip W. Upp, executive secretary, 140 South Dearborn Street, Chicago, Ill. The product of manufacturers in this association consists of drives for the mechanical transmission of power, the drives comprising sheaves with multiple grooves and V-belts operating in these grooves. The membership in the association includes companies which manufacture sheaves, and which sell complete drives and parts thereof.

The standardization and simplification work of this association is carried on through its Engineering Committee, which has considered, or is now conducting, work on the following subjects: number of belt sizes to be recommended; sectional outline of belts, including 
dimensions and angles; determination of most useful lengths of endless belts; groove dimensions in sheaves to cooperate with belt, including careful studies and tests of most suitable angles of the grooves, and allowable variations in those angles. The committee has developed and adopted formula for horsepower ratings for belt drives, and a method of determining the exact center distance in use of endless belts, and a table of center factors for ratios $1: 1$ to $10: 1$. The Engineering Committee cooperates closely with the V-Belt Technical Committee of the Rubber Manufacturers Association for the purpose of improving its belting standards. It also cooperates with a similar committee of the Power Transmission Association.

National Aircraft Standards Committee. (See page 12.)

National-American Wholesale Lumber Association, Sid L. Darling, secretary, 41 East Forty-second Street, New York, N. Y. One of the objects of this association is to aid and more efficiently distribute all lumber and forest products through standardization of grades and sizes, and through the elimination of unfair practices and trade abuses, in cooperation with proper governmental agencies and officials. This association's activities in standardization are carried on in cooperation with the Central Committee on Lumber Standards, on which it maintains official representation in the development of American lumber standards. This organization maintains a Grade-Marking Committee made up of wholesalers familiar with various species of lumber. This committee, which acts in an advisory capacity, cooperates with similar grade-marking committees of lumber manufacturers' associations for the grade-marking of lumber of various species.

National Association of Bedding Manufacturers, S. J. Mills, secretary, 608 South Dearborn Street, Chicago, Ill. One of the main activities of this organization is the promotion of State laws and Federal rules and regulations relating to the production and sale of sanitary and honestly labeled bedding materials, with compulsory requirements for labeling mattresses and pillows in regard to kind and prior usage of filling materials.

Through an Industrial Committee, this association has cooperated with the National Bureau of Standards in the establishment of Simplified Practice Recommendations R2-32 for bedsteads, springs, and mattresses; and R24-37 for hospital beds; and in the development of Commercial Standards CS54-35 for mattresses for hospitals; and CS 55-35 for mattresses for institutions, all of which have been promulgated and published by the National Bureau of Standards. This committee is continuing its cooperation with the National Bureau of Standards by maintaining representation on the standing committees of above-mentioned Simplified Practice Recommendations and Commercial Standards for future revisions.

This association is also collaborating with the American Standards Association with reference to certain standards relative to items or commodities entering into the manufacture of mattresses.

National Association of Builders Exchanges, John B. Dickman, Jr., executive secretary, Bond Building, Washington, D. C. One of the main objects of this association is the promotion of uniform building laws throughout the country. It cooperated with the National Bureau of Standards in the formulation of a uniform mechanics' 
lien law. It has also approved the standard documents of the American Institute of Architects covering the form of agreement and general conditions of the contract, the bond of suretyship, the standard form of agreement between contractor and subcontractor, and the letter of acceptance of subcontractors' proposal.

Among the association's activities in the commodity standardization field is the participation in the establishment and acceptance by industry of various Simplified Practice Recommendations promulgated by the National Bureau of Standards, including partitions for toilets and showers, steel lockers, paint and varnish brushes, forms for concrete floor construction, wheelbarrows, etc. It is cooperating with other organizations, under the procedure of the American Standards Association, in the formulation of a standard recommended practice for brick masonry.

National Association of Building Owners and Managers, Robert B. Beach, executive secretary, 134 South La Salle Street, Chicago, Ill. This association is essentially a service industry, and its membership represents a substantial part of the larger commercial properties of the country. In connection with its other activities, this crganization devotes part of its time to matters relating to standardization. It has adopted a standard method of floor measurements, and has developed standard methods of rating space. It has also prepared standard practices in accounting and a uniform chart of accounts for industrial use.

The association makes studies of cost operations, rental conditions, lease percentage rates, and kindred matters for the purpose of developing standard types of information for the guidance of the industry.

It is represented on the Electrical Committee of the National Fire Protection Association, which has taken an active part in developing the National Electrical Code. It cooperated with sectional committees, functioning under the procedure of the American Standards Association, in the development of standards for cast-iron soil pipe and fittings, specifications for gypsum plastering, and code for pressure piping. The association is also represented on the ASA Sectional Committee on Specifications for Pressure and Vacuum Gages, and on the Safety Code for Elevators, Dumbwaiters and Escalators.

National Association of Dyers and Cleaners of United States and Canada, J. M. Matson, managing executive, Silver Spring, Md. This association cooperated with other units of the industry in the establishment of quality standards for Stoddard solvent, promulgated and published as Commercial Standard CS3-40 by the National Bureau of Standards.

It is now making a study of the characteristics of dry-cleaning solvents with a view to further standardization in the improvement of materials and methods of testing.

The association maintains laboratories of its own, where research work is carried on in the fundamental problems of the dyeing and cleaning industry, and where instruction is given to members in the standard practices developed at the laboratories. It issues technical bulletins from time to time on standard methods and materials developed or tested at its laboratories. Three textbooks on garment cleaning have been published, which contain standard recommended 
practices in the cleaning of various materials; standard tests for: identifying fabrics; standard formulae for soaps and cleaning compounds; etc.

This association has recently completed a standardization of processes to be used in servicing the equipment of the standing army of the United States, particularly the wool uniforms and other articles such as wool blankets.

It is officially represented on three committees of the American Society for Testing Materials dealing with petroleum products and lubricants, soaps and other detergents, and textile materials.

National Association of Fan Manufacturers, L. O. Monroe, secretary, 5-208 General Motors Building, Detroit, Mich. Three committees of this association, namely: Engineering, Standardization, and Statistical, carry on the work relating to standards and specifications. Through the efforts of the Statistical Committee, this association has prepared comparison charts for planing mill exhausters and cast-iron volume fans. The tabulations contained in these charts represent a fair comparison of standard sizes of exhausters and volume fans taken from the published catalogs of member companies.

The Standardization Committee has formulated standards for multiblade and nonoverloading fans which were approved by the association.

Through the joint cooperation of the Engineering Committee of this association and the Fan Test Code Committee of the American Society of Heating and Ventilating Engineers, this association has approved and published a standard test code for centrifugal and axial fans.

Committees of this association are now working on subjects dealing with standard methods for centrifugal fans and blowers, and a tentative code for sound rating of fans.

In furthering its work in standardization, the association is officially represented on six sectional committees functioning under the procedure of the American Standards Association dealing with the following projects: allowance and tolerances for cylindrical parts and limit gages; safety code for conveyors and conveying machinery; ventilation code; safety code for exhaust systems; acoustical measurements and terminology; and work in compressed air. This association has adopted a labeling plan whereby member companies may use the "NAFM" label on printed catalogs for identification to the buying public of fans sold thereunder as having certified ratings based on air deliveries, which are in accordance with the standard test code for centrifugal and propeller fans.

National Association of Finishers of Textile Fabrics, Alice C. Moore, secretary, 40 Worth Street, New York, N. Y. After this association had approved color fastness specifications for dyed or printed cotton or linen piece or woven materials, it made application to the National Bureau of Standards, for a revision of Commercial Standard CS59-39 to include color fastness tests based on the specifications approved by this Association. Commercial Standard CS5941, distributed by the National Bureau of Standards, contains revised tests for color fastness of cotton and linen fabrics based on the specifications approved by this association.

$201072^{\circ}-41-10$ 


\section{Miscellaneous Publications, National Bureau of Standards}

Preceding by many years the adoption of the color fastness standards referred to above, this association made arrangements with a commercial testing laboratory to conduct tests to determine the degree of fastness of fabric to light and washing. Licensed finishers whose goods receive an " $A$ " or " $B$ " rating for fastness are granted the use of the association's NAFAL label, showing that the particular dyeing from which the sample was taken has passed the tests required for the use of that label.

This association has approved a standard method of procedure by finishers in the return of remnants to the converter.

National Association of Flat Rolled Steel Manufacturers, A. N. Flora, president, 1845 Oliver Building, Pittsburgh, Pa. Much work has been accomplished by this association in connection with the development of standard specifications for flat rolled products. As questions relating to standardization arise from time to time, this association appoints committees best qualified in knowledge and experience to work out solutions to the problems involved. Through the work of such committees, this association has approved and adopted standards for permissible variations for dimensions, weights and workmanship for sheets and strip steel, including standard classification of hot- and cold-rolled sheets and strip. It has also adopted standards covering permissible variations from specified gauge weights and size for both coated and uncoated sheets, and also stretcher-leveled and resquared sheets. These standards and others covering practically all types of sheets and strip from the standpoint of gauge thicknesses, widths, and weights, have been developed with a view to standardizing and simplifying specifications as much as possible for both the manufacturer and the consumer.

This association has assisted in formulating and revising building codes in cooperation with technical organizations. It has cooperated with the Public Roads Administration and the American Association of State Highway Officials in preparing specifications covering corrugated galvanized culverts.

The association is at the present time engaged in developing specifications for galvanized roofing. It is also conducting studies in connection with painted and galvanized roofings on matters of weights per square and coating, and in the standardization of patterns. This association is officially represented on sectional committees, functioning under the procedure of the American Standards Association, engaged in the development of standards and specifications for refrigerators, and specifications for zinc coating of iron and steel.

National Association of Food Chains, John A. Logan, president, 726 Jackson Place, Washington, D. C. This association has a Labeling Committee which is giving consideration to the development of quality labels for canned foods, based on specifications and standards prepared and issued by the United States Department of Agriculture.

This committee is working with a similar committee of the National Consumer-Retailer Council. The council is composed of representatives of outstanding national consumer organizations and national associations of various types of retailers. The food com- 
mittee of this council is made up of representatives from consumer groups and chain food stores.

National Association of Hosiery Manufacturers, Earl Constantine, president, 468 Fourth Avenue, New York, N. Y.; E. Max Schenke, director of research, National Bureau of Standards, Washington, D. C. The general purpose of this association is to encourage, promote, and protect the welfare and interests of the hosiery industry of the United States.

Several of the principal activities of this association deal with matters relating to technical research and standardization, which include the development of standards for hosiery and methods for testing hosiery.

For 19 years, the association has maintained a research associateship at the National Bureau of Standards for the purpose of analyzing and studying the cause of defects in hosiery, and suggesting improvements in the methods of manufacture of hosiery. One of the recent developments brought about by the research associates has been the establishment of the methods of test used for the testing of hosiery. These methods are described in Circular C422-Methods of Testing Hosiery, published by the National Bureau of Standards. The test methods given in the publication were selected in order to eliminate unnecessary or undesirable variations in the general testing procedure and to eliminate confusion resulting from a diversity of methods.

The research associates have also prepared a paper on the strength and elongation of silk yarns as affected by humidity, which has been issued as National Bureau of Standards Research Paper RP1363.

In view of the greatly increasing demand for mechanical tests designed to give an indication of the ability of various stockings to withstand wear, it has been found desirable by manufacturers and consumers of hosiery, and necessary for the stabilization of testing laboratories, that standard methods of procedure in making such tests be worked out. In this connection, a study is being made by the research associates and the Association's Research Committee on the machine and practical wear tests on women's silk full-fashioned hosiery, which will ultimately lead to the development of standard methods for testing such hosiery. Work is now going forward in developing a standard on the influence of various factors on the snag resistance of women's silk full-fashioned hosiery. Specially constructed hosiery is being used in making this study.

The research associates of the NAHM serve as advisors for the manufacturers of the hosiery industry and the United States Govermment on technical problems related to hosiery.

The Research Committee, formerly known as the Raw Silk Committee, is the most active standing committee of the association in the testing of raw materials and technical matters pertaining to the manufacture of hosiery.

This committee has carried on an extensive research program with the cooperation of the Japanese Raw Silk Intelligence Bureau, dealing with methods of tests and the effect on various factors of evenness, cleanness, and neatness of the finished product. It also acts as an advisory committee to the Research Department of the association on all studies having to do with standardization. Its work in stand- 


\section{Miscellaneous Publications, National Bureau of Standards}

ardization includes the development of "Hosiery Fabric Defect Standards," the "Raw Silk Color Standards," and the report on the causes of "Two-tone in Hosiery."

This committee and other similar committees representing the Commodity Exchange, Inc., the National Federation of Textiles, Inc., and the Throwsters Research Institute, Inc., compose the Joint Committee on Raw Silk Classification which has done much work on the methods of testing raw silk and which, early in 1938, issued its Second Progress Report dealing with the methods of testing raw silk and raw silk classifications.

Other standards which have been developed and adopted by the association cover dimensions of hosiery boxes, oil content of rayon yarn, and lubricant for knitting machines.

The association sponsored the movement which led to the establishment of Commerical Standard CS11-29 for regain of mercerized cotton yarns, and Commerical Standard CS46-40 for hosiery lengths and sizes. These standards were developed under the auspices of the National Bureau of Standards and promulgated and published by that agency.

National Association of Ice Industries, Mount Taylor, executive secretary, 228 North La Salle Street, Chicago, Ill. Through its regular staff, this association has cooperated with several technical organizations in the development of standards covering subjects of interest to the ice industry. It collaborated with the United States Housing Authority in the development of standard specifications for ice refrigerators for use on government projects. It initiated the movement for the standardization of ice-cake sizes which resulted in Simplified Practice Recommendation R96, and also cooperated in the preparation of Simplified Practice Recommendation R109 for ice-compartment sizes for domestic refrigerators. Both of these recommendations have been promulgated and published by the National Bureau of Standards.

This organization was officially represented on the sectional committee which developed the safety code for mechanical refrigeration approved and published as American standard B9-1933 by the American Standards Association, and also on the ASA sectional committee which developed several standards on pipe flanges and fittings. It is now officially represented on the Sectional Committee for Standards and Specifications for Refrigerators for the purpose of developing grades or qualities of household, hospital, and hotel types of refrigerators.

This association has adopted for the ice industry a seal of approval which will identify ice refrigerators and other ice using appliances that have been subjected to tests by the association, and which measure up to carefully determined standards of construction and performance. This seal on an ice refrigerator or ice chest is a guarantee that it has been carefully tested by the technical department of the association and has been found to meet the rigid requirements, both as to construction and performance, and has been unanimously approved by both this association and the National Association of Ice Refrigerator Manufacturers.

In order to carry on this testing work, the association built and operates its own testing laboratory. Here, every size and model of 
refrigerator on which application is made to use the seal must be subjected to rigid performance tests by the association engineers. In addition to these performance tests, the structural specifications of the refrigerator are studied, and checked against the minimum structural specifications established as a requirement for using the seal.

National Association of Ice Refrigerator Manufacturers, E. G. Vail, secretary, 205 West Wacker Drive, Chicago, Ill. The Standardization Committee of this association is at the present time working with the Sectional Committee of the American Standards Association in developing standard grades or qualities for refrigerators cooled with ice and for self-acting or mechanical refrigerators employing a self-contained refrigerant.

This association has established minimum construction requirements for ice refrigerators for the purpose of securing satisfactory and economical operation. These standards have been established in order to protect the public to the extent of making ice a more efficient, a perfect and economical medium for the preservation of food and health through the use of appliances, the safe and efficient performance and substantial and durable construction of which are assured. Thus, members, whose ice refrigerators conform to the minimum construction requirements established by the association, are permitted to carry the association's insignia which states that the refrigerator is "manufactured by certified member according to specifications of the National Association of Ice Refrigerator Manufacturers."

National Association of Insecticide and Disinfectant Manufacturers, Inc., G. M. Baird, chairman, Specifications \& Purchases Committee, Suite 1307, 110 East Forty-second Street, New York, N. Y. This association cooperated actively with the National Bureau of Standards in the establishment of Commercial Standards for liquid hypochloride disinfectant, deodorant, and germicide; pine oil disinfectant; coal tar disinfectant (emulsifying type) ; cresylic disinfectants; and for househould insecticide (liquid spray type). These standards have been promulgated and published by the National Bureau of Standards.

This association has instituted a labeling program whereby manufacturers are permitted to include on the labels attached to the products or invoices a statement that goods so labeled conform to all of the requirements of the particular standard adopted by the association and recorded in the Commercial Standard issued by the National Bureau of Standards.

National Association of Marble Dealers, R. H. Flint, president, 3208 Shields Avenue, Chicago, Ill. A publication, entitled Standard Specifications for Interior Marble Work, has been issued by the association as a guide in preparing specifications for interior marble on any particular job. These specifications contain information on standard practice, a list and classification of the most commonly used marbles, and 42 illustrative plates of standard construction methods and details.

This association has also prepared and issued a specification covering standard marble and a standard classification of both imported and domestic marbles. 
National Association of Master Plumbers of the United States, Jere L. Murphy, chairman, Standardization Committee, 340 East Forty-fourth Street, New York, N. Y. The Standardization Committee of this association effected a standardization of copper boilers, connections, and outlets. It also prepared standards for connections and dimensions of staple vitreous china plumbing fixtures and for allclay porcelain plumbing fixtures, cast-iron soil pipe and fittings, compression faucets, escutcheons, and connections to plumbing fixtures, and enameled iron sanitary ware. The association cooperated with the United States Department of Commerce in a report dealing with recommended minimum requirements for plumbing.

It is officially represented on three sectional committees functioning under the procedure of the American Standards Association on the following projects: Pipe Thread; Standards for Drawings and Drafting room Practice; and Graphical Symbols and Abbreviations for Use on Drawings.

National Association of Mutual Casualty Companies, J. M. Eaton, secretary, 919 North Michigan Avenue, Chicago, Illinois. All standardization work of this organization is carried on with the American Standards Association of which it is a member body and officially represented on the Board of Directors; Standards Council and Safety Code Correlating Committee. It served as joint sponsor for the safety code for laundry machinery and operation which was approved as American standard by the American Standards Association.

This association is officially represented on ASA technical committees engaged in the development of the following safety codes: Construction industry; building exits; elevators, dumbwaiters, and escalators; use, care, and protection of abrasive wheels; compressed air machinery and equipment; conveyors and conveying machinery; cranes, derricks, and hoists; protection of heads, eyes, and respiratory organs of industrial workers; exhaust systems; grandstands; methods of test for safety glass; work in compressed air; protective occupational footwear, foxie dusts, and gases; accident prevention signs; walkway surfaces; stevedoring; industrial sanitation; quarries; and highway traffic standards.

National Association of Pipe Nipples Manufacturers, H. A. Long, Jr., secretary, 501 Fifth Avenue, New York, N. Y. In cooperation with the National Bureau of Standards, this association initiated the movement for the development of a commercial standard for pipe nipples. This resulted in the establishment of Commercial Standard CS5-40 covering pipe nipples made of brass, copper, steel, and wrought iron. This standard has been promulgated and published by the National Bureau of Standards.

National Association Practical Refrigerating Engineers, Emerson Brandt, secretary, 228 North LaSalle Street, Chicago, Ill. Although this organization does not inaugurate standardization projects in the refrigeration field, it cooperates in the standardizing activities of other organizations, notably the American Standards Association. By its representation on sectional committees, it cooperated in the establishment of the American standard code for mechanical refrigeration, standard specifications for cast-iron flnaged ammonia fittings, and a standard code for pressure piping, both of which have 
been approved as American standards by the American Standards Association.

National Association of Printers' Roller Manufacturers, H. H. Colehower, Jr., secretary, in care of Godfrey Roller Co., Philadelphia, Pa. This is an association composed of 52 roller makers throughout the United States and Canada, comprising approximately 90 percent of the roller makers in the United States. Two committees of this organization are engaged in standardization work. The activity of one of the committees is in standardizing weights on roller composition, while the work of the other committee is in investigating and reporting new types of printing rollers, as a means to measure their worth to the printing industry.

National Association of Purchasing Agents, George A. Renard, executive secretary, 11 Park Place, New York, N. Y. This association, with which are affiliated more than 60 local purchasing associations in this country, parts of Canada and Mexico, represents approximately 6,000 purchasing officials, both public and private. Representing as it does a body of corporate consumers, including purchasing agents of industrial concerns, private and public utilities, and governmental and institutional buyers, this association takes an active part in standardization and simplification programs of value to its members.

Although it does not develop projects within the association, it maintains a definite policy of cooperation with all representative organizations in the preparation of standards and specifications for materials, equipment, and supplies in which the members are interested. This work is carried on through committees functioning with similar committees of other organizations, and by direct representa. tion on many committees of various national technical standardizing bodies.

A few of the early efforts of this association in standardization have been in connection with the preparation of the standard coal contract form in cooperation with the National Coal Association: and the formulation of standard forms of contract for erected and nonerected conveyor equipment in collaboration with the Conveyor Equipment Manufacturers Association.

The Iron and Steel Committee of this association developed a standard code for marking steel bars, which has been adopted by both the Federal Standard Stock Catalogue Board and the Navy Department. This committee also assisted in the development of a standard sales agreement and trade customs for the gray-iron foundry industry.

The Paper Shipping-Containers Buyers Group took an active part in the formulation of specifications for solid fibre containers and for corrugated containers, while the development of standard listings of industrial cotton constructions was made by the Cotton Fabrics Committee.

This association's Electrical Contract Committee cooperated with several national electrical organizations in the proposed development of standard electrical contract forms for the purchase of electrical machinery.

This association participates in the activities of the Central Committee on Lumber Standards in the establishment of American 
lumber standards grading rules for softwood lumber, and is represented on the Planning Committee of the National Bureau of Standards in the development of Simplified Practice Recommendations.

Through its own initiative, this Association undertook a simplification program for the reduction of catalogue sizes. This resulted in the adoption of the national standard sizes for catalogues. The Governmental Purchasers Group and the Institutional Buyers Group actively participate in standardization and simplification programs, either sponsored by or conducted under the auspices of technical organizations or agencies of the Federal Government.

This association initiated simplification programs in cooperation with the National Bureau of Standards which led to the formulation of several Simplified Practice Recommendations. Specifically, there were established, promulgated, and published by the Bureau Simplified Practice Recommendation R37 covering standard sizes of commercial forms (invoice, purchase order, and inquiry); Recommendation R58 relating to classification of iron and steel scrap; and revision of Recommendation R166 with reference to color code for marking steel bars.

The association is represented on sectional committees of the American Standards Association participating in the development of American standards for the following general projects, many of which have already been approved: standardization of gears; specifications for pressure and vacuum gages, specifications for zinc coating of iron and steel; classification of coals; specifications for wood poles; and petroleum products and lubricants. It is also officially represented on the Advisory Committee on Ultimate Consumer Goods, functioning under the auspices of the American Standards Association. The functions of this committee, which are advisory in scope, are to see that the consumer and distributor points of view are adequately taken care of in all activities of the ASA. The association also maintains representation on technical committees of the American Society for Testing Materials engaged in the development of specifications and test methods on subjects relating to coal and coke, soaps and other detergents, and paper and paper products.

The National Education Committee of this association has sponsored an educational program which, although it does not come strictly within the purview of standardization proper, does cover subjects which are either directly or indirectly related to the broad field of standardization and simplification. In an effort to advance further sound principles of purchasing and to elevate the purchasing profession to a higher level, this committee's educational program includes, among other things, the publication of a series of handbooks for the guidance and use of the entire membership of the association. The work of this committee has thus far resulted in the publication of handbooks entitled Commodity Data Sheets, Purchasing Policies and Procedures, Industrial Purchasing-Principles and Practices, and Materials Handbook. Several additional publications are in various stages of completion.

National Association of Real Estate Boards, Herbert U. Nelson, executive vice president, 22 West Monroe Street, Chicago, Ill. Standard forms, such as appraisal work sheets for various types of 
property ; rental- and sales-agency contracts; closing sheet; application for real-estate loan; extension of lease form; apartment, office, loft, and store lease forms; and management agreement form have been adopted by the association. It has also adopted a code of ethics covering professional relations, relations to clients, customers, and the public. The association also adopted standards of practice for realtor appraisers and appraisal committees of member boards, covering appraisal of properties exclusive of agricultural, industrial, public utility, mineral, and forest properties.

The association is cooperating with other organizations under the procedure of the American Standards Association by representation on sectional committees engaged in the development of American standards for the following projects: Building code requirements and good practice recommendations for masonry; specifications for plastering; building code requirements for light and ventilation; and administrative requirements for building codes.

National Association of Sheet Metal Distributors, George A. Fernley, secretary-treasurer, 505 Arch Street, Philadelphia, Pa. This organization of wholesale distributors has cooperated with other units of industry in the establishment of simplified practice recommendations covering standard sizes and varieties of sheet steel, terneplate, and eaves trough and conductor pipe, which were promulgated and published by the National Bureau of Standards. It initiated the movements which resulted in the formulation of the Simplified Practice Recommendations for the last three of the projects enumerated above.

National Association of Silo Manufacturers, Z. W. Craine, secretary, Box 30, Norwich, N. Y. Members of this association manufacture and build silos of many different structural materials such as wood stave, triple-wall wood, tile block, tile stave, concrete stave, and monolithic concrete.

In cooperation with various organizations, this association has developed certain standards with respect to the products manufactured by this industry. Wood silo manufacturers and this association have adopted the silo stave-pattern standard grading and dressing rules of the West Coast Lumbermen's Association.

In collaboration with the Portland Cement Association, this association is working on standards for cement-stave silo; and with the Structural Clay Products Institute in the development of standards for silo tile. It likewise cooperates with several technical associations representing steel manufacturers with reference to specifications for steel used for silo production.

This association has established a Silo Foundation Fund with the New Jersey Agricultural Experiment Station at Rutgers University for the standardization of reinforcing requirements for cylindrical silos of various sizes for all types of forage crops, particulary corn and grasses or legumes. It has already completed some of the problems involved in connection with this project.

In cooperation with the United States Department of Agriculture, it has obtained factual knowledge as to silage pressures and reinforcing requirements for such pressures, which led to the standardization of reinforcing requirements for farm silos.

National Association of Waste Material Dealers, Inc., Chas. M. Haskins, managing director, Times Building, New York, N. Y. One 
of the primary functions of this association is the standardization of commodities, the formulation of classifications of waste material, and the establishment of trade customs.

The association has operating with its officers and the Executive Committee the Secondary Metal Institute, Scrap Rubber Institute, Associated Rag Industries, and the Waste Paper Institute. These organizations are known as divisional associations of the National Association of Waste Material Dealers.

In its Blue Book which is published every five years there are included all classifications having to do with waste materials, whether adopted by the association, itself, or originating with other organizations. Among those originating with the National Association of Waste Material Dealers, Inc., is a complete classification covering cotton rags, mixed twines, and bagging; a classification covering all types of nonferrous metals, also, a classification on scrap rubber, woolen rags, and waste paper.

The association's Blue Book carries Simplified Practice Recommendation R58-36 covering Iron and Steel Scraps as published by the National Bureau of Standards and also carries the Scrap Iron Classification of the Association of American Railroads.

National Association of Wool Manufacturers, Walter Humphreys, secretary, 80 Federal Street, Boston, Mass. Standard definitions for clean wool, shrinkage, content, and condition of wool have been adopted by this association.

In 1922 the association cooperated with the U. S. Department of Agriculture in establishing standards for wool, which standards have been the official government grades since that time.

In connection with the Department of Agriculture's establishment of wool-top standards, the association, through its Wool Top Committee, supervised a project undertaken by the Textile Foundation to settle the question of top standardization and to develop some basic means of measuring fineness. As a result of this work the association presented to the industry a schedule of fineness measurements for the qualities of $80 \mathrm{~s}$ to $50 \mathrm{~s}$, inclusive, which were generally accepted by the trade. These standards formed the basis for new wool-top standards which were promulgated by the Secretary of Agriculture in 1939.

Through its Committee on Olive Oil Alternatives, the association conducted research to determine a suitable lubricant as an alternative for olive oil in processes of wool manufacture. This work led to the formulation of specifications which were issued during the present year.

The association cooperated with the National Bureau of Standards in the establishment and revision of Simplified Practice Recommendation R11-36 relating to bed blanket sizes; also in cooperation with the Bureau initiated the movement which resulted in the establishment of Commercial Standard CS65-38 for wool and part-wool fabrics. It also took an active part in the preparation of Commercial Standard CS39-37 for wool and part-wool blankets and subsequent revisions thereof.

The association maintains representation on technical committee D-13 of the American Society for Testing Materials, which is engaged in developing standards and methods of test for textile materials. 
National Automatic Sprinkler Association, Russell Grinnell, president, 205 East Forty-second Street, New York, N. Y. The primary object of this association is the advancement of the art of automatic control of fire as applies to the conservation of life and property.

This organization does not of itself formulate standards, but rather cooperates with several national technical bodies in the preparation of standards, codes, and regulations. It cooperates with committees of the National Fire Protection Association in connection with the design, installation, inspection, and maintenance of automatic and open sprinkler systems; also in the selection, installation, maintenance, and use of fire extinguishers and other first aid fire extinguishing equipment. It also cooperates in the design, installation, and maintenance of standpipe and hose systems and of private underground systems supplying water for fire extinguishment, including the character and adequacy of water supplies and the selection, installation, and maintenance of valves, hydrants, monitor nozzels, hose and accessory equipments; the supervision of valves controlling water supplies for fire protection.

The association concerns itself with the design and construction of hose houses, and fire department procedure in fighting fires in buildings equipped with automatic sprinklers.

It cooperates also with committees of the National Board of Fire Underwriters, the Underwriters' Laboratories, and the Associated Factory Mutual Laboratories relative to the formulation of standards, specifications, and regulations for fire apparatus and its use.

The association is officially represented on sectional committees, functioning under the procedure of the American Standards Association, engaged in the development and revision of the following projects: code for pressure piping, pipe threads, and pipe flanges and fittings. It assisted in the development of the building exits code which was approved as American Standard A9-1937 by the American Standards Association, and in the scheme for identification of piping systems A13-1928, also approved by the ASA.

National Basketball Committee of the United States and Canada, Oswald Tower, editor, Andover, Mass. In addition to developing playing rules for the game of basketball, this Committee maintains several subcommittees, one of which, the Research Committee, experiments with proposed changes in the rules and in standardizing equipment. Standards have been established relative to dimensions of playing courts for junior high, high school, and college age; also for backboards, baskets, and the ball. The committee is at the present time developing recommended specifications for the lighting of basketball courts.

National Board of Boiler and Pressure Vessel Inspectors, C. O. Myers, secretary, Brunson Building, 145 North High Street, Columbus, Ohio. The objects of this association are to promote uniform boiler laws and rules throughout the jurisdiction of its members; to secure uniform approval of specific designs of boilers and other pressure vessels, as well as appurtenances and devices used in connection with their safe operation; and to promote one uniform code of rules, and one standard stamp to be placed upon all boilers and pressure vessels constructed in accordance with the requirements of that code, and one standard of qualifications and 
examinations for inspectors who are to enforce the requirements of said code.

Whenever it is desired to have the approval of this board on a specific design of a steam boiler, or other pressure vessel, or of any appurtenance or device used in connection with their safe operation, the applicant for such approval shall furnish the secretary of the board six copies of blueprints, specifications, or other data. The secretary shall then refer the matter to the standing committee appointed for such purpose, for such action as may be deemed advisable. Upon a report of this committee, the applicant will furnish the secretary such number of copies of blueprints, specifications, or other data as may be necessary to supply each member of this board with a copy.

The approval of such specific design, appurtenance, or device shall require the 90 percent affirmative vote of the membership of this board. The secretary shall keep a complete record, which shall include reasons upon which any application was rejected. In the event of the failure of the committee to report within a reasonable time, the applicant may appeal directly to the board. Upon receipt of approval by this board, the manufacturer of such specific design, appurtenance, or device, shall distinctly stamp same with a fourleaf clover design bearing the initials NBBPVI. No steam boiler or other pressure vessel shall be stamped as designated, unless it conforms with the rules formulated by the Boiler Code Committee of the American Society of Mechanical Engineers, and has been inspected during construction and upon completion by an inspector who has been qualified in accordance with the requirements of this board's bylaws. The stamp to be used as indicative of construction under the National Board requirements shall be a facsimile of stamping approved by this board. It shall be applied upon completion of construction only to those boilers or other pressure vessels which are distinctly stamped with the ASME symbol. Any steam boiler or other pressure vessel built after July 1, 1921, and stamped ASME and National Board, may be used within the jurisdiction of any member of this board.

National Board of Fire Underwriters, W. E. Mallalieu, general manager, 85 John Street, New York, N. Y. This organization with a membership of 193 stock fire-insurance companies prepares and issues reports, standards, good practice requirements, and suggested codes and ordinances dealing with fire protection equipment and the necessary safeguarding of hazards.

Standardization work or subjects related thereto of the board is carried on under the direction and supervision of several committees, chiefly the Committee on Construction of Buildings and the Committee on Fire Prevention of Engineering Standards. The first is the clearing house for information on fire-resistive building construction and similar technical subjects related to fire safety. It keeps in touch with State and city commissions that are preparing, adopting or revising building laws, and a large percentage of the proposed building codes throughout the United States are sent to it for criticism and review on matters of fire prevention and protection. The committee in 1905 prepared a recommended building code to present the best thought in connection with construction and the reduction of the 
fire hazard to life and property. This code has been thoroughly revised from time to time to keep abreast of modern methods and new materials of construction. In 1931 the fifth edition was published and a revised reprint was issued in 1934. Many municipalities have adopted the provisions of the fifth edition code for local building laws. The aim of the committee is to assist municipalities and towns in the work of framing new building codes, and from the standpoint of fire safety the committee is recognized as an important influence in improving building construction in the United States. This committee cooperates with many organizations including the Building Code Correlating Committee of the American Standards Association.

The Committee on Fire Prevention and Engineering Standards has been continuously engaged since 1892, except for brief interruptions, in making fire surveys of American cities. This activity has been at the foundation of a large part of the improvement within recent years in American municipal conditions in the matter of fire hazard and fire protection. This committee was instrumental in bringing about the standardization of hydrant and hose couplings throughout the country. This effort has resulted in the adoption by more than 5,000 cities and towns of the same threaded hose and hydrant couplings, thereby permitting outside aid to be given by one city to another community in the event of serious fires or a sweeping conflagration.

The National Board of Fire Underwriters in its work cooperates with national technical bodies, Federal, State, and municipal governments and other trade associations through membership on existing committees and through contacts with these interests by its staff of fire protection engineers.

Standards and recommended safeguards prepared and published by the board cover a variety of subjects including fire extinguishing appliances and auxiliaries, flammable liquids, combustible solids, hazardous gases, explosive dust, electrical equipment, and items relating to construction. In addition, it has published standard ordinance for chimney construction, suggested ordinance for fire prevention, fire engine tests and fire stream tables, suggested specifications for municipal fire apparatus, and standard construction of school buildings.

The board is a member of the Fire Protection Group of the American Standards Association, and under the procedure of this association is serving as sponsor or joint sponsor for the following projects: Fire hose coupling screw threads; building code requirements for fire protection and fire resistance; and building code requirements for chimneys and heating appliances. It is officially represented on six ASA sectional committees engaged in the development of standards and codes relating to fire protection.

National Canners Association, Carlos Campbell, director, Division of Statistics, 1739 H Street NW., Washington, D. C. This organization maintains a Committee on Simplification of Containers which has cooperated with the National Bureau of Standards in the establishment of Simplified Practice Recommendation R149-33 for sieve (screen) sizes of canned peas, and R155-40 covering names and dimensions of cans for fruits and vegetables. For the purpose of developing improvements in the metals, materials, and products used in the canning industry, this association maintains research laboratories in San Francisco, Seattle, and Washington, D. C. 
National Canvas Goods Manufacturers Association, James E. McGregor, executive secretary, 224 Endicott Building, St. Paul, Minn. This organization was formerly known as the National Tent and Awning Manufacturers Association.

In its work in the standardization field, this association developed standard definitions of terms relating to cotton fabrics in the awning, tent, and tarpaulin trade in cooperation with the Cotton Textile Institute.

This association, under the auspices of the National Bureau of Standards, initiated the movement which resulted in the establishment of Commercial Standard CS28 covering the basis and method of marking cotton-fabric tents, tarpaulins, and covers, either waterproofed-treated or untreated. It recently undertook a revision of this standard which has been published and promulgated by the $\mathrm{Na}$ tional Bureau of Standards as commercial Standard CS28-41.

National Coal Association, J. D. Battle, executive secretary, Southern Building, Fifteenth and $\mathrm{H}$ Streets NW., Washington, D. C. All of the standardization work of this association is carried on under the auspices of the American Standards Association. Through its cooperation on ASA sectional committees, this association has assisted in the development of a specification for classification of coals by rank and by grade, which have been approved as American standard. It is also cooperating on ASA sectional committees on the standardization of methods of recording and compiling accident statistics, and on specifications for sieves for testing purposes.

National Concrete Burial Vault Association, H. A. Dahlquist, chairman of Specifications Committee, in care of Sterling Concrete Vault Co., 5400 Northwest Highway, Chicago, Ill. Through its specifications Committee, this association has prepared tentative specifications for concrete burial vaults. These specifications cover materials to be used, design, physical tests, method of sealing, and inspection. With reference to these specifications, all vaults made in accordance with this association's specifications shall be marked with the name, or identifying mark of the manufacturer, and labeled to show that they meet current American Concrete Institute specifications.

National Concrete Masonry Association, E. W. Dienhart, asst. secretary, 33 West Grand Avenue, Chicago, Ill. The standards and specifications covering the quality of concrete masonry units made by members of this association are developed in cooperation with several technical organizations, namely; Americal Society for Testing Materials, Federal Specifications Executive Committee, and the Underwriters' Laboratories. This association is officially represented on the Sectional Committee on Building Code Requirements and Good Practice Recommendations for Masonry, functioning under the procedure of the American Standards Association.

National Conference on Street and Highway Safety, A. W. Koehler, secretary, in care of the National Association of Motor Bus Operators, Tower Building, Washington, D. C. This conference was organized in 1924 to reduce the heavy toll of accidents in the streets and highways throughout the country. Its work has developed progressively through extended committee studies and general conferences held in 1924, 1926, 1930, and 1934. In this work 
the conference and its committees have had the constant cooperation of public officials, associations, and individuals from all parts of the country concerned with problems of motor traffic.

The following associations have cooperated with the United States Department of Commerce in organizing and financing the Conference: American Automobile Association, American Transit Association, American Mutual Alliance, Association of American Railroads, Chamber of Commerce of the United States, Motor and Equipment Association, National Association of Taxicab Owners, Automobile Manufacturers Association, National Bureau of Casualty and Surety Underwriters, National Safety Council, and Rubber Manufacturers Association. In addition, contributions of work and financial support to specific projects were made by the Automobile Club of Southern California, the National Research Council, and the American Engineering Council.

At the general session which was held in 1934, the conference reviewed the uniform vehicle code and model traffic ordinances previously prepared by the conference in collaboration with other agencies, and approved the manual on uniform traffic control devices prepared by a joint committee of the conference and the American Association of State Highway Officials. The review of these codes and ordinances was based on a report made by a special committee appointed for the purpose. This committee made a further review of these standards in 1939 and 1940, and developed a set of regulations for bicycles to supplement the model traffic ordinances, which have been approved by the members of the conference.

National Conference on Weights and Measures, R. W. Smith, secretary, in care of National Bureau of Standards, United States Department of Commerce, Washington, D. C. The conference, sponsored by the National Bureau of Standards, is composed primarily of State, county, and city weights and measures officials. It includes also as associate members representatives of manufacturers of commercial weighing and measuring devices, business, industry, railroad, and industrial weighing and scale departments, and others interested in the work of the conference.

The conference meets annually to consider various problems arising in connection with weights and measures administration; to promote efficiency and uniformity in laws, rules, specifications, tolerances, and methods of supervision and test; and to coordinate activities of State and local weights and measures officials.

In the development of codes and specifications, tolerances, and regulations for commercial weighing and measuring devices, the $\mathrm{Na}$ tional Bureau of Standards cooperates closely with the conference Committee on Specifications and Tolerances. Sixteen of the codes mentioned have been adopted by the conference to date. As necessity arises, these codes are modified, and new codes are formulated, thus keeping the entire group in line with changing conditions of the trade and with the developments of the equipment industry.

The conference codes are recommended by the National Burean of Standards for adoption by the States, and these, as well as the reports of the proceedings of each annual meeting of the conference, are published by the Bureau, the former in the handbook series and the latter in the miscellaneous series. 
The conference has adopted a model State law on weights and measures, and from time to time, endorses standard methods of test for commercial apparatus.

At its last annual meeting, the conference gave its final approval to a proposed Federal bill for food package standardization which had been developed by committees of the conference over the past three years. This bill would make mandatory in retail sale the use of packages conforming to certain prescribed units. It adopted numerous changes in its recommended specifications and tolerances for weighing and measuring devices and proposed regulations for the sale of 16 classes of commodities.

The conference has been effective in bringing about a gratifying degree of uniformity and mutual cooperation among the States in the matter of weights and measures supervision.

National Conservation Bureau, Julien $\mathrm{H}$. Harvey, managing director, $60 \mathrm{John}$ Street, New York, N. Y. This bureau is a division of the Association of Casualty and Surety Executives. Practically all of its standardization work is carried on in cooperation with committees of technical organizations and agencies of the Federal Government, namely: The American Standards Association, Underwriters' Laboratories, National Safety Council, United States Department of Labor, and the United States Department of Commerce.

The bureau is represented on 56 committees of the American Standards Association, including representation on the Standards Council and the Safety Code Correlating Committee. The bureau is sponsor or cosponsor for the following projects being carried on under the auspices of the American Standards Association: Safety code for mechanical power transmission apparatus; safety code for conveyors and conveying machinery; safety code for woodworking plants; specifications and methods of test for safety glass; standards for safety shoes, and inspection requirements for motor vehicles. In addition, it maintains representation on ASA sectional committees dealing with the following projects: building exits code; safety in the construction industry; safety code for elevators, dumbwaiters and escalators; American recommended practice for school lighting; safety code for the use, care and protection of abrasive wheels; safety code for mechanical refrigeration; safety code for compressed-air machinery and equipment; safety code for cranes, derricks and hoists; code for pressure piping; National Electrical Safety Code; code for protection against lightning; safety code for the protection of heads, eyes, and respiratory organs of industrial workers; ventilation code; safety code for exhaust systems; safety code for the prevention of dust explosions; standardization of methods of recording and compiling accident statistics; safety code for grandstands; work in compressed air; safety code for lighting factories, mills and other work places; safety code for floor and wall openings, railings and toeboards; safety code for the construction, care and use of ladders; safety code for walkway surfaces; safety code for window cleaning; building code requirements for excavations and foundations; safety code for protection of industrial workers in foundries; safety code for forging and hot metal stamping; safety code for rubber machinery; furnace dimensioning rules; electrical installations on shipboard; 
safety code for identification of gas-mask cylinders; textile safety code; rock dusting in coal mines to prevent coal-dust explosions; safety code for electrical equipment in metal mines; safety code for paper and pulp mills; safety code for industrial sanitation; safety code for laundry machinery operation; specifications for accident prevention signs; and allowable concentrations of toxic dusts and gases.

National Consumer Retailer Council, Harold W. Brightman, chairman, 8 West Fortieth Street, New York, N. Y. Recognizing an imperative need for a meeting place in which consumers and retailers can consider and discuss problems of mutual interest, there was organized in 1937 the above-named organization. Among the stated objects of the council are the promotion of the use of informative labeling and the promotion of the use of adequate standards. Through its standards committee, the council carries on educational work as to the value and use of existing and proposed standards for consumer goods among consumers, distributors and manufacturers.

While the council does not of itself engage in standardization, it does take an active interest in the work of the Advisory Committee on Ultimate Consumer Goods, functioning under the procedure of the American Standards Association. The labeling committee of the council has issued a manual on informative labeling which summarizes the advantages of informative labeling and suggests certain standard procedures for developing labeling programs.

The council is at present conducting an extensive project in the informative and grade labeling of canned goods in which six large distributors with stores in 39 States are cooperating. These distributors are using on certain of their canned goods labels which state the grade of the product in accordance with standards promulgated by the Agricultural Marketing Service of the U. S. Department of Agriculture. This project has resulted in a much wider use of these standards.

In addition to the Informative Labeling manual, the council has published Informative Selling which presents a store-wide informative selling program for department and specialty stores. This book suggests how retailers may make wider use of standards in both the buying and selling of merchandise. The council has also published, in cooperation with the Bureau of Home Economics of the U. S. Department of Agriculture, "Standard sizes for children's clothes-a primer for the consumer and the trade." The primer describes the benefits to the retailer and the consumer of the use of standard sizes for children's garments.

National Cottonseed Products Association, Inc., S. M. Harmon, secretary, Sterick Building, Memphis, Tenn. This association maintains trading rules for its members which provide standards of quality, weights and measures for all cottonseed products, as well as general terms covering contracts between buyers and sellers who are members of the association. These rules, in addition to defining grade and quality of products, provide for adjustments and permissible variations in grade and quality; standard packaging; terms for performance of the contract; inspection service; and sampling service. They also provide standard methods of chemical analysis $201072^{\circ}-41-11$ 


\section{Miscellaneous Publications, National Bureau of Standards}

to arrive at the quality and grade of cottonseed products, with a final provision for arbitration of differences between members.

The association maintains a chemists' committee, composed of leading oil chemists who recommend such changes in the methods of chemical analysis as experience and research find necessary. It also has a Committee on Seed Grading which works in conjunction with the United States Department of Agriculture to provide scientific methods of evaluating cottonseed by chemical analysis to determine both quantitative and qualitative value of cottonseed; also a Technical Advisory Committee made up of a number of leading chemists who cooperate with the Bureau of Agricultural Chemistry and Engineering on all matters pertaining to cottonseed and cottonseed products; and a committee on Uniform Rules and Standards for Cottonseed Cake and Meal, which cooperates with the Association of American Feed Control Officials in standardizing definitions of grade and quality of cottonseed cake and meal. In addition, the association maintains a fellowship in the Bureau of Agricultural Chemistry and Engineering.

The association also interests itself in better packaging of goods and cooperates directly with feed control officials in the various States, in efforts to see that the members ship cottonseed cake and meal of contract quality and grade, and where this is not done to assist the feed control officials in getting proper adjustments, where possible.

National Council of American Shipbuilders, Clifford C. Knerr, secretary, 21 West Street, New York, N. Y. One of the main functions of the activities of this council is to correlate and disseminate information relative to developments in shipbuilding and shiprepairing and allied industries. Although this organizaton does not deal directly in standardization problems, it has through its board of directors organized a technical committee whose purpose is to keep in touch with technical developments in the shipbuilding and allied industries. It also maintains a Committee on Standard Contracts and Forms to study contracts and forms of contracts for the purpose of obtaining reasonable uniformity in both Government and private contracts.

One of the accomplishments of the technical committee of this council during the past year has been in connection with an analysis made of the proposed ocean and coastwise general rules and regulations, as prepared by the Bureau of Marine Inspection and Navigation, United States Department of Commerce. The recommendations of this committee were forwarded to that bureau for consideration and approval.

National Crepe Paper Association of America, George J. Lincoln, Jr., secretary, Lincoln-Liberty Building, Philadelphia, Pa. This organization did considerable work in the standardization and simplification of sizes and grades of crepe paper developed by the industry. Over a period of years it has brought about a reduction in the number of colors of crepe paper to 50 which have been standardized. It has also established standard sizes for the packing of crepe paper, either by the fold or in jumbo rolls.

National Crushed Stone Association (Inc.), A. T. Goldbeck, engineering director, 1735 Fourteenth Street NW., Washington, D. C. 
The only standardization activity developed within the association itself has been a standard cost accounting system. This association does cooperate with technical organizations in standardizing either test methods or specifications governing crushed stone, or pertaining to equipment used in its production.

Through a joint committee composed of representatives of the National Sand and Gravel Association, the National Slag Association, and this association, a simplification program was initiated under the auspices of the National Bureau of Standards which resulted in the establishment of Simplified Practice Recommendations R147-33 on wire diameters for mineral aggregate production screens, and R163-39 on coarse aggregates (crushed stone, gravel, and slag).

The association is represented on technical committees of the American Society for Testing Materials dealing with subjects on soils for engineering purposes, specifications for concrete and concrete products, and specifications for road and paving materials. It is also officially represented on the Sectional Committees on Building Code Requirements and Good Practice Recommendations for Masonry, and on Specifications for Sieves for Testing Purposes.

In addition, it is represented on the Joint Technical Committee of Mineral Aggregate Associations, which is made up of representatives of the National Sand and Gravel Association, the National Slag Association, and this organization. The purpose of this joint committee is to coordinate the technical intelligence of the three associations on problems of mutual interest to the mineral aggregates industry as a whole.

National District Heating Association, John F. Collins, Jr., secretary-treasurer, 827 North Euclid Avenue, Pittsburgh, Pa. This association is engaged in furnishing technical information to its members to improve the methods of generating, distributing, and utilization of steam in district heating. It has organized several committees dealing with steam station engineering, meters and accessories, research, chemistry, and distribution. These committees cooperate with similar committees of other organizations, notably the National Association of Building Owners and Managers, the American Society of Heating and Ventilating Engineers, the American Society of Mechanical Engineers, and the American Standards Association.

Several years ago this association published a handbook which provides an authoritative and complete manual of practice for the use of those actively engaged in district heating work.

This association is officially represented on sectional committees functioning under the procedure of the American standards Association for the following projects: code for pressure piping; standardization of dimensions and materials of wrought iron and wrought steel pipe and tubing; and graphical symbols and abbreviations for use on drawings. It is also represented on the Coordinating Committee on Corrosion of the American Society for Testing Materials.

National Door Manufacturers Association, Inc., S. O. Hall, secretary-manager, 332 South Michigan Avenue, Chicago, Ill. There is functioning under the auspices of this association at the present time a Preservative Standards Advisory Committee, which, as its name indicates, deals with the subject of preservative minimum standards. This committee is composed of representatives of noncommercial 
laboratories engaged in research on wood preservation, chemical manufacturers whose products are used in wood preservation, and representatives of sash and door plants using wood preservatives. The work completed by this committee which has been adopted by the association includes minimum standards for toxic preservation of millwork. Manufacturers adhering to these standards in the preservative treatment of their products are permitted to use the association seal of approval.

The association has also promulgated standard details for check rail windows and for six-panel colonial doors. These standards are published in A Manual of Standard Construction for Stock Sash, Doors and Frames, which also contains recommended architectural specifications and grading rules for pine sash, doors and frames. The association is actively engaged in further standardization of the subjects referred to above.

This organization maintains a branch office in Washington, D. C., whose sole purpose is to cooperate with various agencies of the Federal Government in developing practical details and specifications for the products of this industry. Recent activities in connection with these projects relate to the development of a simple standard window frame for mobilization buildings, and standard details for housing-type wood windows and frames.

National Electrical Contractors Association, Laurence W. Davis, Secretary, 420 Lexington Avenue, New York, N. Y. 'This association, organized in 1901 under its present name was called the Association of Electragists, International, from 1921 to 1931. This organization has taken an active leadership in developing standards for wiring installations and engineering design of wiring adequacy. It has cooperated with other organizations in the development of the $\mathrm{Na}$ tional Electrical Code which was approved as an American Standard C1-1940, and the National Electrical Safety Code which has been approved as American Standard C2.1 to 5-1939 to 1941, by the American Standards Association.

This association, which was originally a joint sponsor of the ASA standard symbols for electrical equipment of buildings, C10-1924, is now represented on the ASA sectional committee on graphical symbols and abbreviations for use on drawings (Z10).

It has sponsored, through the National Bureau of Standards, a schedule of standard sizes of copper conductors for building purposes, which resulted in the establishment of Simplified Practice Recommendation R180-41, promulgated and published by the National Bureau of Standards.

National Electrical Manufacturers Association, W. J. Donald, managing director; C. M. Cogan, manager, Engineering Department, 155 East Forty-forth Street, New York, N. Y. One of the oldest and most important activities of this association is standardization. It is carried out in carefully organized committees consisting of members. Most proposals for standardization must be approved by a 90 percent affirmative vote of the interested members before they can be approved as standard. Each company has but one vote. The committee concerned with standardization is the Codes and Standards Committee, which guides the work on standards and fire and 
safety codes, both within the association and in cooperation with other organizations.

The association is sole sponsor for two standardization projects under auspices of the American Standards Association, namely; terminal markings for electrical apparatus; and carbon, graphite and metal graphite brushes. It is cosponsor for the following ASA projects: industrial control apparatus; and rolled threads for screw shells of electric socket and lamp bases. The association is represented on the Electrical Standards Committee of the American Standards Association, which is concerned with the development of all ASA electrical projects, among which should be noted rotating electrical machinery, transformers, switchgear, electrical measuring instruments, wires and cables, insulators for electric power lines, national electrical safety code and national electrical code.

The association by means of joint committees with the Edison Electric Institute has published the first report on the standards for distribution transformers and test specifications for automatic electric storage water heaters. Other joint committees with the Edison Electric Institute are now handling preferred voltage ratings for a-c systems and equipment, preferred ratings for power circuit breakers, standards for distribution cutouts and fuses, coordination of high voltage insulation and coordination of radio reception.

The association, upon invitation, furnishes the Federal Specifications Executive Committee information and recommendations for use in preparing initial drafts or revisions of Federal specifications used for government purchases. The association has or is now contributing in the preparation of some 25 Federal specifications involving such subjects as fuses, panelboards, wire and cable, insulating materials and fans.

Other governmental bodies, on which the association furnishes information and recommendations for use in the preparation of specifications, are: Rural Electrification Administration, United States Housing Authority, Home Owners' Loan Corporation, War Department, Navy Department, and United States Department of Commerce. In addition, the association frequently furnishes recommendations to various municipal bodies for use in the preparation of specifications. Members of the association cooperate in an advisory capacity with the Underwriters' Laboratories, Inc., in the development of standards for fire and safety.

The association also reviews and makes recommendations on standards for wiring materials, wiring devices and utilization equipment developed by the Canadian Engineering Standards Association.

It cooperates with the National Fire Protection Association, National Safety Council, and other bodies in the development of safety codes for the installation of electrical equipment. Other associations having joint product interest are contacted as occasion arises. The necessary joint committees are set up or representation arranged, all for the purpose of developing standards for products having a joint interest. Such joint relations have been set up with Hydraulic Institute, National Machine Tool Builders Association, American Welding Society, International Association of Electrical Inspectors, National Electrical Contractors Association, American Gear Manufacturers Association, Radio Manufacturers Association, International 
Electrotechnical Commission, International Municipal Signal Association, Engineering Foundation, Institute of Traffic Engineers, National Association of Fan Manufacturers, and National ConsumerRetailer Council.

The association has issued during the past year some 37 standards, which it keeps under constant revision, covering standards for the manufacture, performance and test of electrical apparatus, devices and supplies.

National Elevator Manufacturing Industry, Inc., John McArdle, commissioner, 101 Park Avenue, New York, N. Y. Two committees of this organization are concerned with the development of standards and specifications. The Standards Committee has for some time been developing initial engineering standards for the industry. Its work thus far has resulted in the formulation of standards covering car sizes and hatchway dimensions. This committee is now devoting its time in formulating basic engineering specification outlines, some of which are in various stages of completion.

The Central Code Committee of this organization is concerned with the development, interpretation, revision, and adoption of all safety codes for elevators, dumbwaiters and escalators. The committee, working through regional subcommittees throughout the country, has taken an active part in securing the adoption of new State and city elevator codes, and the revision of existing codes conforming to the American standard safety code for elevators, and in securing uniform interpretations of codes. This committee, working in conjunction with the sectional committee of the American Standards Association, assisted in the development of the American Standard Safety Code for Elevators which was approved as American standard A17.1-1937. The Central Code Committee is continuing its work in connection with changes and revision of this code.

National Feldspar Association, W. N. Guthrie, secretary, 19 West Forty-fourth Street, New York, N. Y. In cooperation with members of the industry and the National Bureau of Standards, this association initiated the movement which led to the establishment of a Commercial Standard classification covering ground feldspar used in the production of ceramic products, based on particle size and chemical composition. This standard, which was accepted by the industry, was promulgated and published by the National Bureau of Standards as Commercial Standard CS23-30.

National Fertilizer Association, Inc., Charles J. Brand, executive secretary, 616 Investment Building, Washington, D. C. This association has attempted to bring about standardization along two principal lines, namely; simplification and uniformity in State fertilizer control laws, and reduction in the number of grades of fertilizer offered for sale. As a result of its efforts with the aid of State control officials, all 47 State laws (Nevada has no fertilizer law) now require that plant food guaranties be made in terms of nitrogen, available phosphoric acid, and potash, and in that order. Formerly, some laws required guaranties in terms of ammonia instead of nitrogen, and required that phosphoric acid be stated first in the order of guaranties. Most of the work on this problem was carried on by members of the association staff with aid from members of the Chemical Control Committee of the association. 
This committee also collaborates with the Association of Official Agricultural Chemists and the fertilizer division of the American Chemical Society in the development of standard analytical methods for the determination of the plant-food content of fertilizers. A survey was made in 1939, in conjunction with the Division of Fertilizer Investigations of the Bureau of Agricultural Chemistry and Engineering of the United States Department of Agriculture, to determine the grades of fertilizer sold in each State and the amount of each. The results indicate approximately 1,000 different grades are being sold in the entire United States; over 500 are being sold in Florida alone.

For the past 15 years, the State chemist of Texas, the fertilizer manufactures doing business in Texas, representatives of the State Agricultural Experiment Station, and representatives of the $\mathrm{Na}$ tional Fertilizer Association have held an annual conference to determine the grades of fertilizer to be sold the following year. Every effort is made to keep the number at a minimum that will satisfy the agronomic needs of the State. From 22 to 24 grades have been selected on each of the last few years and no others are registered or sold. This procedure has been gradually spreading to other States, and representatives from Louisiana, Arkansas, and Oklahoma attend the same meeting as Texas and select a list of grades for their States. Alabama and Mississippi hold conferences for the same purpose in their respective States. In the Middle West a list of recommended grades is selected as a result of similar conferences. The manufacturers specially advertise and push these grades and the State agronomists confine their recommendations to this list. Similar conferences have been held with the Middle Atlantic States and lists of recommended grades for each State adopted.

Another type of standardization work carried on by this association was in connection with cost-accounting methods. 'The Cost-Accounting Committee of the association prepared and distributed manuals setting forth basic principles of cost accounting in an endeavor to have all members of the industry keep accurate and complete cost records.

National Fire Protection Association, Percy Bugbee, general manager; Robert S. Moulton, technical secretary, 60 Batterymarch Street, Boston, Mass. This association is the clearing house for all that is authoritative on the subject of fire waste, fire protection and fire prevention. Its present membership includes 135 national and regional organizations, and more than 5,000 individuals, firms, and corporations.

The two main functions of this association are to make standards under the guidance of which the fire waste may be checked, and to educate people in the observance of those standards and point out the grievous economical penalties for ignoring them.

The character of the technical standards formulated or adopted by the association relate to the installation, maintenance, and use of equipment, and are drawn in the form of performance standards rather than as specifications. They deal with the safeguarding of equipment and processes that may cause fire, fire extinguishing equipment and procedure, and measures for restricting the spread of fire and minimizing damage. 
Standards are prepared by impartial committees made up of representatives of organization members of the association, United States and Canadian governmental departments, and other cooperating bodies. They represent reasonable safety without prohibitive expense or undue inconvenience. These standards are widely used as the basis of State, provincial, and municipal legislation, insurance requirements, and as a guide by the increasing number of property owners who demand the maximum of fire safety irrespective of legal or insurance requirements. Periodic revisions are made to keep these standards in constant step with progress in science, invention, and the industrial arts.

The association has adopted some 100 standards covering all phases of fire protection, the safeguarding of hazards, and organization for fire safety. Subjects covered include automatic sprinklers, open sprinklers, acetylene equipment, air conditioning, warm-air heating, air cooling and ventilating systems, anesthetic gases and oxygen, automobile fire apparatus, fire and life safety in aviation, blower and exhaust systems for dust, stock and vapor removal, building construction operations, carbon dioxide extinguishing systems, combustible fibres, dip tanks, dust explosions (12 separate codes), drycleaning and dry dyeing, exits (stairs, fire escapes, etc.), electric cars and trolley busses, electric wiring and apparatus, fire-alarm systems (public and private), fire pumps, fire brigades, fire extinguishers, fire hose, foam extinguisher systems, gas piping and valves, garages, gasoline equipment of various types, hose, hose couplings and hose houses, internal combustion engines, liquefied petroleum gases, lightning protection, marine fire hazards, marine terminal operation, motorboat protection, motion-picture film, oil-burning equipment, ovens, outside protection and hydrants, paint spraying and spray booths, photographic and X-ray film, piers and wharves, protection of openings in walls and partitions, pyroxylin plastic, record protection, rural fire protection, spark arresters, static electricity, standpipe and hose systems, tanks, water systems for fire protection, and many others. About half of these standards have been adopted and promulgated by the National Board of Fire Underwriters. Others are published by the National Fire Protection Association and various other organizations. The association publishes a Handbook of Fire Protection and various compilations of standards in book form.

The association carries on considerable work under the auspices of the American Standards Association. It is a member of the ASA Fire Protection Group and served as sponsor or joint sponsor for the following projects which were developed or are in various stages of development under ASA procedure: Building exits code; building code requirements for fire protection and fire resistance; building code requirements for fire extinguishing equipment; National Electrical Code; fire fighting equipment in metal mines; safety codes for the prevention of dust explosions; recommended practice for the installation, maintenance and use of pipings and fittings for city gas; and fire protection for blower and exhaust systems. It is officially represented on $15 \mathrm{ASA}$ sectional committees engaged in development of standards related to fire protection and prevention.

National Founders Association, Jeffrey M. Taylor, secretary, 120 South La Salle Street, Chicago, Ill. In its work in standardization 
this organization has issued a booklet entitled "Minimum Standards of Foundry Apprenticeship" in which are set forth the requirements for thorough apprenticeship training and the necessary steps to be taken in developing a four-year foundry schedule.

It served as joint sponsor with the American Foundrymen's Association, functioning under the procedure of the American Standards Association, in the establishment of the American standard safety code for the protection of industrial workers in foundries. It is also officially represented on four ASA sectional committees in the development of standards for the following projects: Manhole frames and covers; safety code for the use, care, and protection of abrasive wheels; safety code for the protection of heads, eyes, and respiratory organs of industrial workers; and safety code for exhaust systems.

National Hardwood Lumber Association, John W. McClure, secretary-treasurer, Suite 2408, 59 East Van Buren Street, Chicago, Ill. One of the principal functions of this organization for the past 40 years has been the maintenance of standards for the grading of hardwood lumber, and an inspection staff for the official application of the standards.

This association issues annually a new edition of the rules for the measurement and inspection of hardwood lumber, cypress, veneers, and thin lumber. In addition, it has also issued standard specifications for structural stress grades of hardwoods and cypress for joist and plank beams and stringers, posts, and timbers. The association also prepared and published standard specifications for grades of haröwoods and cypress lumber for freight cars and locomotives. These specifications are in accordance with recommended practices of the Mechanical Division of the Association of American Railroads revised in 1933, and are also in conformity with the American lumber standards.

The association maintains licensed and bonded inspectors in the principal hardwood markets and producing districts of the United States and Canada who are authorized to issue certificates of inspection on hardwood lumber and cypress, the correctness of the grades and measurements shown on the certificate being guaranteed by the financial resources of the association. This official inspection service is available to the members and nonmembers on government contracts, including Federal, State, or local. Extensive use of this service is also being made by the United States Navy Department, United States War Department, and the United States Treasury Department.

In cooperation with the National Bureau of Standards, this association was instrumental in bringing about the establishment of a commercial standard for solid hardwood wall paneling. This resulted in the formulation and promulgation by the United States Department of Commerce of Commercial Standard CS74-39 providing two classes of wall paneling.

National Hay Association, Inc., Fred K. Sale, secretary-treasurer, 600 Board of Trade Building, Indianapolis, Ind. In 1914 this association established standards for various grades of hay and straw which have been kept under constant revision. These grades have been adopted by exchanges in 28 markets located in various parts of the country. Grades of hay and straw developed by this association have become the basis for the formulation of Federal Specifications on which government purchases are made. 


\section{Miscellaneous Publications, National Bureau of Standards}

This association will examine any inspector being employed by an organization using the association rules, upon request by that organization. If found qualified, the inspector is approved by the association. One of the duties of the inspector is to attend the annual meeting of the association and to provide an exhibit of those grades of hay generally handled at his market. The samples exhibited, together with those furnished by other inspectors, are used for comparison of application and interpretation of the grade rules by the different inspectors and members of the association.

National Industrial Sand Association, V. P. Ahearn, executive secretary, and Stanton Walker, Consulting Engineer, Munsey Building, Washington, D. C. Two committees, one the Research Committee, which is considered the main committee, and the other a subsidiary committee, known as the Committee on Foundry Sands, carry on the work of this association in the field of standardization.

This association does not issue standards or specifications, but it does cooperate actively with committees of technical organizations, notably the American Society for Testing Materials, Air Hygiene Foundation of America, American Foundrymen's Association, and other similar bodies, in the formulation of standards and specifications issued by these organizations. In this way, the work of this association's technical committees in developing information is reflected in the specifications issued by the standards-making bodies with which they cooperate.

National League of Wholesale Fresh Fruit and Vegetable Distributors, J. R. Van Arnum, transportation secretary, 512 F Street NW., Washington, D. C. This organization cooperates with various shipping bodies relative to the development of specifications for standard containers for the shipping of fresh fruit and vegetables. The league has had under consideration for the past several years the preparation of specifications for standard containers for fresh fruits, vegetables, melons, and berries for shipment by railroad. This work is being carried forward in cooperation with the Freight Container Bureau of the Association of American Railroads and the United States Department of Agriculture. The results of the standard container activities are published in railroad tariffs known as Freight Container Bureau Tariffs which are filed with the Interstate Commerce Commission.

National Lime Association, W. Vernon Brumbaugh, secretary, 927 Fifteenth Street NW., Washington, D.C. In order to encourage a public appreciation of the economic value of lime in all its uses, this association has issued a series of brochures covering uses of lime in various manufacturing processes, and has included in them the recommended general requirements for lime entering into specific processes. In addition, this association has prepared specifications for lime plaster and lime stucco, suggested specifications for repair of leaky masonry walls, and specifications for mortars for use in unit masonry.

It is officially represented on sectional committees, functioning under the procedure of the American Standards Association, concerned with development of the following projects: building code requirements and good practice recommendations for masonry; specifications for plastering; and specifications for sieves for testing 
purposes. It is also represented on technical committees of the American Society for Testing Materials engaged in the development of standard specifications for lime and lime products, and mortars for unit masonry.

National Lubricating Grease Institute, George W. Miller, executive secretary, 498 Winspear Avenue, Buffalo, N. Y. The Technical Committee of this institute is charged with developing data pertinent to the manufacture, standardization, and application of the products of the industry. This committee and individual members of the institute cooperate with committees of technical organizations in matters relating to standards and specifications.

The institute is officially represented on the Sectional Committee for Petroleum Products of the American Society for Testing Materials as sponsored by the American Standards Association; and Committee D-2 of the American Society for Testing Materials, the Society of Automotive Engineers, and American Petroleum Institute dealing also with petroleum and petroleum products.

National Lumber Manufacturers Association, Wilson Compton, secretary and manager, 1337 Connecticut Avenue, Washington, D. C. The activities of this association are largely concerned with problems which are national in scope, and in dealing with such problems it represents in a national way its affiliated associations, which include the American Walnut Manufacturers Association, Appalachian Hardwood Manufacturers, Inc., Maple Flooring Manufacturers Association, California Redwood Association, Hardwood Dimension Manufacturers Association, Mahogany Association, Inc., Northeastern Lumber Manufacturers Association, Northern Hemlock and Hardwood Manufacturers Association, Northern Pine Manufacturers Association, Southern Cypress Manufacturers Association, Southern Hardwood Producers, Inc., Southern Pine Association, Veneer Association, West Coast Lumbermen's Association, and Western Pine Association.

This association took an active part in the formulation of American lumber standards which have been promulgated as Simplified Practice Recommendation R16 by the National Bureau of Standards. The various regional and species associations and other agencies prepare and publish grading rules adapted to their respective species in accordance with these standards. The grading rules are then used for the grading of American lumber.

National Machine Tool Builders' Association, Tell Berna, general manager, 10525 Carnegie Avenue, Cleveland, Ohio. All of the standardization work in which this association is interested is carried on through the American Standards Association in cooperation with technical committees of the American Society of Mechanical Engineers and the Society of Automotive Engineers. In connection with these two organizations, this association is joint sponsor, under the auspices of the American Standards Association, for all projects covering standards for small tools and machine tool elements. Standards already developed as American standards under the joint sponsorship of these organizations include T-slots, their bolts, nuts, tongues, and cutters; tool holder shanks and tool post openings; nomenclature, diameters, and thicknesses of milling cutters; taps, cut and ground threads; rotating cylinders and adapters; jig bushings ; 
circular and dovetail forming tool blanks; chucks and chuck jaws for turret lathes and automatic lathes; adjustable adapters for multiple spindle drilling heads; twist drills, and straight shank; terminology and definitions for single-point cutting tools; and side bearing involute splines. It is also serving as joint sponsor with the National Conservation Bureau in the development of a safety code for machine tools covering operation of machine tools, including lathes, planers, drillers, shapers, slots, gear cutters, and milling machines.

It cooperated with the ASA sectional committee in the development of the American standard safety code for the use, care, and protection of abrasive wheels. This association is also officially represented on the ASA sectional committees concerned with the development of the following projects: standardization and unification of screw thread; ball and roller bearings; allowance and tolerances for cylindrical parts and limit gages; bolt, nut, and rivet proportions; classification and designation of surface qualities; and petroleum products and lubricants.

Through its Committee on Electrical Problems and with the cooperation of the National Electrical Manufacturers Association, this association is now engaged in drawing up a machine-tool electrical specification that will outline in detail the methods to be used in applying control and motors to machine tools. Its purpose is to supplement the National Electrical Code, which is intended primarily for the wiring of factories and residences, and will be submitted to the American Standards Association for adoption as an American standard.

National Municipal League, Howard P. Jones, secretary, 299 Broadway, New York, N. Y. Model laws are devised, published, and distributed by this organization and are intended to serve as standards and to stimulate uniformity in State, county, and city legislation. They include a model bond law, budget law, city charter (which provides the council-manager form of government), county manager law, election administration system, liquor law, model real property tax collection law, registration system, State civil service law, and model State constitution.

The organization of two important joint committees was initiated by this league. They are the National Committee on Municipal Standards and the National Committee on Municipal Reporting, and are made up of representatives of the National Municipal League, the Government Research Association, and the International City Managers' Association, the latter of the two committees having representatives also of the American Municipal Association.

The National Committee on Municipal Standards acts as an advisory body, the work being carried on by the International City Mangers' Association, the latter of the two committees having counting and reporting forms in various cities for measuring the results of street sanitation.

The National Committee on Municipal Reporting issued a report entitled Public Reporting, embodying specifications by which the clepartment head or chief executive in a city can prepare periodic or annual reports.

National Oak Flooring Manufacturers' Association, Inc., Ralph E. Hill, secretary, 830 Derman Building, Memphis, Tenn. Stand- 
ardization and simplification activities of this association are carried on by its Grading, Milling and Inspection Committee, whch has been functioning for more than 30 years.

This association has adopted official rules on oak, birch, beech, hard maple, and pecan flooring, which cover in detail the grades and sizes of quartered and plain sawn stock. It cooperated with the National Bureau of Standards in the establishment of Commercial Standard CS56-41 covering grading rules for white and red oak flooring, which was promulgated and published by that Bureau; also with the Federal Specifications Executive Committee in the formulation of the Federal specification for hardwood flooring, which includes references to the grading rules of this association for oak, birch, beech, and hard maple flooring.

This association maintains a rigid supervision of species, manufacture, kiln drying, bundling, and all other features pertaining to oak, birch, beech, and hard maple so that the integrity of its sizes and grades will be maintained. The use of the association's registered trade name "NOFMA" has been granted to all of its members whose stock of oak flooring has been found to comply with the association's official grading rules. It also maintains a reinspection service available for the retail dealers who purchase products of member companies, so that, in the event there is doubt concerning the quality of stock bought, a reinspection may be had and the matter settled immediately. The label which is applied to bundles of oak flooring carries with it the following wording: "This oak flooring is guaranteed and marked for grade by the manufacturer, is inspected and certified by the National Oak Flooring Manufacturers' Association to meet all requirements of Commercial Standard CS56-41 as issued by the National Bureau of Standards of the United States Department of Commerce."

National Paint, Varnish and Lacquer Association, Inc., Henry A. Gardner, director, Scientific Section (also director, Institute of Paint and Varnish Research), 1500 Rhode Island Avenue NW., Washington, D. C. This association cooperates with the National Bureau of Standards on research problems, and with the Federal Specifications Executive Committee in preparing specifications for paints and varnish.

During the past 30 years the association has issued over 700 publications relating to its researches, including several voltumes. It has also issued a textbook of methods for the physical and chemical examination of paint products. The methods given in this book have become more or less standard in the industry.

The association is represented on the American Society for Testing Materials' committee dealing with the development of specifications for paint, varnish, lacquer, and related products; and on the Sectional Committee on Specifications for Sieves for Testing Purposes, functioning under the procedure of the Americand Standards Association.

National Paperboard Association, H. S. Adler, secretary, 80 East Jackson Boulevard, Chicago, Ill. The only standardization activity conducted by this association up to the present time has been in connection with the development of standard gage lists for box board and container boards, together with rules and regulations 
governing them. The standard gage lists, Nos. 1 to 8, for box board are identical with Simplified Practice Recommendation R44-36 covering box board thicknesses, promulgated by the National Bureau of Standards.

National Paving Brick Association, W. H. Cullimore, engineersecretary, National Press Building, Washington, D. C. This associaton initiated the movement which resulted in the development of Simplified Practice Recommendation No. 1 for paving brick, which was promulgated and published by the National Bureau of Standards. It has for the past 20 years made a regular annual survey of the paving brick industry, with a view to further simplification of varieties and sizes of paving brick.

The association is represented on the Committee on Manufactured Masonry of the American Society for Testing Materials, and in this connection assisted in drafting specifications for paving brick which were issued by that society. It is also represented on the ASTM Committee on Road and Paving Materials.

In order to assist municipal engineers in the proper utilization of vitrified paving brick as a paving material, this association adopted the specifications of the American Public Works Association for vitrified brick paving, and the specifications of the American Association of State Highway Officials for bituminous filled brick pavements. Members of this association cooperated with the Federal Specifications Executive Committee in the formulation and revision of Federal specifications covering paving brick. The association cooperates also with the Highway Research Board of the National Research Council in connection with projects relating to design, road types, and fillers for brick and block paving.

National Petroleum Association, Fayette B. Dow, general counsel, Munsey Building, Washington, D. C. This association has a Department of Standards and Tests, which has organized groups in all of the refining centers in which the members are located. Its purpose is to call attention to the lack of uniform results in testing and to bring about greater uniformity by the distribution of samples of the same oils to the member laboratories. These samples are tested and the results forwarded to the association's headquarters, where they are tabulated, identified by a number, and sent out as a bulletin to the members. Each member is informed as to the test of its laboratory and is therefore in a position to compare the results.

This association in its early history undertook and promulgated certain specifications in cooperation with the American Society for Testing Materials, the American Standards Association, the Society of Automotive Engineers, the American Society of Mechanical Engineers, the American Petroleum Institute, and other similar organizations. This association established color standards. Through its members, it is represented on the Technical Committee and Subcommittees on Petroleum Products and Lubricants, functioning under the auspices of the American Society for Testing Materials and on similar committees under the procedure of the American Standards Association.

National Photographic Dealers Association (Inc.), H. O. Bodine, executive secretary, Time-Life Building, Radio City, 9 Rockefeller Plaza, New York, N. Y. The only work in standardization which 
this association is carrying on at the present time is in connection with the development of specifications for photographic apparatus and materials. In this connection, it is cooperating with four subcommittees of the American Standards Association's Sectional Committee on Photography, Z38, dealing with exposing equipment, processing equipment, printing and projection equipment, and processing.

National Preservers Association, Inc., W. Lowe Walde, managing director, 839 Seventeenth Street NW., Washington, D. C. Definitions and standards for fruits preserves, jams, jellies, and fruit butters were officially published by the Food and Drug Administration. to be effective December 5, 1940. These standards are in principle identical with Federal Specifications for the above mentioned products. The preserve manufacturing industry operates under Rules of Fair Trade Practice issued by the Federal Trade Commission. These rules also incorporate the essential features of the Food and Drug standards for products of this industry. This association cooperated with the National Bureau of Standards in the establishment of Simplified Practice Recommendation R91 for standard sizes of glass containers.

National Ready Mixed Concrete Association, V. P. Ahearn, executive secretary, and Stanton Walker, director of engineering, Munsey Building, Washington, D. C. Much of the standardization work of this association is carried on in cooperation with committees of technical organizations.

At the present time the association maintains a Technical Problems Committee, a subsidiary committee known as the Standards Committee, and a committee subordinate to the latter on truck mixers and agitators. This latter committee has established tentative standards for operation of truck mixers and agitators, and is now engaged in developing testing procedure for measuring the mixing efficiency of concrete truck mixers, procedure for sampling concrete from a truck mixer or an agitator, and development of certain minimum standards applicable to the manufacturer of the equipment.

The association is represented on technical committees of the American Society for Testing Materials dealing with subjects relating to concrete and concrete aggregates, lime and lime products; and mortars for unit masonry. It also cooperates with the American Concrete Institute, American Public Works Association, and other bodies on problems relating to ready-mixed concrete.

Although not directly related to the subject of standardization, this association has issued publications which are important from the point of view of mixing concrete as, for example, estimating quantities for concrete, and the proportioning of concrete for strength, durability, and impermeability.

National Research Council, Ross G. Harrison, chairman, 2101 Constitution Avenue, Washington, D. C. The council is a cooperative organization of the scientific men of America. Its members include, however, not only scientific and technical men and engineers, but also businessmen interested in the utilization of science in industry. The council was established in 1916 by the National Academy of Sciences, and is supported by the cooperation of the major scientific and technical societies of the country. The membership of the coun- 
cil is composed largely of appointed representatives of some 88 of these societies, and includes representatives also of certain other research organizations, representatives of government scientific bureaus, and a limited number of members at large, numbering about 240 in all. These members receive their appointments from the president of the National Academy of Sciences.

Under its present organization, the work of administration of the council is carried on by a small group of officers and an Executive Board, with an Administrative Committee which acts for the Board between its annual meetings. The council itself is composed of nine major divisions arranged in two groups. One group comprises seven divisions of science and technology representing, respectively, physics, mathematics, and astronomy; engineering and industrial research; chemistry and chemical technology; geology and geography; the medical sciences; biology and agriculture; and anthropology and psychology. The other group comprises two divisions of general relations, representing foreign relations and educational relations. With these divisions are associated various technical committees, appointed to take charge of projects undertaken by the council. There are certain other committees, administrative and technical, which affiliate directly with the Executive Board of the council. The library of the council, a limited collection of directories and source books in science, is available for reference services insofar as its facilities extend.

The council has issued numerous publications both in its own series of Bulletins (105) and Reprints and Circulars (109), and also commercially. Among these are the "International Critical Tables of Numerical Data, Physics, Chemistry, and Technology" ( 7 volumes and index); a treatise on the "Physics of the Earth" (8 volumes and one in preparation); a series of monographs on current problems in the physical sciences, a "Glossary of Physical Terms," and several bibliographies.

The council is the cooperating agency in the United States for the editing of the "Annual Tables of Constants and Numerical Data of Chemistry, Physics, Biology, and Technology." At intervals during the past twenty years the council has issued a directory of "Industrial Research Laboratories of the United States," of which the seventh edition (NRC Bulletin 104, 1940) lists 2,264 such institutions; also a "Handbook of Scientific Societies of the United States and Canada" (third edition, NRC Bulletin 101, 1937; fourth edition in preparation). Other publications prepared by committees of the council include: "Ring Index: a List of Ring Systems Used in Organic Chemistry" (1940), prepared in cooperation with the American Chemical Society; and a treatise on "Measurement of Radiant Energy" (1937). In 1941 the council completed a survey of the development of scientific research in American industry, undertaken at the request of the National Resources Committee (National Resources Planning Board), which has been published by the Government Printing Office, "Research-A National Resource: 2. Industrial Research" (1940).

Work of the several divisions of the council depends upon the determination of scientific standards and has contributed also to the establishment of these standards, directly and through the sup- 
port of fundamental researches in the basic sciences. These investigational programs have included among other topics: hydrodynamics, optical properties of plastics, "fatigue" in metals, electrical insulation, heat transmission, test codes for thermal insulation at different ranges, welding research, highway planning, construction and management, traffic signs, safety codes for brakes and brake testing, ceramics, catalysis, photochemistry, low temperature scales, eutectic diagrams of ammonium salts, thermodynamic data for chemical industries, terminology of inorganic, organic, and biological chemistry, scientific results of drilling, gravity measurements, field data of earthquakes, meteorological observations and records of precipitation, sea-level determinations, geological color charts, density currents, measurement of geologic time, sedimentation, stratigraphy, the chemistry and physiology of narcotic drugs, blood grouping and agglutination tests, medico-legal problems, case registries of pathology, military medicine, biological stains, nutrition of animals and of man, biological nomenclature, genetics, intelligence tests, classification and vocational tests, tests for selection and training of aircraft pilots, food habits, racial characters, etc.

The Division of Engineering and Industrial Research is organized particularly to coordinate research interests of the engineering professions through representation of a number of engineering societies. Through contacts with international scientific organizations, including membership in the international Unions afiiliated with the International Council of Scientific Unions, the National Research Council is in touch with various movements for the coordination of scientific work.

The council cooperates with the American Standards Association, and with other American organizations in the definition of electrical terms and electrical and magnetic units, the testing and classification of coal and coke, the standardization of library work and documentation, and the coordination of investigations on corrosion, and with the Advisory Council of the Board of Surveys and Maps of the Federal Government.

National Restaurant Association, F. J. Wiffler, secretary, 666 Lake Shore Drive, Chicago, Ill. A standard system for record keeping for restaurants has been approved by this association, including standard accounts. It has also formulated a model law, and has sponsored its adoption by States and cities, covering the regulation of sanitary conditions in restaurants and other public eating places. This association took an active part in establishing standard sizes of cafeteria and restaurant chinaware under the auspices of the National Bureau of Standards. These sizes are set forth in Simplified Practice Recommendation R33 promulgated by the United States Department of Commerce. It also cooperated in the formulation of a Simplified Practice Recommendation relative to standard sizes of restaurant guest checks.

National Retail Dry Goods Association, Lew Hahn, general manager, 101 West Thirty-first Street, New York, N. Y. This association, through its Committee on Standards, takes an active part in the formulation of standards and specifications relative to retail 
store organization, retail systems, retail trade terminology, business practices, and specifications for commodities used in the trade.

In carrying forward this work, the association cooperates actively with the National Bureau of Standards and the American Standards Association and other technical and trade organizations. This association initiated programs for the establishment of Simplified Practice Recommendations covering set-up for paper boxes, folding paper boxes, corrugated-fiber boxes, and notion and millinery paper bags, under the auspices of the National Bureau of Standards. During the past year it cooperated with the Bureau in the revision of these Recommendations which are designated as R126, R127, R128, and R129. It also cooperated in the development of Simplified Practice Recommendation $\mathrm{R} 177$ relating to single-phase corrugated board-rolls.

In collaboration also with the National Bureau of Standards, it assisted in the development of Commercial Standards CS62-38 for colors for kitchen accessories, and CS63-38 for colors for bathroom accessories; also in the establishment of Commercial Standards CS59-41 for woven dress fabrics (testing and reporting), and CS3937 for wool and part-wool blankets. This latter Standard defines the terms used to describe the fiber content of blankets, if represented in any way to be made wholly or in part of wool; regulates the sizes of type to be used in describing the fiber content of part-wool blankets; provides methods of test for determining the percentage by weight of the total fiber content represented by wool fibers therein in cases where the buyer and seller do not agree on method; and illustrates the manner by which manufacturers and distributors may guarantee compliance with the Commercial Standard.

This organization is a member body of the American Standards Association, and participates actively in the work of several of the committees functioning under its procedure. It is officially represented on the Sectional Committee on Standards and Specifications for Refrigerators. It is also represented on the ASA Advisory Committee on Ultimate Consumer Goods and its various subcommittees in connection with standardization problems relating to consumer goods.

National Retail Hardware Association, Rivers Peterson, managing director, 333 North Pennsylvania Street, Indianapolis, Ind. For a number of years this association has cooperated with other organizations under the auspices of the National Bureau of Standards in establishing lists of standard stock sizes and varieties of hardware items. These activities have resulted in the adoption by industry of Simplified Practice Recommendations covering files, rasps, paint and varnish brushes, cut tacks and small cut nails, loaded paper shot shells, builders' hardware, woven-wire fence, shovels, garden hose, and forged tools, all of which have been promulgated and published by the National Bureau of Standards. Within its own particular field it has done much in the simplifying of retail hardware accounting practices, budget operation, control of stocks, improvement of store equipment, and the reduction of duplications and other forms of waste elimination.

The association is officially represented on the Sectional Com. mittee on Standards and Specifications for Refrigerators, function. 
ing under the procedure of the American Standards Association.

National Safety Council, W. H. Cameron, managing director, 20 North Wacker Drive, Chicago, Illinois. The purpose of this organization is the conservation of human life through a continuous campaign of accident prevention and the promotion of industrial health. It promotes industrial, public, and home safety chiefly through the gathering and distribution of information about the causes of accidents and methods for their prevention. The council investigates and compares methods of making mechanical equipment safer and of protecting those who use it; precautions in using hazardous devices, materials and processes; and develops programs for stimulating interest in safety.

In cooperation with other organizations the council takes part in the standardization work of the American Standards Association. It is sponsor or joint sponsor for the following projects which have been or are being developed under ASA procedure: Standardization of methods of recording and compiling accident statistics; safety code for paper and pulp mills; textile safety code; code for identification of gas mask canisters; safety code for window cleaning; scheme for the identification of piping systems; safety code for floor and wall openings, railings and toe boards; safety in the construction industry; safety code for power presses and foot and hand presses; safety code for forging and hot-metal stamping; safety code for rubber mill machinery; safety code for construction, care and use of ladders; safety code for compressed air machinery and equipment; performance requirements for protecting occupational footwear; safety code for walking surfaces; and specifications for accident prevention signs. In addition, it is officially represented on approximately 50 ASA sectional committees in preparing standards on various subjects in connection with safety of individuals or the use of equipment and devices.

The council has prepared and issued 150 safe and health practices pamphlets which provide safety engineering and industrial health reference material.

A number of important pieces of scientific research have been completed by the council within the past few years. These include such subjects as the hazards of benzol, spray coating, the effects of annealing chains, and others.

National Sand and Gravel Association, V. P. Ahearn, executive secretary, and Stanton Walker, director of engineering, Munsey Building, Washington, D. C. This association has a number of technical committees carrying on work in simplification and standardization, among which the following may be named: The Research Committee, Standards Committee, and the Committee on Gravel Ballast.

In general, this association does not prepare and issue standards, but it does cooperate actively with committees of national organizations in developing standards and specifications issued by these bodies. In this connection, the association is represented on technical committees of the American Society for Testing Materials dealing with development of specifications for concrete and concrete aggregates, and for road and paving materials. It is also officially represented on the Sectional Committees on specifications for Plaster- 
ing, Buildings Code Requirements and Good Practice Recommendations for Masonry, and Specifications for Sieves for Testing Purposes, functioning under the procedure of the American Standards Association. In addition, the association is represented on the Joint Technical Committee of Mineral Aggregate Associations, which is made up of representatives of the National Crushed Stone Association, the National Slag Association, and the National Sand and Gravel Association. The purpose of this committee is to coordinate the technical intelligence of the three associations on problems of mutual interest to the mineral aggregates industry.

The association has prepared and issued loose-leaf data sheets covering summaries of State highway specifications for sand and gravel for concrete pavement construction; physical requirements for sieves for testing purposes; tables of quantities of materials for concrete; specifications for fine and coarse aggregate for concrete; determination of clay and silt in sand; and requirements for filter sand, sand for sheet asphalt, filter gravel, and glass sand.

Through a joint committee composed of representatives of the National Slag Association, the National Crushed Stone Association, and this Association, a simplification program was initiated under the auspices of the National Bureau of Standards which resulted in the establishment of Simplified Practice Recommendations R147-33 on wire diameters for mineral aggregate production screens and R.163-39 on coarse aggregates (crushed stone, gravel, and slag).

National Scale Men's Association, Harry Mayer, president, in care of Chicago and Northwestern Railway, Chicago, Ill. This organization is composed of approximately 400 technical men engaged in the design, production, installation, maintenance, testing, and operation of weighing machines.

It has organized fourteen committees which are assigned to study and to develop certain phases of the scale industry, including the development of standards and specifications covering railway and industrial track scales; highway vehicle scales; built-in, self-contained, and portable scales; counter scales; grain scales, automatic and hand-operated scales; automatic indicating and recording railway and industrial scales, automatic indicating and recording scales, other than large-capacity; pits and foundations; weighing practices, scales used for transportation and labor charges; weighing practices, scales used for purposes of barter; corrosion prevention; construction materials; and welding and heat treatment.

This association has adopted specifications for overhauling and repair of heavy capacity scales; light industrial service track scales; railway track-scale test weight cars; standard code of rules relating to maintenance and transportation of track scale test weight cars; and a definition of a standard test of a railway track scale.

The standards and codes which have been adopted by the association have received the indorsement of the National Conference on Weights and Measures and the American Railway Engineering Association.

National School Supplies and Equipment Association, L. E. Parmenter, executive secretary, Palmer House, Chicago, Ill. The simplification of school supplies constitutes an important function of this association. It initiated programs for the simplification of 
sizes of composition blackboard, and folding and portable wooden chairs, which resulted in the establishment of Simplified Practice Recommendations R75 and R80, respectively, which were promulgated and published by the National Bureau of Standards. It also initiated, under the auspices of the National Bureau of Standards, the program for a simplified list of standard colors for school furniture which resulted in the establishment of Simplified Practice Recommendation R111.

This association has inaugurated a certification and labeling program whereby all janitor supplies used in schools will be properly labeled as conforming to certain standards promulgated and adopted by the association. The manufacturers or distributors of janitor supplies may submit samples of their regular janitor supply products to the association for certification purposes. These samples are tested in the laboratory of the association. When the samples tested conform to the different standards established, quality labels are issued and the companies are privileged to use the certification seals. The association also makes use of labels to identify school furniture complying in color with the Simplified Practice Recommendation referred to above.

National Sign Association (Inc.), Orville J. Grisier, secretary, 729 Broadway, Denver, Colo. The Standardization Committee of this association has devoted its efforts through the past year to building up a standardization of paint colors, to be approved by the association which will serve as a useful purpose to firms who furnish paint for the use of sign companies.

The Legal and Ordinance Committee of this organization is endeavoring to formulate a model recommended ordinance for cities for the purpose of bringing about standardization in sign advertising. In carrying forward this work, the association is cooperating with the Outdoor Advertising Association, the National Electric Manufacturers Association, and the American Standards Association. Plans are also under way in the development of a method of standardization of colors used in fluorescent tubing.

National Slag Association, H. J. Love, managing director, Earle Building, Washington, D. C. This association has one technical committee which is known as the Problems Committee, consisting of 12 technical men of the mineral aggregates industry. The duties of this committee are to keep informed as to technical and other developments affecting the use of slag, and knowledge concerning its qualities and adaptability to useful purposes. It also determines in what particulars and directions the knowledge and proof of the character and qualities of slag for use in various types of construction is lacking, and from this outlines programs of investigation and test.

In connection with its research activities, this association maintains a laboratory at Bessemer, $\mathrm{Pa}$., where research investigations developed and approved by the Problems Committee may be executed under the supervision of the association's director of research. Investigations completed or in progress include studies of bituminous mixtures incorporating various types of aggregates, concrete and concrete aggregates, and durability studies as measured by artificial and natural freezing and thawing methods. Through its laboratory, 
the association has in the past cooperated, and continues its collaboration, with other laboratories in cooperative research programs and interpretation of resulting data, to the end that aggregate materials and products incorporating them may be improved, standardized, and satisfactory specifications governing their use established.

Members of the Problems Committee maintain representation on technical committees of various national organizations, such as the American Society for Testing Materials, American Concrete Institute, Association of Asphalt Paving Technologists, American Standards Association, and others. In addition, the association has two members representing it, together with the National Crushed Stone Association and the National Sand and Gravel Association, on the Joint Technical Committee of Mineral Aggregates Associations. The purpose of this committee is to coordinate the technical intelligence of the three associations on problems of mutual interest to the mineral aggregates industry as a whole.

The association is also officially represented on the Sectional Committees on Specifications for Sieves for Testing Purposes, and on Building Code Requirements and Good Practice Recommendations for Masonry, functioning under the procedure of the American Standards Association.

Through a joint committee composed of representatives of the National Crushed Stone Association, the National Sand and Gravel Association, and this Association, simplification programs were initiated under the auspices of the National Bureau of Standards, which resulted in the establishment of Simplified Practice Recommendations R147-33 on wire diameters for mineral aggregate production screens, and R163-39 on coarse aggregates (crushed stone, gravel, and slag).

This association cooperates actively with the Federal Specifications Executive Committee in the formulation and revision of Federal specifications covering aggregate specifications for Portland cement concrete, bituminous concrete and macadam, railway ballast, sewage trickle filter media, and for other types of construction required by the Federal Government.

National Slate Association, W. S. Hays, secretary, 325 East Fiftyseventh Street, New York, N. Y. Standard specifications have been formulated and adopted by this association covering the use of slate for fioors, terraces, walks, and roofs. These specifications are in the form in which they may be incorporated into architects' specifications or made the subject of construction contracts, and include requirements on metal work, weight, and laying of felt, laying of slate, etc.

This association cooperated with the National Bureau of Standards in simplification activities which resulted in the establishment of standard sizes of structural slate for plumbing and sanitary purposes, roofing slate, and blackboard slate, promulgated and published as Simplified Practice Recommendations by the National Bureau of Standards.

The association is represented on the Sectional Committees on Safety Code for Cranes, Derricks, and Hoists; and on Minimum Requirements for Plumbing and Standardization of Plumbing Equipment, functioning under the procedure of the American Standards Association. 
National Soybean Processors Association, Edward J. Dies, presiident, 3818 Board of Trade Building, Chicago, Ill. Standardization of quantity and grades of soybean oil and development of standard grading rules constitute important activities of this association. Upon recommendation of its Finished Materials Standards Committee this association adopted standard specifications for crude domestic soybean oil covering quality, grade, and methods of analysis. These specifications are made a part of the trading rules of this association relative to the purchase and sale of soybean oil. In addition to the trading rules already referred to, the Trading Rules Committee also developed rules to govern the purchase and sale of soybean oil meal.

The association's Soybean Grades and Contracts Committee is currently cooperating with the Agricultural Marketing Service, United States Department of Agriculture, in seeing that fair and just grades for soybeans are established by the United States Department of Agriculture and other bodies, so that equal protection is afforded to buyer and seller.

National Supply and Machinery Distributo:s Association, Henry R. Rinehart, secretary-treasurer; George A. Fernley, secretary, 505 Arch Street, Philadelphia, $\mathrm{Pa}$. One of the important functions of this association in the field of simplification has been its cooperation with other organizations and members of industry in establishing simplified lists of standard sizes and varieties of hardware items and machinery supplies which are set forth in several Simplified Practice Recommendations promulgated and published by the National Bureau of Standards.

National Terra Cotta Society, J. J. Carney, secretary, 2 West Forty-fifth Street, New York, N. Y. This organization cooperated with the American Institute of Architects in formulating standard specifications for the manufacture, furnishing, and setting of terra cotta. In its volume entitled Terra Cotta-Standard Construction, the society has included, among other things, 67 large-scale plates relating to typical architectural details for the purpose of assisting architects and engineers in drawing up specifications concerning the proper use of terra cotta. The society has also prepared technical standards relating to strength and absorption of architectural terra cotta.

National Terrazzo and Mosaic Association (Inc.), Theodore L. Medford, executive secretary, 1420 New York Avenue NW., Washington, D. C. This organization's work in the field of standardization has led to the development of terrazzo construction standards covering floors, bases and shower stalls, stair construction, door trim and window stool, wainscots and partitions. This association has also prepared and published specifications for terrazzo work and for mosaics. At the present time, it is engaged in making a study of the qualities and characteristics of the aggregates used in the industry, with the aim of establishing a standard set of tests and requirements for the producers and marketers of this material.

National Tuberculosis Association, H. E. Kleinschmidt, director, Health Education, 1790 Broadway, New York, N. Y. The Committee on Diagnostic Standards, the personnel of which is made up of members of the American Trudeau Society and this association, has revised and issued the 1940 edition of Diagnostic Standards 
and Classification of Tuberculosis. These standards are generally used as a guide throughout the country by tuberculosis sanatoria, tuberculosis specialists, and medical schools. Another committee of this association, in cooperation with a similar committee of the American Sanitarium Association (now American Trudeau Society) has adopted basic standards in connection with equipment, staff personnel, and administration of the tuberculosis sanatoria and hospitals throughout the United States.

National Warm Air Heating and Air Conditioning Association, George Boeddener, managing director, 145 Public Square, Cleveland, Ohio. Through several research and technical committees, this association devotes much of its time in the development of codes relating to heating and air conditioning. For the past 20 years the Research and Advisory Committee of this association has carried on research and engineering work on a cooperative basis with the Engineering Experiment Station of the University of Illinois. The information which has been developed has brought about a greater efficiency in the standards of installation, design, and construction of both gravity and forced warm air heating, with the result that the public is now enjoying greater comfort, convenience, and economy.

The Installation Codes Committee has correlated the information developed through research and engineering and has prepared and published standard codes in the name of the association covering gravity heating and practical and technical codes relative to forced warm air heating.

A new booklet entitled Yardstick for Evaluation of a Forced Warm Air Heating System is now available, which covers standards of installation of forced warm air heating systems as well as setting up minimum standards covering quality of equipment to be used.

The association has recently organized a Committee on Elimination of Waste for the purpose of eliminating unnecessary sizes of registers, furnace pipe and fittings, and furnaces, and in the estabiishment of standard stock sizes. The association is officially represented on the sectional committee dealing with the development of a ventilation code, functioning under the procedure of the American Standards Association.

National Wholesale Hardware Association of the United States, George A. Fernley, secretary, 505 Arch Street, Philadelphia, Pa. This organization of wholesale distributors has cooperated with other units of industry in the establishment of Simplified Practice Recommendations covering standard sizes and varieties of sheet steel, flashlight cases, insectide and fungicide packages, hacksaw blades, shovels, spades, scoops, loaded paper shot shells, terneplate, and eaves trough and conductor pipe, which were promulgated and published by the National Bureau of Standards. It initiated the movements which resulted in the formulation of the Simplified Practice Recommendations for the last three projects enumerated above.

National Wooden Box Association, C. D. Hudson, manager, 308 Barr Building, Washington, D. C. The activities of this organization in the field of simplification deal with the fabrication of wooden cases used for packing canned foods and vegetables.

This association cooperated with the National Bureau of Standards in establishing a simplified list of stock sizes of wooden boxes for 
canned fruit and vegetables, which resulted in the formulation of simplified practice recommendation R171-38. It also cooperates with the Freight Container Bureau of the Association of American Railroads in the formulation of specifications for fruit and vegetable containers.

The Specification Division of this association is currently engaged in developing specifications covering boxes and crates used for the shipments of fruits and vegetables from West Coast origins.

Natural Gasoline Association of America, William F. Lowe, secretary, 923 Kennedy Building, Tulsa, Okla. This association is an organization composed of natural gasoline manufacturers and affiliated interests. Its chief aim is to protect and advance the interests of the industry which it represents. In carrying forward its work in the field of standardization, it cooperates closely with the American Society for Testing Materials; American Gas Association, Bureau of Explosives, Society of Automotive Engineers, National Bureau of Standards, and other technical bodies.

This association has developed specifications and testing methods for commercial propane and butane which cover composition in terms of vapor pressure and end point, total sulfur and moisture in case of propane. With reference to butane, the specifications cover vapor pressure, end point, total sulfur content and entrained water. It has also developed and adopted official specifications and methods of sampling and testing for natural gasoline covering six grades.

New England Council, Dudley Harmon, executive vice-president, Statler Building, Boston, Mass. Since 1926, the council has carried forward a farm marketing program to encourage producers to grade and pack their products according to official State standards, and to identify them by means of quality labels placed on the containers in which the goods are packed. In making this program effective, the commissioner of agriculture in each of the six States has been granted legislative authority to establish and promulgate voluntary grades and standards for farm products. Several such grades are now in use in each State. The commissioner of agriculture has also been given the authority to adopt a suitable label for identifying such products graded and packed according to established standards. The New England quality label has been adopted by each of the six States.

In establishing official grades and standards for farm products, conferences are held by the commissioner of agriculture with groups of producers who are especially interested in the products for which grades and standards are to be adopted. At these conferences tentative standards and descriptive terms are freely discussed before final adoption. An attempt is made to keep the grade names, requirements, and descriptive terms as uniform as possible in all New England States, and in harmony with the recommendations of the Federal Government. Before the adopted grades and standards can become effective, they must be advertised in the press according to the law requirements of the States. Permission to use the New England quality label must be obtained from the Commissioner of Agriculture, and it may only be used on goods packed in accordance with official State grades. To protect the reputation of the quality 
label, each State department of agriculture maintains an inspection service with trained field men whose duties are to examine graded and labeled products to determine whether or not they comply with the necessary requirements.

New York Produce Exchange, Lloyd V. Juan, secretary, 2 Broadway, New York, N. Y. This exchange has, throughout its existence of many years, adopted and maintained standards of quality of various commodities dealt in by its members and the rules governing their transactions. These include vegetable oils, waxes and fats, prime crude soybean oil, black pepper, animal oils and fats, tallow, cottonseed products, flour, grains, etc. The official methods adopted by the American Oil Chemists Society are employed in grading, analyzing, testing for color and cold test in cottonseed oils and in testing animal and vegetable oils; and in the absence of prescribed or adequate methods, those of the Association of Official Agricultural Chemists constitute the official procedure. The methods of the American Association of Cereal Chemists are official for flour. The United States Department of Agriculture standards and methods are used in grain grading and testing.

For many years the New York Produce Exchange Grain Inspection Department certificates have been recognized throughout the markets of the world, particularly in the United Kingdom and Continental terminal points, and, as such, have been a guarantee to foreign buyers as to the quality of the grain as exported from North America.

While the exchange is not a future market for grain such as wheat, rye, oats, etc., it is the center of export activity from North America and well above 90 percent of all such grain exported from either the United States or Canada reaches in some way the members of this exchange for the making of contracts, the booking of cargo space, and the arranging for credits and transfer of documents.

Non-Ferrous Hot Water Tank Manufacturers Association, Inc., F. Richmond Fletcher, 75 Federal Street, Boston, Mass. As a result of laboratory studies conducted by this association, and upon observations of field performance of hot-water tanks in service over a long period of years under different conditions of installation and operation, it adopted specifications for nonferrous range boilers and hot-water tanks used for storing water under street pressure.

Members of this association are at the present time engaged in a simplification program in an effort to reduce the number of sizes of boilers regularly carried in stock. This project when completed will be submitted to the National Bureau of Standards for development into a Simplified Practice Recommendation.

Non-Ferrous Ingot Metal Institute, R. D. T. Hollowell, secretary, 308 West Washington Street, Chicago, Ill. This institute's technical program relative to the development of standards and specifications covering ingot brass and bronze is directed by its Metallurgists' Advisory Committee, which is composed of the chief metallurgists of all member companies. In carrying forward this work, the institute cooperates with the American Society for Testing Materials through representation on the latter's technical committee dealing with the development of specifications for copper base alloys in ingot form.

In order to assist those interested in nonferrous foundry alloys to utilize quality copper base alloys in ingot form with maximum econ- 
omv and efficiency, this institute has prepared and published a manual entitled Ingot Brass and Bronze. This manual contains specifications issued by the institute and those which have been approved and adopted by various organized technical societies and governmental agencies.

For the past 10 years, the institute has maintained a research associate at the National Bureau of Standards for the purpose of checking the factors of impurities on alloys.

Northeastern Lumber Manufacturers Association, Inc., R. E. Broderick, secretary, 271 Madison Avenue, New York, N. Y. The lumber industry represented by this association is confined for the most part to the northeastern section of the United States. Through its Standardization and Inspection Committee, this association has adopted standard grading rules for northern white pine, Norway pine, eastern spruce, and balsam fir. These species of lumber are manufactured and graded in conformity with American lumber standards which are set forth in the current edition of Simplified Practice Recommendation R16, promulgated and published by the National Bureau of Standards, except as trade demands require otherwise or as may be stipulated between buyer and seller. In all cases, grade definitions and sizes that do not conform to American lumber standards are plainly marked as follows, thus (*).

It cooperated with other lumber organizations under the auspices of the National Bureau of Standards, in the establishment of Commercial Standard CS74-39 providing for two classes of solid hardwood wall paneling.

This association sponsored the grade-marking of northeastern softwood lumber and set up the necessary machinery whereby lumber graded in accordance with the rules of this association may be grade marked. In carrying forward this program, a standard license agreement is entered into between certified member mills and the association. Mill numbers are assigned by the association to each member which appear with the mark. The identity of each mill is known only to, and kept confidential by, the association.

Northern Hemlock and Hardwood Manufacturers Association, O. T. Swan, secretary, Oshkosh, Wis. This association has a committee designated as the Bureau of Grades which deals with standards in lumber grading rules, standard sizes, association inspection and claim work. Through the work of this committee, the association has adopted standard grading rules and sizes for northern hemlock and tamarack, and also rules for the grading of northern white cedar shingles. In 1941 this association adopted and published grading rules to cover northern white pine, Norway pine, and northern spruce. It has also adopted the hardwood grading rules of the $\mathrm{Na}$ tional Hardwood Lumber Association to cover its production in northern hardwoods, including hard and soft maple, birch, baswood, hard and soft elm, oak, beech, and minor hardwoods. This association"s softwood rules comply with American lumber standards which were developed in cooperation with the Central Committee on Lumber Standards, and set forth in the current edition of Simplified Practice Recommendation R16, promulgated and published by the National Bureau of Standards.

This association has adopted and published in its 1941 issue of its grading rules a set of stress grades for softwoods, as suggested by 
the Federal Housing Administration and the United States Forest Products Laboratory, under descriptions such that a strength rating can be given to each grade.

It has cooperated with the Federal Housing Administration in various proposals made with respect to grades and inspection.

The committee is considering various problems connected with association branding and grade-marking of standard lumber which has long been a feature of its association's standardization activities. A complete set of marks has been adopted and are now being used by the association for the purpose of identifying the grades of northern hemlock and northern white pine manufactured in the Lake States. These marks identify lumber graded under the Northern Hemlock and Hardwood Manufacturers Association supervision, and in accordance with its published official grading rules and other rules for the grading of northern lumber adopted and used by the association. These marks are copyrighted trade-marks and can be placed on lumber only by an association inspector, or by an operator who has executed the specific licensing agreement and whose grading practices are under regular periodic inspection by the association's Bureau of Grades. These marks show specie identification, the grade of the lumber to which the mark has been applied, and an identification by means of the license number of the mill that manufactured and graded the lumber. Further, the association has adopted a system of certificates whereby the manufacturer, by the use of "manufacturers certificates" endeavors to further protect purchasers and consumers against deception by showing on the certificate the detail of the inspection report covering the contents of the car. These certificates are enclosed in an official association envelope, designed for use with such certificates, and are placed in the car containing the shipment when the tallying and loading have been completed. These certificates are used for hemlock, hardwood, and pine lumber shipments, and are registered as to serial numbers in the association office so that a shipper of any particular consignment can be readily identified. The privilege of using this association car-card shipment plan likewise is provided for by a licensing agreement, and mills executing the association licensing agreement, and whose inspection has been approved by the association's Bureau of Grades, may grade-mark and issue shipper's certificates. The association inspectors will make original inspections and issue a certificate or place the association brand and mark on lumber for either members or nonmembers, and will make reinspections of lumber for either members or nonmembers in order to adjust misunderstandings or claims. The association license covering these activities by a manufacturer (who may have the periodical association lumber inspection check-up, and who is found competent in manufacture and grading) is available to any lumber manufacturer or concentrating yard in Wisconsin, Michigan, or Minnesota. The license is revocable after a hearing whenever the association finds that the licensee is not maintaining the standards.

Northern Pine Manufacturers' Association, W. A. Ellinger, secretary, 4438 Wentworth Avenue, Minneapolis, Minn. Simplification and standardization activities of this association are carried on by a committee known as the Bureau of Grades, which is charged with 
the duty of establishing standard grades for the products of its members. This association has adopted standard grading rules for northern white pine, Norway pine, jack pine, eastern spruce, western white spruce, balsam, tamarack, and aspen lumber. These grading rules are in harmony with American lumber standards, in the formulation of which this association took an active part in cooperation with the Central Committee on Lumber Standards.

Oil Burner Institute (Inc.), C. F. Curtin, secretary, 30 Rockefeller Plaza, New York, N. Y. This institute was formed to foster the interests of the oil burner industry. Recognizing the need for standards for the guidance of manufacturers, distributors, installing contractors, and users, the industry authorized the formation of a Standards Committee to consider the subject.

Following a series of industry-wide meetings for the development of standards for mechanical draft oil burners, the industry's Standards Committee and the institute requested the cooperation of the National Bureau of Standards in formulating a standard which resulted in the establishment of Commercial Standard CS75-39 for automatic mechanical draft oil burners designed for domestic installations. This standard sets forth minimum standard specifications and methods of test for automatic mechanical draft oil burners. It includes also requirements for the issuance of a certificate by the installer which is posted after installation. This certificate is the guarantee or affidavit to the ultimate consumer that the installation complies with the minimum standards given in the Commercial Standard.

In order that purchasers of oil burners may become familiar with the significance of minimum standard requirements and tests, as a basis for fair competition and improved confidence in oil burner performance, the Commercial Standard recommends the use of a statement by manufacturers to be included in warranties, labels, invoices, contracts, and sales literature to the effect that the manufacturer certifies the oil burner to be in accordance with Commercial Standard CS75-39. The statement bears the seal of the official inspection agency of the oil burner industry evidencing compliance therewith.

This institute also cooperates with the American Standards Association on several projects. It is officially represented on ASA sectional committees dealing with allowance and tolerances for cylindrical parts and limit gages, specifications for pressure and vacuum gages, ventilation code, and petroleum products and lubricants.

Open Steel Flooring Institute, Inc., Stuart J. Swensson, secretarytreasurer, 903 American Bank Building, Pittsburgh, Pa. All matters pertaining to standardization of products of the industry are handled by the institute's Standardization Committee. This institute has approved and adopted the committee's specifications for steel grating. It has also adopted the safe load and deflection table for grating, which is set forth in Federal Specification RR-G-661a covering steel floor gratings.

Optical Society of America, K. S. Gibson, president, National Bureau of Standards, Washington, D. C. The standardization and specification work of this society is handled entirely by technical committees which have already published reports in the society's journal on visual sensitometry; colorimetry; photometry; standard 
wavelengths; nomenclature and standards; photographic standards of intensity; geometrical, physiological, and physical optics; photochemistry and photography; radiometry; and spectrophotometry.

The society is sponsor for the Sectional Committee on Photography functioning under the procedure of the American Standards Association; and is also represented on ASA sectional committees dealing with standards for motion pictures, and specifications and methods of test for safety glass. In addition, it maintains representation on committees or boards of the American Institute of Physics, National Research Council, American Association for the Advancement of Science, United States National Committee of the International Commission on Illumination, American National Committee on International Congresses on Photography, and InterSociety Color Council.

Packaging Machinery Manufacturers Institute, Inc., H. L. Stratton, secretary, 342 Madison Avenue, New York, N. Y. This institute is concerned primarily with technical phases of packaging by automatic equipment, through the exchange of interindustry information. The institute does not issue standards but does through several committees engage in work leading to simplification and standardization.

It maintains the Committee on Standards which is part of a joint committee of divisions of the Packaging Institute. The function of this committee is to consider matters of packaging technique and packaging problems.

Through its Committee on Glass Packaging Problems, the institute is cooperating with several organizations on ways to improve glass packaging by the elimination of certain difficulties in handling glass without detriment to the consumer.

This institute was represented on a committee of the Packaging Institute which cooperated with the Federal Government in the formulation of a standard plan for cartoning collapsible tubes under the Food, Drug, and Cosmetic Act.

Painting and Decorating Contractors of America, G. S. Stuart, secretary, Brown Building, Philadelphia, Pa. One of the stated objects of this organization is its effort to protect members and the general public by endeavoring to maintain a high standard of workmanship in the application of painting and decorating service.

This association maintains a Specifications Committee whose purpose is to make studies in connection with the development of standards and specifications relative to painting and decorating. This committee has prepared standard painting specifications as a basis for the proper use and application of material used in the painting industry. These specifications cover methods and quality of materials to be used in connection with exterior and interior painting as apply to concrete, brick, stucco, stone, shingle roofs and sidings, wood floors, plaster walls, and wood trim.

Paper Bag Manufacturers Institute, J. A. C. Kavanagh, secretary, 369 Lexington Avenue, New York, N. Y. This organization took an active part, through members of the industry which it represents, in the establishment of standards for capacity of self-opening grocers' bags, square grocers' bags, and flat grocers' bags. These minimum cubic capacities were established under the auspices of the National Bureau of Standards and are set forth in Simplified Practice Recommendation R42, promulgated and published by the Bureau. 
This industry, because of economic changes and greater competition, has realized the need for a broader base of product standardization. In this connection, the institute has undertaken a survey of grocers' bags standards. In an effort to indicate the extent to which the industry's product varies, the institute has compiled and analyzed some 3,000 bags from 33 different markets. This information is being submitted to the National Bureau of Standards for use in revising the Simplified Practice Recommendation referred to above.

Paper Stationery and Tablet Manufacturers Association, Inc., Edgar P. Eaton, executive secretary, 527 Fifth Avenue, New York, N. Y. Through its Committee on Standardization and Simplification of Products, this association has adopted recommended standards for tablets, loose-leaf notebook fillers, composition and memorandum books, and similar items. These standards cover recommended sizes of goods, both wire-bound and not wire-bound. The committee is at the present time conducting further investigation to determine whether or not recommended sizes thus far established can be further simplified and standardized.

Pipe Fabrication Institute, R. Kennedy Hanson, president-commissioner, 1108 Clark Building, Pittsburgh, Pa. The activities of this institute in the field of standardization are carried on in cooperation with the American Standards Association, the American Society of Mechanical Engineers, the American Society for Testing Materials, and other technical engineering bodies. Through its members, this institute is officially represented on technical committees of the organizations mentioned above. The institute has adopted standard specifications for power piping recommended as minimum requirements for a safe, economical, and commercial installation. These specifications have been prepared as a guide for framing actual specifications for an installation job, and cover the conditions ordinarily encountered in power-plant piping.

Plain Washer Manufacturers' Association, Eugene Caldwell, secretary, 2100 South Bay Street, Milwaukee, Wis. Although this association maintains no standing committee on standardization, much of the work in this field is done at regular association meetings, at which the entire membership is present.

This association has developed standard lists of stock items covering washer sizes and tolerances. These refer to sizes and diameters for plain washers, light steel washers, plain timber-construction washers, riveting washers, regular plain washers, round flat washers (steel, brass, and iron), formed washers (countersunk type), hardened spring tension washers, lock washers (spring, shake-proof, external, and internal types), and steel expansion plugs.

It cooperated with the National Bureau of Standards in the establishment of Simplified Practice Recommendation for the Packaging of Carriage, Machine, and Lag Bolts. It is officially represented on the Sectional Committee on the Standardization of Plain and Lock Washers, functioning under the procedure of the American Standards Association.

Porcelain Enamel Institute, Inc., Charles S. Pearce, managing director, 612 N. Michigan Avenue, Chicago, Ill. This institute represents the porcelain enameling industry, and numbers in its member- 
ship those plants engaged in contract or job enameling; manufacturers of table tops and breakfast sets, signs, architectural panels, reflectors; suppliers of enameling iron and steel sheets, chemicals, oxides, plant equipment, and porcelain enamel frits. Its purpose is to promote porcelain enamel as a finish for metal products in both old and new fields. To this end, it maintains a technical division devoted to research on all phases of manufacture and performance of the material. The entire technical division of the institute is known as the Product Standards Section. Under this main section is the Committee on Standardization of Tests for Products. Special subcommittees are appointed to work on various test projects, results of which are printed in pamphlet form as standards or tentative standards for the industry.

The institute maintains a research associate at the National $\mathrm{Bu}$ reau of Standards and a technical director at the Ohio State University on research and studies of porcelain enamel. Subjects which have been studied, or are being studied at the present time, include acid resistance, abrasion resistance, opacity, ball mill practice, screen testing, sag resistance of metals, chipping resistance, weathering, color matching, proper design of metal parts, cast iron enameling, caulking compounds, and patching materials.

A special Architectural Committee has been established in the interest of furthering the industry's market for architectural parts. It has recently developed a standard contract for the purchase of porcelain enameled parts for building purposes, and a standard specification covering such parts. It has been of service to the engineers of the various government projects in specifying and recommending proper porcelain enamel standards and installation methods covering signs, reflectors, and building interiors and exteriors. Work carried on at the National Bureau of Standards on weathering, color matching, and caulking compounds is closely related to the work of this committee.

The Table-Top Division of this institute has prepared and issued specifications for first quality tops for breakfast sets, dinette sets, kitchen tables, and kitchen cabinets.

A special program of standardization has recently been organized by the institute's members in the frit division to promulgate a standard, together with an identifying label or seal of approval, for the porcelain enamel finish on the exterior and interior of refrigerator cabinets. This group has worked very closely with the National Bureau of Standards in drafting a proposed Commercial Standard.

Portland Cement Association, 33 West Grand Avenue, Chicago, III. Standardization work of this association is carried on mainly in cooperation with certain technical organizations through representation on their committees.

The association does not of itself develop standards or specifications, but it does issue recommended or suggested specifications on what it believes to be good practice. These include proposed recommended practice for the manufacture of concrete building block and tile; specification for cement-bound macadam pavement; construction of concrete sidewalks; concrete shore protection; specification and special provisions for soil-cement and concrete for airport, road, and street pavement; concrete structures for flood control (soil and water con- 
servation); concrete floor finishes; and concrete for industrial buildings and garages.

It has prepared and issued suggested specifications for concrete walks, architectural concrete, driveways, aprons, terraces, porch floors, and retaining and garden walls; cast-in-place concrete basement walls, floors and footings; concrete footings and reinforced concrete masonry walls; concrete masonry chimneys and fireplaces; concrete stairs and steps; concrete flat roof construction and applying firesafe coverings on pitched roofs; applying finishes and coverings on concrete residence floors; interior wall and ceiling finishes; application of portland cement paint on exposed concrete masonry walls; concrete footings and concrete masonry walls; portland cement stucco on concrete masonry walls; and precast joist concrete floors with cast-in-place concrete slab.

In addition, the association has also issued a plasterers' manual; and publications dealing with concrete for industrial buildings and garages; design, manufacture, and driving of concrete piles; and design and control of concrete mixtures.

In its standardization work with other technical bodies, the association cooperates with committees of the American Concrete Institute on research and other phases covering the various uses of concrete; with the American Public Works Association on specifications for cement concrete pavements; with the American Railway Engineering Association on roadway, ballast, and masonry; with the American Road Builders' Association on roadway surfaces, pavement joists, and motor-vehicle transportation; with the American Society of Agricultural Engineers on specifications for building materials and structures; with the American Transit Engineering Association on ways and structures; and with the American Water Works Association on the joint administration and collection of water and sewer accounts.

The association also cooperates actively with the American Society for Testing Materials on projects dealing with the development of standard specifications and methods of test for cement, drain tile, concrete and concrete aggregates, mortars for unit masonry, concrete pipe, manufactured masonry units, road and paving materials, and fire tests of materials and construction.

Its cooperative efforts with other organizations, through representation on sectional committees, functioning under the procedure of the American Standards Association, cover projects for the establishment of American standards relating to building code requirements and good practice recommendations for masonry, plastering, building-code requirements for excavations and foundations, safety code for grandstands, sieves for testing purposes, and coordination of dimensions of building materials and equipment.

Its activities with the Highway Research Board of the National Research Council include the development of projects on methods of handling and placing concrete in highway construction, warping of concrete pavements, crack filling and sealing of expansion joints in concrete pavements, and maintenance equipment.

By means of representation on the Joint Committee on Standard Specifications for Concrete and Reinforced Concrete, consisting of $201072^{\circ}-41-13$ 
affiliated committees of severai organizations, the Portland Cement Association cooperated in the preparation and publication of a report on Recommended Practice and Standard Specifications for Concrete and Reinforced Concrete.

Poultry Equipment Association, H. L. Ashworth, executive secretary, 125 East Wells Street, Milwaukee, Wis. This association has developed a uniform schedule of capacity ratings for poultry equipment which was adopted by the members of this association during the past year. These ratings include standard capacity of electric brooders, capacities of coal, oil, or gas brooders, and fountains of the vacuum and float types.

Radio Manufacturers Association, Bond Geddes, general manager, 1317 F Street NW., Washington, D. C. Work in connection with the development of standards in the radio field is carried on by the Engineering Department of this association. Under the jurisdiction of this department function a number of sections and their committees dealing with various engineering subjects in the radio field. These committees initiate and conduct the technical and standardization work of the association.

Material for standardization may be proposed by any of the committees after which the proposed material is circulated to the association membership as a "standards proposal" to secure comment and criticism. Such comments and criticisms are collected and submitted to the General Standards Committee in meeting with the original proposal. The General Standards Committee acting as a judicial body determines, from examination of the comments, if the item is suitable for standardization. If so it becomes an RMA standard or an RMA recommended practice and is published in the RMA Handbook of Standards and Engineering Information.

Standards or recommended practices which have been developed by the engineering committees and adopted by the association cover general subjects such as terms, nomenclature, and definitions; tests and test methods; general standards and definitions for radio receivers; component parts; acoustical devices; phonograph amplifiers; automotive radio equipment; vacuum tubes; and facsimile televison.

The Data Bureau of the RMA Engineering Department serves as a clearing house for receiving tube standardization and assignment of type numbers as well as the coordination of other matters. The National Television System Committee, now incorporated within the structure of the RMA Engineering Department, conducts studies on the system aspect of television and is expected to make recommendations or improvements and developments from time to time.

Committees of this association cooperate, as the occasion arises, with similar committees of the Institute of Radio Engineers, on certain joint committees with the National Electrical Manufacturers Association and the Edison Electric Institute, and with the Underwriters' Laboratories in the formulation of standards for power operated radio receiving appliances. Liaisons are maintained with the National Association of Broadcasters and the Society of Automotive Engineers.

The association is officially represented on sectional committees functioning under the procedure of the American Standards Association in connection with the development of American standards 
covering the following projects: Classification and designation of surface qualities, radio, electrical measuring instruments, standardization of vacuum tubes for industrial purposes, radio-electrical coordination, and acoustical measurements and terminology. It is also represented on technical committees of the American Society for Testing Materials dealing with plastics and electrical insulating materials.

Rail Steel Bar Association, H. P. Bigler, director, 228 North La Salle Street, Chicago, Ill. For approximately two years the member mills of this association have followed a certification plan by which deformed rail steel reinforcing bars are marked with a permanently rolled symbol. This symbol is evidence of manufacture by a member of the association and designates the material as rail steel rolled in accordance with the general standards of the industry and meeting the requirements of the association for quality. The symbol further indicates a willingness to certify to this quality. As now operating, certification is made on a basis of the requirements of any one of the following standards, all of which are in substantial agreement: American Society for Testing Materials specification A16-35 for rail-steel concrete reinforcement bars; Federal Specification QQ-B71a and specification G31-1938 of the Canadian Engineering Standards Association on the same subject. Policing of quality is performed by general tests by the association's committee on metallurgy and by routine tests by the individual mill's inspection departments, as well as by routine inspection customarily required by the consumer. The association has engaged in or has been sponsor for several cooperative research projects with other technical groups. These include studies at University of Delaware, Iowa State College, and an extensive study of the use of rail steel for highway construction by the National Research Council.

The association cooperates by official representation with the technical committee on steel of the American Society for Testing Materials in the development and standard specifications covering steel and steel products. It has also been represented on the several building code committees of the American Concrete Institute, on the Joint Committee on Concrete and Reinforced Concrete, and similar organizations.

Railway and Industrial Spring Association, C. R. Ould, secretary, Room 1401, 30 Church Street, New York, N. Y. The members of this association comprise manufacturers of springs of all descriptions for use on both steam and electric railways in the United States. This association maintains a Technical Committee whose duty is to give consideration to standardization of springs for railway equipment; to investigate all the merits of alloy and special steel to determine their value in the manufacture of springs; and to the testing of various new coatings applied to springs for the purpose of resisting corrosion. This committee does not issue publications on the results obtained from their investigations, but it does cooperate with technical committees of the Association of American Railroads and the American Society for Testing Materials. The standards and specifications developed by these agencies relating to springs and spring material become the adopted standards of this association for use by its members in the manufacture of springs. 
Railway Tie Association, Roy M. Edmonds, secretary, 903 Syndicate Trust Building, St. Louis, Mo. Several of the main objects of this association are with reference to standardization of cross ties, collection and dissemination of statistics concerning cross ties, proper methods and practices in preventing forest fires, and preservation and conservation of forests and forest products in the several States of the Union.

Through work of its Committee on Specifications and Inspection, this association at its last annual meeting adopted specifications for cross and switch ties, and specifications for narrow-gage cross ties and switch ties. This association is continuing its efforts in developing additional standards for the products of the industry which it represents.

Red Cedar Shingle Bureau, W. W. Woodbridge, Secretary Manager, G. A. Brewer, assistant manager, White Building, Seattle, Wash. At the request of this bureau, a general conference of representative manufacturers, distributors, and users of red cedar shingles was called in 1931 under the auspices of the National Bureau of Standards, following which there was adopted a Commercial Standard for this commodity. At the request of the groups at interest, the standard was later revised to include California redwood and tidewater red cypress shingles, and issued as Commercial Standard for wood shingles CS31-33. It was revised in 1938 and accepted and approved for promulgation by the National Bureau of Standards. This standard covers No. 1 grade shingles.

In order that interest may be increased in the manufacture, sale and use of high-grade shingles, and consumers may be protected on the basis of quality, the Red Cedar Shingle Bureau inaugurated a certification program. In accordance with this program, the bureau has developed a quality label which manufacturers place on bundles of No. 1 grade of red-cedar shingles with a statement of guarantee that the shingles meet all the quality requirements of the commercial standard. In addition, the bureau maintains a corps of trained inspectors who visit the plants at irregular intervals to check on the quality of shingles. Failure on the part of producers to comply with the requirements of the Commercial Standard will mean the loss of the right to use the labels until satisfactory adjustment has been made. Labels are also issued and placed on bundles of shingles for No. 2 and No. 3 grades which are indicated in plain figures on the labels, and carry statements that the shingles are guaranteed to meet all quality requirements of the respective grades, as shown in current grading and packing rules of the Red Cedar Shingle Bureau.

Resistance Welder Manufacturers Association, George A. Fernley, secretary, 505 Arch Street, Philadelphia, $\mathrm{Pa}$. The development of standards and specifications of this association is carried on by subcommittees which are appointed from time to time. This association has developed standard specifications for spot, butt, flash, seam, and press welders. It has also developed and adopted standard specifications for replaceable resistance welding tips, Morse No. 1 and No. 2. These cover pointed, dome, flat, and offset tips.

Through the work of subcommittees standards have also been prepared for seam welding electrodes and standard specifications covering transformers for resistance welding. A table covering the class- 
ification of comparative alloys and their minimum requirements, together with a memorandum covering their recommended uses, has also been prepared.

A committee of this association is at the present time working on a table covering recommended electrode materials for spot welding similar and dissimilar metals. Another committee is cooperating with the American Welding Society in the development of standard nomenclature on welding.

Rice Millers' Association, W. M. Reid, executive vice president, P. O. Box 1289, New Orleans, La. This association has promulgated rules governing transactions in rice that include uniform specifications regarding weights, terms of payment, rates of brokerage, methods and manner of arbitration, packaging requirements, etc. It has prescribed forms of sales contracts for use in the rice trade in the United States, in Cuba, and Puerto Rico. The association adopted and uses standards for milled rice promulgated by the United States Department of Agriculture. The standards are the basis for the inspection service in issuance of certificates as to grades which are carried on by this association.

Rolled Gold Platers' Association, W. A. Cunningham, secretary, in care of Horton Angell Company, Attleboro, Mass. This association, in cooperation with the New England Manufacturing Jewelers' and Silversmiths' Association, initiated the development of a commercial standard for marking gold filled and rolled gold plate articles other than watchcases. This resulted in the establishment of Commercial Standard CS47-34 which was promulgated and published by the National Bureau of Standards.

In order that consumers may become familiar with the significance of quality marks, all gold covered articles conforming to Commercial Standard CS47-34 may be accompanied by a certificate, tag, card, or other label stating that the article so marked for quality is guaranteed to be in strict accordance with the provisions of the Commercial Standard.

Rubber Manufacturers Association (Inc.), R. H. Goebel, secretary, 444 Madison Avenue, New York, N. Y. For a number of years this association has devoted considerable time in cooperative work with organizations in developing specifications covering a large variety of rubber products. It maintains technical committees whose duty it is to prepare customers specifications for tires, rubber and canvas footwear, mechanical rubber goods, rubberized materials, and a number of other products.

The Tire Manufacturers Division of this association cooperates with the Tire and Rim Association in the development of standard combination of tire tube sizes.

The Mechanical Rubber Goods Specification Committee has prepared and adopted standard specifications for wrapped and braided water hose, and transmission belts.

Through several of its other committees, this association cooperates with the National Bureau of Standards in the establishment of Commercial Standards for cotton cloth for rubber and pyroxylin coating, rubber sheeting, and surgeons' rubber and latex gloves.

In addition, technical committees of this association participate in the formulation and revision of many Federal specifications covering mechanical rubber goods and rubber products. 
The Simplification Committee, organized by members of the Tire Division of the association and several manufacturers of truck tires, who represent a considerable proportion of total industry output, have eliminated wrapping of all truck tires as part of industry's simplification and conservation program in the interest of national defense. This committee has also eliminated approximately 40 percent of the individual items in all lines of passenger tires below the " 100 " level, and has effected a consolidation of truck solid and cushion tire lines, the reduction of unnecessary passenger mud and snow tire lines, the combination of high pressure and balloon truck and bus tubes, and many other "cut-the-waste" programs. At present, the Simplification Committee is cooperating with the Agricultural Tire Simplification Committee, composed of representatives of the leading farm equipment manufacturers and agricultural tire suppliers, in reducing the number of unnecessary sizes and types of tires. Other active programs relating to the reduction of unpopular sizes being carried on by the association involve studies of all existing truck tire sizes, industrial tires, and airplane tires.

This association cooperated with the American Standards Association in the development of American standards specifications for cotton rubber-lined fire hose, for public and private fire department use. It is officially represented on the ASA sectional committee dealing with development of standards for the inspection of motor vehicles.

Safe Manufacturers National Association, A. O. Boniface, executive secretary, 366 Madison Avenue, New York, N. Y. This association has formulated and adopted specifications for fire-insulated safes, fire-insulated cabinets, fire-insulated filing devices, fire-insulated vault doors, file-storage-room doors, burglary-resistive chests, and robbery-resistive containers. The test requirements for fireinsulated safes are essentially similar to those which have been established by the National Bureau of Standards and Underwriters' Laboratories.

To safeguard the public against unwarranted claims as to the fire resistance and/or burglary resistance of products of the fire-resistive safe industry, members of the association use labels on their products. The label on a fire-insulated product is a certification by the manufacturer that that design has been shown by test to comply with the specification and rating indicated on the label, and that the product has been shown by the manufacturer's inspection-in-course-of-manufacture to warrant the label attached thereto. Fire-resistance ratings are stated as the number of hours that the product was subjected to American standard time-temperature curve conditions, in a furnace, without failure. The label on a burglary or robbery-resistive product indicates compliance with the SMNA construction specification for the type (group) indicated on the label.

Safety Equipment Manufacturers Association, Inc., R. S. Armstrong, manager, 350 Madison Avenue, New York, N. Y. This association in cooperation with the National Bureau of Standards, initiated the development of commercial standards for automotive lighting and signaling equipment. This has resulted, to date, in the establishment of the following commercial standards, which were promulgated and published by the National Bureau of Standards: 
CS80-41 electric direction signal systems other than semaphore type for commercial and other vehicles subject to special motor vehicle laws (after market); CS81-41 adverse-weather lamps for vehicles (after market); CS82-41 inner-controlled spotlamps for vehicles (after market) ; CS83-41 clearance, marker and identification lamps for vehicles (after market); CS84-41 electric tail lamps for vehicles (after market); CS85-41 electric license-plate lamps for vehicles (after market) ; CS86-41 electric stop lamps for vehicles (after market) ; CS87-41 red electric warning lanterns; and CS88-41 liquidburning flares. Additional commercial standards for items of equipment not as yet covered are now pending or in the process of development.

In order to provide the purchaser with a ready means of distinguishing between lamps and signal equipment which meet the requirements of the commercial standards and those which do not, the association has adopted the following for labels or statements on cartons: "This (name of item) marked SEMA APPROVED is certified by the Safety Equipment Manufacturers Association and by the manufacturer as conforming to Commercial Standard (number of CS)."

Salt Producers Association, W. G. Wilcox, chairman, Standardization Committee, 154 Bagley Avenue, Detroit, Mich. This association's activities in the field of standardization are carried on by its Standardization Committee, which has been functioning for approximately 15 years. This committee has conducted surveys from time to time for the purpose of standardizing and simplifying the packages and packs used by the salt producers. Considerable work has been done in eliminating packs or packages which had become obsolete in the industry. A committee has also made a study of textiles used by the salt industry in its shipments, and has also made studies of the possibilities of using multiwall moisture-proof paper bags. Through extensive research work, a committee has also investigated the matter of standard package fill, using the most modern type of equipment therefor.

In cooperation with the National Bureau of Standards, this association initiated the movement for the elimination of unnecessary varieties and sizes of salt packages. This led to the establishment of a simplified schedule of sizes of packs originally set forth in Simplified Practice Recommendation R70, promulgated and published by the National Bureau of Standards. This Recommendation has recently been revised in order to bring it in conformity with current practices in the industry.

Sanitary Brass Institute, A. G. Zibell, chairman, Commercial Standards Committee, Kohler Co., Kohler, Wis. This organization, together with the Sanitary Cast Iron Enameled Ware Association and the Vitreous China Plumbing Fixtures Association, is cooperating with the Federal Specifications Executive Committee and the National Bureau of Standards in developing standards and specifications covering the products of this industry.

This institute has appointed a Commercial Standards Committee for the purpose of preparing standards covering sanitary cast brass items to be submitted under the auspices of the National Bureau of Standards for development into a Commercial Standard. 
Sanitary Cast Iron Enameled Ware Association, R. Kennedy Hanson, secretary, 1108 Clark Building, Pittsburgh, Pa. Two committees of this association, the Federal Specifications Committee and the Commercial Standards Committee, carry on work in the development of standards and specifications covering this industry's products. Through the Commercial Standards Committee, this association initiated the movement which led to the establishment of Commercial Standard CS77-40, providing minimum requirements for sanitary cast iron enamelware, including bath tubs, lavatories, kitchen sinks, laundry trays, drinking fountains, and similar fixtures. This standard was promulgated and published by the National Bureau of Standards.

The Federal Specifications Committee is cooperating with the Federal Specifications Executive Committee of the United States Government in the formulation of Federal specifications for cast iron enamelware purchased by various departments and establishments of the Federal Government.

Sanitary Institute of America, E. D. Szold, secretary, 105 West Monroe Street, Chicago, Ill. This organization has adopted specifications for the sale of wiping cloths which cover process of sterilization and grading. In addition, it also has adopted an official label, the presence of which on a bale of industrial wipers represents a guarantee that the contents of the bale conform to the specifications. The wording of the label reads as follows: "The wiping cloths contained in this bale or package have been produced and packed according to specification of the Sanitary Institute of America." Each member of the institute issues an affidavit certifying that he, as a manufacturer of the particular bale or package of wiping cloths, has complied with all rules and regulations of the State and city health departments along with the regulations of the board of underwriters and the city sealer. The manufacturer also certifies that the wipers contained in a given shipment are correct in weight, and that he has complied with all of the recommendations set down by the Sanitary Institute of America.

Concerning enforcement of specifications, label, and affidavit, the institute relies chiefly upon the integrity of its members, each of whom pledges himself to the institute's specifications upon becoming a member of the institute. A Complaints Committee investigates any alleged failure to conform. Violation of the pledge is punishable by expulsion from the institute, with attendant loss of the privilege of using the institute label. During the past year several committees of the institute have cooperated with technical committees of the Navy Department in preparation of specifications for purchase of wiping cloths for the United States Navy.

Scientific Apparatus Makers of America, John M. Roberts, president, Room 3014, 20 North Wacker Drive, Chicago, Ill. This organization has been one of the pioneer groups engaged in standardization, especially in the elimination of obsolete designs and useless sizes and shapes of apparatus. In carrying out its work, it cooperates with the American Chemical Society, the American Physical Society, the American Society for Testing Materials, and the National Bureau of Standards. 
The results of this organization's work in the field of standardization are published, not by itself, but by the organizations with which it cooperates. This organization is officially represented on the Sectional Committees on Electrical Measuring Instruments and on Specifications for Pressure and Vacuum Gages, functioning under the procedure of the American Standards Association.

Seamless Steel Tube Institute, C. G. Macdonald, secretary, Gulf Building, Pittsburgh, $\mathrm{Pa}$. This organization does not formulate standards or specifications, but it does maintain a Committee on Standardization and Simplification, whose function it is to keep the members of the institute informed as to changes in specifications for seamless tubular products (alloy and carbon steel) established by the American Society for Testing Materials, the American Society of Mechanical Engineers, the Association of American Railroads, and other technical bodies. These changes, as they affect the production or the physical standards or chemical analyses of products in which the members of this institute are concerned, are brought to their attention through publication of a book of specifications compiled by the institute, in which the specifications are kept up to date for the benefit of their own mills as well as for the benefit of their customers.

Shoe Lace Institute, L. K. Loomis, executive secretary, Box 45, East Side Station, Providence, R. I. This institute initiated the program for a simplification of lengths of braided shoe laces which was conducted under the auspices of the National Bureau of Standards. This resulted in the establishment of Simplified Practice Recommendation R168, in which are set forth a list of stock sizes of laces approved by the industry and promulgated and published by the National Bureau of Standards.

Society of Automotive Engineers (Inc.), John A. C. Warner, secretary and general manager, 29 West Thirty-ninth Street, New York, N. Y. Standardization has been a fundamental branch of the society's activities since the earliest days of its history.

The comprehensive structure of practical SAE standardization activity is the logical result of a sound growth begun in 1902 with adoption of standards by the National Association of Automobile Manufacturers that was organized in 1900. In 1903 the Association of Licensed Automobile Manufacturers was organized by manufacturers licensed under the Selden patent. The Mechanical Branch of the ALAM, organized in 1905 with restricted membership, gathered data exclusively for its members but a desire for a nonexclusive engineering body resulted in the organization of the Society of Automobile Engineers also in January 1905. In 1910 the Society took over from the Mechanical Branch of the ALAM its work of preparing technical data and appointed the first Standards Committee in the automotive industry. During the years immediately following, other industries began to use internal combustion engines more widely, and it became evident that the SAE was the logical body in which to centralize all such activities. In 1917 the American Society of Aeronautic Engineers and the Society of Tractor Engineers merged with the SAE and soon thereafter the National Association of Engine and Boat Manufacturers and the National Gas Engine Asspciation merged their engineering and standardization 
work in the SAE, and the Society of Automobile Engineers then became the Society of Automotive Engineers, Inc.

In 1926 the Society initiated standardization in automotive production engineering, and in 1931 adopted the first standardization in the motor transport field. As the regular manufacture of passenger car or "house" trailers became an established industry, the first trailer committee was organized in 1936 and the first trailer standards were adopted in 1938 .

SAE standardization, like the Society's general activities, extends into all industries manufacturing and employing internal combustion powered equipment and those furnishing the related accessory units, parts, and materials. These include motor vehicles, aircraft, tractors, industrial equipment, motorboats, and railroads and associated industries such as petroleum, steel and nonferrous metals, fabrics, protective materials, and many others.

The Society's standards are approved and adopted only on evidence of acceptability by the industry at large. Its organization and procedure as approved by the Council have consistently grown, and have been modified from time to time as experience and results have indicated was desirable.

Standardization projects are scheduled only on request from responsible sources in industry. A suggested project is referred to the proper committee or sometimes circularized generally for decision as to whether a standard is generally desired and would be of practical value. If the response is affirmative the project is assigned to the proper committee and data on current practices and requirements form the basis for a recommendation that may be further circularized as conditions may require. Before adoption and publication as a standard the recommendation must be reviewed and approved successively by the Division of the Standards Committee to which it was assigned, by the general Standards Committee, and finally by the Council.

The preparation of all standards is by producer and user representation, augmented by such other competent interests as may be helpful to insure general agreement on the standards and the broadest cooperation in their preparation.

The general organization for carrying on the Society's standards work is indicated under the SAE Standards Committee, the Sectional Committees, and SAE Representatives on Other Organizations and Committees. Special and Cooperating Committees of the Society are frequently appointed to prepare reports or recommendations on special assignments relating to standards or associated projects.

For many years the Society has cooperated in the American Standards Association on many national and international projects, and at the present time is a sponsor for ten Sectional Committees and is represented on 28 others that are concerned with broader but specific mechanical subjects. Sponsorship involves responsibility for the organization and administration of a committee and approval of its reports before their final approval by the American Standards Association, and publication.

The SAE Handbook is the official publication of the Society that contains the current standards and recommended practices adopted by the society, except aeronautic standards which are issued separately 
in loose-leaf form. New and revised standards and recommended practices issued during a current year are incorporated in the next annual edition. If a regular edition of the complete Handbook is not published due to unusual conditions, a supplement is generally issued that contains the then currently adopted revised and new standards.

Many of the SAE standards for aircraft give references to ArmyNavy (AN) Standards. The AN Standards are specifications for aircraft parts and materials that have been adopted in common by the Government air services, and many of which are used extensively in commercial aircraft. They include other requirements and data not given in the SAE specifications, which are adopted by the society primarily for use in designing, but conform as far as possible with AN specifications.

In 1938 and 1939 the rapid increase in production, the development of higher powered aircraft and the use of higher quality materials made a reduction desirable in the variety of specifications for materials used by manufacturers and Governmental air services. The Engine Technical Committee of the Aeronautical Chamber of Commerce of America appointed a Materials Committee to draft a series of specifications that would be used uniformly by the aircraft industry and associated material suppliers and the committee later recommended that the project be centralized in a recognized standardizing agency of the aircraft and associated materials industries.

Accordingly, the ACCA proposed that this work be undertaken by the Society of Automotive Engineers, and in response the SAE Council established the Aircraft Materials Division of the SAE Standards Committee in 1939, which took over the specifications drafted by the ACCA Committee up to then, and has since prepared additional ones.

In 1941, at the request of the Office of Production Management, the society undertook a comprehensive program of standardization in the field of aircraft powerplants and their accessories and propellers. An Aeronautics Division of the SAE Standards Committee was organized to direct this work. This division was given general responsibility for, and supervision of, all standardization activities of the society in the aircraft field.

The division's purpose is to prepare specifications for all classes of parts and materials used in aircraft, their engines and major accessory equipment and for methods, processes, and tests where such standards may be feasible. The specifications are coordinated so far as possible with existing SAE Standards for similar parts and materials, but because of the more specialized requirements for aircraft use, the specifications are complete enough for use in the purchase and acceptance of parts and materials.

These specifications, known as SAE Aeronautical Specifications, are published by the Society in bound sets or separately on $81 / 2$ by 11 sheets adapted to standard ring binders.

In cooperation with the Automobile Manufacturers Association and the American Petroleum Institute, the society maintains 13 research associates at the National Bureau of Standards working on problems dealing with motor fuel knock rating and fuel requirements of cars, and flow characteristics of aircraft fuel systems. 
Society of Motion Picture Engineers, Paul J. Larsen, secretary; Sylvan Harris, editor and office manager, Hotel Pennsylvania, New York, N. Y. Standardization of materials, supplies, and equipment used in the motion-picture industry constitutes an important activity of the society.

The society's work is carried on by a number of technical committees. The titles of these committees are indicated by the subjects considered by them which are as follows: Cinematography, color, exchange practice, laboratory practice, nontheatrical equipment, preservation of film sound, standards, studio lighting, television, and theatre engineering. Projects which are suitable for standardization are first approved by the society and then submitted to the sectional committee on motion pictures, functioning under the procedure of the American Standards Association, of which the society is sponsor. In this way the society maintains active cooperation with other leading interested technical or engineering organizations, manufacturers, distributors, and users of products used in the motion-picture industry.

More than 35 standards and recommended practices developed under the auspices of the ASA Sectional committee have been recently revised and approved as American standards or American recommended practices. These include specifications for sound and silent films, cutting and perforating negative and positive raw stock, projector sprockets, and American recommended practices relating to film splices, sensitometry, photographic density, projection rooms and screens, nomenclature for safety film, fader setting instructions, and nomenclature for filters.

The society, through the American Standards Association, cooperates with foreign standardizing bodies affiliated with the International Standards Association in the development of international motion picture standards.

Society of Naval Architects and Marine Engineers, J. H. King, secretary, 29 West Thirty-ninth Street, New York, N. Y. This society takes an active part in the standardization movement in cooperation with other interested organizations. Through representation on sectional committees functioning under the procedure of the American Standards Association, it cooperates in the development of standards covering the following projects: Minimum requirements for plumbing and standardization of plumbing equipment; standardization and unification of screw thread; allowance and tolerances for cylindrical parts and limit gages; pipe flanges and fittings; standardization of shafting; bolt, nut and rivet proportions; plain and lock washers; code for pressure piping; standardization of dimensions and materials of wrought iron and wrought steel pipe and tubing; specifications for pressure and vacuum gages; classification and designation of surface qualities; specifications for zinc coating of iron and steel; ventilation code; standards for drawings and drafting room practice (exclusive of architectural drawings); and methods of testing wood.

Society for the Promotion of Engineering Education, F. L. Bishop, secretary, University of Pittsburgh, Pittsburgh, Pa. Standardization activities of this society are carried on in cooperation with other organizations under the procedure of the American Standards Association. The society is joint sponsor for ASA sectional committees on letter symbols and abbreviations for science and engineering, 
and standards for drawings and drafting room practice (exclusive of architectural drawings). It is also officially represented on four ASA sectional committees dealing with the following projects: Definitions of electrical terms; electric and magnetic magnitudes and units; standards for graphic presentation; and graphical symbols and abbreviations for use on drawings.

Southern Cypress Manufacturers Association, B. R. Ellis, secretary, 721-24 Barnett National Bank Building, Jacksonville, Fla. This association has formulated and adopted standard specifications for grades of tidewater red cypress, which are in conformity with American lumber standards as set forth in the current edition of Simplified Practice Recommendation R16, and Commercial Standard CS92-41 for cedar, cypress, and redwood tank-stock lumber, promulgated and published by the National Bureau of Standards.

Recognizing the need for uniform marking and authoritative supervision of the marking of standard grades of red cypress lumber, this association has adopted standard grade marks. The insignia SCMA is the property of the Southern Cyress Manufacturers Association. Only licensed inspectors of this association or competent inspectors or manufacturers authorized by this association of officially grade-mark cypress, are permitted to place this mark on lumber. Lumber bearing this symbol is officially grade-marked. The appearance of official marks on planing mill products, such as flooring, ceiling, bevel siding, drop siding, etc., indicate an official grademark for that particular product of the planing mill.

Southern Hardwood Producers, Inc., Ed. R. Linn, secretary-manager, 805 Sterick Building, Memphis, Tenn. Southern hardwoods are graded under the rules of the National Hardwood Lumber Association, as are all hardwoods manufactured in the United States and Canada. This organization cooperates with the National Hardwood Lumber Association in grade standardization of hardwood lumber; also with Government agencies and all lumber associations in the development of American lumber standards fostered by the Department of Commerce.

This organization has also cooperated with the National Oak Flooring Manufacturers Association, and the Hardwood Dimension Manufacturers Association, in formulating Commercial Standards for flooring, trim, paneling, etc. These standards have been promulgated and issued by the National Bureau of Standards, United States Department of Commerce.

Southern Pine Inspection Bureau, A. S. Boisfontaine, secretary, Interstate Bank Building, New Orleans, La. This bureau is an autonomous agency of the Southern Pine Association and is considered the recognized agency in the southern pine industry for the formulation and maintenance of grading standards. For more than 25 years the Southern Pine Association has carried on a standardization program in developing grading rules for southern pine lumber. All of the grading rules prepared and published by the association have been adopted by the Southern Pine Inspection Bureau. These rules are in conformity with American lumber standards as set forth in the current edition of Simplified Practice Recommendation R16, which were promulgated and published by the National Bureau of Standards. 
The Southern Pine Association took an active part in cooperation with the Central Committee on Lumber Standards in the formulation of these standards. This bureau is officially represented on the Technical Comittee on Timber of the American Society for Testing Materials with reference to the preparation of standard specifications for timber and timber products.

It is the function of this bureau not only to maintain standards of size and definite grade classifications, as reflected in its published grading and inspection rules, for the benefit of the lumber-using public and of the industry, but to provide competent and adequate inspection facilities. These inspection facilities are universally regarded as fair and impartial, and are used not only as a means of adjudicating disputes as to grades between buyers and sellers, but also for the certification of southern pine lumber before shipment from the mill. The grading and manufacture of subscribers to the bureau are under the supervision of bureau inspectors, and those mills which prove their efficiency in grading and agree to maintain the established standards of size and grade are licensed to grade-mark their lumber with a bureau mark symbolizing such supervision and efficiency.

Southern Supply and Machinery Distributors' Association, Alvin M. Smith, secretary-treasurer, care of Smith-Courtney Co., Richmond, Va. As an organization of distributors, this association has participated in standardization projects carried out by industry in general, and it cooperated in the preparation and revision of Simplified Practice Recommendations promulgated by the National Bureau of Standards covering standard sizes of wrought-iron and wrought-steel pipe, valves, and fittings; standard packaging of carriage, machine, and lag bolts; and standard sizes of hacksaw blades.

This association is represented on the American Standards Association Sectional Committee on Standardization of Gears, which has already developed the American standard for spur-gear tooth form (B6.1-1932), and the American recommended practice for gear materials and blanks (B6.2-1933).

Special Tool, Die, and Machine Shop Institute (The Tool and Die Institute), George J. Huebner, secretary, 323 Fairmount-Cedar Building, Cleveland, Ohio. This organization, a national trade association, represents the contract builders of tools and gages, dies and molds, jigs and fixtures, special machines and accessories which, because of their nature, do not often lend themselves to standardization of design or construction. However, this same precision tooling is one of the important means by which the products of almost all mass production industries are standardized.

Through its monthly publication, The Tool and Die Journal, it disseminates information of technical value and interest to more than 15,000 firms and individuals who are charged with the responsibility for providing production tooling for mass production of parts and products in the stamping, plastics, die casting, forging, ceramics, rubber, and glass industries.

One of this association's activities which is being recognized as an effort to effectuate standardization is the development of a standard to predetermine the time required for machining and assembling the parts of a die. The method is described in its publication entitled 
"Die Designing and Estimating" of which the first edition has been sold and a second edition, enlarged and revised, is in the process of printing.

Another effort for standardization is the new publication entitled "Plastics Mold Designing," which is the first practical authoritative shop text on all sizes of mold making. A 100-term nomenclature of mold parts and processes, compiled with the assistance of 14 leading authorities, may definitely be considered a contribution toward standardization in behalf of the mold makers who supply the plastics industry.

Sporting Arms and Ammunition Manufacturers' Institute, C. S. Comeaux, secretary, 103 Park Avenue, New York, N. Y. Two cominittees of this organization are actively engaged in carrying on simplification and standardization work for the industry represented by this institute. The Committee on Simplified Practice, in cooperation with the National Bureau of Standards, initiated the movement which resulted in the establishment of Simplified Practice Recommendation R31 covering standard sizes of loaded paper shot shells. A similar movement for the development of a program for the eiimination of unnecessary varieties and sizes of metallic cartridges was also initiated by this committee which led to the establishment of Simplified Practice Recommendation R62 for metallic cartridges, promulgated and published by the National Bureau of Standards. Both of these recommendations have, through the efforts of this committee, been revised from time to time to keep them in harmony with improvements made by industry.

The activities of the Technical Committee in the field of standardization have been varied. Through this committee, the institute gives continuous attention to the establishment of maximum measurements for loaded paper shot shells and metallic cartridges, and minimum chamber dimensions for sporting arms in which these shells and cartridges are used. This committee has also carried on standardization on what are known as definitive proof loads for factory testing of shotguns, sporting rifles, pistols, and revolvers, thereby insuring greater safety to the users of such arms. Another activity of this committee is in developing standardization of ballistic test methods and equipment, and the formulation of specifications to aid in the preparation of such tests.

The Technical Committee cooperates closely with the Ordnance Department of the War Department in comnection with manufacturing, testing, and performance specifications covering ammunition of numerous calibers purchased by the Ordnance Department. This institute is officially represented on the Sectional Committee on Allowances and Tolerances for Cylindrical Parts and Limit Gages, functioning under the procedure of the American Standards Association.

Standard Container Manufacturers Association, Inc., Russell W. Bennett, secretary-manager, 311 W. Duval Street, Jacksonville, Fla. This association represents the veneer package industry of the southeastern part of the United States which is engaged in the manufacture of wooden boxes, crates, hampers, baskets, tubs, and tills. This association's activities in the field of standardization have led to the development of standard specifications for wooden 
containers for marketing fresh fruits and vegetables. These specifications establish standards of dimensions and design which admit a wide interchange of parts between containers for different commodities, and are embodied in the freight classification and tariffs of the southeastern railroads.

The association has also worked in close cooperation with the Bureau of Agricultural Economics of the United States Department of Agriculture, the Florida State Marketing Bureau, and with the Freight Container Bureau of the Association of American Railroads in the development of container standards, and in problem relating to marketing of perishable food products.

Steel Barrel Manufacturers Council, W. B. Thomas, secretary, Keith Building, Cleveland, Ohio. The manufacturing standards and practices of this industry are carried on by the council in cooperation with committees of technical organizations. It cooperates with the Bureau of Explosives of the Interstate Commerce Commission in the preparation of specifications for shipping containers for transportation of explosives and other dangerous articles. It also cooperates with the Federal Specifications Executive Committee in the formulation and revision of Federal specifications covering steel containers; and with the Consolidated Freight Classification Committee in the development of specifications relating to materials and construction of steel containers.

This organization initiated the movement for the development of standard sizes of steel barrels and drums, which resulted in the establishment of Simplified Practice Recommendation R20, under the auspices of the National Bureau of Standards.

Steel Founders' Society of America, Col. Merrill G. Baker, executive vice president, 920 Midland Building, Cleveland, Ohio. Through representation on committees of other organizations, this society cooperates in developing standards and specifications for materials used in products of the steel foundry industry. It cooperates with technical committees of the American Society for Testing Materials in the development of standards and methods of test for steel and steel products, metallography, on corrosion of iron and steel, and on radiographic testing.

Steel Heating Boiler Institute, R. A. Locke, manager, Middleton, $\mathrm{Pa}$. The Simplification and Standardization Committee of this institute drafted a proposed recommendation for steel horizontal fire-box heating boilers which was approved by a general conference of the industry and other interested groups. This proposal was submitted to the National Bureau of Standards, which resulted in the establishment of Simplified Practice Recommendation R157-37 and promulgated and published by the Bureau. In accordance with this Recommendation, the manufacturers of boilers whose products conform to this recommendation shall attach a cast or etched label to the boiler in a conspicuous location, which shall be worded as follows: "Conforms with the industry's Simplified Practice Recommendation R157-37 issued by the United States Department of Commerce."

Steel Joist Institute, James A. Schad, secretary, 201 North Wells Street, Chicago, Ill. Standardization activities of this institute are carried on by its Board of Directors with the aid of a Technical 
Committee, to which all matters relating to technical standards and specifications are referred for study and recommendations. During the past year, this institute has completed a revision of its Standard Specifications for Steel Joists, which cover materials, connections, methods of design and stresses, erection, etc.

A number of years ago, this institute developed and adopted a Code of Standard Practice, which is a part of every contract between members of the institute and purchasers of steel joists and accessories unless specific provision to the contrary is made.

This institute initiated the movement for the establishment of standard sizes of open-web steel joists, which resulted in the formulation of Simplified Practice Recommendation R94-30, promulgated and published by the National Bureau of Standards. In addition to setting forth the standard sizes of joists, this recommendation establishes specifications for properties and allowable total loads in pounds per linear foot of open-web steel joists.

More recently, this institute has been reviewing its standards for open-web nailer type steel joists, with a view toward cooperation with the National Bureau of Standards in the development of a Simplified Practice Recommendation pertaining thereto.

During the past year or so several members of the institute have cooperated with the National Bureau of Standards in having fire tests conducted to develop further data relative to fire-resistance ratings for steel joist construction.

The institute is officially represented on the Sectional Committee on Building Code Requirements for Iron and Steel, functioning under the procedure of the American Standards Association. In this connection, the institute has prepared suggested building regulations for steel joist construction which are being submitted to the American Standards Association Building Code Correlating Committee for approval as an American standard.

Steel Kitchen Cabinet Institute, S. S. Keeney, 1621 Euclid Avenue, Cleveland, Ohio. Because of the rapid development of the steel kitchen cabinet industry, and in order to protect the public and specifiers of steel kitchen cabinets against underweight steel, faulty or weak construction, inferior hardware, and cheap finishes, this institute embarked on a standardization and approval labeling program. Through its Standardization and Simplification Committee, the institute has been engaged for the past two years in setting up minimum standards of quality for the industry. In addition, it has adopted the committee's report with reference to approval requirements for steel kitchen cabinets and has also adopted a quality seal of approval.

The institute has engaged the services of a commercial testing laboratory to make tests of steel kitchen cabinets in accordance with the minimum standards established by the institute. Lines of cabinets which have been found to have met the requirements of the standards carry the institute's seal of approval, which indicates that production specimens have been tested and have met the approval requirements.

Steel Package Manufacturers Institute, W. B. Thomas, secretary, Keith Building, Cleveland, Ohio. Standardization work of this 
institute is carried on in cooperation with the Bureau of Explosives of the Association of American Railroads and the Interstate Commerce Commission in developing specifications for shipping containers for transportation of explosives and other dangerous articles. It also cooperates with the Consolidated Freight Classification Committee in formulating steel-container specifications relating to requirements on materials, construction, strength of parts, and marking and packing.

This institute also took an active part in the formulation of Federal specification for steel containers developed under the auspices of the Federal Specifications Executive Committee, and continues its cooperation in the revision of these specifications.

Stoker Manufacturers Association, Marc G. Bluth, secretary, 307 North Michigan Avenue, Chicago, Ill. The work in standardization carried on by this association is handled through its Engineering Committee, which is composed of chief engineers from several of its member companies. This committee is empowered and authorized by the association to undertake such studies on standardization as will help to simplify practice dealing with installation, ratings, and servicing of coal-burning stoker equipment. Codes formulated by the Engineering Committee and the Executive Committee of the association must have the unanimous approval of the entire membership of the association before they are officially adopted and published.

In cooperation with engineering and technical committees from other organizations, the Engineering Committee of this association formulated and adopted a uniform stoker rating code and a minimum setting heights code. In collaboration with the American Society of Heating and Ventilating Engineers and other heating trade organizations, a committee of this association prepared a standard code for testing stoker-fired steam-heating boilers, which was adopted and published by this association.

Structural Clay Products Institute, Harry C. Plummer, director of Engineering and Research, $1756 \mathrm{~K}$ Street NW., Washington, D. C. This institute cooperates actively with committees of technical organizations in the standardization of structural clay products. It is represented on technical committees of the American Society for Testing Materials dealing with fire tests of materials and construction; specifications for lime; mortars for unit masonry; and manufactured masonry units. It is also oflicially represented on sectional committees functioning under the procedure of the American Standards Association on Coordination of Building Materials and Equipment; and Building Code Requirements and Good Practice Recommendations for Masonry. The institute cooperates with the Federal Specifications Executive Committee in the formulation and revision of specifications for building brick, structural clay tile, and mortar, and is now collaborating with the National Bureau of Standards in bringing about a revision of Simplified Practice Recommendation $R 12$ covering standard sizes of hollow building tile (load bearing, partition, and floor tile).

The institute is conducting and sponsoring research at various universities on reinforced brick masonry under the sponsorship of the RBM Research Board, and at the National Bureau of Standards 
on wall properties covering strength, heat transmission, and permeability. While this work is not directed primarily toward standardization, it is providing data that will be of material assistance both in the development of specifications and in the standardization of products.

Sun Glass Institute, Inc., A. C. Boniface, executive secretary, 366 Madison Avenue, New York, N. Y. This organization, through its Committee on Standards, initiated the movement for the development of standards for sunglasses. This led to the establishment of Commerial Standards CS78-40 for ground and polished lenses for sunglasses, and CS79-40 for blown, drawn, and dropped lenses for sunglasses, both of which were promulgated and published by the National Bureau of Standards.

In accordance with these Standards, the institute has adopted a labeling program whereby members place on the sun glasses a label which states that the lenses have been tested and have been found to be at or above the minimum requirements of the Commercial Standard developed by the Sun Glass Institute, under the procedure of the National Bureau of Standards. The use of these labels is an aid to the public for identifying sunglass lenses (other than prescription lenses) which are of a grade suitable for protecting eyes against discomfort and fatigue in the presence of sun glare.

Tag Manufacturers Institute, Frank H. Baxter, executive director, 370 Lexington Avenue, New York, N. Y. Work of this institute in the field of standardization is under the supervision of its Technical Committee. During the past several years this committee, working with the members of the institute and other manufacturers, suppliers of materials and buyers, has conducted work which led to the development of specifications covering tag materials and sizes.

It has cooperated with the Federal Specifications Executive Committee in the formulation of Federal Specification UU-T-81b for paper and cloth tags; and with the National Bureau of Standards in the establishment and revision of Simplified Practice Recommendation R93-39 covering standard sizes and materials of paper shipping tags.

Tanners' Council of America, J. Louis Nelson, secretary, 100 Gold Street, New York, N. Y. This organization initiated the movement for a standardization of selling thicknesses for bag, case, and strap leather. This project was conducted under the auspices of the National Bureau of Standards, and led to the establishment of Commercial Standard CS34-31 which was promulgated and published by the Bureau. The upholstery leather division of this organization has prepared and adopted standard grades and specifications for upholstery leather which are regarded as the standards for use in the leather upholstery field.

Technical Association of the Pulp and Paper Industry, R. G. Macdonald, secretary, 122 East Forty-second Street, New York, N. Y. Several of the stated objects of this association are to promote investigation, research and interchange of ideas among its members, and to provide technical facts and standards fundamental to $\mathrm{pu}^{\mathrm{l}} \mathrm{p}$ and paper manufacture and use.

The association is divided into six divisions dealing with problems relating to engineering, pulp and paper manufacture, research de- 
velopment, testing, converting, and industrial. Under these divisions function a number of committees engaged in research and development of standards on projects coming within the scope of activities of each division.

Standards or specifications, recommended practices, and testing methods prepared by any committee are submitted to the Standards Committee for approval. The purpose of this latter committee is to establish regulations governing standards; to review and edit existing and proposed standards; and to coordinate standardization activities within the association and with other organizations.

All standards, recommended practices, and testing methods when so approved by the Standards Committee and the association in accordance with the prescribed rules and regulations are published in the association's Manual of Standards. Standards included in the manual cover subjects relating to equipment, heat and power, material of construction, alkaline and acid pulping, fibrous materials testing, pulp and paper testing, and nonfibrous materials testing.

The association cooperatives actively with the American Society for Testing Materials. Through representation on ASTM technical committees, it assists in the development of standards covering the following projects: Iron-chromium, iron-chromium-nickel and related alloys; bituminous waterproofing and roofing materials; electrical insulating materials; lime; paper and paper products; and corrosion. It also cooperates with the American Society of Mechanical Engineers on boiler studies, and with the Inter-Society Color Council in developing color standards.

Telephone Group. This group, which functions under the auspices of the American Standards Association, consists of the Bell Telephone System and the United States Independent Telephone Association. The secretary of the group is H. L. Huber of the American Telephone and Telegraph Company, 195 Broadway, New York, N. Y. Through its representatives, this group is now assisting in the preparation and revision of 82 standards under the procedure of the American Standards Association. It is officially represented on 40 ASA sectional committees dealing with the following projects: Safety code for construction, care and use of ladders; manhole frames and covers (cosponsor); standardization and unification of screw threads; allowances and tolerances for cylindrical parts and limit gages; standards for small tools and machine tool elements; bolt, nut and rivet proportions; plain and lock washers; wire and sheath metal gages; classification and designation of surface qualities; materials for tools, fixtures and gages; National Electrical Code; National Electrical Safety Code; Code for Protection against Lightning; insulated wires and cables; radio; dry cells and batteries; mercury arc rectifiers; electrical measuring instruments; definitions of electrical terms; rotating electrical machinery; electrical insulating materials in general; electric and magnetic magnitudes and units; preferred voltages below 100; radio-electric coordination; inspection of motor vehicles; zinc coating of iron and steel; copper wire; methods of testing wood; specifications for wood poles (sponsor); protection of heads, eyes, and respiratory organs of industrial workers; Safety Code for industrial sanitation; letter symbols and abbreviations for science and engineering; petroleum products and lubricants; graphic 
representation; preferred numbers; speeds of machinery, acoustical measurements and terminology; graphic symbols and abbreviations for use on drawings; accident prevention signs; and performance requirements for protective occupational footwear. In addition, the group is represented on the committees of such organizations as the American Society for Testing Materials and the American Institute of Electrical Engineers in the preparation and revision of 40 standards, which have been approved by the ASA in which these organizations are proprietary sponsors.

Additional standardization work is carried on through representation on committees of various engineering societies and on committees cooperating with regulatory bodies, such as State commissions, national, and international bureaus. Cooperative work is handled with numerous committees of the Telegraph and Telephone Section of the Association of American Railroads, which body is engaged in the formulation of recommendations and specifications dealing with various phases of communication on railroads.

Textile Color Card Association of the United States, Inc., Margaret Hayden Rorke, secretary and managing director, 200 Madison Avenue, New York, N. Y. This association, which is international in scope, has over 1,600 members interested in the adoption of standard colors. It cooperates with leading textile, millinery, leather, hosiery, garment, and kindred industrial trade association groups, as well as important retail organizations, in the selection of basic shades, and is organized for the promotion of color and its correlation in every related branch of industry.

This association is the creator of the Standard Color Card of America, showing over 200 staple colors, as well as seasonal cards portraying the newest fashion shades, all widely used in the textile and allied industries here and abroad. Each spring and fall, cards are issued for the textile and related trades, including silks, woolens, millinery, men's hats, shoe and leather (men's and women's), gloves and hosiery. The United States Army color card showing the official colors for arms and services, as approved and accepted by the Quartermaster General of the United States Army, is likewise issued by the Textile Color Card Association. The colors on all cards are identified by standard names as well as by cable numbers, thus insuring an exact color interpretation. The association works in close cooperation with the various divisions of the United States Department of Commerce, including the National Bureau of Standards.

Tile Manufacturers' Association (Inc.), G. M. Gilroy, president, 50 East Forty-second Street, New York, N. Y. This association has prepared and issued a fourth edition of its publication, entitled "Basic Specification for Tile Work, No. K-300," which gives in detail the specifications for the installations in connection with practically every type of construction, including installations in small residences or large office buildings. It has also adopted as standards for the tile industry 56 wall tile trimmers which are set forth in a chart published by the association. These trimmers include complementary angles, corners and stops, and are designed to care for every normal trimmer requirement. 


\section{Miscellaneous Publications, National Bureau of Standards}

This association sponsored the movement for the establishment of standard sizes of clay tiles for floors and walls which resulted in the formulation of Simplified Practice Recommendation R61 under the auspices of the Department of Commerce, National Bureau of Standards.

Through its Tile Industry Research Bureau, this organization carries on general research on tile, better methods for tile installations, and the development of specifications. The association has adopted uniform grade names and a color scheme for grade marking, and certificates to accompany packages of various types of tiles manufactured in accordance with the above-mentioned Simplified Practice Recommendation. If required in the architect's specification, typical samples of each kind and grade of tiles as specified and proposed to be used, and shop or setting drawings or rubbings, shall be submitted to the architect for approval. Each sample shall be marked with the name of the manufacturer and the grade of the tile. Approved samples shall be retained by both the architect and the tile contractor. Before setting any tiles, the tile contractor shall furnish to the architect a certificate of grade, properly filled in on the form of grade certificate issued by the association. The certificate shall be signed by the manufacturer of the tiles; shall state the grade, kind, and full quantities of tiles; and give identification marks for all packages of tiles furnished under the contract. Packages shall be branded with corresponding shipping marks, and shall be subject to inspection by the architect or his representative before being opened.

Tire and Rim Association, Inc., C. E. Bonnett, general manager, 305 Peoples Bank Building, Corner Main and Exchange Streets, Akron, Ohio. This association is the technical standardizing body of tires, tubes, and rims. It also carries on rim and wheel inspection to insure satisfactory tire application and performance. All standardizing activities of this association clear through its Standards Committee, which is charged with the duty of establishing loads, inflations, tire cross sectional limits, recommended rims and dual spacings, rim dimensions and tolerances, and valve and valve hole dimensions, for tire and rim equipment used on passenger cars, motorcycles, trucks, busses, earth movers, road graders, agricultural tractors and implements, industrial tractors and implements, and airplanes.

In addition to the above-mentioned Standards Committee, this association maintains other committees which cooperate with various agencies of the Federal Government. The Government Tire Specifications Committee cooperates with the National Bureau of Standards and the Federal Specifications Executive Committee in formulating specifications for Federal purchases of bicycle, motorcycle, passenger car, truck and bus, and industrial tires and tubes. The Airplane Tire Standards Committee cooperates with the Materiel Aeronautics of the Navy Department in preparing procurement specifications for airplane tires, tubes, wheels, brakes, and axles and with the Civil Aeronautics Authority in the drafting of civil air regulations pertaining to tires and rims. This association initiated the movement for the establishment of standard stock sizes of industrial truck and trailer solid tires, which resulted in the formulation of Simplified Practice Recommendation R103-33, promulgated and published by the National Bureau of Standards. 
Tubular Plumbing Goods Institute, Robert S. Booth, secretary, 74 Trinity Place, New York, N. Y. This institute has appointed a Committee on Standardization and Simplification, which is endeavoring to establish standards relative to gages of metal to be used, number and type of threads on products made by members of the institute. This committee is working in close harmony with a joint manufacturers committee of the entire plumbing industry and the National Bureau of Standards in endeavoring to formulate standards on various plumbing products for the use and guidance of plumbing inspectors all over the United States.

Twisted Jute Packing and Oakum Institute, Lester B. Platt, secretary, 19 West Forty-fourth Street, New York, N. Y. In connection with standardization matters arising in this industry, this institute has appointed a Standardization Committee whose sole function is to prepare and recommend standards covering the institute's members' products. This committee cooperated with the Plumbing Fixtures Committee of the Federal Specifications Executive Committee in the development of Federal specifications for marine oakum and twisted jute packing. These specifications are in use at the present time by the Federal Government agencies on which to base contracts for purchases.

Underwriters' Laboratories, Inc., Alvah Small, president, 207 East Ohio Street, Chicago, Ill. This organization was established to maintain and operate laboratories for the examination and testing of devices, systems, and materials. Founded in 1894, the enterprise is sponsored by the National Board of Fire Underwriters, and is operated for service, not for profit. It is chartered as a nonprofit corporation without capital stock, under the laws of the State of Delaware.

Testing laboratories are maintained at Chicago, New York, and San Francisco. For the follow-up of commercial production of products found to comply with Laboratories' requirements, factoryinspection centers are established in some 200 cities throughout the United States and Canada.

The objects of Underwriters' Laboratories are to conduct scientific investigations, studies, experiments, and tests to determine the relation of various materials, devices, constructions, and methods to life, fire, and casualty hazards, and to ascertain, define, and publish standards, classifications, and specifications for materials, devices, constructions, and methods affecting such hazards, and other information tending to reduce and prevent loss of life and property from fire, crime, and casualty.

The majority of underwriters in the United States, and many Federal, State, and municipal authorities, plant operators, and architects, building owners and users either accept or require listing by Underwriters' Laboratories, Inc., as a condition of their recognition of devices, systems, and materials having a bearing upon life and fire hazards, and upon theft and accident prevention.

It should, however, be noted that findings of Underwriters' Laboratories, Inc., in any case represent only its independent opinion arrived at in accordance with its aims and purposes. The correctness of this opinion cannot be guaranteed, nor can Underwriters' Laboratories, Inc., guarantee that its findings will be accepted or recognized 
in any individual case. Such assurances can be obtained only from the authority having jurisdiction.

It should be noted as well that products labeled or listed are not necessarily equivalent in quality, efficiency, or merit. Labeling or listing merely indicates compliance with the requirements of Underwriters' Laboratories, Inc.

There exist permanent arrangements between Underwriters' Laboratories, Inc., and the National Bureau of Standards whereby, in the event of a fixed difference of opinion on an engineering or technical matter between Underwriters' Laboratories, Inc., and any of its clients, the question at issue may be submitted to the Bureau.

The Underwriters' Laboratories is divided into several engineering departments, each dealing with distinct and separate subjects as follows: Burglary protection, casualty and automotive, chemical, electrical, and gases and oils, hydraulic, and fire protection. Each of these departments has prepared standards providing specifications and requirements for construction and performance under test and actual use of systems, materials, and appliances of numerous classes submitted to the Laboratories.

The Underwriters' Laboratories has issued more than 150 of these standards and sets of requirements based on sound engineering principles, actual experience, and an appreciation of the problems of manufacturing, installation, and utility. These standards are the result of years of research and collaboration by Laboratories' engineers, manufacturers, and recognized specialists in many fields, including the members of the four Laboratories' Consulting Engineering Councils.

The requirements of a standard are so stated that if correctly applied, there is no discrimination between the products of two or more manufacturer-submittors.

The standards are not intended for use by others except as manufacturers may find them useful as guides to design. They are published so that others may know the basis for Laboratories' opinions and the standards must necessarily justify the opinions.

The standards are an important tool of Underwriters' Laboratories, Inc., in its established policy of stating the facts concerning products investigated, and its opinion concerning these facts.

A manufacturer whose product passes the Laboratories' requirements and for which factory inspection service is to be established is provided with a procedure, prepared by Laboratories' engineers as part of the work under the application. This procedure describes and illustrates the product in detail, particularly as to the construction or performance of the features tested. It becomes the manufacturer's guide for future production, and is used by inspectors of Underwriters' Laboratories in reexamination and periodic check testing. The Laboratories' factory inspection service of listed products is intended to supplement and check the manufacturer's own regular inspections to insure compliance of the factory output with the requirements established for the product.

Manufacturers, regularly employing inspection service, are freely consulted in all matters concerning standards of performance and inspection in their respective industries. 
Label service consists of inspections of devices, systems, and materials at the factories by inspectors of Underwriters' Laboratories, Inc., and the manifesting of goods found to conform to Laboratories' requirements by labels (which may be in any form or of any material adapted to the product and its use), whereby they may be identified at all times. All such labels (manifests of inspection) include the words "Underwriters' Laboratories, Inc., Inspected," and are obtainable only from Underwriters' Laboratories, Inc. Label service includes listing in the published records of Underwriters' Laboratories, Inc.

In addition, in many cases, supplementary examinations and tests at the Laboratories of samples of labeled goods purchased in the open market or received from inspectors or users serve as counterchecks upon the factory inspection work.

More than $438,000,000$ labels were delivered to manufacturersubscribers to the label service during 1940.

A number of Federal specifications covering material or appliances of classes which are under supervision of Underwriters' Laboratories include certain requirements of the Laboratories, including their label, as satisfying part of the requirements of such Federal specifications.

The bidder shall submit to the purchasing agency proof that the material or appliance he proposes to supply under this specification conforms to the standards of the Underwriters' Laboratories as regards fire and casualty hazards. The label of the Underwriters' Laboratories will be accepted as conforming with this requirement. In lieu of the label, the bidder may submit independent proof satisfactory to the purchasing agency that his material or appliance conforms to the published standard, including methods of test, of Underwriters' Laboratories, Inc.

In its work in standardization, the Underwriters' Laboratories has cooperated with other organizations. It has worked with the American Standards Association in the development of American standards relative to building exit code and safety code for mechanical refrigeration; with the National Board of Fire Underwriters in establishing standards for electric wiring and apparatus, industrial control apparatus, rolled threads for screw shells of electric sockets and lamp bases, rotating electrical machinery; and with the Fire Protection Group in establishing ASA specifications for cotton rubber-lined fire hose for public and private fire department use. It is serving as proprietary sponsor for the American standard on power-operated radio receiving appliances, and for specifications and standards for electrical devices and materials with relation to fire and casualty hazards. It is also officially represented on 12 ASA sectional committees.

The Underwriters' Laboratories also cooperates with the American Society for Testing Materials through representation on technical committees dealing with the development of standards and methods of test for gypsum, electrical insulating materials, rubber products, bituminous waterproofing and roofing materials, and petroleum products and lubricants.

United Roofing Contractors' Association, James McCawley, secretary, 53 West Forth-sixth Street, New York, N. Y. Standards and specifications covering roofing materials have been developed by 
this association. It has issued specifications covering the weights of materials, construction and installation requirements; specifications for gravel and slide roofing; and also a standard practice of providing in the construction of insulating roofs a mopped felt seal course of tarred or asphalted felt at intervals of not more than 30 feet in each direction.

The association permits manufacturers to use its trade-mark label on materials inspected and found to comply with its specifications.

United States Cap Screw Service Bureau, G. P. Byrne, managing director, 53 Park Place, New York, N. Y. The Standardization and Simplification Committee of this organization considers the dimensional standards of the products of the industry having to do with diameter, length, pitch of thread, type of head, etc. Development work of this committee is submitted to the Sectional Committee on Bolt, Nut, and Rivet Proportions, functioning under the procedure of the American Standards Association, on which this bureau maintains representation. This sectional committee has already developed several standards relative to dimensions, material, and nomenclature of rivets, bolts, and nuts which have been approved as American standards by the American Standards Association.

United States Golf Association, Charles W. Littlefield, counsel, 1 Wall Street, New York, N. Y. The only standardization work carried on by this association is through its Implements and Balls Committee, which has developed standards for golf balls and golf equipment. In its current booklet, Rules of Golf, this association's specifications concerning the style and make of clubs, and the size and weight of golf balls, are included. These specifications are applicable only to equipment and balls used in connection with tournaments conducted by this association, or under its rules.

United States Independent Telephone Association, Louis Pitcher, executive vice-president, 616 South Michigan Avenue, Chicago, Ill. Standardization work of this association is carried on in cooperation with committees of technical organizations and various agencies of the Federal Government. It has recently organized several committees whose duties are to cooperate with the Federal Government in the program of national defense.

This association participated in the activities of a sectional committee of the American Standards Association in the development of American standards and specifications for dry cells and batteries. It is at the present time officially represented on four ASA sectional committees dealing with the following projects: Manhole frames and covers; definitions of electrical terms; letter symbols and abbreviations for science and engineering; and standards for drawings and drafting room practice (exclusive of architectural drawings).

United States Machine Screw Service Bureau, G. P. Byrne, managing director, 53 Park Place, New York, N. Y. The Standardization and Simplification Committee of this organization considers the dimensional standards of the products of the industry having to do with diameter, length, pitch of thread, type of head, etc. This organization is officially represented on the Sectional Committees on Bolt, Nut, and Rivet Proportions; and on Standardization and Unification of Screw Threads, functioning under the procedure of the American Standards Association. All development work of the bu- 
reau's committee is submitted to the ASA sectional committees for approval and adoption as American standards.

United States Pharmacopoeial Convention, Inc., E. Fullerton Cook, chairman, Committee of Revision of the Pharmacopoeia of the United States of America, Forty-third Street and Woodland Avenue, Philadelphia, Pa. This convention, which meets every 10 years for the purpose of revising the Pharmacopoeia of the United States of America, is made up of representatives of the Departments of the Federal Government interested in medicine and health, including the Public Health Service, the Food and Drug Administration, the National Bureau of Standards, and the Surgeons General of the Army and Navy. Delegates are also sent from the national associations of medicine and pharmacy and also from State associations. Medical and pharmaceutical colleges are also invited to send delegates, and special research institutions, such as the Mellon Institute of Industrial Research and the Rockefeller Foundation. The convention elects the members of the Committee of Revision, which in turn are divided into 15 subcommittees, each one dealing with a special division of the pharmacopoeia.

The particular objects and business of this organization are the encouragement and promotion of the science and art of medicine and pharmacy by selecting by research and experiment and other proper methods and by naming such materials as may be considered by the Committee of Revision, in each revised period, the most important used as medicines and drugs with formulas for their preparation; by establishing one uniform standard and guide for the use of those engaged in the practice of medicine and pharmacy in the United States whereby the identity, strength, and purity of all such medicines and drugs may be accurately determined, and for other like and similar purposes; and by printing and distributing at suitable intervals such formulas and the results of such and similar selections, names, and determinations among the members of this association, pharmacists, and physicians generally in the United States and others interested in pharmacy and medicine.

The Pharmacopoeia of the United States is published periodically, formerly every 10 years and now every 5 years, with supplements as they are necessary. The Pharmacopoeia is a book of standards for medicinal substances considered the most important in medical practice. The standards given in the Pharmacopoeia are recognized as the legal standards in the enforcement of the Federal Food, Drug and Cosmetic Act and the various State drug laws.

United States Shellac Importers Association, Inc., George E. Ashby, secretary, 155 John Street, New York, N. Y. This association collaborated with the American Bleached Shellac Manufacturers Association in the establishment of standard rules and regulations for the sampling and analysis of shellac, and has adopted official standard methods of analyses for the determination of rosin, wax, moisture, and arsenic in shellac; also for water soluble extract in orange and white shellac, moisture in dry-bleached shellac, and the determination of the body of shellac varnish. This association has also adopted standards for the principal commercial grades and net weights of packages of shellac. 
It inaugurated a plan for the sampling of all shipments of shellac imported into the United States. The plan provides for a standardization bureau which shall examine each importation of shellac. An Examination Committee, composed of representatives of member firms, is entrusted with the duty of examining samples of the various grades of shellac and passing upon their quality in accordance with the official rules and regulations of the association. The Examination Committee issues certificates in triplicate on each lot examined, stating grade, mark, lot number, name of vessel, date of examination, and the committee's award. Copies of certificates are furnished to buyer and seller and another copy is filed with the association. Under the plan, provision is also made for the settlement of any disputes which may arise in the operation of the plan, through existing arbitration machinery set up by the association. This organization maintains a research bureau at the Polytechnic Institute of Brooklyn to deal with problems arising concerning the uses of shellac.

United States Wood Screw Service Bureau, G. P. Byrne, managing director, 53 Park Place, New York, N. Y. The Standardization and Simplification Committee of this organization develops dimensional standards of the products of the industry having to do with diameter, length, pitch of thread, type of head, etc. The results of work of this committee are submitted to the Sectional Committee on Bolt, Nut, and Rivet Proportions, functioning under the procedure of the American Standards Association, on which this bureau maintains representation. This sectional comittee has already developed several standards relative to dimensions, material, and nomenclature of rivets, bolts, and nuts which have been approved as American standards by the the American Standards Association.

United Typothetae of America, Donald Rein, executive vice president, 719 Fifteenth Street NW., Washington, D. C. This organization, which is international in scope, includes in its membership, establishments engaged in the production of printing by any and all processes, both private and commercial printing plants.

In its work in standardization this organization has adopted standard cost finding systems, standard printing forms, and the development of new management control standards and procedures based on engineering standard costing. These new management control procedures are new to the industry, and it is expected that their installation will have a vital effect on the management policies of printing firms throughout the country.

Vacuum Cleaner Manufacturers Association, C. G. Frantz, secretary, 1070 East One Hundred Fifty-second Street, Cleveland, Ohio. Standardization work of this association is carried on from time to time by its Executive Committee. Although this organization does not develop any standards of its own, it does carry on standardization work with respect to certain types of material covering cord and plug for electrical connections, and also with reference to standard sizes and diameters of vacuum cleaner hose. These standards have been accepted by the industry and have been in use a number of years.

Another matter of considerable importance which was developed by the association dealt with a standard method of testing the operating efficiency and performance of vacuum cleaners for comparative tests. 
At the present time the association is cooperating with the Federal Specifications Executive Committee in the proposed revision of Federal specifications for electric portable vacuum cleaners. The association is officially represented on the sectional committee dealing with the development of safety codes for the prevention of dust explosions, functioning under the procedure of the American Standards Association.

Veneer Association, Charles E. Close, secretary, 616 South Michigan Avenue, Chicago, Ill. Through the work of its several committees, this association deals with the establishment of grade ard specifications for face veneer and commercial veneer. It cooperated with the National Bureau of Standards in the development of Commercial Standard CS 64-37 covering grading rules for walnut veneers, in which are included rules for face veneer. It also cooperated with the National Hardwood Lumber Association in formulating grades and specifications for commercial veneer, which are set forth in the rules for the measurement and inspection of hardwood lumber, cypress, veneers, and thin lumber issued by the latter association. It collaborates with the American Walnut Manufacturers Association and the Mahogany Association, Inc., in connection with the establishment of grading rules for veneers.

From time to time the association assists various agencies of the Federal Government in matters relating to veneers, and especially with the Federal Specifications Executive Committee in the development of Federal specifications covering the purchase of veneer products.

Vitreous China Plumbing Fixtures Association, R. Kennedy Hanson, secretary, 1108 Clark Building, Pittsburgh, Pa. Two committees of this association, one the Federal Specifications Committee and the other the Commercial Standards Committee, carry on work in the development of standards and specifications on behalf of the vitreous china plumbing fixtures industry. This association, through the Commercial Standards Committee, initiated the movement which led to the establishment of Commercial Standard CS20-36, relating to standards and grades for staple vitreous china plumbing fixtures. This standard was promulgated and published by the National Bureau of Standards and accepted by industry as a basis for the manufacture of plumbing fixtures.

The Federal Specifications Committee is cooperating with the Federal Specifications Executive Committee of the U. S. Government in the preparation and revision of Federal specifications covering plumbing fixtures. The Commercial Standard referred to above contains a provision that all vitreous china plumbing fixtures shall be plainly and permanently branded for identification with the name or trade-mark of the manufacturer. "First quality" labels shall be used only on such ware as conforms to the requirements for first quality, as set forth in the grading rules given in the Commercial Standard and shall contain the following wording: "We certify that this piece of vitreous china is first quality ware, graded according to Commercial Standard CS 20-36 issued by the National Bureau of Standards of the United States Department of Commerce."

Wall Paper Institute, W. L. Carver, secretary, 19 West Fortyfourth Street, New York, N. Y. Through the Trade Practices and 


\section{8

Standards Committee, the Wall Paper Manufacturers' Association, predecessor of this institute, cooperated with the National Bureau of Standards in the establishment of Commercial Standard CS16-29 covering quality of wall paper. A special technical committee of the institute is now working on further simplification and modernization of the standards for wall paper, and the revision of the Commercial Standard to include standards for washability.

Webbing Manufacturers Institute, Wilwyn Herbert, secretary, 309 State Street, New London, Conn. This organization cooperated with the National Bureau of Standards in the establishment of Commercial Standard CS58-36 covering woven elastic fabrics for use in overalls. The Standardization Committee of this organization is engaged at the present time in developing performance standards for products manufactured by members of the institute.

West Coast Lumbermen's Association, W. B. Greeley, secretarymanager, 364 Stuart Building, Seattle, Wash. This association has adopted and revised its standard grading and dressing rules for Douglas fir, sitka spruce, west coast hemlock, and western red cedar lumber. These rules are in conformity with American lumber standards which are set forth in the current edition of Simplified Practice Recommendation R16, promulgated and published by the National Bureau of Standards. It maintains a Committee on Lumber Grades, which cooperates with similar committees of other lumber manufacturing associations, including the Central Committee on Lumber Standards, relative to the adoption and maintenance of American lumber standards.

This association has adopted a grade and trade-mark insignia which is officially registered by the association and may only be applied under individual mill licenses or by inspectors of the association's Bureau of Grades and Inspection. Graders who use the official stamp are subject to examination for grading efficiency prior to license being issued. Following the issue of the license, their work is subject to regular unannounced check-up by the association's supervisors of grades to insure efficient and accurate application of the official stamps. The license may be revoked unless the efficiency is maintained at 95 percent as measured by the association's standards of grade and official review by grading supervisors. The official trade- and grade-marks used by this association are for the purpose of identifying the quality of Douglas fir, west coast hemlock, western red cedar, and sitka spruce. These marks identify west coast lumber as the grades described in the association's standard grading and dressing rules. In the use of the association's grademark trade-mark, a manufacturer is identified by a firm name or trade-mark or by a number assigned to him by the association. These marks thus identify the lumber bearing them as of a standard west coast grade, graded at operations which receive regular inspection from the association's Bureau of Grades and Inspection.

Western Pine Association, S. V. Fullaway, Jr., secretary-manager, Yeon Building, Portland, Oreg. This association has adopted standard grading rules for ponderosa pine, sugar pine, Idaho white pine, larch Douglas fir, white fir, Engelmann spruce, incense cedar, and red cedar lumber. These grading rules are in conformity with the American lumber standards which are set forth in the current edition 
of Simplified Practice Recommendation R16, promulgated and published by the National Bureau of Standards. In the development of American lumber standards, this association took an active part in cooperating with the Central Committee on Lumber Standards, under whose auspices the lumber standards were developed.

In order that the manufacturers in the Western Pine Region may be in a position to meet such requirements from the buyers and users of their products, this organization has formulated official grade, trade, and species marks. The symbol of the association indicates that a piece bearing this mark is graded under the standard grading rules of the association. It further signifies that the stock is seasoned, manufactured to standard association size, and graded under association supervision. Under special arrangements with the association stock shipped by a nonmember mill may bear the association mark. As to mill identification, this information is given by use of the firm name, brand, or an assigned number. The grade is shown by the standard grade name referred to in the association's standard grading rules. The kind of wood is disclosed by species mark or common name. These marks are protected and can be placed on lumber only by a Western Pine Association inspector or by an operator whose grading practices are given regular and periodic inspection by the association's Bureau of Grades, under whose jurisdiction the marks are used. When a lumber inspector's certificate issued by the association is required on a shipment of lumber and the official grade-marks are not used, the stock is identified by an imprint of the association mark and the number of the shipping mill.

Western Red and Northern White Cedar Association, W. $\mathbf{H}$. Jones, secretary, 715 Peyton Building, Spokane, Wash. This organization is a consolidation of the Western Red Cedar Association and the Northern White Cedar Association. Official specifications covering western red cedar posts, red cedar piling, and western red cedar, and northern white cedar poles have been adopted by this association. Representatives of this organization serve on the Sectional Committee on Wood Poles, functioning under the procedure of the American Standards Association. One of the projects handled by this committee resulted in the development of American standard specifications covering western red cedar poles.

Wine Institute, H. A. Caddow, secretary, 83 Second Street, San Francisco, Calif. This institute does not of itself sponsor any standards or specifications for the products of its members, but it does devote efforts in standardization primarily towards advocating the adoption of wine and brandy quality standards as established by Federal and State agencies. This institute's Standardization Committee makes studies and recommendations in connection with standards of identity and quality for wine and brandy. These recommendations are then placed before official agencies for consideration in connection with the establishment of new standards or the revision of existing standards.

Wire Cloth Manufacturers' Association, A. M. Ferry, secretary, 1427 Eye Street NW., Washington, D. C. In the desire of manufacturers of Fourdrinier wire cloth for papermaking machines to make high-grade products which will give maximum service and satisfactory use, this association initiated the project for develop- 
ment of a quality grade of wire cloth under the auspices of the National Bureau of Standards. The result of this effort led to the establishment of Commercial Standard CS36-33, which was promulgated and published by the Bureau.

In order to assure purchasers that Fourdrinier wire cloth is manufactured in accordance with the quality set forth in the Commercial Standard, manufacturers place wrappers on the cloth which carry the statement that it is certified to comply with the requirements of Commercial Standard CS36-33. 


\section{SERVICES OF THE NATIONAL BUREAU OF STANDARDS AND OF THE PROCUREMENT DIVISION}

In the simplification and commodity standardization activities of the Federal Government, two agencies, namely the National Bureau of Standards, United States Department of Commerce, and the Procurement Division, United States Treasury Department, take a leading part. For this reason, it has been found desirable to include in this publication outlines of the functions of these two agencies insofar as they relate to the preparation of commodity specifications used by Federal agencies.

In Appendix 1, there is outlined somewhat in detail the work of the National Bureau of Standards in research and testing of commodities, and in commercial standardization. Specific mention is made of some of the more important activities of the Bureau in connection with the investigations of certain lines of commodities and the development of test methods to determine qualities. The cooperative work of the Bureau with the Federal Specifications Executive Committee relative to the formulation of specifications, and inspection and sampling methods used for the purpose of determining whether deliveries made comply with samples tested is also outlined. Similar treatment is given to the cooperative work of the National Bureau of Standards in the development of engineering and safety codes, simplified practice recommendations, and commercial standards of quality and performance.

The activities of the Procurement Division in the preparation of Federal and other specifications are set forth in Appendix 2. In it are included the organizational set-up and the procedure employed by the Federal Specifications Executive Committee in preparing Federal specifications for Government purchases. Also, there is briefly described the work in developing other standards and specifications for Government purchases, and the methods employed in inspecting goods delivered to governmental agencies. 


\section{Appendix 1.}

\section{NATIONAL BUREAU OF STANDARDS}

\section{(FUNCTIONS AND ACTIVITIES)}

The National Bureau of Standards, United States Department of Commerce, created by the Act of Congress approved March 3, 1901, ${ }^{1}$ is charged with "the custody of the standards; the comparison of the standards used in scientific investigations, engineering, manufacturing, commerce, and educational institutions with the standards adopted or recognized by the Government, the construction, when necessary, of standards, their multiples and subdivisions, the testing and calibration of standard measuring apparatus; the solution of problems which arise in connection with standards; the determination of physical constants and the properties of materials, when such data are of great importance to scientific or manufacturing interests and are not to be obtained of sufficient accuracy elsewhere.

"The Bureau shall exercise its functions for the Government of the United States; for any State or municipal government within the United States; or for any scientific society, educational institution, firm, corporation, or individual within the United States engaged in manufacturing or other pursuits requiring the use of standards or standard measuring instruments."

In the Act making appropriations for the Bureau for the current fiscal year (as has been true annually since 1935) it is stated that the funds are being provided "for carrying out the provisions of the Act establishing the National Bureau of Standards, approved March 3, 1901, and of Acts supplementary thereto affecting the functions of the Bureau, and specifically including the functions as set forth under the Bureau of Standards in the "Department of Commerce Appropriation Act 1935,' approved April 7, 1934."

In the 1935 Act, definite approval was given to "the establishment of standards of performance of mechanical appliances"; "the development of standards of more durable quality and methods of measurement of textiles, paper, leather and rubber"; "the establishment of standards, methods of testing and inspection of instruments, equipment, tools and electrical and mechanical devices used in the industries and by the Government, including the practical specifications for quality and performance of such devices, and the formulation of methods of inspection, laboratory and service tests," and the collection and dissemination of information concerning "approved methods in building, planning and construction, standardization and adaptability of structural units, including building materials and codes, economy in the manufacture and utilization of building materials and supplies, and such other matters as may tend to encourage, improve, and cheapen construction and housing."

\footnotetext{
1 Public Act No. 177 establishing the National Bureau of Standards, March 3, 1901, and amendments, June 30, 1932.
} 
The Bureau performs its functions through two major groups: Research and Testing Group and Commercial Standardizatilon Group.

\section{RESEARCH AND TESTING GROUP}

The Research and Testing Group is subdivided into nine divisions: Electricity, Weights and Measures, Heat and Power, Optics, Chemistry, Mechanics and Sound, Organic and Fibrous Materials, Metallurgy, and Clay and Silicate Products. This group handles all matters pertaining to investigations and research, testing, and measuring.

The work of the National Bureau of Standards in establishing and maintaining standards of measurement, quality, performance, and practice serves not only Federal and tax-supported agencies, but the general public as well.

Its unique research and testing facilities are used to discover and evaluate material standards and to solve basic technical problems.

The Bureau's work on standards of measurement is designed to assist in the standardization of containers and products, in promoting systematic inspection of trade weights and measures, and facilitate research in science and technology. The establishment of more precise values for the standard constants furnishes an exact basis for scientific experiment and design and makes possible the efficient technical control of industrial processes.

The Bureau's work on standards of quality sets up attainable standards and test methods to assure high utility in the products of industry and furnishes a scientific basis for fair dealing by promoting truthful branding and advertising.

The Bureau likewise develops standards of performance; that is, specifications for the operative efficiency or accuracy of machines or devices. These are numerical statements of speed, uniformity, durability, output, economy, and other factors which together define the net efficiency of an appliance or machine. The ultimate purpose is to make exact knowledge the basis of the buyer's choice and to clarify the understanding between the manufacturer, distributor, retailer, and consumer.

Another function of the National Bureau of Standards of very general interest is the development of standards of practice, that is, collection of data and formulation of codes of practice for public utilities and other services. These codes are prepared in cooperation with the technical and commercial agencies concerned, and relate to the technical regulation of construction, installation, and operation. These codes are based upon standards of measurement, standards of quality, and standards of performance. The purpose of such work is to afford a single impersonal standard of practice mutually agreed upon by all concerned and clearly defined in measurable terms.

Testing and Inspection for Governmental Agencies.-The law requires that the National Bureau of Standards carry out investigations and tests for the Federal and State Governments, and for many years the Bureau has served as a testing and research laboratory for practically every branch of the Government service.

The testing of scientific apparatus, materials, and supplies by the Bureau for other Government departments and for the various State 
governments is widely appreciated and utilized, and requests for the Bureau's assistance in such matters are steadily increasing.

Another important service is the calibration of instruments and apparatus for Federal and State Governments in terms of the national standards.

Commodities purchased by the various departments and establishments of the Federal Government, excepting foods, drugs, and cosmetics, are tested by the National Bureau of Standards to determine whether they comply with the requirements of the specifications on which they are purchased. This gives the Bureau an unusual opportunity to observe how buying under specifications works out in practice. The experience of the National Bureau of Standards in this field is available in the preparation of performance standards.

Test Methods, Testing Machines or Devices, and Tests.-The National Bureau of Standards is concerned not only with basic scientific research, but also with the development of standardized methods for testing matcrials, as well as with the actual testing of materials and commodities.

Dental Research.-Most people at one time or another find it necessary to call upon the dental profession for assistance. The cooperative research on dental materials affords a striking example of the value of the Bureau's researches to the public.

Dental science has made tremendous advances during the last century. The metallic inlay, the blended-color filling cement, the vulcanite denture, and the fused-porcelain restoration are definite examples. These now give the nation an effective defense against the ravages of decay, injury, and other defects which, if not corrected, seriously interfere with the health of the people.

New materials and new technics are being introduced so rapidly that individual dentists find it impossible to evaluate the new or to make accurate comparisons with the old.

Unfortunately, many items and practices have been introduced in the dental profession without supporting laboratory or clinical records. Dental amalgam fillings have been used for more than 100 years, but it is only during the last 30 years that the dentist has been accurately advised on its two greatest defects; excessive shrinkage and flow. The dental research program at the National Bureau of Standards has attacked these defects, rated manufacturers' products and, because of its support, defective amalgams have practically been driven from the market.

With a standard amalgam alloy, demanded by the Federal Government's specification and developed through the Bureau's laboratory tests, the dentist can now insert an amalgam restoration which will give increased service and satisfaction.

The invention of the gold inlay brought both satisfaction and disappointment. Dentists attempted to control the seven or more variables encountered in producing and setting inlays. Numerous attempts were made to master the art, but inlays, as made by most dentists, continued to fail in service. In 1922, the National Bureau of Standards was requested to set up a cooperative research through a fellowship arrangement with a prominent dental research laboratory. After measuring the effects of dental technics on wax patterns, investments, wax elimination temperatures, gold alloys, casting tem- 
peratures, casting shrinkages, and cements, the Bureau was able to show dentists how their inlay technics could be so arranged as to produce an accurate inlay. Thousands of dentists who have mastered this science are today placing inlays which will give entire satisfaction. Such inlays do not "drop out," and recurrent decay is reduced appreciably.

Since 1928 an extensive research program has been maintained in cooperation with the American Dental Association, which supports several research associates at the Bureau. The results of the dental research are quickly available to the profession. Materials are rated by the research associates and Bureau members, and the ratings are communicated to the profession through the American Dental Association. Lists of satisfactory materials, such as amalgam alloys, dental gold alloys, cements, and others are printed in the Association's journal and are used as buyers' guides by the members of the profession.

Manufacturers interested in producing high-quality dental supplies are giving their wholehearted cooperation to the plan as this affords them a protection against the inferior products which heretofore have ravaged their field, created confusion in the dentists' practice, and extracted heavy tolls from an uninformed and unprotected public.

Cooperation between the dental profession and the National Bureau of Standards enables the profession to set up specifications for supplies, to secure the best materials, to employ the best manipulative technics, to arrest the fads which have so frequently invaded dentistry, to speak with authority in its field, and to give the best dental service possible.

Dry Cells aNd BATteries.-Recognizing the need of a governmental standard for dry cells and batteries during the last World War period, the National Bureau of Standards undertook the preparation of specifications to include sizes of cells, arrangement of batteries, tests, and required performance. These standards were submitted to a committee consisting of representatives of manufacturers, the War Industries Board, and several Federal Government departments. Since that time periodic revisions have been made of the specifications to keep abreast of new developments to meet new industrial and commercial uses. These specifications have been approved as American Standard by the American Standards Association. The Bureau conducts systematic tests at stated intervals on the product of those manufacturers who are willing to cooperate. These tests, known as "qualification tests," include intermittent and long-time tests which are necessary to demonstrate the quality of the product. The results of these tests are available to Government purchasing officers for whom the tests are made, and each manufacturer is informed of the results on his own product. Several thousand cells and batteries are tested each year to determine their compliance with the requirements of the standard.

Advances in the quality of dry cells and batteries were made possible by the ability and willingness of manufacturers to improve their product, and as a result, the available output of the better brands of older types is now three-to-fourfold greater than 20 years ago. The resulting benefits of this work of the Bureau are shared by the Government and the consuming public alike. 


\section{Miscellaneous Publications, National Bureau of Standards}

EleCtric Lamps.-The National Bureau of Standards maintains the national standard of light. It gives technical advice on the performance characteristics to be included in Federal specifications for lamps, and it tests lamps for the Federal Government which is a large user of lamps. During the fiscal year that ended June 30, 1941 , over 10,000,000 incandescent electric lamps were inspected before shipment, and more than.11,000 samples selected from these lamps were life-tested at the National Bureau of Standards.

These lamps were purchased from contractors, each one of whom supplied lamps which by inspection and test were found to comply with the requirements of the Federal specification for incandescent lamps.

These inspections and tests for the Federal Government of its lamp purchases have a very great effect upon the quality of all incandescent lamps, whether the manufacturers are contractors to supply lamps to the Government or not. All manufacturers of incandescent lamps, on account of the sharp competition, are anxious to supply lamps to their customers that can be guaranteed to comply with the Federal specifications, even though the makers are not actually supplying lamps to Federal departments.

Gas Service and Burner Design.-Precautions as to gas appliance attachments are set forth in Bureau Circular C404. It is pointed out that few attachments tested by the Bureau showed any special economy in the use of gas, whereas most of them created hazards when used on appliances otherwise considered safe.

Information regarding the action of and the most favorable design for burners of the type commonly employed in domestic and in some industrial appliances for the use of gas as a fuel is given in Circular C394. Experimental studies in the interest of the gas consumer have included the best design of gas burners for domestic use, and the effect of altitude on the limits of safe operation of gas appliances.

An important publication on gas is the Bureau's Circular C405, Standards for Gas Service. This circular is intended to serve as a manual of recognized good practice for gas companies and public utility commissions.

Motor Fuels.-Motor fuels present many difficult problems which involve both the producers of fuels and the builders of the motor vehicles in which they are used. The National Bureau of Standards has for years represented the consumer in a triangular research group devoted to reaching the solution best for all concerned. The Federal Government itself is one of the largest consumers of motor fuels and its interests in this respect are almost identical with those of the public.

Fuel dopes designed or sold to improve the quality of gasoline are tested at the Bureau to determine their effectiveness, if any. The routine engine tests of fuel dopes and special fuels which are made for the public are outlined in a mimeographed circular.

Paint and Varnish.-A major purpose of household paint is decoration but its durability is equally important, since it involves the question of frequency and expense of repainting. Researches conducted at the Bureau furnish data on the probable life of paint, and have resulted in the development of test equipment which simulates the action of weather and accelerates its effects. Studies are made of 
the characteristics of paint films. Additional information concerning the composition of paints and varnishes for various purposes is made available through specifications used by the Federal Government agencies, in the preparation of which the Bureau takes an active part.

Paper and Paper Proddcts.-The Bureau has worked continuously on the development and improvement of testing procedures for measuring the quality of paper products.

The user of record materials is often concerned as to their probable longevity, and for several years the Bureau has been making exhaustive studies of writing and printing papers to find the qualities required for a given service and to find the best means of prolonging their service life as much as possible. From this work has been " evolved a recommended classification of papers to be used for record purposes, which is based primarily on purity of the cellulose comprising the fibers, and on the strength of the papers.

Information on storage conditions for records was obtained by a survey of library conditions, by testing the paper of identical issues of books stored in libraries under different conditions, and by laboratory investigations of influences indicated as harmful by the results of the survey and testing. These studies led to recommended storage practice relative to illumination, purification of the air, humidity, and temperature. Other studies yielded information on protection against insects and on increasing the resistance of papers to wear by covering them with transparent sheetings. Information on the use of both paper and motion-picture film for reproduction of records, for the purpose of preserving records contained on impermanent material, or for minimizing the handling of valuable documents has also been obtained.

Rubber and Rubber Products.-Tires and brake linings have a great deal to do with the safety and comfort of the motorist. These two products are of importance to the Government on account of the large-scale use of automotive equipment by the Post Office, Interior, War, and other departments, and they have been singled out for detailed study so that purchase specifications can be brought up to date and kept in line with developments in the industry.

An important part of investigations of this kind consists in designing, constructing, and developing testing equipment. Endurance machines for tires have been built so that a tire may be run at any desired speed and load against a heavy drum which takes the place of the road. By the selection of appropriate conditions any one of the common types of tire failure such as the breaking of the carcass or cracking of the tread can be brought out or accentuated.

Equipment for the testing of brake lining is designed to measure not only the durability but also the performance of linings under a variety of conditions, hot or cold, wet or dry, and with frequent or infrequent stops. Since thousands of stops must be made with any particular sample in order to obtain a reliable indication of the way it will perform, the testing machine is designed to operate automatically according to any predetermined schedule, the results being recorded autographically.

Less extensive studies have recently been made in connection with purchase specifications for products such as rubber sheeting, sur- 


\section{Miscellaneous Publications, National Bureau of Standards}

geon's gloves, adhesive plaster, and rubber-insulated wires and cables. Recent technical advances have made it possible to greatly increase the life of rubber. Hence the principal feature of these studies has been the development of better accelerated aging tests so as to insure that the Government or the public using Government specifications will get the benefit of the improved quality, which is now possible.

Srows.-Work is being carried on by the Bureau in obtaining information which will be of assistance in preparing standards for leather shoes. The method of preparing such standards on the basis of construction and material specifications has been discarded in favor of developing performance tests. The wear of the sole and the comfort of the shoe as indicated by the porosity of the leather are important properties for the determination of which the Bureau now has adequate tests. Consequently, attention has been turned to developing a machine for testing the shoe as a whole with respect to its ability to hold its shape and resist break-down. At the present time a machine of this kind is in constant operation testing shoes to determine the influence of the welt, McKay, turn, stitch-down, and cement types of construction on the ability of the shoe as a whole to stand up under simulated service conditions of flexure and pressure.

Soaps and Other Cleaning Materials.-Detergents (soaps and other cleaning materials) are essential in maintaining the appearance and sanitary condition of public and private places, and it is equally important that they should be suitable for use on the articles or surfaces to be cleaned. The National Bureau of Standards, in cooperation with manufacturers, the Federal Specifications Executive Committee, and the public, has developed many of the Government's specifications for such products. Detergents are purchased on the basis of these specifications, and laboratory tests are regularly conducted by the Bureau to determine compliance with these standards of quality and performance. This work tends to bring about better quality of material.

Much of the Bureau's information on this subject is being utilized by numerous State and municipal agencies, institutions, and other large users in the preparation of their own specifications for cleaning materials.

Textrles.-Textile studies at the National Bureau of Standards are concerned with a variety of problems of interest to governmental agencies and the public as well as to the manufacturer. They range from studies of the ultimate nature of the fibers themselves, through investigations of the relation of the yarn and fabric construction and finish, to the properties of the finished product, and include studies of utilization, storage, and maintenance. Many of these studies have led to the development of standards, specifications, and test methods which are utilized by producers in bringing about an improvement in the quality of their products. Among the subjects to which the Bureau has given consideration in the textile field are: Carpets, cotton textiles, dress fabrics, dry-cleaning solvents, gloves, hosiery, silk textiles, underwear, and waterproofed fabrics.

WeIghts aNd Measures.-The National Bureau of Standards renders an important Nation-wide service to the Government and the public through the direct or indirect standardization of devices used in weighing and measuring commodities purchased by over-the- 
counter buyers. The Bureau is the custodian of the national standards of weight and measure; it tests, on the one hand, the control standards which govern the manufacture of commercial weighing and measuring devices, and on the other hand, the reference standards of the States upon which their official tests of commercial devices are based. The Bureau exercises no regulatory powers along weights and measures lines, such supervision having been left by the Congress almost exclusively to the jurisdiction of the States; however, by cooperative action the Bureau promotes uniformity of weights and measures laws and administration throughout the country, and serves as a clearing house for information on this subject.

The Bureau's work on weights and measures led to the formation of the National Conference on Weights and Measures which is composed of State and local officials engaged in the inspection of weights and measures and in the enforcement of laws and regulations on the subject. Although it is an unofficial organization with no direct authority to enforce its recommendations, the conference exerts a powerful influence on weights and measures affairs, largely through the adoption of codes and specifications, tolerances, and regulations for commercial weighing and measuring devices which are recommended to the States for official promulgation. These codes are published by the Bureau from time to time.

The National Conference seeks to place weights and measures administration on a uniform basis throughout the country. It looks toward adopting the most efficient methods for carrying on all phases of the work.

Since 1914 the Bureau has been conducting field tests of railway track scales such as are used for the weighing of railway freight cars; these tests have played an important part in the improvement effected during the past two decades in the accuracy of these large scales, the weights from which are used not only for assessing freight charges for rail transportation but also as the basis of sale for goods sold in carload lots. Three railway track scale-testing equipments are maintained in service by the Bureau, with which more than 1,000 tests are made annually.

There was inaugurated by the Bureau in 1936, and is still in progress, a somewhat similar program directed to another class of largecapacity weighing machines. This program is being carried on in cooperation with State and local weights and measures officials, and provides for the testing and inspection, with Bureau equipment and personnel, of a representative number of wagon and motor-truck scales in each State which is not provided with adequate equipment for this character of testing. The purpose of the program is partly educational, in that suitable testing equipment and methods are demonstrated, and partly factual, in that data are developed which clearly show the need for improved equipment, better methods, and much greater attention to this important class of commercial weighing scale. This work of the Bureau has met with a most cordial response from scale owners and officials.

Metal and Metal Products.-The Bureau conducts research on the selection, treatments, and properties of metals required in the development of standards of measurement and construction of 
measuring instruments. It is constantly engaged in developing improved methods of measurement in the field of physical metallurgy, and to determine physical constants of metals and auxiliary metallurgical materials. The Bureau serves as a centralized laboratory of physical metallurgy for Government agencies for examining failures of metals, and for developing more satisfactory metals and alloys for specified services. It assists in developing metal specifications and to test metals for compliance therewith. In cooperation with industry, the Bureau assists in developing broader and more effective utilization of metals.

Clay and Silicate Products.-Another function of the National Bureau of Standards is its work in determining the physical and chemical properties of clay products, cement and concrete, lime, gypsum, glass, and building stone. Investigations are carried out for the purpose of bringing about more effective use of these materials. The Bureau cooperates with industry and Government in preparing standards and specifications covering clay and silicate products, and conducts tests for Government agencies to determine compliance of material in accordance with the specifications on which they are purchased.

Building Materials Research.-Much interest is evidenced at the present time in the movement going forward in the development of better housing facilities throughout the country, particularly with reference to low-cost housing. At the instance of the Central Housing Committee, composed of representatives of Federal agencies interested in housing matters, the National Bureau of Standards was selected as the agency to conduct investigations and tests on the physical properties of materials, except wood, entering into housing construction.

It is believed that the results of the present program have fully demonstrated the value of this type of research on housing not only to the Government housing agencies but also to the artchitects, the building industry, and the public.

Widespread interest has been shown in the reports which are now appearing in printed form and available to all groups interested in housing.

Many of the agencies have found it practicable to make decisions on the basis of objective tests by the Bureau and other pertinent data rather than on individual experience, perhaps satisfactory in some cases, but not necessarily of general application.

Some specific examples of results of the building materials research program which lead to a reduction of cost are set forth herewith.

Methods have been developed for the successful application of plaster on fiber insulating lath. Thus, a single material serves as plaster base and as thermal insulation and it is possible to obtain a specified degree of insulation at lower cost. The research also indicated that the plaster must be a strong plaster and at least onehalf inch thick if cracking of the plaster is to be avoided.

Structural tests have shown the possibilities of using fiber insulating boards as sheathing. Here again one material serves two functions and the cost of obtaining a specified thermal insulation is reduced. 
In cooperation with various manufacturers of masonry materials, methods of constructing masonry walls of less material and of less costly materials, such as cinder block, concrete block, tile, etc., either singly or in combination, have been investigated. It has been determined that 8-inch walls may often be substituted for 12-inch walls and that the cavity type of construction offers opportunity for obtaining a given performance as to structural strength and resistance to rain penetration at lower cost.

The results of studies of mortars in relation to building walls which prevent the penetration of rain have been incorporated in the specifications for new housing projects. The maintenance and repair costs of these structures may be expected to be considerably reduced.

The results of research have prevented the unnecessary expenditure of money on plasticizers and other admixtures in mortars.

Accelerated aging tests on wall boards give the basis for a specification for obtaining a material of longer life at the same cost. A method recently developed is the use of incombustible fillings. In a recent housing project, the required resistance was obtained by filling the partition around a stair enclosed with scrap brick, mortar, and plaster. In other cases, partition walls filled with mineral wool and plastered with gypsum plaster could be used instead of tile partitions. By the use of incombustible fillings, the field of application of the less-expensive wooden construction can be extended.

In cooperation with manufacturers, several types of fire-resistant floor construction, which are less expensive than reinforced concrete slabs, have been studied.

Studies of paints by practical performance tests make possible the avoidance of unnecessarily expensive materials. The relative merits of various types of paints and pretreatments for sheet steel, both galvanized and ungalvanized, have been determined. The work on cement-water paints is expected to lead to formulae by which any contractor may mix satisfactory paint on the job from relatively inexpensive materials. Research has already shown that these paints properly applied are a reasonably satisfactory means of waterproofing leaky masonry walls.

Formulae for satisfactory nonproprietary calking compounds have been developed.

Tests of heating equipment enable a satisfactory evaluation of costs of the equipment. In recent tests, one class of devices was found to be considerably overrated so that the bids including that type did not correspond to the same actual heating capacity as bids on other types. An oil-burning combination domestic hot-water supply and hot-water heating system was found satisfactory for small houses in a recent project.

The use of 3-inch soil stacks in the plumbing systems of small houses rather than 4-inch stacks has been found entirely satisfactory. Simplified piping systems have been developed for small houses and apartment houses. The adequacy of various methods of protection against the back flow of polluted water into the water supply system has been studied. All contribute to cost reduction, but major cost reductions in this field are to be expected only with prefabricated equipment.

The Bureau cooperates with industry to eliminate superfluous sizes and varieties of building materials, avoiding waste and reduc- 
ing costs. Recent recommendations cover concrete building units, lumber, and roofing ternes.

The Bureau assists industry in the development and establishment of commercial standards of quality for building materials. Recent work has covered stock doors, flooring, plywood, and hardwood paneling, trim, and molding.

The Bureau takes an active part in building code revision and modernization. It lends its influence toward the use of performance requirements and toward setting the requirements only as high as the safety and health of the public require. Placing the requirements on a performance basis makes possible the use of lower cost methods of giving the performance as soon as they are developed.

ResearoH Associates.-At the present time over 80 research associates are maintained at the Bureau under its Research Associate Plan. Under this plan, a manufacturer, distributor, or user of a particular commodity, generally through the recognized national association representing the particular group, maintains one or more technicians in the laboratories and shops of the Bureau under the supervision and regular procedure of the Bureau for the purpose of carrying on research in a field of mutual concern. An examination of the list of projects upon which these associates are now working discloses that about one half of the research associates receive all or a part of their pay from organizations that are interested in research problems from the viewpoint of the user of the product rather than of that of the manufacturer. It should be pointed out that the results obtained by the research associates working under this plan are given to the public through publications of the Bureau. One example is research in motor fuels; another, research in dental products.

\section{COMMERCIAL STANDARDIZATION GROUP}

The Commercial Standardization Group is subdivided into three divisions: Simplified Practice, Trade Standards, and Codes and Specifications.

Simplification.-The term "simplification," when used in the sense of eliminating unnecessary variety, is sometimes confused with standardization, but the two activities are essentially different. "Standardization" is primarily technical and creative: its function is to determine and establish in use the best design, quality, method, or process for performing a desired function. Simplification, on the other hand, is commercial and selective; its function is to determine which sizes or items of a product are most important, and to concentrate production on them wherever possible. Simplification may be applied to articles already standardized as to design or size, or it may be applied as a step preliminary to standardization, thereby reducing the number of items to be standardized.

The Division of Simplified Practice serves as a clearing house through which manufacturers, distributors, and consumer groups cooperate on a voluntary basis in furthering a Nation-wide program for the elimination of the excessive and needless variety of sizes, types, and dimensions of manufactured products, which tends to reduce costs of production and distribution. In addition to the industry itself, direct cooperators in and beneficiaries of this activity are Federal, State, and municipal agencies and the public in general. 
The success of a simplified practice project depends largely upon the completeness and accuracy of the data collected through a survey of the specific industry. Studies of sales figures for different commodity lines frequently show that about 80 percent of a year's business is done in approximately 20 percent of the varieties in which the product is offered. The remaining 80 percent of the varieties which bring in only 20 percent of the volume is often an economic burden on industry causing excessive inventories, higher carrying costs, slow turn-over, and heavy obsolescence, with consequent loss to all concerned.

Procedure in Developing a Simplified Practice Recommendation.The procedure employed in the development of a Simplified Practice Recommendation includes the following steps:

1. A survey by a representative committee of the proponent group covering sizes, varieties, and types of the article made during each year of a given period, the volume of each item produced annually, the relative importance of the items, the probable future trends, and the items which can be eliminated with varying degrees of advantage.

2. Preparation of a statement consolidating this information.

3. Presentation of the statement to a general conference of all interested groups representing producers, distributors, and consumers.

4. Adoption by the conference, on the basis of the survey findings, of a simplified-practice recommendation, usually in the form of a list of sizes or types of the product which appear adequate to meet all normal demands.

5. Appointment by the general conference of a standing committee of representatives of producer, distributor and user groups to maintain the recommendation, through revisions when necessary.

6. Circulation by the division to all concerned of a full report of the conference action for final acceptance of the recommendation.

7. Promulgation of the program by the Department of Commerce, through the National Bureau of Standards, and publication of the recommendation, upon receipt of adequate written support by manufacturers, distributors, and users.

The division thereafter cooperates with the standing committee in conducting, from time to time, surveys to determine the degree of adherence, to maintain and extend support of the recommendation, and to secure data for reaffirmation or revision to meet changing industrial conditions.

Of the 181 Simplified Practice Recommendations developed to date many have undergone 1 or more revisions.

The first Simplified Practice Recommendation was for vitrified paving brick; others cover a wide range of commodities including construction materials, metal products, tools, ceramic products, textiles, paper and cardboard products, mechanical products, containers, invoices, and warehouse receipts.

Commercial Standards.-The Division of Trade Standards of the National Bureau of Standards, with the assistance of interested groups, sets up and promulgates Commercial Standards.

These are voluntary recorded standards agreed upon by producers, distributors, and consumers, covering terminology, types, classifications, grades, sizes, and use characteristics of manufactured products as a basis for better understanding between buyers and seller. They 
include standard methods of test, rating, certification, and labeling, and provide a uniform basis for fair competition. They are made effective by means of voluntary guarantees on invoices, on labels, or by grade marks on the goods themselves.

The use of the Commercial Standards promulgated by the National Bureau of Standards is entirely voluntary on the part of producers, distributors, and consumers.

Any group, whether producers, distributors, or consumers, may request the cooperation of the National Bureau of Standards in the establishment of a commercial standard. In initiating the work, the proponent group is expected to assume certain responsibilities, such as the selection of the specification; the preparation of the tentative draft; and supplying data, information, or advice as the situation may require.

Although differing in some details, the procedure in developing a commercial standard requested by an interested group or by an industry is similar to that employed in developing a simplified practice recommendation. Each proposal for a commercial standard requires a special approach adapted to the character of the particular commodity to be standardized, and the conditions in that industry.

Codes and Specifications.-The work of the Division of Codes and Specifications is carried on by five sections dealing with safety codes, building codes, building practices and specifications, producer contacts and certification, and consumer contacts and labeling.

This Division cooperates with Federal, State, and municipal agencies in the development of safety codes. It investigates materials and apparatus incidental to the establishment of safety standards; also accidents and field conditions and current practices in industry. It cooperates with State and municipal officials in the application of safety standards, and with engineering, insurance, and other organizations in preparing their own standards. It prepares publications bearing on the application of safety standards.

In cooperation with Federal, State, and municipal agencies and technical and trade organizations, the Division of Codes and Specifications prepares minimum requirements suitable for adoption in building and plumbing ordinances. It compiles and disseminates information concerning the status of building and plumbing codes. It also assists local code committees in the revision of their local codes.

The Division collects and disseminates scientific, practical, and statistical information showing approved methods of building, planning, construction, standardization, and adaptability of structural units, including the selection and economic utilization of building materials. It investigates current developments in construction of dwelling houses, including new types of materials and their uses and new uses for existing materials. It assembles information concerning the care and maintenance of the various parts of houses and prepares pamphlets, articles, and reports on subjects of interest to home builders and home owners.

The Division establishes contacts with agencies making purchases out of tax moneys and with representatives of "over-the-counter" buyers to show benefits derived by using nationally recognized standards and specifications under the certification plan. It encourages manufacturers of staple goods to identify their commodities by labels 
to guarantee compliance with Federal specifications and commercial standards. It aids public purchasers in formulating, selecting, and unifying specifications and commodity acceptance testing methods. The Division compiles and keeps up to date directories of commercial testing and college research laboratories, and governmental testing laboratories. It prepares the National Directory of Commodity Specifications in which are classified and indexed references to all nationally recognized standards and specifications of technical societies and trade associations and agencies of the Federal Government.

The certification plan referred to above consists in the compilation and distribution by the National Bureau. of Standards of lists of sources of supply of commodities covered by certain selected Federal specifications and commercial standards. These lists contain the names of firms who have indicated their willingness to certify to purchasers, upon request, that the material supplied by them on contracts based on the selected specifications and standards does actually comply with the requirements and tests thereof and is so guaranteed by them.

This plan has already been applied to 810 Federal specifications and 54 commercial standards. The lists of sources of supply are distributed to tax-supported agencies (Federal, State, county, and municipal) and to all others upon request.

\section{COOPERATION WITH OTHER AGENCIES}

Much of the Bureau's work in research and testing is utilized in preparing commodity specifications for the Federal Government and other tax-supported agencies, in determining whether commodities purchased do actually comply with the specification requirements. A large part of the Federal purchases are tested at the National Bureau of Standards.

In cooperation with the Federal Specifications Executive Committee, Procurement Division, Treasury Department, of which the director of the National Bureau of Standards is chairman, members of the Bureau staff take a leading part in the preparation of Federal specifications. The Bureau is represented on 63 of the 71 technical committees functioning to date. It furnishes chairmen for 35, vice chairmen for 8 , and secretaries for 4 of these technical committees.

The staff of the Bureau takes part in the activities of 127 technical and trade organizations representing various fields of endeavor, including science, technical research, and trade, both national and international. It has representation on 910 technical committees of these organizations, many of which depend upon the Bureau's cooperation in carrying forward their scientific and technical activities. The Bureau has representation on 300 technical committees and subcommittees of the American Society for Testing Materials, which is devoted to the promotion of the knowledge of engineering and the standardization of specifications and methods of testing. Through this representation the Bureau holds chairmanship of 30 of the ASTM committees, vice chairmanship of 4, and secretaryship of 6 .

The Bureau is sponsor (or cosponsor) of 27 projects carried out under the procedure of the American Standards Association. It holds representation on 161 ASA technical committees, having chair- 
manship of 16, vice chairmanship of 2 , and secretaryship of 7. It is represented on the following coordinating agencies of the association: Board of Directors; Standards Council; Electrical Standards Committee; Mechanical Standards Committee; Advisory Committee on Ultimate Consumer Goods; Safety Code Correlating Committee; and Building Code Correlating Committee. All of the safety code, building code, and plumbing code requirements thus far formulated under the auspices of the Bureau have been accepted as a basis for the development of safety, building, and plumbing codes under the American Standards Association procedure. Two members of the staff of the association are located at the Bureau to facilitate the cooperative work of the two organizations.

The Bureau is specifically authorized by Congress to cooperate with tax-supported purchasing agencies, industries, and national organizations in developing specifications and facilitating their use; to encourage the application of the latest development in the utilization and standardization of building materials; and to develop engineering and safety codes, simplified practice recommendations, and commercial standards of quality and performance.

\section{COOPERATION WITH NATIONAL DEFENSE AGENCIES}

The National Bureau of Standards cooperates actively with the Office of Production Management, the Office of Price Administration War and Navy Departments, and other agencies of the Federal Government in many problems dealing with research and testing, simplification of manufactured products, unification of standards and specifications, conservation of materials, and utilization of substitute materials. Surveys and studies have already been made by the $\mathrm{Bu}-$ reau relative to conservation of scarce materials and other industrial items needed for immediate defense purposes. 
Appendix 2.

\section{PROCUREMENT DIVISION, U. S. TREASURY DEPARTMENT}

(Preparation of Federal and Procurement Division specifications)

The Procurement Division which was created in the United States Treasury Department by an Executive Order ${ }^{2}$ is responsible for the determination of policies and methods of procurement, warehousing, and distribution of property, facilities, improvements, machinery, equipment, stores, and supplies for all Federal establishments; and, with the exception of the Army, Navy, and Marine Corps, is directed to undertake the performance of procurement of all materials, supplies, and equipment for use either at the seat of the Federal Government or in the field for all existing Government agencies and such agencies hereafter created.

Standardization.-Standardization is an element considered in the operation of each specification. It is fundamental that the statement of quality shall be limited to that which is appropriate and necessary to the requirements to be served. That is to say, if a study of a need discloses that the quality originally indicated is inadequate or unnecessarily high for the purpose to be served, revision of the specification upward or downward to the level of the requirements is in order.

The chief responsibility for promoting standardization in procurement work centers in the Federal Specifications Division which is charged with the responsibility of determining the necessity for a Federal or Procurement Division specification.

Specifications.-Three types of specifications are developed in the Procurement Division:

1. A Federal Specification which is a formally approved standard of quality and essential characteristics (design, dimensions, composition, physical and chemical requirements, workmanship, finish, performance, etc.) of a material, article, or piece of equipment desired for a particular use by two or more departments or establishments of the Federal Government.

2. A Federal Procurement Division Specification which is a formally approved standard of quality and essential characterstic of a commodity to be incorporated in an invitation to bid issued by the Procurement Division.

\footnotetext{
2 Executive Order No. 6166, dated June 10, 1933, pursuant to the act of March 3, 1933 (47 Stat. 1517).
} 
3. A "specification" used in the Procurement Division which covers an item not covered by a Federal Specification and represents a commodity not in sufficient current demand to justify the develop. ment of a Federal Procurement Division Specification. It is referred to merely as "Procurement Division Specification."

Preparation of Federal Specifications.-With the installation of the Bureau of the Budget in 1921, it was considered to be desirable to prepare standardized purchase specifications for many of the commonly used articles purchased by the Federal Government; and the Federal Specifications Board was established for that purpose by Circular No. 42 of the Bureau of the Budget, dated October 10, 1921, which was issued by the Director of the Bureau of the Budget, by authority of the President. The Board functioned under the Chief Coordinator, whose office was also set up by Executive Order, each department and establishment purchasing materials and supplies in accordance with specifications, designating a representative to serve as a member of the Board. The chairman ex officio was the Director of the National Bureau of Standards. Technical committees were formed, composed of qualified representatives from the various branches of the Government, to formulate the specifications. 'These specifications, after consultation with the interested industries, were submitted to the departments for comment and criticism, and after consideration of these comments by the technical committees, were approved and promulgated by the Federal Specifications Board. On June 10, 1933, the Federal Specifications Board and several other interdepartmental boards were transferred to the jurisdiction of the newly established Procurement Division, United States Treasury Department. The Federal Specifications Board and several other activities of the Government were abolished by the order of the executive director of the National Emergency Council dated January $24,1935$.

To take the place of the former Federal Specifications Board members, the Director of Procurement, United States Treasury Department, requested the head of each department and establishment to designate a technical liaison with whom the Procurement Division was to collaborate, for that department or establishment, on technical matters. There was also established a Federal Specifications Executive Committee, consisting of the Director of the National Bureau of Standards, chairman; the Chief of the Federal Specifications Division, vice chairman; the assistant chief, Specifications Division of the Procurement Division, technical secretary; and the technical liaisons from the Navy Department, War Department, the Department of Agriculture, the Post Office Department, and Veterans' Administration. Technical committees were formed, composed of specialists from the various branches of the Government. 
There are 71 interdepartmental technical committees on Federal Specifications, covering the following group of materials:

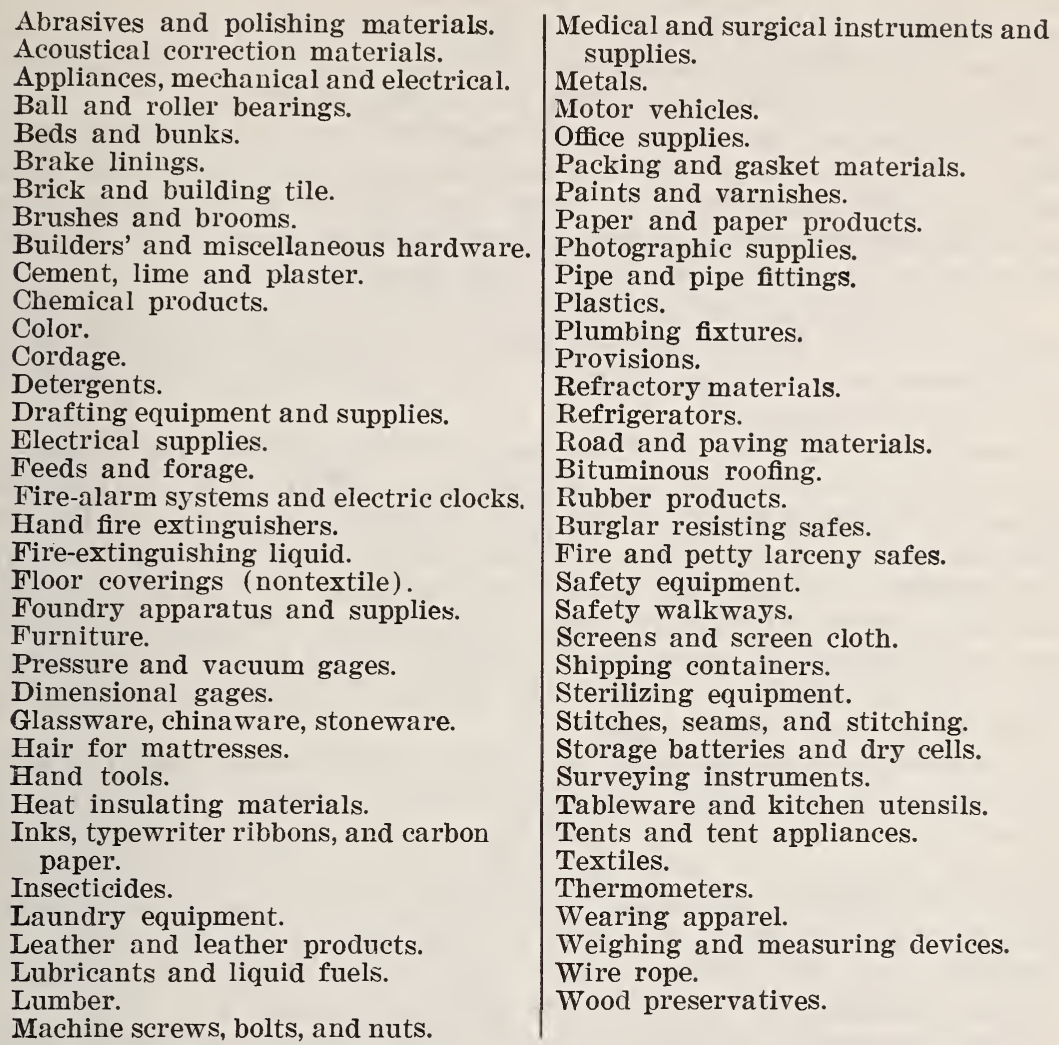

The procedure for the preparation of Federal Specifications is as follows: The interdepartmental need of a specification for a given article or material, for either technical or business reasons, having been decided upon, the subject is then referred to a technical committee composed of officially designated representatives from the various branches of the Government, who are most interested in the particular subject, for consideration of all existing governmental and industrial specifications. A specification is selected, or formulated, which will be suitable for the intended use by all departments and establishments of the Government. The cooperation and advice of interested commercial and industrial concerns is requested and their recommendations are fully considered by the technical committee. The specification, as tentatively agreed upon by the technical committee, is then submitted to all departments and establishments of the Government, through the respective technical liaisons with the Procurement Division, for comment and criticism. All criticisms received are referred to the respective technical committee for consideration. 
Specifications submitted in final form by the various technical committees, after consideration of all comments, are recommended by the Chairman of the Federal Specifications Executive Committee to the Director of Procurement for approval, after which they are printed and officially promulgated by the Director of Procurement for use by the various agencies of the Government.

In the preparation of Federal Specifications for material, supplies, and equipment, an effort is made to bring the specifications into harmony with commercial practice wherever conditions permit, to establish uniform nomenclature, and to standardize the types, grades, and sizes of articles purchased by the Government.

Federal Specifications are continually being revised to keep them abreast of the best current manufacturing practice, and the needs of the Government. Up to August 1, 1941, 1,354 Federal specifications had been promulgated. ${ }^{3}$

Preparation of Federal Procurement Division Specifications.Federal Procurement Division specifications are prepared in the office of the Federal Specifications Division, Procurement Division, United States Treasury Department. These specifications are approved by the Director of Procurement, and are primarily for use by that Department but may be used by any other agency. Procurement Division specifications frequently are preliminary to a Federal specification. Up to August 1, 1941, 242 Federal Procurement Division specifications have been issued."

Inspection.-The inspection activities of the Procurement Division are centered in the Inspection Division of the Stores and Operation Branch which inspects, in Washington and as occasion requires in the field, supplies and materials delivered on Procurement Division order. On request, it also makes inspections for other governmental agencies. In addition, it makes or has made tests of samples of materials, supplies, and equipment submitted with bids to determine whether the samples comply with the specifications.

When necessary, the Inspection Division investigates requests from various Federal agencies for clearance to buy in the open market items listed in the General Schedule of Supplies or carried in the warehouse stock of the Procurement Division. In the event that the contract or stock items meet all practical requirements of the need, such clearance to buy in the open market is denied.

The Inspection Division also contributes to the development of new or improved Federal Specifications or Federal Procurement Division specifications by recommending the formulation of specifications for new items or by suggesting modifications or improvements in existing specifications. These recommendations and suggestions are, in many cases, the result of conferences between the Inspection Division and contractors relative to rejected deliveries. These conferences frequently involve the interpretation by the Inspection Division of the provisions of the applicable specification. The Inspection Division also arranges for all technical help necessary for adequate inspection, either through its own limited facilities

\footnotetext{
3 An index of Federal specifications, and also the specifications listed therein, may be purchased from the Superintendent of Documents, United States Government Printing Office, Washington, D. C.

4 These specifications may be obtained on application to the Director of Procurement, United States Treasury Department, Washington, D. C.
} 
or through the laboratories of the National Bureau of Standards, the United States Department of Agriculture, or other recognized agencies.

All deliveries made through the Procurement Division are inspected by the Inspection Division. Responsibility for inspecting deliveries made in the field is generally fixed on the consignee but occasionally this Division makes inspections at the shipping point or at the factory.

The Inspection Division maintains a sample room where specimens of items included under General Schedule of Supplies contracts are stored and kept available for examination of prospective purchasing officers or for purposes of comparison with delivery samples.

The principal function of the Inspection Division is to assure that all commodities delivered are in conformity with the applicable specifications. In performing this work it-

1. Receives, records, has custody of, displays, and eventually disposes of bidders' contractors' samples;

2. Conducts or arranges for tests and prepares reports thereof;

3. Makes qualitative inspections at the Procurement Division warehouse, at various Treasury and other governmental agencies, and contractors' storage warehouses in the Washington area, and occasionally at points of manufacture or delivery in the field;

4. Investigates quality of, and reported deficiencies in deliveries to governmental departments and agencies in the Washington area (principally under General Schedule of Supplies contracts); and

5. Conducts interviews with contractors regarding interpretation of specifications and kindred matters resulting from rejected deliveries or other phases of inspection activity.

Inspection may be either an examination by a qualified individual or it may require the use of mechanical or chemical facilities in the laboratory. Many of the items purchased for stock, for instance, are approved largely on the basis of judgment of qualified inspectors. This applies particularly to commodities which are bought regularly and where simple measurement, comparison for color, and examination as to other qualities by experienced inspectors are adequate to establish compliance with specifications. However, a field delivery of heavy equipment may be tested by a selected engineer as to general fulfillment of specifications, including a performance test; or experts may be sent to inspect a large order of furniture or textiles in process at the factory or mill.

Cooperation in the National Defrense Program.-The Federal Specifications Executive Committee is collaborating with the Office of Production Management in the National defense program.

In order to conserve certain strategic materials for immediate defense purposes, the technical committees of the FSEC are making reviews of commodities covered by Federal specifications and issuing "emergency alternate" Federal specifications, wherever possible. Emergency alternate specifications, are developed under the direction of the Federal Specifications Executive Committee with the collaboration of the Purchases Division, Office of Production Management. These specifications, when approved by the Chairman of the Federal Specifications Executive Committee and by the Director of Procurement, are submitted for the immediate use of all departments and 
establishments of the Federal Government in the purchase of commodities covered by them. They may be considered as suitable alternates to the existing Federal specifications to which they apply.

Emergency alternate Federal specifications are limited only for the duration of the National emergency, following which the existing Federal specifications will automatically be in full force and effect again. 


\section{BIBLIOGRAPHY ON STANDARDIZATION}

[Compiled by Anne L. Baden, Division of Bibliography, Library of Congress, under the direction of Florence S. Hellman, chief bibliographer]

The following bibliography comprises references to the literature on the general subject of standardization.

Adams, James T., ed. Dictionary of American history. Vol. 5. New York, Charles Scribner's sons, 1940. 515 p. E171.A43, v. 5.

Bureau of Standards, by Wirt Bowden, p. 157.

Agnew, Paul G:

Defense needs spell speed-up for national standards: demands for new standards and need of revisions to bring existing standards up-to-date place heavy strain on American standards association machinery. Industrial standardization and commercial standards monthly, Dec. 1940, v. 11: 314-319. HD62.A15, v. 11.

Developing standards for consumer goods. Forecast, Nov. 1939, v. 55: 435-436. TX1.F7, v. 55.

Consumer standards on the way. Industrial standardization and com. mercial standards monthly, Feb. 1940, v. 11: 43-46. HD62.A15, v. 11.

How consumer standards fit into American standards association program : the organization of the Advisory committee on ultimate consumer goods and its relation to the general work of the American standards association. Industrial standardization and commercial standards monthly, Jan. 1937, v. 8: 167-170. HD62.A15, จ. 8.

How standards eliminate trade barriers. Industrial standardization and commercial standards monthly, Apr. 1940, v. 11: 81-87. HD62.A15, v. 11.

In step with the consumer; retailers now work with representatives of the public [American standards association]. Printers' ink, v. 179, June 3, 1937: 17, 20-21. HF5001.P7, v. 179.

International standardization in technology, industry and business ; United States and Latin America. Mechanical engineering, Feb. 1941, v. 63 : 139-140. TJ1.A72, จ. 63.

Man's love of round numbers; new American standard rules for rounding off numerical values. Industrial standardization and commercial standards monthly, Sept. 1940, v. 11: 230-233. HD62.A15, v. 11.

The movement for standards for consumer goods. American academy of political and social science. Annals, May 1934, v. 173: 60-69. H1.A4, v. 173. National standardization in America. Industrial standardization, July 1933, จ. 4: 107-114. HD62.A15, v. 4.

Discusses what industrial standardization is, types of standards, why standards are needed, standardizing agencies, and when to standardize.

Standards: action versus wishful waiting. Journal of home economics, Nov. 1934, v. $26: 541-545$. TX1.J7, v. 26.

Standards in our social order. Industrial standardization and commercial standards monthly, June, 1940, v. 11: 141-148. HD62.A15, v. 11.

Twenty years of standardization. Industrial standardization and commercial standards monthly, Oct. 1938, v. 9: 229-237. HD62.A15, v. 9. 


\section{Miscellaneous Publications, National Bureau of Standards}

Agnew, Paul G., and J. W. McNair. Certification and labeling activities in sixty commodity fields. American standards association. Bulletin, Jan. 1932, $\mathbf{v}$. 3: $1-24$.

Albrecht, G. Rationalisierung. (In Elster, Ludwig, ed. Wörterbuch de volkswirtschaften. 4. Aufl. Jena, Fischer, 1932, v. 2, p. 1193-1201.) HB61.E5, v. 2.

Alford, Leon Pratt. Principles of industrial management for engineers ... New York, The Ronald press company [ $\left.{ }^{\mathrm{c}} 1940\right]$. xxii, 531 p. incl. illus., diagrs., forms. $24^{\mathrm{cm}}$. HD31.A4.

"References for reading" at end of each chapter.

Simplified practice and engineering standards: p. 192-206. A few references are given.

American academy of political and social science. Standards in industry ... Editor in charge of this volume: Richard H. Lansburgh ... Philadelphia, The American academy of political and social science, 1928. viii, 282 p. illus., diagrs. $2412^{\mathrm{cm}}$. (Its Annals, vol. exxxvii [no. 226] May 1928.) H1.A4, v. 137. HD62.A6.

Contents. Foreword.-Standardization programs in industry.-Standardization programs of specific industries.-Standardization programs outside of industry.-Standardization and the consumer.

American hospital association. Manual of specifications for the purchase of hospital supplies and equipment. Chicago, American hospital association, 1941.

Specifications were prepared by several federal agencies including the Bureau of Standards, Navy Department, War Department, Veterans' administration, etc.

American management association. ... Standardizing office procedures, by H. C. Wheeler ... Marie P. Sealy ... John F. Pierce ... [and others] New York, N. Y., American management association, ${ }^{c} 1937.42 \mathrm{p}$. illus. (incl. form) diagrs. $23^{\mathrm{cm}}$. (Its Office management series, no. 80). HF5547.A68.

"Presented at the Office management conference of the American management association held at [New York] ... October 21-22, 1937."-p. [2]

American management association. The management index, a subject index to publications of the American management association, January 1923-January 1932. New York, N. Y., American management association, 1932. 92 p. Z7914.A2A5.

— Supplement. New York, 1934. 10 numb. 1.

- Supplement. New York, 1940. $47 \mathrm{p}$.

Includes references on standards.

American petroleum institute. Committee on the standardization of oil-field equipment. Report. American petroleum institute. Proceedings, May, 1939, จ. 20M (4) : 104-217. TN860.A53, v. 20M.

American public works association. Standard specifications for public works construction, prepared by the specifications committees of the American public works association. Chicago, Ill., American public works association, ${ }^{\mathrm{c}} 1937 . \quad 1$ v. TA180.A55.

American society for testing materials:

Book of A. S. T. M. standards including tentative standards (a triennial publication), 1939. Philadelphia, American society for testing materials, 1939. 3 v. TA401.A653 1939.

Part 1, Metals; part 2, Nonmetallic materials : constructional; part 3, Nonmetallic materials : general.

A. S. T. M. standards, including tentative standards; 1940 supplement. Philadelphia, American society for testing materials 1940 . $3 \mathrm{v}$.

Part 1, Metals; part 2, Nonmetallic materials : constructional; part 3, nonmetallic materials ; general. 
American society for testing materials-Continued.

Brief review of work of American society for testing materials during 1940: important accomplishments. Its Bulletin, no. 102, Jan. 1940: 50-52. TA401.A68, no. 102.

Bulletin. Philadelphia, American society for testing materials, 1933 date. TA401.A68.

Index to A. S. T. M. standards, including tentative standards of December, 1940. Philadelphia, American society for testing materials, 1940. $164 \mathrm{p}$. TA401.A652 1940 .

Index to proceedings, 1931-1935. Philadelphia, American society for testing materials, 1937. 194 p. TA401.A5 Index.

See also Index to proceedings. volumes 26-30 (1926-1930). Philadelphia, 1932. 251 p.

Outline of standardization procedure. Its Bulletin, no. 106, Oct. 1940: 45. TA401.A68, no. 106.

Proceedings of the $43 \mathrm{~d}$ annual meeting held at Atlantic City, N. J., June 24-28, 1940; committee reports, technical papers. Philadelphia( American society for testing materials, 1941. 1396 p. TA401.A5 1940.

See also previous issues.

Records broken in 1939- much active work under way. Committee officers outline many active research and standardization projects in process; several new and important accomplishments during 1939. Its Bulletin, no. 102, Jan. 1940: 8-10, 43-55. TA401.A68, no. 102.

Standardization activities under way. Committees have many specifications and tests in process. Its Bulletin, no. 105, Aug. 1940: 46-49. TA401.A68, no. 105 .

Year book, 1940. Philadelphia, American society for testing materials, 1940. 112 p. TA401.A6.

See also previous volumes.

American society for testing materials committees propose 72 new standards. Industrial standardization and commercial standards monthly, Aug. 1938, v. 9: 191-194. HD62.A15, v. 9.

American society for testing materials approves $\mathbf{7 7}$ new tentative standards. Industrial standardization and commercial standards monthly, Aug. 1940, v. 11: 214-219. HD62.A15, v. 11.

American society for testing materials committees plan more work and undertake new research programs. Industrial standardization and commercial standards monthly, Apr. 1941, v. 12: 92-95. HD62.A15, v. 12.

American Standards Association:

American standards approved by the American standards association, March 15, 1937: indexed list of engineering and industrial standards and safety codes. New York, American standards association, 1937. 12 p. Z7914.A22A5 1937.

American standards [indexed]. New York, American standards association, 1941. $15 \mathrm{p}$.

American standards association: what it is, how it works, membership, services. Industrial standardization and commercial standards monthly, June 1939, v. $10: 140-141$. HD62.A15, v. 10.

American standards year book. New York City, American standards association, 1922-1938. TA1.A645. 


\section{Miscellaneous Publications, National Bureau of Standards}

American standards association-Continued.

Committee on standards for graphic presentation. Time-series charts; a manual of design and construction. American standards, approved by American standards association, November 1938. Prepared by Committee on standards for graphic presentation. The American society of mechanical engineers, sponsor body. New York, N. Y. [1938]. 68 p. diagr's. $261 / 2 \times 201 / 2^{\mathrm{cm}}$. QA90.A65 1938.

"This manual represents a rather comprehensive revision of the material issued in April, 1936, under the title, "Code of preferred practice for graphic presentation-timeseries charts'."-Foreword.

New foreign standards received by the American Standards Association. Industrial standardization and commercial standards monthly, Feb.-Mar. 1941, v. 12: 47 ; 66. HD62.A15, v. 12.

These standards are available to members of the Association.

Price lists of American standards; indexed. New York, American standards association, 1940. $12 \mathrm{p}$.

Standards activities. Industrial standardization and commercial standards monthly, Apr. 1941, v. 12: 107. HD62.A15, v. 12.

American standards association. Science, n. s., v. 91, Jan. 12, 1940: 38. Q1.S35, n. s., v. 91.

American standards association and the United States Treasury. Science, n. s., v. 91, Mar. 17, 1940: 470. Q1.S35, n. S., v. 91.

American standards association completes its twenty-first year; progress ; projects. Science, n. s., v. 91, Jan. 12, 1940: 38-39. Q1.S35, n. s., v. 91.

Anderson, R. P.:

Committees show active year on standardization projects ; American standards association's standards council. Industrial standardization and commercial standards monthly, Dec. 1940, v. 11: 308-313. HD62.A15, v. 11.

How American standards are produced; the what and why of American standards association procedure. Industrial standardization and commercial standards monthly, Feb. 1939, v. 10: 33-35. HD62.A15, v. 10.

Armstrong, E. F. Standards of quality and methods for establishing them. Royal society of arts (London). Journal, Dec. 30, 1938, v. 87: 184-198. T1.S64, v. 87.

Discussion of industrial standardization in Great Britain and development and activities of British standards institution; includes brief reference to standardization in the United States.

Aronson, Jacob P. Legal aspects of standardization. Legal issues involved in buying and selling under statutory standards reviewed. U. S. Bureau of Standards. Commercial standards monthly. Dec. 1931, v. 8: 184-185. HD62.U3, v. 8.

Balderston, C. Canby. Management of an enterprise, by C. Canby Balderston ... Victor S. Karabasz ... and Robert P. Brecht ... New York, Prentice-Hall, inc., 1935, xiv p. 1 l., 470 p. illus., diagrs. $231 / 2^{\mathrm{cm}}$. T56.B3.

Output and operating standards : chapter 7. Selected bibliography : p. 457-461.

Barley, L. J. The riddle of rationalisation. London, G. Allen and Unwin, It 1932. 148 p. HD82.B3.

Barnes, Ralph Mosser. Motion and time study ... 2d ed. New York, J. Wiley \& sons, inc.; London, Chapman \& Hall, limited, $1940 . \quad$ xi, 390 p. illus., double plates, diagrs. $231 / 2{ }^{\mathrm{cm}}$. T58.B245 1940 .

Bibliography : p. 379-382.

Standardization; written standard practice: p. 245-249, 
Barnum, D. D. :

The American standards association; what it is doing for industry. Industrial standardization and commercial standards monthly, Mar. 1936, v. 7: 53-56. HD62.A15, v. 7.

Business and government cooperate for progress in standardization. Industrial standardization and commercial standards monthly, Aug. 1936, จ. $7:$ 209-211. HD62.A15, v. 7.

1937 emphasizes growth in American standards association program. Industrial standardization and commercial standards monthly, Dec. 1937, v. 8: 315-317. HD62.A15, v. 8.

Bassett, H. N. The value of specifications in control of supplies. Society of chemical industry. Journal (Chem. \& ind.), Sept. 18, 1931, v. 50: 772-774. TP1.S6, v. 50 .

Batt, W. S. Management and the public: standardization. Industrial standardization and commercial standards monthly, Dec. 1938, v. 9: 292-295. HD62.A15, จ. 9 .

Benkert, H. Wege der rationalisierung in industrie-betrieb. Vereines deutscher ingenieure (Berlin). Zeitschrift Nov. 12, 1938, v. 82: 1314-1323. TA3,V5, จ. 82.

Berg, Rose M. Bibliography of management literature (up to January, 1931). New York, N. Y., The American society of mechanical engineers, 1931. $142 \mathrm{p}$. Z7914.A2B4 1931.

Standardization : p. 122-127.

Supplement. New York, N. Y., 1937. 88 p. Processed. Z7914.A2B4 1931, suppl.

Standardization: p. 76 .

Berger, Maurice. Principes généraux de normalisation. Société des ingénieurs de l'automobile. Journal, Feb. 1938, ₹. 11: 31-50.

Discusses general principles of standardization, fundamental standards for current application with reference to French practice. References are given.

Bills, Marion Almira. Measuring, standardizing and compensating for office operations. ... New' York, N. Y., American management association, '1929. 40 p. $23^{\mathrm{cm}}$. [American management association] Office management series: no. 44.) HF5549.B47.

Discussion : p. 17-39.

Birble, J. Le Ve congrès de l'international standardizing association (Stockhnlm, septembre 1934) Gènie civil (Paris) Dec. 1, 1934, v. 105: 502-504. TA2.G3, จ. 105.

Reports of subcommittees on standardization of rolling mills, automobiles, agricultural products, aviation, preferred numbers, etc.

Blauchet, P. La normalisation dans les industries mécaniques. Association technique maritime et aeronautique (Paris). Bulletin, 1937, no. 41:361-374. VM2.A75, no. 41.

Deals with the principles of standardization, methods and aims, preferred numbers. tolerances, standardization of dimensions, temperatures, etc.

Bogart, Ernest L., and Charles E. Landon. Modern industry. New York, Longmans, Green \& co., 1927. 593 p. HD2321.Bร̌5.

The benefits of standardization: p. 567-568.

Bonow, Mauritz. Some aspects of the rationalization of production and distribution, based on Swedish experience. Society for the adrancement of management. Journal, July-Sept. 1938, v. 3: 120-125. T58.T4A12, v. 3. 
Boren bill and standards for consumer goods. Journal of home economics, Mar. 1940, v. $32:$ 170-172. TX1.J7, v. 32.

Brady, Robert A. The meaning of rationalization: an analysis of the literature. Quarterly journal of economies, May 1932, v. 46 : 526-540. HB1.Q3 v. 46.

Footnote references are given.

Brady, Robert. The rationalization movement in German industry; a study in the evolution of economic planning, by Robert A. Brady. Berkeley, Calif., University of California press, 1933 . xxi, $466 \mathrm{p}$. tables ( 1 fold.) diagrs. $24^{\mathrm{cm}}$. HC286.3.B66.

Organizations promoting rationalization in Germany: p. 422-426. Bibliographical footnotes.

Contents: Part 1, The elements and organization of the German rationalization movement; part 2, Evolution and problems of the German rationalization movement in selected industries. 1924-1929; part 3, The incidence and implications of rationalization.

Briggs, Lyman J.:

Commercial standardization services of the Bureau of Standards. Industrial standardization, Aug. 1933, v. 4: 129-130. HD62.A15, v. 4.

Government specifications; pioneer consumer standards. Industrial standardization and commercial standards monthly, June 1937, v. 8: 170-172. HD62.A15, v. 8.

The National bureau of standards. Applied physics, May 1937, จ. 8: 298-306.

Gives a history of the Bureau and discusses its functions, organization, laborators facilities and present work.

Some problems of the National bureau of standards. Franklin institute. Journal, Jan. 1937, v. 223 : 1-21. T1.F8, v. 223.

Services of the National Bureau of Standards. American academy of political and social science. Annals, May 1934, v. 173: 153-166. H1.A4, v. 173.

Contents include: Appropriations for the Bureau; Bureau activities of value to consumers; Relative merits of competing commodities; The certification plan; The labeling plan.

British standards institution. Handbook of information: including annual report, 1938-1939, indexed lists of British standards, and British standards method of test, July, 1939. London, British standards institution, 1939. 214 p. QC100.B7 1939.

British standards institution. [Reports]. London, British standards institution, 1933-1939. TA368.B8.

Bureau international des poids et mesures. Revue scientifique, Nov. 14, 1936, v. 74: 670. Q2.R53, v. 74 .

Burnham, Thomas H. Engineering economics. Book II: works organization and management. London, Sir I. Pitman \& sons ltd., 1937. 312 p. T56.B8 1937.

Standardization : p. 85-94. Includes discussion of simplification, the field of standardization, advantages of standardization, and its disadvantages and foreign standardizing organizations. References: p. 94.

Carlson, John A. Industriens rationalisering. En praktisk handbok. 2. omarb. uff. Stockholm, Natur o. kultur, 1940. 136 p.

Carpenter, Charles E. Dollars and sense. Garden City, New York, Doubledav, Doran \& co. 1928.256 p. HD62.C3 1928.

Contents include chapters on: Standardization, Standardized specifications, More standardized specifications, and the National Bureau of Standards. 
Chamber of commerce of the United States. Domestic distribution committee. Standardization of consumers' goods. Report. Washington, D. C., Chamber of commerce of the United States, 1934. 14 p. Leg. Ref. Ser.

Contents include: The movement for standards; Inclustrial and consumers' grades ; Commercial standards and grading; Simplification; Brands-labeling-certification ; The Bureau of Standards; Goverumental-imposed standards; Other standardization agencies; American standards association.

Chase, Stuart. The tragedy of waste. New York, The Macmillan co., 1925. 296 p. HC106.3.C53.

Bibliography : p. 281-292

Standardization and simplification : p. 167-174.

Chisholm, Cecil. Simplified practice. London, Chapman \& Hall. Itd., 1927. 151 p. T58.C43.

Bibliography of simplification : p. 147.

Clarkson, Grosvenor B. Industrial America in the World War; the strategy behind the line, 1917-1918. New York, Houghton Mifflin co., 1923. 573 p. HC106.2.C67.

Consult Index under Standardization.

Cogan, C. M. Electrical manufacturers cooperate in national standardization program. Industrial standardization and commercial standards monthl, , June 1939, $\nabla$. . 10: 165-167.

National industrial manufacturers associations, and other trade associations and technical societies which have effective standardization programs, coordinate their standards through American standards association to eliminate duplication of effor't and conflicting requirements.

Cohan, S. Two years of reconstruction [text is in Russian]. Vestnik standartizatsii, Sept.-Oct. 1934, no. 50: 3-6. HD62.A184, no. 50 .

A review of two years standardization progress in Russia with special reference to policies by the government in 1932 and 1933.

Coles, Jessie Vee :

Standards for consumers' goods. Scholastic, v. 26, Feb. 9, 1935: 14-15. AP2.S295, v. 25.

Standardization of consumers' goods; an aid to consumer-buying ... New York, The Ronald press company [ $\left.{ }^{\mathrm{C}} 1932\right]$. $\mathrm{x}, 323 \mathrm{p} .22^{\mathrm{cm}}$.

Bibliography : p. 299-312.

Contents include: Part II, The nature of standards and standardization; part III, The process of standardization; part IV, Present status of standardization.

Committee on standards for libraries and periodicals. School and society, Aug. 13, 1938, v. 48: 197. L11.S36, v. 48.

Conference on weights and measures of the United States. ... Standardization of packages. (Reprinted from Miscellaneous publication M164) Issued April 2, 1940. Washington, U. S. Govt. print. off., 1940 . ii, 79-128 p. $23^{\mathrm{cm}}$. (U. S. National bureau of standards. National bureau of standards miscellaneous publication M165) QC100.U57, no. 165. HF5770.C55.

"The material comprising this publication is a direct reprint from National bureau of standards Miscellaneous publication M164, Report of the twenty-ninth national Conference on weights and measures, and presents the full text of the report for the fifth and sixth sessions of the Conference, which were devoted entirely to the subject of standardization of packages."-Pref.

Les Conférences internationalen de normalisation (Paris, 14-26 juin 1937). Génie civil (Paris) Aug. 18, 1937, v. 111: 194-195. TA2.G3, v. 111.

Coonley, Howard :

The American standards association ; outline of work. Electrical engineering, July 1935, v. 54: 791. TK1.E45, v. 54. 
Coonley, Howard-Continued.

Standards-effective tool for managerial control. Industrial standards and commercial standards monthly, June 1939, v. 10: 133-136. HD62.A15, v. 10.

The experience of the author's firm, manufacturers of pipe fittings and valves, with standardization as a managerial tool.

Coonley, Howard, and Paul G. Agnew :

The role of standards in the system of free enterprise; a study of voluntary standards as alternative to legislative and commission control. Prepared by request of the Temporary national economic committee. New York, American standards association, 1941. 12 p. (Industrial standardization and commercial standards monthly, April 1941, part 2) HD62.A15.

Contents include: Standardization; Standards as definition; Standardization methods and machinery; Group standards; National standards; Developing a consensus; The human element; The three fundamentals; Industry-government relations ; Comparison of the common-law, statute-law and commercial methods with standardization method; Flexibility of the standardization method; Solution rather than compromise; Limitation of the standardization method; What should not be standardized; Forms of business and social control ; National standards as preventatives of trade barriers; Employer-employee relations ; Standards for consumer goods ; Certification and labeling; Standards needed to determine truth or falsity of advertising; Standards reveal concealed price increases in periods of changing price levels; Importance in national defense.

Cornell, William Bouck. Organization and management in industry and business ; a revision of "Industrial organization and management" ... New York, The Ronald press co. [ $\left.{ }^{c} 1936\right]$ xxiii, 802 p. incl. illus., diagrs., forms. fold. plan. $21^{\mathrm{cm}}$. T56.C55 1936.

Bibliography : p. 785-790.

See Index under Standaardization; Standards.

Courtney, J. H. :

The federal government and standardization: chart showing the present organization, with analysis showing sections interested in standardization. Industrial standardization and commercial standards monthly, Nov. 1939, จ. $10: 279-281$. HD 62.A15, v. 10.

How federal government agencies carry out standardization activities. Industrial standardization and commercial standards monthly, July-Aug. 1939, v. 10 : 169-174; 211-214. HD62.A15, v. 10.

Coutrot, J. La normalisation: régulateur de l'economie complément du progrès technique. Chimie et industrie, Jan. 5, 1940, v. 43: 81-82. TP1.C44, v. 43.

Crowell, Evelyn M. The buyer in wonderland. Commonweal, Mar. 15, 1940, v. 31: 450-453. AP2.C6897, v. 31.

Curti, R., and C. A. Silvestri. L'unificazione in Italia. Ingegnere (Milan) Sept. 15, 1939, v. 17 : 785-790. TA4.117, v. 17.

Reviews the development of the principal standardization organizations of Italy and their work; enforcement of standards in Italy; program for further development.

Denny, A. Industrial standardization, 1910-1935. Engineering (London) May 3, 1935 (special jubilee section) : 17. TA1.E55, v. 139.

Dodge, H. F. Statistical methods as aid to quality standardization and control. American society for testing materials. Bulletin, no. 84, Jan. 1937:8-9. TA401.A68, no. 84 .

Donovan, John M. F., Jr. How trade associations activities aid standardization activities. Dun's review, v. 47, Feb. 1939: 13-18. HF1.D8, v. 47.

"Trade association activity in standardization of products has resulted in tremendous and almost inestimable benefits to many American businesses. The only obstacles to prevent full and complete adoption of all forms and types of standardization are the prohibitions laid down by the Federal anti-trust laws and interpretive decisions thereunder"; p. 13. 
Dresser, C., and J. O. Cooke. Industrial standardization in the mechanical engineering industry. ( $I n$ Institution of mechanical engineers. Proceedings. London, 1934. v. 124, p. 737-742.) TJ1.I5, v. 124.

Dunkley, S. F. Standardization and quality control. Gas journal (London) Jan. 30-Feb. 6, 1935, v. $209: 252-258 ; 317-325 . \quad$ TP700.J8, v. 209.

Edwards, Alice Leora. Product standards and labeling for consumers. New York, The Ronald press company [ $\left.{ }^{\mathrm{c}} 1940\right]$ viii, $134 \mathrm{p} .22^{\mathrm{cm}}$. HD62.E35.

Contents: Standards: stepping stones to progress; Tools of industrial conquest; Guides for ultimate consumers; Developing new procedures ; The agriculturalist's friend; Guards for public protection; Simplification and standards; Toward fairness for all; With common interests; Industry in the lead; From both sides of the retail counter; By way of illustration; Pointing the way ; Appendix.

References : p. 125-126.

Elbourne, Edward Tregaskiss. Fundamentals of industrial administration; an introduction to industrial organisation, management and economics, by Edward Tregaskiss Elbourne ... assisted by Kenneth B. Elbourne ... and P. J. Amer. London, Macdonald \& Evans, 1934. xviii p., 1 l., 644 p. illus., diagrs. $22^{\mathrm{cm}}$. HD31.E5.

Bibliographical index : p. 622-626.

See Index under Standardization.

Ely, Edwin W. Applying simplified practice to machinery. Investigation carried on by Bureau of standards in cooperation with industry. U. S. Bureau of standards. Commercial standards monthly, Apr. 1932, v. 8: 305. HD62.U3, v. 8.

Engel, Leonard H. Wearing things out; scientists destroy all manner of things to see how good they are. Science news letter, Sept. 10, 1934, v. 34: 170-172. Q1.S76, v. 34 .

Engineering Index, 1933-39. New York, Engineering index, inc., 1934-1940. Z5851.E62.

See each volume under Standardization.

Entea nazionale per l'unificazione nell' industria. Industria meccanica (Milan) July 1933, v. 15 : 542-545. TJ4.I5, v. 15.

A review of standardization progress by the Italian National committee on industrial standardization and similar bodies, and includes a list of recently published foreign standardization documents.

Farmer, F. M. New projects, national and international, broaden the scope of American standards association's activities. Industrial standardization and commercial standards monthly, Dec. 1938, v. 9: 288-291. HD62.A15, v. 9.

Farmer, F. M. Standardization and the institute. Electrical engineering, Oct. 1940, v. 59: 395-397. TK1.E45, จ. 59.

Farrer, H. E. Standards activities of the American institute of electrical engineers and American standards association. Electrical engineering, Apr. 1939, จ. 58: 164. TK1.E45, จ. 58.

Fawcett, W. Standardization of specifications. American dyestuff reporter, Mar. 11, 1935 v. 24: 132-134. TP890.A6, v. 24.

Ffield, Paul. Specifications in shipbuilding. American society for testing materials. Bulletin, no. 103, Mar. 1940: 25-26. TA401.A68, no. 103.

Fisher, Mrs. Dorothea (Canfield). Lo, the poor introvert. Harper's magazine, Dec. 1932, v. 166: 78-85. AP2.H3, v. 166.

Fleming, P. Preferred numbers and the civil engineer. Engineering news, June 11, 1936, v. 116: 846-847. TA1.E6, v. 116. 
Forbes, Russell. Expert on governmental purchasing discusses buying on specifications. American standards association. Bulletin, v. 2, Dec. 1931: 11-15.

Foth, Joseph H. Trade associations; their services to industry. New York, The Ronald press co., 1930. 338 p. HD2425.F6.

Industrial standardization and simplification: chapter 9.

Quality standardization: chapter 10.

Frank, O. Die anwendung der dezimalklassifikation in der normung. Sparwirtschaft, Oct. 1935, v. 13: 216-264.

Use of decimal classification in international standardization, etc.

Frey, Albert Wesley. Manufacturers' product, package, and price policies; modern merchandise management .... New York, The Ronald press company ['1940]. xii, 429 p. $22^{\mathrm{cm}}$. HF5415.F79.

References at end of most of the chapters.

Influences affecting standards: chapter 4; Simplification: chapter 8 . See also Index under Standardization; Standards.

Gaillard, John :

Industrial standardization, its principles and application ... New York, The H. W. Wilson co., 1934. 3 p. l., 123 p. diagrs. $24^{\mathrm{cm}}$. T59.G3 1934.

Issued also as the author's inaugural dissertation, Delft. 1933, under title : A study of the fundamentals of industrial standardization and its practical application, especially in the mechanical field.

Contents : Evolution of standardization : Essential functions of industrial standardization; Definition and characteristics of a standard; Normal values and limits : Derelopment of the practical application of standardization; Standardization in a manufacturing concern; Organization of standardization work.

The value of national standardization to American industry. American standards help to effect savings in manufacturing. Industrial standardization, Sept. 1932, v. 3: 243-246.

Paper presented before the American society of mechanical engineers, Cincinnati, Ohio, May 12, 1932.

International developments in standardization work; report on Interna. tional standards association meetings, Budapest, September, 1936. Industrial standardization and commercial standards monthly, Dec. 1936, v. 7 : 323-325. HD62.A15, v. 7.

Library work; a field for standardization. Industrial standardization and commercial standards monthly, June 1938, v. 9: 141-142. HD62.A15, v. 9.

Nineteen International standards association committees meet to consider standards. Industrial standardization and commercial standards monthly, Oct. 1937, v. 8 : 269-273. HD62.A15, จ. 8.

Standardization, the automatic pilot of management; standards in merchandising, selling, research; organizing for standardization. Advanced management, 1939 , v. 4 , no. 5: 145-159.

With special reference to standards departments.

Standardization, the key to coordination; streamlined management. Industrial standardization and commercial standards monthly, Sept. 1936, v. 7 : 221-225. HD62.A15, จ. 7.

This mechanical age: American standards speed production. Industrial standardization and commercial standards monthly, Sept. 1937, v. 8: 237-240. HD62.A15, v. 8.

Where to start company standardization. Industrial standardization and commercial standards monthly, Sept. 1938, v. 9: 209-210. HD62.A15, v. 9.

Girardeau, R. De la normalisation en général. Revue scientifique, Nov. 23, 1935, v. 72: 728-731. Q2.R53, v. 72. 
Glover, John George. Managerial control ; instruments and methods in industry, by John G. Glorer ... [and] Coleman L. Maze ... New York, The Ronald press co., [ ${ }^{\mathrm{c}} 1937$ ]. xviii, $574 \mathrm{p}$. incl. illus., forms. diagrs. (1 fold.) $\left(21^{\mathrm{cm}}\right.$. HD31.G55.

See Index under Standardization.

Gnatorski, S. :

The most important stages in standardization [text is in Russian]. Vestnik standartizatssi, Jan.-Feb. 1934, no. 55: 13-21; Mar.-Apr. no. 56: 13-20. HD62.A184, nos. 55-56.

Includes discussion of the difficulties of the Russian Standardization Committee in enforcing standards in various industries.

Scientific research work in standardization [text is in Russian]. Vestnik standartizatsii, Sept.-Oct., 1934, no. 50:6-13. HD62.A184, no. 50.

Reviews the relation between scientific research and standardization of all production in Russia, and recommends measures for improvement of standardization activities within scientific research institutes.

Good, P. How industry and government work through British standards institution. Industrial standardization and commercial standards monthly, June 1939, จ. 10 : 163-164. HD62.A15, v. 10.

Deals with standardization principles under which British industry and government cooperate in the development of national standards through British standards institution; both the British national standardizing body and American standards association operate in much the same way.

Grades in commercial standards. Journal of home economics, Feb. 1937, จ. 29: 104-105. TX1.J7, จ. 29.

Gramenz, Karl. ... Die din-passungen und ihre anwendung ... 3. rollständig, neubearb. auf. Berlin, Beuth-rerlag. gmbh., 1934. 232 p. incl. tables, diagrs. $21^{\mathrm{cm}}$. (Dinbuch 4) TJ233.G6 1934 .

Literaturnachweis: p. 230-231.

Gratama, B. M. The development of international standardization. Engineering (London), July 1, 1932, v. 134: 25-27. TA1.E5̄5, v. 134.

Grimes, Mary A. Report of the Texas committee on the standardization of consumer goods. Journal of home economics, Mar. 1940, v. 32: 162-164. TX1.J7, v. 32 .

Guadfliege, F. H. Rationalisierung und organisches prinzip. Deutsche volkswirtschaft, Feb. 1939, v. 8: 143-146.

Gual Villalbí, Pedro. ... Principios y aplicaciones de la organización científica đel trabajo (obra de vulgarización) Barcelona, Editorial Juventud, s. a. [1929]. $378 \mathrm{p}$. incl. illus., diagrs., forms. $\times \mathrm{pl} .211 / 2^{\mathrm{cm}}$ : T56.G8.

Chapters 6 and 7 deal with standardization.

Harper, H. American standards guide manufacturing and selling. Industrial standardization and commercial standards monthly, May 1934, v. 5: 88-89. HD62.A15, v. 5.

Harriman, Norman Follett. Standards and stardardization. 1st ed. New York [etc.] McGraw-Hill book company, inc., 1928. xvi, 265 p. illus., diagrs. $231 / 2^{\mathrm{cm}}$. (McGraw-Hill industrial management series. D. S. Kimball, consulting editor). QC100.H3.

Bibliography : p 243-247.

Contents: Evolution of standards, industry and standardization ; Standards ; Standardization, general considerations ; Standardization, particular considerations; Standardization of quality, specifications; National standardizing bodies; Investigational and national standardizing laboratories; Trend of standardization; Standardization and coordination of government purchases.

$201072^{\circ}-41-17$ 
Harvey, J. Standardization, force in promoting safety. Industrial standardization and commercial standards monthly, July 1939, v. 10: 189-191. HD62.A15, v. 10.

National conservation bureau cooperates in American standards association program, developing national standards to consolidate gains in combating accidents.

Hays, Margaret B. Consumer specifications for textiles. Journal of home economics, Oct. 1939, v. 31: 560-652. TX1.J7, v. 31 .

Hecker, G. C. The transit industry's 36-year program proves the value of standardization. Industrial standardization and commercial standards monthly, Oct. 1939, v. 10: 258-262. HD62.A15, v. 10.

Hellmund, R. E. :

Standardization and profits aided by preferred numbers. Electrical world, Aug. 18, 1934, v. 104: 208-211. TK1.E5, v. 104.

Standardizing sizes and ratings. Electrical engineering, Jan. 1932, v. 51: 14-19. TK1.A613, v. 51.

Argues that marked economies may be secured by standardizing industrial products to eliminate all unnecessary sizes and ratings. Based upon a system of preferred numbers, selection of desirable sizes may be made with reasonable accuracy through the use of algebra and geometry supplemented by jurgment and common sense.

Hildage, Henry Thomas. The new management, by H. T. Hildage ... T. G. Marple ... and F. L. Meyenberg ... London, Macdonald \& Evans, 1938. xxiii, 358 p. diagrs. $22^{\mathrm{cm}}$. T56.H5.

Rationalisation: p. 187-201. See also Index under Standards.

Holden, James W. :

Uncle Sam's house of wonders. Review of reviews, v. 96, July 1937: 40 AP2.R4, v. 96. Same abstracted Reader's digest, v. 31, July 1937: 65-68. AP2.R255, v. 31.

Deals with the activities of the United States National Bureau of Standards.

Holden, Paul E., L. S. Fish and H. L. Smith. Top-management organization and control ; a research study of the management policies and practices of thirtyone leading industrial corporations, conducted under the auspices of the graduate school of business, Stanford university. Stanford University, Calif., Stanford university press, 1941. 239 p. Standard practices: p. 165-169. HD31.H6.

Hotchkiss, G. B. Milestones in the history of standardizing consumers' goods. American marketing journal, Jan. 1936, v. 3: 70-78. HF5415.A2A6, v. 3.

House subcommittee completes hearing on Boren bill to establish standards for consumer goods. Industrial standardization and commercial standards monthly, v. 11, Feb. 1940: 40-41. HD62.A15, v. 11.

How Argentina develops its national standards. Industrial standardization and commercial standards monthly, Mar. 1941, v. 12: 58-59. HD62.A15, v. 12.

Deals with the organization and work of the Argentine Institute of Standardization of Materials.

How the Army and Navy cooperate on standards for purchasing. Industrial standardization and commercial standards monthly, Dec. 1940, v. 11: 114-119. HD62.A15, v. 11.

Hubbard, G. Has your organization a standards book? Management review, Dec. 1936, v. 25: 386-387. T58.A2M37, v. 25.

Huber-Ruf, A. International standardization. Engineering (London) Aug. 31, 1934, v. 138: 219. TA1.E55, v. 138.

Brief discussion of the particulars of the activities of the International federation of national standardizing association. 
Hudson, Ray. M. Government interest in the advancement of standardization. (In World power conference, 2d, Berlin, 1930. Transactions. Berlin, 1931, v. 18, p. 255-275) TJ5.W6 1930, v. 18.

Historical sketch of the standardization movement in the United States.

Iddles, A. National defense production needs coordinated standards. Industrial standardization and commercial standards monthly, July 1940, v. 11: 165169. HD62.A15, v. 11.

Industrial Arts Index; subject index to a selected list of engineering, trade and business periodicals, books, and pamphlets. New York, The H. W. Wilson co., 1933-date. Z7913.17.

See each vol. under Standardization; Standards.

International labor office, Geneva. The social aspects of rationalisation. Introductory studies. Geneva, International labor office, London, P. S. King and son, 1931. 381 p. (Studies and reports, series B, Economic conditions no. 18.) HD4813.15, ser. B., no. 18.

International management institute., Bulletin, August, 1927-December, 1933. Geneva, 1927-1934. 7 v. T58.A21852.

No more published.

In English, French, and German.

Irwin, J. C. 1936 standardization program lists many pressing problems. Industrial standardization and commercial standards monthly, Dec. 1936, v. 7: 307-310. HD62.A15, v. 7.

Jamesen A. Winning a government. New outlook, v. 164, Dec. 1934: 10-14. Reply by A. V. Fowler, v. 165, Feb. 1935: 4. AP2.08, v. 164.

Jenkins, F. G. Material standardization. Iron age, v. 147, Feb. 20, 1941: 35-39; Feb. $27: 52-55$. T1.17, v. 147.

Jewett, F. B. Some fundamentals in standardization; thirty years in retrospect. Edison electric institute. Bulletin, Dec. 1937, v. 5: 501-504. TK1.E12, v. 5. Same. Industrial standardization and commercial standards monthly, Dec. 1937, v. 8:323-339. HD62.A15, v. 8. Bell telephone quarterly, Jan. 1938, v. 17: 17-27. TK1.B47, v. 17. Electrical engineering, Feb. 1938, v. 57: 57-60. TK1.E45, v. 57.

Deals with industrial standardization being best administered by some voluntary associates, but need for closer cooperation between government and existing standards organizations.

Johnson, Louis. The role of standards in industrial preparedness. Industrial standardization and commercial standard monthly, Mar. 1939, v. 10: 52-57. HD62.A15, v. 10.

Jones, Thomas Roy. Engineering and shop standardization. New York, N. Y., American management association. 1931. $12 \mathrm{p} .23^{\mathrm{cm}}$. [American management association.] Production series, Pro. 100). HD62.J6.

Presented at the A. M. A. Production conference held in Rochester, N. Y., June 1, 1931. -p. 2.

Discussion : p. 9-12.

Kaidanovsky, S. P. Industrial standardization proves profitable to manufacturer and ultimately to consumer. Industrial standardization and commercial standards monthly, Oct. 1935, v. 6:279-281. HD62.A15, v. 6.

Kaidanovsky, S. P., and A. L. Edwards. Consumer standards. Washington, U. S. Govt. print. off., 1941. 433 p. (U. S. Temporary national economic committee. Investigation of concentration of economic power. Monograph, no. 24).

Kennelly, A. E. The work of the American institute of electrical engineers in standardization. Electrical engineering, May 1934, v. 53: 676-680. TK1.E45, v. 53. 
Kienzie, O. Die normungszahlen und ihre anwendung. Vereines deutscher ingenieure (Berlin). Zeitschrift. June 17, 1939, v. 83: 717-724. TA3.V5, v. 83.

Kirsh, Benjamin Sollow. Trade associations in law and business ... in collaboration with Harold Roland Shapiro ... New York, Central book company, 1938. 399 p. $231 / 2^{\mathrm{cm}}$. HD2425.K47.

See Index under Standardization.

Klein, Julius. 120 industries are saving $\$ 250,000,000$ yearly by simplification of sizes and other standardization. New York Times, May 25, 1931, p. 2, col. 4.

La Normalisation [Symposium on standardization presented at joint meeting of French engineering societies held February 11, 1938]. Société des ingenieurs civils de France. Mémoires, Jan.-Feb. 1938, v. 91: 24-72. TA2.S4, v. 91.

Origins and objects of standardization, P. Nicolau; Rules of standardization, $M$. Berger; Metrology - means of standardization, Androuin; Standardization a factor of engineering progress, P. Blanchet; Standardization as a factor of economic and social progress, Merie-Bussy ; Examples of national application of standards, PLU ; Standardization in electric industry, C. Duval, etc.

Lansburgh, Richard H. Standards as an integrating community force. Industrial trial standardization and commercial standards monthly, Jan. 1940, v. 11: 9-13. HD62.A15, v. 11.

Lansburgh, Richard Hines, and William R. Spriegel. Industrial management ... 3 ed., rewritten and reset. New York, J. Wiley \& sons, inc.; London, Chapman \& Hall, limited, 1940 . xi, 666 p. illus., diagrs. (part fold.) forms (1 fold.) $23 \frac{1}{2}{ }^{\mathrm{cm}}$. T56.L35 1940 .

Bibliography : p. 647-656.

Simplification and standardization of products : p 212-222.

LeMaistre, Charles. The British standardization movement and its public significance. In World power conference, 2d Berlin, 1931. Transactions. Berlin, 1931, v. 18, p. 231-241.) TJ5.W6, 1930, v. 18.

Leonard, F. H. Controlling production by means of standards. Iron age, v. 139, Apr. 8, 1937: 47-49. T1.17, v. 139.

Lhoste, E. La normalisation en temps de guerre. Société des ingénieurs civils de France. Mémoires, May 1939, v. 92: 402-413. TA2.S6, v. 92.

Lhoste, E. Les travaux de l'association française de normalisation. Méthodes (Paris), Mar. 1939, v. 7: 101-106.

Deals with the work of the International standardization association.

Lockwood, R. L. Railroad standards. Harvard business review', July, 1934, v. 12: 398-406. HF5001.H3, v. 12.

Lord, Arthur R. Economic significance of specifications. Engineering and contracting, Jan. 1932, v. 71 : 30-32. TA201.E5, v. 70.

Lowry, Stewart McKinley. Time and motion study and formulas for wage incentives, by Stewart M. Lowry ... Harold B. Maynard ... [and] G. J. Stegemerten ... 3d ed. New York and London, McGraw-Hill book company, inc., 1940. xiii, 432 p. illus. tables, diagrs. $231 / 2^{\mathrm{cm}}$. Half-title: McGraw-Hill industrial management series; D. S. Kimball, consulting ed. T58.L6 1940.

Standardizing the job (manufacturing aspects of standardization, materials, machine tools, small tools, relation of standardization to time study) : p. 161-168.

MacGregor, D. H. The adjustment of agriculture to industrial rationalization. Agricultural economics society. Journal of proceedings, Mar. 1932, v. 2: $10-28$.

McAllister, A. S. :

Simplification methods great aid to business. Washington Post (D. C.), Dec. 31, 1931, p. 9, col. 1-5.

Benefit of the Bureau of Standards' work to the public, U. S. Bureau of Standards. Commercial standards monthly, July 1932, v. 9: 24. HD62.U3, จ. 9. 
McCain, J. S. The use of American standards in Argentine is vital to all American manufacturers. Industrial standardization and commercial standards monthly, Oct. 1938, v. 9: 243-244. HD62.A15, v. 9.

McCall plan hit. American home economics association deals body blow to Institute of Standards by refusing to participate. Business week, Nov. 30 , 1940: 32-33. HF5001.B89, 1940.

McConnell, D. W. The Bureau of Standards and the ultimate consumer. American academy of political and social science. Annals, May 1934, v. 173: 146152. H1.A4, v. 173.

Contents include : Alleged benefits to consumers; Quality standards; Advantages of standardization; Bias in favor of business; Public interests should be paramount; Methods of promulgation.

McMurtrie, Douglas Crawford. Standardization in Europe covers paper and printing, by Douglas C. McMurtrie. Chicago, Ill., Priv. print., 1933. p. $22^{\mathrm{cm}}$. Z246.M196.

Madhava, K. B. [Standardization in industry.] Sankhyä (Calcutta) Dec. 1938, v. 4: 251-258. HA1.S3, v. 4.

Marcotte, E. La Bureau des Standards à Washington et son importance dans l'economie Americaine. Revue industrielle (Paris), Sept.-Dec. 1932, v. 62: 433-439; 497-501; 542-544; 593-595; Feb. 1933, v. 63: 94-98. T2.R4, v. 62-63.

Martino, Robert A. :

How the National Bureau of Standards and the American standards association cooperate. American standards association. Bulletin, June 1932, v. $3: 176-177$.

Fostering standardization. Cooperation of the National Bureau of Standards and the American Standards Association. U. S. Bureau of Standards. Commercial standards monthly, May 1932, v. 8: 332-334. HD62.U3, v. 8.

Laws for grading and inspection. Resumé of some legal standards adopted by various states. National Bureau of Standards, commercial standards monthly, Dec. 1931, v. 8: 174-175. HD62.U3, v. 8.

Maxwell, Alexander. Some principles for making standards. Edison electric institute. Bulletin, Aug. 1938, v. 6:353-354. TK1.E12, v. 6.

Maynard, Harold Howard. Principles of marketing, by Harold H. Maynard ... Walter C. Weidler ... [and] Theodore N. Beckman ... 3d ed. New York, The Ronald press company [c1939]. $\mathrm{xxi}, 700$ p. illus., plates, diagrs. $24^{\mathrm{cm}}$. HF5415.M35, 1939.

References at end of each chapter.

Standardization and simplification: chapter 26. Deals with history, the services of standardization, standardization and the consumer, examples of simplification, limitations to standardization and simplification, etc.

Meckel, A. Beitrage sur weiterentwicklung des deutschen werkstoffnormen. Maschinenbau, Oct. 1934, v. 12 : 525-526.

Deals with further development of German material standardization, and the activities of the German industrial standards committee.

Meltzer, S. Development of industrial standardization. South African engineer and electrical review, Feb. 1939, v. $30: 3-7,27$.

Reviews the achievements in standardization of material and methods in South Africa.

Mitchell, William Norman. Organization and management of production. New York and London, McGraw-Hill book co., inc., 1939. xii, 417 p. incl. diagrs., forms. $231 / 2^{\mathrm{cm}}$. (Business and economics publications; W. H. Spencer, editor.) HD31.M5.

First edition.

Bibliography, questions, and exercises : p. [315]-407.

See Index under Standardization; Standards. 
Mond, Sir Alfred M. Industry and politics. London, Macmillan \& co., 1927. 337 p. The rationalisation of industry : p. 210-221. HC256.3.M6.

Montgomery, Donald E. Consumer standards and marketing. American academy of political and social science. Annals, May 1940, v. 209: 141-148. H1.A4, v. 209.

Municipal year book and encyclopedia of local government administration, 1939. Edited by James Ford. London, The Muncipal journal, limited, 1939. $1670 \mathrm{p}$. JS3003, 1939.

British standard specifications : p. 775-782. See also issue for 1940, p. 447-454.

Myers, Herbert J. How to set standards; Jordan prize competition, by Herbert J. Myers ... William L. Keating ... [and] J. C. Metsch ... New York city, National association of cost accountants [ ${ }^{c} 1931$ ]. iv. p., 3 l., 98 p. incl. diagr., forms. $22^{1 / 2} \mathrm{~cm}$. HD62.M8.

Contains the three prize winning essays of a competition open to members of the National association of cost accountants. $c f$. Foreword.

National and international standardization. Nature (London) July 3, 1937, $\nabla$. 140: 19. Q1.N2, v. 140.

National industrial conference board. Industrial standardization. New York, National industrial conference board, inc., 1929. xiv, 306 p. diagrs. $23 \frac{1 / 2}{}{ }^{\mathrm{m}}$. HD62.N3.

Thesis (PH. D.)-Columbia university, 1929.

Without thesis note.

"The present investigation was made, and this volume was prepared, . . by Mr. Robert A. Brady."-Pref.

Contents: Historical setting for the standardization movement; Terminology of standardization; Company standardization; Standardization work of engineering and other technical societies; Trade association standardization; The American standards association and other standardizing bodies; The National bureau of standards; Standards in government purchasing; International and regional standardization; Agricultural standardization; Business savings from standardization; Standardization and marketing, technique; Standardization and size of business; Standardization as an aid in the stabilization of business; Standardization and the ultimate consumer: The trend of industrial standardization, etc.

National industrial conference board. Rationalization of German industry. New York, National industrial conference board, 1931. 182 p. HC286.3.N25.

Contents: Meaning, causes, and methods of rationalization; Structure and organization of German industry; The mining industry-coal and potash; The iron and steel industry; The electrotechnical industry; The chemical industry; The foreign trade of Germany.

Neuhaus, Fritz. Die internationalen fortschritte der normung. Internationale wirtschaft (Paris), Dec. 1938, v. 10: 32-35. HF294.I7153, v. 10.

Neuhaus, Fritz. Normung. Vereines deutscher ingenieure (Berlin). Zeitschrift, July 16, 1938, v. 82: 847-848. TA3.V5, v. 82.

Discusses the problems, duties, and position of standardization in engineering and national life.

New American standards association committee starts work on standards for libraries; three subcommittees are named to start national program and to operate with International standardization committee. Industrial standardization and commercial standards monthly, May 1940, v. 11: 119-120. HD62.A15, v. 11.

New York. Public library. Municipal reference Library. Specifications and standards. Its Municipal reference library notes, v. 22, Feb. 1936: 9-;2c. Z7164.L8N6, v. 22.

New Zealand standards institute. Index to New Zealand standard specifications. Wellington, New Zealand standards institute, 1939. 
Nicholson, Joseph W. How standardization effects saving for city of Milwaukee. City purchasing agent outlines standardization plan under which city has saved thousands of dollars. U. S. Bureau of standards. Commercial standards monthly, Sept. 1932, v. 9: 65. HD62.U3, v. 9.

Paterson, C. C. Uniformity as the gauge of quality. Institution of electrical engineers (London) Journal, Dec. 1936 v. 79: 655-666. TK1.I4, v. 79.

Pearson, Egon Sharpe. The application of statistical methods to industrial standardization and quality control. London, British standards institution, 1935. 161 p. incl. tables (1 fold.) diagrs. (part fold.) $21^{1 / 2} \mathrm{~cm}$. (British standards institution. [Report] no. 600)

List of principal statistical books, papers, etc., referred to in the text: p. 132-133.

Phillips, Charles Franklin. Marketing ... Boston, New York [etc.] Houghton Mifflin company ['1938] xviii, 781 p. ${ }^{\mathrm{c}}$ diagrs. $221 / 2{ }^{\mathrm{cm}}$ HF5415.P48.

Bibliography : p. [731]-763.

See Index under Standardization; Standards.

Photographic grades: American Standards Association tackles job of developing standards for photographic materials. Business week, Oct. 8, 1938: 39. HF5001.B89, 1938.

Plan [of the American Standards Association] to set up standard methods and procedures. Science, n. S., v. 87, Apr. 29, 1938: 184. Q1.S35, n. s., v. 87.

Porter, Robert W. Design for industrial co-ordination; a technique for coordinating the primary functions in the field of industrial organization ... New York and London, Harper \& brothers, 1941. xv. 249 p. diagrs. $24^{\mathrm{cm}}$. HD45.P65.

Price, F. M. :

Savings through standardization of purchases. Power plant engineering, Juily 1, 1932, v. 36 : 525. TJ1.P77, จ. 36.

The standardization work of the Detroit Edison Company. American standards association. Bulletin, Feb.-Apr. 1932, v. 3: 47-59; 85-95; 111-122.

Includes discussion of the accomplishments and benefits of standardization.

Public Affairs information service. Bulletin. New York, Public affairs information service, 1933-date. Z7163.P9.

See each vol. under Standardization.

Raitt, E. I. What can business do to remove consumer suspicion. Journal of home economics, Jan. 1936, v. 28: 5-8. TX1.J7, v. 28.

Rather, Allan W. Is Britain decadent? London, S. Low, Marston \& company, ltd., 1931. 300 p. HC256.3.R3.

Rationalization in Germany and Great Britain is discussed in chapters 4 and 5.

Rationalization. Index, Aug. 1931, v. 11: 186-190. HC10.15, v. 11.

A discussion of the question in the United States, Great Britain, and Germany.

Rationalization-a Socialist view. International management institute. Bulletin, Sept. 1931, จ. 5: 165-173. T58.A21852, จ. 5.

Rationalization in Europe and America. Guaranty survey, v. 11, Aug. 1931: 3-6. HC1.G83, v. 11.

Rationalization in the Dutch East Indies. International management institute. Bulletin, Mar. 1932, v. 6 :45. T58.A21852, v. 6.

Deals with the establishment of the Standardization board in 1930 . 
Razous, P. Évolution de la normalisation. Génie civil (Paris) May 20, 1939, จ. $114:$ 422-423. TA2.G3, v. 114.

Razous, P. La journée d'études et de propagande de la normalisation (Paris, 21 decembre 1939). Génie, civil (Paris), v. 116, Jan. 13, 1940: 27-29. TA2.G3, v. 116.

Reichardt, W. Ergebnisse der internationalen normentagung Berlin, 1938. Vereines deutscher ingenieure (Berlin). Zeistchrift, Oct. 22, 1938, v. 82: 1258-1261. TA3.V5, v. 82.

Renesse, Herwarth von. Die deutsche werkstoffnormung. Im auftrage des Deutschen normenausschusses bearb. von dr.-ing $H$. von Renesse. Berlin, Beuth-verlag g. m. b. h., 1933. 61 p. $21^{\mathrm{cm}}$. TA410.R4.

Contents. Ziel, umfang und grundlage der werkstoffnormen.-Die werkstoffnormen für stahl und eisen.-Die werkstoffnormen für nichteisenmetalle.-Die normen für werkstoffprüfung.-Anwendungen der werkstoffinormen.-Anhang (symbole).

Reuter, Fritz. Handbuch der rationalisierung. 3. vollst. neubarb. aufl. Berlin, Industrieverlag Spaeth \& Linde, 1932. 1327 p. HD45.R4.

Reynolds, F. W. The determination of quality as a basis for commodity standards. Review of scientific instruments, July 1932, v. 3: 371-377.

Rice, Calvin W. Fifty years of the American society of mechanical engineers. Mechanical engineering, Apr. 1930, v. 52: 261-276. TJ1.A72, v. 52.

History of its standardization activities : p. 270-271.

Rice, Henry L. Value of standards to the War Department. U. S. National Bureau of standards. Commercial standards monthly, May 1930, v. 6: 338-339. HD62.U3, v. 6.

Richards, Oscar W. Photographic equipment standards on trial. Industrial standardization and commercial standards monthly, Mar. 1941, v. 12: 53-55. HD62.A15, จ. 12.

Robbins, Edwin Clyde. Industrial management; a case book, by E. C. Robbins ... and F. E. Folts ... 1st ed. New York and London, McGraw-Hill book co., inc., 1932. xiii, $757 \mathrm{p}$. incl., illus. maps, diagrs., forms. $231 / 2^{\mathrm{cm}}$. TS155.R57.

Simplification and standardization : p. 58-116.

Russell, Ralph. Terminology of government food grades. Journal of home economics, v. 30, Feb. 1938: 90-92. TX1.J7, v. 30.

Russell Sage foundation, New York. Library. ... Standards in social work fields, 1926-1936. New York, Russell Sage foundation [1937]. folder (6 p.) $23^{\mathrm{cm}}$. (Its Bulletin, no. 141. February 1937.) Z881.N667, no. 141.

Compiled by Agnes H. Campbell.

Samans, Walter. Why mechanical engineers need American standards associaciation's program. Industrial standardization and commercial standards monthly, Mar. 1937, v. 8: 69-73. HD62.A15, v. 8.

Samson, H. W. How standardization works in General electric. Industrial standardization and commercial standard monthly, Mar. 1939, v. 10: 265-269. HD62.A15, v. 10.

Seelye, H. P. :

The fundamentals of standards and specifications. Edison electric institute. Bulletin, Mar. 1937. v. 5: 75-76. TK1.E12, v. 5.

Standardization; its scope and limitations: work of the Edison electric institute. Edison electric institute. Bulletin, Dec. 1935, v. 3: 471-474. TK1.E12, v. 3. 
Shumard, Frederick Warren. A primer of time study ... New York and London, McGraw-Hill book company, inc., 1940. xii, 519 p., incl. illus., tables, diagrs., forms. $23 \frac{1}{2}{ }^{\mathrm{cm}}$. T58.S58.

Time study standardization: p. 445-468.

Skinner, C. E. The Institute and industrial standardization. Electrical engineering, May 1934, v. 53 : 681-684. TK1.E5, v. 53.

Smalley, B. M. Standards and specifications from the manufacturers' point of view. Edison electric institute. Bulletin Mar. 1937, v. 5; 77-78. TK1.E12, v. 5.

With reference to hardware standards and specifications.

Smith, Elliott Dunlap. Technology \& labor; a study of the human problems of labor saving [by] Elliott Dunlap Smith ... in collaboration with Richmond Carter Nyman ... New Haven, Pub. for the Institute of human relations by Yale university press; London, H. Milford, Oxford university press, 1939. xiv, 222 p. $2312^{\mathrm{cm}}$. T58.S585.

"We confined our studies to ... the labor-saving development in cotton weaving called by management the 'multiple loom' or 'extended labor' system and by labor 'the stretchout'."-Introd.

See Index under Standardization.

Soule, George. Standardization. (In Encyclopedia of the social sciences, edited by Edwin R. A. Seligman and Alvin Johnson. New York, The Macmillan co., 1940, vol. 14, p. 319-322.) H41.E6, 1930a.

References are given.

See also the Index vol. of this publication under the subject-heading Standardization.

Standardization as applied to production engineering. Institution of production engineers (London), Journal, Dec. 1933, v. 12: 525-664.

Papers with discussion on some subjects presented before local sections by $C$. LeMaistre, R. Dumas, R. A. Wright, R. Allen, E. W. Bedford, W. M. Pudge, S. Gilberts, S. C. Smith, R. B. Cole, J. W. Griffiths, J. A. Boyes, W. N. Shaw and H. Eckerlsey.

Standardization. A résumé of accomplishments of the recent AN Standards conference and of the Standards committee of the Society of automotive engineers. Aviation, Aug. 1931, v. 30:485-487. TL501.A8, v. 30.

Standardization a problem for management. U. S. Bureau of standards. Commercial standards monthly, Jan. 1932, v. 8: 221. HD62.U3, v. 8.

Standardization a recognized means of stabilizing employment. American standards association. Bulletin, v. 2, May 1931: 13-14.

Standardization aids home building. Grade marking items purchased for use in the home strongly recommended by President's Conference on home ownership. U. S. Bureau of standards. Commercial standards monthly, Jan. 1932, v. 8: 209. HD62.U3, v. 8.

Standardization an aid to industrial progress. Index, Oct. 1931, v. 11: 221-225. HC10.15, v. 11.

Discuss the benefits of standardization to both producer and consumer.

Standardization and progress. American machinist, Mar. 3, 1932, v. 76: 291. TJ1.A5, v. 76.

Standardization as an aid to retail merchandising. U. S. Bureau of standards. Commercial standards monthly, May 1932, v. 8: 336 . HD62.U3, v. 8.

Standardization in the chemical industry; work of the British standards institution. Chemical age (London) Jan. 11, 1936, v. $34: 30$. TP1.C33, v. 34.

Standardization work in photography [of the American Standards Association]. Science, n. s., v. 88, Oct. 7, 1938:319. Q1.S35, n. s., 1. 1. 88. 
Standards for houses; reference studies on design and planning. Architectural record, Mar. 1940, v. 87:93-107. NA1.A6, v. 87.

State law index; an index and digest to the legislation of the States of the United States enacted during the biennium. 1925-26; 1927-28; 1929-30; 1931-32; 1933-34 ; 1935-36 ; 1937-38. Washington, U. S. Govt. print. off., 1929-1940. 7 v.

Compiled by the Legislative Reference Service of the Library of Congress, under the immediate direction of Miss Margaret Stewart.

See each vol. under Weights and measures law.

Stetson, George A. Save time and space with American standard abbreviations. Industrial standardization and commercial standards monthly, Apr. 1941, v. 12: 81-83. HD62.A15, v. 12.

Stilliard, M. Huge savings made by British chemical firm; official reports. Industrial standardization and commercial standards monthly, May 1936, v. 7: 107-109. HD62.A15, v. 7.

Swift, Ernest Haywood. Part I, Preparation of standard solutions, from A system of chemical analysis. [New York] Prentice-Hall, inc. [ ${ }^{\mathrm{c}} 1938$ ]. 2 p. 1., 3-149 p. illus., diagrs. $23^{\mathrm{cm}}$. QD77.S95.

Includes bibliographies.

Swinbank, L. H. How the Imperial chemical industries, Itd., saves through its standardization program. Industrial standardization and commercial standards monthly, July 1938, v. 9: 174-175. HF62.A15, v. 9.

Tenney, H. W. How preferred numbers can be applied in a standardization program. Industrial standardization and commercial standards monthly, Oct. 1939, v. 10: 265-269. HD62. A15, v. 10.

Toovere, U. [The rationalisation movement in Scandinavia and Germany.] Konjunktuur (Revel) Sept. 30, 1939, no. 57-58: 455-463.

Townsend, J. R. Planning for the collection of standardization data. (In American society for testing materials. Proceedings, 1933. Philadelphia, 1934, v. 33, pt. 2, p. 770-785.) TA401.A5, v. 33.

States that careful planning and much preliminary work is necessary to obtain good data, and discusses two engineering investigations leading to standardization by the Society, illustrating how this method of planning works out in practice.

Tratman, Edward Ernest Russell. Specifications and standards for public works engineering; abstracts of more than 100 specifications for materials and construction. Supplemented by standard rules and regulations ... Prepared by E. E. Russell Tratman ... with the cooperation of the editorial staff of Engineering news-record. New York, N. Y., McGraw-Hill publishing company, inc., 1933.8 p. l., 3-180 p. illus. $19 \frac{1 / 2 \mathrm{~cm}}{}$. TA180.T7.

Twenty-four national standardizing bodies. Industrial standardization and commercial standards monthly, Mar. 1935, v. 6: 69. HD62.A15, v. 6.

Uncle Sam's own Bureau of Standards. Constitution authorized Congress to fix a standard of weights and measures. Result is one of the greatest scientific institutions of the world. It cooperates with industry in the realm of standardization and points the way to progress in many activities. Sphere, v. 16, July 1935: 29-31. HC101.S6, v. 16.

U. S. Congress. House. H. R. 6652 , a bill to aid consumers in setting up standards of quality based on performance as a guide in the purchasing of consumers goods. Introduced by Mr. Boren, June 5, 1939. Washington, Govt. print. off., $1939.4 \mathrm{p}$.

U. S. Bureau of labor statistics. Transfer of safety-code work from Bureau of standards to American standards association. Its Monthly labor review, Sept. 1933, จ. 37: 581-582. HD8051.A78, v, 37. 
U. S. Library of Congress. Division of Bibliography. Bibliography on standardization. Compiled by Anne L. Baden under the direction of the Chief Bibliographer. (In U. S. National Bureau of Standards. Standards yearbook, 1928, p. 353-372.)

— Supplement. Standards yearbook 1929, p. 387-392.

Supplement. Standards yearbook, 1930, p. 271-281.

Supplement. U. S. National Bureau of Standards. Miscellaneous publication no. $136.19 \mathrm{p}$.

Supplement. Standards yearbook, 1933. p. 231-244.

QC100.U57, QC100.U576.

U. S. National bureau of standards:

Annual report of the director. Washington, U. S. Govt. print. off., 1903-date. QC00.U55.

Circular. Washington, U. S. Govt. print. off., 1903-date. QC 100.U555.

Commercial standards and their value to business. 3d ed. Washington, U. S. Govt. print. off., 1940. 22 p.

Commercial standards monthly. A review of progress in commercial standardization and simplification ... v. [1-]9. [April 15, 1925-] June 1983. Washington [U. S. Govt. print. off., 1925-]33. 9 v. in. $2.31^{\mathrm{cm}}$ HD62.U3.

No more published.

Issued by the Bureau of standards as a mimeographed bulletin, April 15,1925 to June 15, 1929 ; as a printed magazine, July 15, 1929-June 1933 . Nos. 1 to 51 April 15 , 1925 to June 15, 1929 were arbitrarily assigned as volumes 1 to 5 of this series. Title varies : no. 1-45, April 15, 1925-Dec. 15, 1928, Monthly news bulletin ... no. 46-49 Jan. 15-April 15, 1929. Commercial standards monthly. Monthly news bulletin of commercial standardization group, Bureau of standards ... no. 50-51, May 15-June 15, 1929, Commercial standards monthly ... July 1929-June 1933, Commercial standards monthly. A review of progress in commercial standardization and simplification ...

List of commercial standards: publications of the National bureau of standards : revised to Jan. 1, 1940. Washington, D. C., 1940. 5 p. Processed.

List of publications of interest to the general public: revised to May 1, 1940. Washington, U. S. Govt. print. off., 1940. 26 p. Processed.

Journal of research. Washington, U. S. Govt. print. off., 1928-date, QC1.U52.

... Legal weights per bushel for various commodities. (Issued January 9, 1940) Washington, U. S. Govt. print. off., 1940 . ii, $12 \mathrm{p}$. incl tables. $23^{\mathrm{cm}}$ (Circular of the National bureau of standards C425.) QC100.U555, no. 425; QC89.U5A215, 1940.

At head of title: U. S. Department of commerce, Harry L. Hopkins, secretary. National bureau of standards. Lyman J. Briggs, director ...

This Circular supersedes the fourth edition of Circular C10, issued in 1924, and the bushel lists published in the appendix to the third edition of NBS Miscellaneous publication M20, issued in 1926."-Pref., p. ii.

Weights and measures publications of general interest. April 1, 1937. Washington, D. C., 1937. 5 p. Mimeographed.

Miscellaneous publications. Washington, U. S. Govt. print. off., 1918date. QC100.U57.

Model state law on weights and measures adopted by the National confer. ence on weights and measures and recommended by the National bureau of standards. Washington, D. C., 1940. 46 p. Processed.

Research paper. Washington, U. S. Govt. print. off., 1928-date.

National conference on weights and measures Report of the 29th National conference on weights and measures attended by representatives from various States, held at the National Bureau of standards, Washington, D. C., June 6-9, 1939. Washington, U. S. Govt. print. off., 1940. 148 p. (Miscellaneous publication M164) QC100.U57, M64). 


\section{Miscellaneous Publications, National Bureau of Standards}

... National directory of commodity specifications, classified and alphabetical lists and brief descriptions of specifications of national recognition ... [Rev. ed.] Prepared by Clarence W. Ingels under the direction of A. S. McAllister, chief of the Division of specifications. Washington, U. S. Govt. print. off., 1932. vi, 548 p. $271 / 2^{\mathrm{cm}}$. (Miscellaneous publication M130). QC100.U57, No. 130 ; HF1041.U6, 1932.

On cover: U. S. Department of commerce. Bureau of standards. Directory of specifications. 1932. M130.

"(Supersedes Miscellaneous publication, no. 65)"

The work was carried out under the joint auspices of the National bureau of standards and the Bureau of foreign and domestic commerce. cf. Letter of submittal, p. iii..

... Services of the National bureau of standards to the consumer. [Wash. ington, U. S. Govt. prtg. off., 1937]. cover-title, 27 p. illus. $27^{\mathrm{cm}}$ QC100.U58, 1937.

Simplified practice; its purpose and application. Washington, D. C., April 15, 1940. $16 \mathrm{p}$. Processed.

Simplified practice recommendations. Washington, U. S. Govt. print. off., 1922-date. QC100.U575.

Standards and specifications for building and construction materials, fixtures, supplies and equipment: revised to November 20, 1940. Washington, D. C., November 20, 1940. 14 p. Processed.

... Standards yearbook, 1927[-1933] ::: Washington, U. S. Govt. print. off., 1927-33. $7 \mathrm{v}$. plates, tables. $231 / 2^{\mathrm{cm}}$. (Miscellaneous publications, M77, M83, M91, M106, M119, M133, M139.) QC100.U57; QC100.U576.

Compiled by the Bureau of standards.

... Technical news bulletin ... Washington, U. S. Govt. print. off., 1925-date. v. $241 / 2^{\mathrm{cm}}$. monthly. T1.U45.

Previously issued in mimeographed form, the first 26 numbers, issued between Dec. 1917, and June, 1919, were entitled Confidential bulletin.-Monthly catalogue United States public documents, May 1925, p. 817.

U. S. National youth administration. Standards. By C. M. Wiltse. Washington, U. S. Govt. print. off., 1940. 48 p. (Modern world at work, no. 2). T7.U6, no. 2.

References are given.

U. S. Superintendent of documents:

Federal specifications, federal standard stock catalog. List of publications relating to above subjects for sale by the Superintendent of Documents. Washington, U. S. Govt. print. off., 1940. 38 p. (Price list 75-7th edition). Z1223.A191, no. 75. Z7914.A22U65.

Standards of weight and measure, tests of metals, cement and concrete, iron, electricity, clays, photography. List of publications relating to above subjects for sale by the Superintendent of Documents, United States Government printing office, Washington, U. S. Govt. print. off., $1940.100 \mathrm{p}$. (Price list 64-26th edition). Z1223.A191, no. 64. Z7144.W4U6.

U. S. War dept. Standards division. Planning branch. Army specification guide, 1941. Washington, U. S. Govt. print. off., 1941.

Contains valuable information for those who are concerned with national defense.

Copies may be obtained from the Standards Division, Planning Branch, Office of the Under Secretary of War, Washington, D. C.

Wainwright, D. B. The value of specifications to industry. Standardization of specifications has been a major factor in attaining industrial leadership. U. S. Bureau of standards. Commercial standards monthly, Nov. 1931, v. 8: 135-137. HD62.U3, v. 8. 
Waite, Warren Cleland. The consumer and the economic order, by Warren C. Waite ... and Ralph Cassady, jr. ... 1st ed. New York and London, McGrawHill book company, inc., $1939 . \quad x, 389$ p. incl. tables, diagrs. $23^{1 / 2} \mathrm{~cm}$. HB801.W24.

See Index under Standardization.

Warwick, C. L. American society for testing materials and the national defense program. American society for testing materials. Bulletin, no. 107, Dec. 1940: 5-6. TA401.A68, no. 107.

Whitehead, Thomas N. Planning standardized components to secure variety in products. Harvard business review, Apr. 1932, v. 10: 257-268. HF5001.H3, v. 10.

Whitkin, Z. Engineering analysis of five-year plans for Russian rehabilitation; rationalization program for future construction. Engineering news, Aug. 30, 1935, v. $113: 272-275$. TA1.E6, v. 113.

World power conference. Central office. A survey of the present organization of standardization, national and international. London, The Central office of the World power conference, 1936. viii, 55, [1] p. $26^{1 / 2}{ }^{\mathrm{cm}}$. T59.W6.

Deals with national organization of standardization in thirty-three countries; organizations in each country are described and their functions explained.

Wüster, Eugen. Grundzüge der sprachnormung in der technik, von dr.-ing. Eugen Wüster ... Berlin, VDI-verlag, 1934. 4 p. l., 92 p. diagrs. (part fold.) $21^{\mathrm{cm}}$. P41.W8.

"Vorliegendes buch ist eine verkleinerte und stellenweise ergänzte ausgabe meines 1931 er'schienenen buches 'Internationale sprachnormung in der technik, besonders in der elektrotechnik'."-Vorwort.

Wyand, Charles Samuel:

The economics of consumption ... New York, The Macmillan company, 1937. xiii, 565 p. diagrs. $22^{\mathrm{cm}}$. HB801.W9.

Consumer standards: chapter 11. Deals with the need for standards, commercial objections to consumer standards, existing governmental standards, existing commercial standards, and the changing seller.

Must buying standards be technical? Consumers digest, v. 1, Mar. 1937: 67-72. TX1.C6, v. 1.

Young, Lieut. Col. William C. Materials standards in national preparedness. American society for testing materials. Bulletin, no. 105, Aug. 1940: 17-22. TA401.A68, no. 105.

Deals with planning to reduce the time factor, production and educational orders, production studies, economics, munitions, industrial mobilization, standards for materials.

Zimmerman, R. E. Standardization in the steel industry. Industrial standardization and commercial standards monthly, Sept. 1940, v. 11: 242-244. HD62.A15, v. 11. 



\section{INDEX}

A

Abbreviations and letter symbols for science and engineering _._._- 16, 200

Abdominal packs, specifications_._-_-

Abrasive cloth

Grain Association -

grain sizes__-_._-_._-_-_._-_-

Paper \& Cloth Manufacturers' Association - -

Abrasive-coated products

Accepted foods and their nutritional significance (book)

Accident prevention in construction, manual of (AGC) statistics, standardization of methods of recording and compiling 127,175

Accidents, industrial

prevention of, railroad.

Accounting system for cities_._-_--

Accounts, railway

Acetylene equipment

Acids, fastness to

Acoustical devices measurements

Society of America

Acoustics

Acrylic denture resin

Adapters, adjustable, for multiple spindle drilling heads_._._._.

Adapters, cylinders, and rotating

Administrative requirements for building codes

Advertising, food products sign, standardization.

Advisory Committee on Ultimate Consumer Goods, ASA_--- $\overline{37}, \overline{135}, \overline{148,}, \overline{1}$

Aeronautical Chamber ố Commerce of America

Aeronautics

Aggregate for concrete, specifications

Aggregates, coarse concrete

Agitators, operation

Agricultural Insecticide \& Fungicide Association -. machines _- - - products, chemical analysis tractors

Air compressors

Conditioning \& Refrigerating $\mathbf{M a}$ chinery Association conditioning standards coolers

cooling systems corps, War Department.-heaters

Hygience Foundation of America-infiltration through windows, tests_ standard methods for examination

Aircraft

engines

Fuel systems, flow characteristicsmaterials and parts__________-_ standards

Airframes

Airplanes__.

Airplane tires.-

Airport, concrete for

20,
174
Page

Alfalfa

, fastness to

All-clay porcelain plumbing fixtures_- $\quad 146$

117

steel -.-----

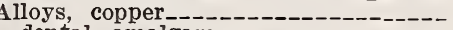
dental amalgam. impurities

183

182

wrought gold

Aluminum _old -

conductors, hard drawn

methods of sampling _._-_._-_ 16

Research Institute_.

Secondary-_. tubes, sizes

Athletic Union of the United States_-_-_-_-_-_-_-_-_American Association for the Advance of Science

ists As $16,59,182$

Medical Milk Commissions_____ 17, 96

Nurserymen_._.

Port Authorities._. 17

State Highway Offials_-_-

Textile Chemists \& Colorists $5,70,142,170$

University Women _._.

American Automobile Association.-- 20, 155

Bakers Association _-_-_..-_-_-- 21

Bleached Shellac Manufacturers Association -- Affiliated Industries

Bottlers of Carbonated Beverages_- 23, 103 Brush Manufacturers Association-- 24 Bureau of Shipping......... 24,71

Bureau of Welding

Ceramic Society-_.-.

Chemical Society_-..-- 25, 105, 163

College of Surgeons

Concrete Institute_........ 27, 154,171

Concrete Pipe Association------ 28

Cranberry Exchange ----------- 28

Dental Trade Association

Drug Manufacturers Association_-- 29

Dry Milk Institute

Electro-Platers' Society-_- $\quad 30$

Feed Manufacturers' Association-- 31,79

Foundrymens association $-\overline{31} \overline{58}, \overline{10} \overline{4}, \overline{1} 33,166$

Fruit \& Vegetable Shippers' Association --_--_-_-_-_-_-_-_-_-_ 125

Gage Design Committee.- 32

Gas Association

Gear Manufacturers Association_-- 35

Gem Society _. - -

Glassware Association-- 36

Gum Importers Association, Inc--- $\quad 36$

Hospital Association

Hot Dip Galvanizers Association-- 37,38

Hotel Association of the United States and Canada-_.-...-

Institute of Architects Department of Technical Services_____ 27, 39, 140

Institute of Baking

Institute of Bolt, Nut and Rivet Manufacturers _...-........

Institute of Chemical Engineers---

Institute of Consulting Engineers -- 
American Automobile Association- Page Continued.

Institute of Electrical Engineers

Institute of Laundering

Institute of Mining and Metallurgical Engineers

Institute of Refrigeration

Institute of Steel Construction

Iron and Steel Institute

Leather Belting Association-.--

Leather Chemists Association

Lighting Equipment Association--- 46

Match Manufacturers' Association-

Meat Institute

Medical Association, Chemical Laboratory Council on Foods Council on Industrial Health istry on Physical Therapy--Council on Physical Therapy---Mining Congress

Municipal Association

Mutual Alliance-_.

Oil Chemists Society-_.

Optometric Association

Paper \& Pulp Association______ 53, 88

Petroleum Institute

Pharmaceutical Association _-_ 55, 98, 134

Pharmaceutical Manufacturers' Association

Public Health Association - 6 - 55,55 Public Works Association

Railway Bridge \& Building Associa-

tion---- Car Institute

Railway Car Institute--- Engineering Association

Refractories Institute_-_-_-_-_-_-_ 58, 133

Road Builders' Association.-- 58, 60

Society of Aeronautic Engineers_-_- 197

Agricultural Engineers - - - - $\quad 59$

$\begin{array}{lr}\text { Bakery Engineers } & 59 \\ \text { Civil Engineers } & \end{array}$

Heating \& Ventilating Engineers ${ }_{-} 60$,

Mechanical Engineers 63, 74, 119,

$4 \overline{5}, \overline{6} \overline{1} \overline{1} \overline{1}, \overline{1} 27,159$

Municipal Engineers

Refrigerating Engineers

Safety Engineers

Sanitary

Sanitary Engineering --.---

Institute

Spice Trade Association

standards

Standards Association

Sugar Cane League

Transit Engineering Association-- 64, 155

Trucking Associations_._-_._--- 65

Trudeau Society

Uniform Boiler Law Society_-_-_-_

Veneer Package Association

Veterinary Medical Association--ciation

Walnut Manufacturers Association_

Warehousemen's Association -

Washer \& Ironer Manufacturers' Association

$-\overline{68}, 72,95$

Water Works Association--- 26, 68, 72, 95

Waxed Paper Association $--\overline{4}-\overline{70}, \overline{10}, 192$

Wood-Preservers' Association, 72

Zinc Institute

Ammonia compressors

A plifers, phonograph

ysis of sulfated oils

Anesthetic gases and oxygen

Animal oils

Annual Congress on Industrial Health_

Municipal Report
Annular ball bearings

Antennas, radio -

Anthracite coal_-_-_-_-_-_-_--

Industries, Inc

Institute

Anthropology

Anti-Friction Bearing Manufacturers Association -

Appalachian Hardwood Manufactur-

ers, Inc _-

Apparatus, electrical

tests and performance

industrial control

mechanical power transmission,

safety code

motor fire

nonmedicinal

physical therapy-_-_-_scientific

standard sizes and shapes

Apple-grading law, standard.-growers Association wraps

Apples, grades and standards

Appliances, fire extinguishing

counter, gas

gas -

ice using

oilburning, pot-type

Approval equipment (pamphlet) gas requirements _._seals, gas appliances tag of IES

Aprons, concrete, specifications

Arc-welding electrodes

Architectural specifications

Arkansas Soft Pine Bureau

Army-Navy standards (aircraft) -..

Aromatic Red Cedar Closet Lining Association

Arresters, lightning, standards ----

Artificial leather

Arts, graphic

Aspen lumber -

Asphalt grades

Institute

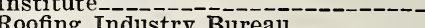

roofing products Bureau.--

Asphaltic road materials, liquid.--

Associated Cooperage Industries of America - panies, Inspection Department_--

General Contractors of America,

Rag Industries

Association of American Battery Manufacturers -

American Feed Control Ofials, Inc _American Railroads :

Bureau of Explosives________ 80, 121

Engineering Division, Electrical Section

Engineering Division, Signal Section -

Freight Claim Division

Freight Container Bureau_-_ 82, 166

Joint Committee On Grade Crossing Protection

Mechanical Division-------

Electrical Section, Mechan-

ical Division - perating-Transportation Division

Operating-Transportation $\overline{\mathrm{D}} \overline{\mathrm{i}}-$ vision, Fire and Insurance Section

Operating-Transportation Division, Medical and Surgical Section

Operating-Transportation Division, Operating Section --

Operating-Transportation Division, Protective Section --

Operating-Transportation Division, Safety Section_-_._-
Page

75

122
74

73

74
172

74

75

162

161

61
138

51

51
196

26

75
75

75

153

34
33

144

120

78
34

34
118

189

70
64

76

199

76

121

61
185

76

76
77

77
76

77

78

78

79

80

81

82
166

82

84

85 
Association of American Battery Manufacturers-Continued.

American Feed Control Officials, Inc.-Continued.

American Railroads-Continued. Operating-Transportation Division, Telegraph and Telephone Section

Purchases and Stores Division--American Wood Pulp Importers--Casualty and Surety Executives-Edison Illuminating Companies--Electragists, International Gas Appliance \& Equipment Manufacturers

Iron \& Steel Electrical Engineers-

Lift Truck \& Portable Elevator Manufacturers - - - -

Manufacturers of Chilled Car

Official Agricultural Chemists of North America-_-
Official Agricultural Chemists_--

Official Seed Analysts

Pyroxylin Coated Fabric Manufacturers_

Refrigerated Warehouses

Roller \& Silent Chain Manufacturers

Astronomy

Athletic sports

Audiometers

Automatic block signaling systems crossing gates, railway sprinkler systems

Automobile Club of Southern California fire apparatus Manufacturers Association-.--

Automotive industry

lighting and signaling equipment.radio equipment

Aviation lighting

Axial

(1) airplane._-_-_-_-_-_-_-_-_-_ passenger car, railway...-. steel

\section{B}

Bacon, sliced, cartons

Bagging classification

Bags, paper (all kinds) paper, millinery

Bakery equipment -_-

Baking industry

Ball bearings -

Ballast, concrete-_railway

Balling, specifications

Balls, golf

Bals, golf

Bands, strip steel_-_-_-_-_-_-_-

Barley strip steel----------------

Barrel heading, slack and tight_----

Barrel law, standard._. standard, for fruits and vegetables_ staves, slack, tight

Barrels, lime, standardization pork

slack

Bars, carbon steel reinforcing, plain and deformed.-steel, marking _-_-_-_-_-_-_-_-steel rail

Baseball

Baseplate wax

Basket act, standard

Basketball _._-

Baskets veneer

Battelle Memorial Institute.-

Batteries_-_-_-_-_-_-_-_-_-_-_-_primary and secondary $201072^{\circ}-41-18$
Page

Battery-charging motor generators

Bearings, ball

ball, annular.--_-_-_-_-_-_-_

thrust

Bed springs_._-_-_-_-_-_-

Bedding - - -

Beds, hospital

Bedsheets

Bedsteads

Beech flooring

Beef trolleys

33, 89 Beer bottles, standardization-_-_- 112

Bell Telephone System. Belt drives leather, vegetable-tanned

Belts, transmission - - - Beverage bottle dimensions...-..Bicycle tires and tubes_-_._-_._-_-_ Binders board

Binders Board Manufacturers Association -

Biological products, standard methods_ standardization

Biological stains -
91

16

14

81

151

155

164

91

197

194

190

117

141

45

210
Birogy

Biscuit flours--- 133,169

Bismuth preparations --

Bituminous roofing materials

waterproofing materials --_--- 58, 46

Black-walnut lumber---

Blackboard, composition.- 177

Blades, hacksaw---------------- 116 tungsten and high-speed, standard sizes -

Blankets, wool and part-wool____- 150

Blanks, gage --_-_-_-_-_-_--- 32

Blasting caps -122
Bleached shellac-

Block and tile, building, concrete-_- 188

Block system devices, railway____-_ 81

Blouses, boys'-- 125

Blower and exhaust systems, fire protection -..-

Blower and exhaust systems for dust, stock and vapor removal_._._._-_-

Blowers, centrifugal__-__-__-_._-

Board, binders building, insulated.- 123 chip, for bookbinding purposes_-_- 92, 107 insulating roof structural insulating

Board-rolls, corrugated_-_-_._- 174

Boiler construction code, ASME__-_- 62 $\begin{array}{lr}\text { feed water studies_- } & 23 \\ \text { laws and rules_-_- }\end{array}$

Boilers, copper heating, fire-box_-_-_-_-_-_-- 204 $\begin{array}{lr}\text { industrial, gas } & 34 \\ \text { low pressure heating, rating code-- } & 120\end{array}$ magazine, test code-_._- 74

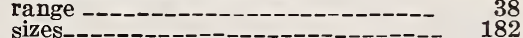

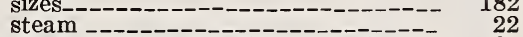
steam heating, burning fuel oil--- $\quad 60$ steam-heating, stoker-fired, code for testing steam heating, test codes-_- 60

Boilers and fireboxes_-_-_._-_--- 83

Bolt, nut, and rivet proportions--_--- 61

Bolts and nuts_____ 38,40

Bolts, packaging.-- 187

Bone-plates, steel_- 26

Book cloths_. Manufacturers' Institute-_-- 92, 107, 120

Books, composition and memorandum- 187

Bordeaux mixture_-_-_-_-_-_-_ 15

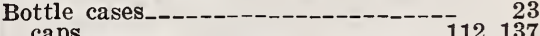
caps_-_- 
Bottles -- standardization
beer, sta carbonated beverage, standardization_-_-_-_-_-_-_-_-_-_-_--

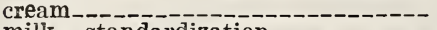
milk, standardization

Box board, gage list thicknesses

Boxes, fiber light steel match

millinery

paper wooden, nailed

Boxing

Brake and brake testing, safety code-

Brake Lining Manufacturers' Association, Inc

Page

Brake lining testing machine

Brakes, airplane._freight

Brandy standards

Brass ingot

items, cast, sanitary-co pipe nipples_.

Brassieres.

Breakfast sets, porcelain enamel-

Brick, fireclay molds, ice cream, sizes._. pavements paving, vitrified

Brick and tile, glazed

Bridge construction, specifications -Bridges, highway, specifications for (book)

steel for steel raiîway.wood - - .

Bronze castings ingot - - - - -

Brooders, gas, electric, coal, or oil, capacity -- Brown University

Brush wheels, dental

Brushes, calcimine carbon, graphite and metal graphite_ counter paint and varnish radiator

window -

Buckrams for bookbinding purposes_

Buff \& Polishing Wheel Manufacturers Association_-_._-_-_-_-_-_-_-

Buffing equipment sanitation code_--Buffing wheels

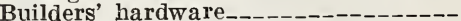

Building board, insulating code, recommended requirements for

chimneys and heating appli-

fire extinguishing equipment fire protection and fire resistance iron and steel-

Building codes, administrative requirements --

Building construction, fire tests exits code_.........laws, uniform materials, fire tests_._-_._-_-_-_research

officials Conference of America.-ordinances - standards standards --- fusion welding steel, fusion welding school, construction steel for Bureau of Aeronautics, U. S. Navy ---
Agricultural Chemistry and Engineering - Inspection and NavigaMarine Inspection and $71,102,121,13$ Burial vaults, concrete........
Burlapping, specifications___-_-_-_Burners, domestic _-_-_---_-gas conversion -

Bushings, jig Busses, refrigerated Bus tires and tubes.--Butane

\section{C}

Cabinets, fire insulated__-_-_-- 194 kitchen, porcelain enamel-_. 188 kitchen, steel-_. 205 Cables and wires, insulated Cables, electric, insulated, metallic coverings -_.--_-_-

electric, ozone resistant type insulation----cover, impregnated paperinsulated parkway, rubber insulated._-_-_ 123 power, rubber insulated signal__._. 128

varnished cambric insulated.-- 123

Cafeteria chinaware

Cake, cottonseed.-1 158

ice, sizes peanut oil

Caicimine brushes

Calcium Chloride Association...California Fruit Exchange----_--Olive Association -

Redwood Association Ripe Olive Standardization Act Walnut Growers Association Canadian Department of AgricultureEngineering Standards Association_

Canned fruits

goods, labeling

peas, sizes_._-__-_-_-___- 153

Canners League of California_-_-_- 94

Canning industry

Cans, fruits and vegetables, dionsions - and vetables, dimenice cream, tinned steel-_.-lard-_. light sheet iron tin, sizes

Capacitors, standards Cap screws_..

Caps, blasting bottle

milk bottle -

Carbon and alloy steel castings

Carbon dioxide extinguishing systems_ steel bars

Carboys, glass, boxed.--

Car loading rules sizes, elevator-_-_-_---------wheels, chilled.-

Carpet, cork Cars, coal mine, specifications
freight, designs of light-weight ---railroad, standard designs tank tank, chlorine-

Cartons, bacon, sliced ice cream, sizes_____-__

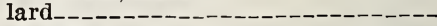
sausage _. Cartridges, metallic Cases, bottle wooden Cast brass items, sanitary iron, nickel-base austenitic Iron Pressure Pipe Institute iron radiators sanitary enamelware--water pipe nickel copper alloy. stone 
Page

Castings, bronze

carbon and alloy steel cast iron

die, zinc base alloy.

gray-iron

iron and steel

malleable

Catalog sizes

Catalysis

Cellulose Plastics Manufacturer's Association - .

Cement-bound macadam pavement---

Cement, portland.

Cement-stave silo

Cement stucco, portland.---

Cements, silicate zinc phosphate

Central Committee on Lumber Standards

Centrifugal blowers.--fans --

Cedar, incense lumber

Ceramics-ense lumber--------

Cereal chemistry laboratory methods $(\mathrm{book})$

Cereals_-_-_-_-_-_-_-_-_-_-_-_-_-

Certification of janitor supplies.--

plan for rail steel bars
Certified heating standards.---.-milk

Milk Producers Association of America (Inc.) _. A oak flooring -

Chain hoists Institute, Inc _. malleable.

Chains, roller, transmission. roller and silent__._._-_._-_. sizes - folding and portable

Chairs, folding and portable

Chalk--Chamber of Commerce of the United

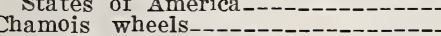

Checks, guest, restaurant.-.

Cheesecloth

Chemical analysis for foods, drugs, and agricultural products

technology ------

Chemicals

textile industry-

Chemistry cereal

Cherries, grades and standards

Chests, burglary resistive__._.

Chilled car wheels

Chimney construction, ordinance--

China plumbing fixtures, vitreous _.--

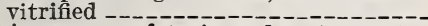

Chinaware, cafeteria and restaurant-hospital hotel

Chip board---1nstitute, Inc-tank cars

Chucks and chuck jaws for turret lathes and automatic lathes_._-

Cinema tography

Circuit breakers, oil

Civil Aeronautics Authority-..-_-_.service law, State._.

Claims, freight

Classification of coats material, standard.

scrap, standard

tuberculosis

-

Clay and silt in sand determination.-

Clay pipe

Products Association -

products, structural

Sewer Pipe Association.

206

tile, structural
Clays, foundry, testing and grading --

Page

Cleaning vacuum--- compounds, standard formulas

Closet lining, aromatic red-cedar

Cloth, abrasive tags

wire, Fourdrinier

Clothes, childrens, standard sizes.-dryers, gas
Cloths, wiping Coal

anthracite

handling equipment, outside mine cars, specifications mine tracks, signal and switches_-

tar disinfectant_._._._.

\begin{tabular}{ll} 
Coal-burning stoker equipment-- & $--\overline{7}$ \\
Coals, classification & 206 \\
\hline
\end{tabular}

Coarse aggregates_._-

Coating, zinc_-_-_-_-_---

Code, boiler construction, $\mathrm{ASME}$

buffing equipment, sanitation.-.-- 31

building exits_-_-

domestic boilers

electric meters

foundry

grinding-- $\quad 31$

heating and ventilating $\quad 60$

identification of gas-mask canisters_ $\quad 175$

metal cleaning

oil-heater rating tests.-- 120

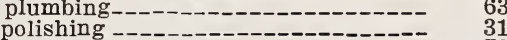

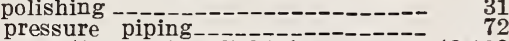

protection against lightning---- 42,128

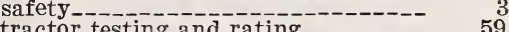

unfired pressure vessels_-_- 62

$\begin{array}{ll}\text { unfired pressure vessels_-_-_--_--- } & 62 \\ \text { vehicle uniform } & 20\end{array}$

Codes and specifications.--- 234

Coils, refrigerator

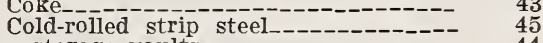

storage vaults_-_._- 44

Collapsible Tube Manufacturers Association _-_-______- 97

Color card of American standard--- $\quad 209$

United States Army

$\begin{array}{ll}\text { chart for milk bottle caps_------ } & 137 \\ \text { fastness of cotton and linen fabrics_- } & 141\end{array}$

fastness of cotton and linen fabrics-
marking for anesthetic-gas cylinders

specifications

standards, raw silk--

Colored textiles, fastness

Colorimetry -

cessories used in fluorescent tubing paint, standardization-_.-school furniture-_-_-_-_-_-_-_-_standard

water, standard.-

Columbia University

Combustible fibers...solids

Combustion engines, internal-_---- 124

Commercial feeds_._-_-_-____-_- 31

refrigerating equipment, rating -.-Refrigerator Manufacturers Association -..soaps -- - - standardization standards stokers, test code.-veneer Biological Stains__._Commodity data sheets (book) _._--Commodity Exchange, Inc ----_--Compartments, ice, refrigerator----Compounds, impression-_.

31
16

19

34
96


Compressed Air Institute air machinery, safety code for-cork_Gas Manufacturers Association--

gases, safe transportation_____-

Compressors, air._---_-_ammonia

Concrete aggregates

airport, road, and street pavement building block and tile burial vaults.

floors

flor finishes

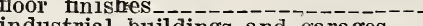
industrial buildings and garages

Masonry Association-_masonry units mixers and pavers

pipe

ready mixed

(1)

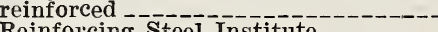

Reinforcing Steel Institute sewer pipe-sewers, monolithic shore protection sidewalks silos

staves

structures for flood control

volume studies

Concrete and reinforced concrete, report standard

Condenser section standards

Condensers, Freon-12

Conditioning, air copper, standard sizes_._copper-type, on overhead power lines.

Conduits

Cones, felt

Consolidated Freight Classification Committee --- ---------------

Construction industry, safety-----safety

steel

Consumer education service goods

goods standardization

Container boards, gage list of standards _-

Containers, fiber

freight

fruits and vegetables

glass_-

milk size--------

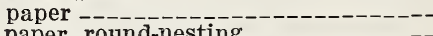

paper, round-nesting

$\begin{array}{lr}\text { robbery resistive- } & 194 \\ \text { spice } & \\ \text { standardization } & \end{array}$

steel

steel, light

Contracting Plasterers International Association $--1-{ }_{0}$

Contractors Pump Bureausafety code

Cook stoves

Cooking \& Heating Appliance Manufacturers -

Coolers, air._--_meat,

milk

water, drinking

Cooling tower lumber

Cooper wire nails_--_--_-----_---

Cooperage

Copper alloys

conductors, standard sizes

pipe nipples_--

Wire Engineering Association
\& Brass Research Association
Page

188

154

Copper-type conductors on overhead power lines Corn standard quality.

Cordage, hard fiber

Institute

Cork carpet

Composition Manufacturers Association compressed Institute of AmericaInsulation Manufacturers Association. life preservers

Marine Goods Manufacturers Association pipe covering, molded.ring buoys sheets for ring life buoys Stopper Manufacturers Association_ Tile Manufacturers Association---Corrosion in refrigerating plants.--investigations iron and steel

Corrugated board rolls fiber boxes and containers.---- 110,174 galvanized culverts

Corset \& Brassiere Asssociation of America____-_-_-_-_-_-_-_-_-_

Cotton Duck Association.fabrics -- - - - - - - - - - - - rags, classification-- 102 Textile Institute textiles, hospital and institutional Thread Institute

Cottonseed cake-_-_._-_-_-_-_meal___- 158 methods of analysis products_.

Counter appliances, gas_-_-_-_-_-_-- 34

brushes___-_-_-_-_-_-_-_-_--_ 24

$\begin{array}{ll}\text { Couplings, hose, standardization of --- } & \mathbf{1 5 3} \\ \text { Courts, basketball, lighting of } & \mathbf{1 5 1}\end{array}$

Coverings, metallic for insulated electric cables_-_-_-_- 123

Cracker flours

Cranberries - - - -

Cranes, derricks, and hoists, safety $\begin{array}{rr}\text { codes }- & 61 \\ \text { traveling, electric overhead_- }\end{array}$ traveling, rules for safe operation of - 89

Crates.-.-.- 181, 203 Crayon, Water Color \& Craft Institute

Cream bottles-- 112

Crepe paper

Cresylic disinfectant-- 145

Crows ties-- Manufacturers Association of America - 103 Crucible Manufacturers' Association- 104 Crucibles, plumbago, dimensions of - - 32,104 Crude glycerine_-_. 53 Crushed stone-_. 159 \begin{tabular}{ll} 
Culverts, corrugated galvanized----- & 142 \\
\hline
\end{tabular} Cup caps, ice cream, sizes of --_---- $\mathbf{1 2 6}$ Cupola refractories_--- $\quad 58$ Cups, ice cream, sizes of Curbs -Cut tacks.

Cutters -..--_glass, tests --

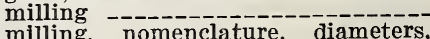
milling, nomenclature, diameters,
and thicknesses Cutting tools, metal
single-point, definitions Cylinders and adapters, rotating.-.Cylinders, anesthetic-gas, color marking -- for storing compressed Cylinders for storing compressed
gases Cypress lumber Cypress lumber for freight cars and locomotives -........- 165 
Page

Dairy equipment_-

Industries Supply Association, Inc-

products, methods of examination.

Deaerator heater section standards

Decorating and painting standards.-

Deep-well turbine pumps

Definitions, electrical terms gear

Dental amalgam alloys (n) mirrors hypodermic needles

lathe grinding wheels materials

mercury -

research

Denture rubber.

Dermatology

Derricks, cranes, and hoists, safety codes -- frozen, methods of analysis_-

Detergents

Devices, accoustical fire protection, testing and approval_ nonmedicinal

weighing and measuring-------

Diagnostic standards

Diamond Core Drill Manufacturers Association

Dictionary of paper

Dies and molds

Dies, metal

Diesel Engine Manufacturers' Associa-

tion -- Dimensions, beverage bottle-.-

Dinette sets, porcelain enamel_-_-_-_

Dip tanks

Discus

Dishes, disinfection--

Disinfectants

Distilled Spirits Institute, Inc------

Domestic burners gas ranges

Doors, file-storage-room, fire insulated fir, grading rules_... wood

Dough mixers, high speed.--

Douglas fir

Douglas Fir Plywood Association.--

Douglas fir pressure treatment_-----

Draft gears

hoods, gas

Drainage of coal mines

Drain tile

Drawings and drafting room practice, standards

Dressings, first-aid, packaging of unit_ surgica classification__._._._._. surgical, sizes

Drill fittings, diamond core

Drilling equipment, oil country-..-

Drills -

twist_---

Drinking-water coolers

Driveways, concrete, specifications --

Drop Forging Association.

Drugs

chemical analysis standardization -

Drums, steel.

Dry cells tests

Dry cleaning dyeing milk

Dryers, clothes, gas hair, gas _..

Ducks, cotton

Dumbwaiters, safety code- explosions, safety code for prevention

explosive
104

104 ,

126

56

115

117

42,80

36
28

28
29

29

29

28

224

28
49

61

56
228

190

78

151

179

104

53

135

104

23
188

164

16

145

105

73
34

194

110

160

59
218

105

73

84
34

52

28, 97

201

26
27

7, 125

104

135

6,168

63
138

189

106

42,55

90
29

204

225

164

164

30

34

102
0,61

164

153
Dyed or printed rayons, standard methods - - -

silks, standard methods

Dyed wool, standard methods Dyeing, dry _. Dyestuffs, fastness.--

\section{$\mathbf{E}$}

Earth movers, tire and rim equipment -10
Eastern spruce lumber Eaves trough Economics, home.- 37 Edison Electric Institute-_-_-_-_--- 42,106 Ejector, steam-jet, standards Elbows, union_._. Electric :

flatirons, domestic $-----\overline{-}----$
Fuse Manufacturers Guil hand lanterns for trainmen----Hoist Manufacturers Association.incandescent lamps...--.--

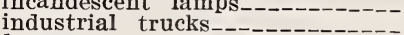
lamps

Overhead Crane Institute

overhead traveling cranes----railway material, packaging ranges, household, test specifications

storage water heaters.-welded steel tubing Electrical apparatus, terminal markings

106

106

88
107

118

119

107

89

65

106

106

111

161

apparatus, tests and performance 42,162

devices and materials with relation to fire and casuaity hazards, standards
equipment in buildings, standard symbols equipment in coal mines, safety rules for installing and using equipment on railroad cars insulating materials_._. insulation _._machinery safety code, national--- 80 standards terms, definitions Testing Laboratories Electroacoustics ---_----------- 122

Electrodes, arc welding seam welding

Electronics -122

Electroplating

$\begin{array}{ll}\text { Electrotypes - } & 125 \\ \text { Elevator car sizes } & \end{array}$

Elevators, portable safety code Employing Bookbinders of America-107, 92 ,

$\begin{array}{lll}\text { Enamelware, sanitary, cast iron_--- } & 107, & 120 \\ & & 196\end{array}$

$\begin{array}{ll}\text { Engelmann spruce lumber } & \\ \text { Engine tests, fire } & \end{array}$

Engineering Foundation, Welding Research Committee manual

mechanical specifications

Engines, a ircraft combustion, internal diesel

Engraving, standards.

Equipment, automotive bakery dairy -fire fighting, in metal mines gas --_road building

Escalators, safety code_._-

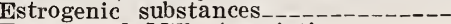
Evaporated Milk Association_._-
160

82

25 42 0 2 8 
Evergreens, commercial grades

Exhoust systems safety code---

Exits code building

Explosive dust

Explosives, regulations for safe use and handling

safe transportation underground blasting

Explosives for use in mines

Explosives in bituminous coal mines, recommended practice_-_-_-_-_Explosion, dust (codes)

Explosions, dust, safety code for prevention

prevention
Extinguishers, fire

\section{F}

Fabrics, cotton

cotton and linen, color fastness

impregnated, for bookbinding purposes pyroxylin coated.

standard tests for identifying wool and part-wool woven dress

woven elastic

Face veneer

Facsimile television.

Factory Mutual Laboratories

Fans, centrifugal and axial electric

Farm equipment industry Equipment Institute marketing program

produts, grades and standards silos

Farmers \& Manufacturers Beet Sugar Association

Fasteners, paper, steel

Fastness of colored textiles dyestuffs

Fastness to acids alkalies -- - light. perspiration

Fatigue in metals

Fats refined, methods of analysis

Federal Specifications Board.

Federal Specifications Executive Committee $-28,38,46,125,132,154,235$

Federal specifications, preparatoon.-

Federal Trade Commission

Feed, commercial water problems

Feeding stuffs, laws and regulations

Feldspar, ground

Felt cones wheels

Fence, chain-link woven-wire

Ferroalloys

(1) state control laws

wiberboard, insulating

Fibre Box Association

Fiber boxes and containers

Fibers, combustible.

Files and rasps

Files, gold vulcanite

File-storage-room doors, fire insulated.

Filing devices, fire insulated

Fillers for brick and block paving

Films, sound and silent

Filter gravel.

Filters, milk

Fine Wire Manufacturers' Association.

Fir, balsam Door Institute Douglas Douglas, pressure treatment white, lumber
Page

17

2, 164

153

122

132

121

138

164

164

151

164

102

141

7, 120

121

150

174

218

190

78

141

59
109

109
181

181

149

109

137

19
19

19

19

19

173

182

53
238

238

238
238

36,67

31

22
79

162

162
29
Fire alarm systems, municipal__apparatus, automobile__. motor -

regulations

box heating boilers engine tests boilersextinguishers extinguishing appliances

equipment, building code requirements_. 164

fighting equipment in metal mines- 52,164

hose coupling screw threads____- 153

hydrants, specifications

nsulated safes, chests, vaults, and doors otection of blowers and exhaust

systems --_-_-_-

codes

devices, testing and approval

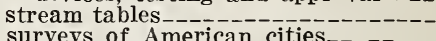
tests of building construction.

building materials waste, prevention, and protection-Fireboxes and boilers____-__-

Fireclay brick protection and fire resistance, ire protection and fire resistance,
building code requirements Fittings and flanges, pipe-_-

Fittings and tubing, gas appliance--- 34

Fittings, lead malleable-iron -- 131 pipe screw -------- 131 wrought-iron and wrought-steel, sizes of 132 Fixtures, plumbing, hospital residence lighting

Flammable liquids

Flanges and fittings, pipe

Flanges and flanged fittings, bronze- 131

Flat-rolled steel-_------------- 142

$\begin{array}{ll}\text { Flatirons, domestic, electric-- } & 106 \\ \text { Flood control, concrete structures for- } & 188\end{array}$

\begin{tabular}{lr} 
Floodlighting for railway crossings-- & 83 \\
\hline
\end{tabular}

Floodlights, specifications___-__- 118

Floor finishes, concrete_-___-_-_ 189 measurements, standard method of_ 140 Flooring, hardwood (various species) - 169 maple, beech, and birch

$\begin{array}{lr}\text { Floors, concrete--- } & 27 \\ \text { Florida } & 204\end{array}$

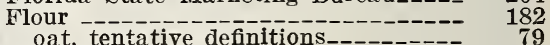

Flours, biscuit_------------------ 17

cracker -- 17

$\begin{array}{lr}\text { phosphated- } & 17 \\ \text { Fluorescent tubing, colors used in } & 177\end{array}$

Folding Paper Box Association of

America

Food and Drug Administration
Food service equipment industry

Foods, accepted, and their nutritional canned, quality labels for chemical analysis

Footwear, occupational, performance requirements for protecting - - rubber and canvas orging and hot-metal stamping,

Forgings, steel_--_-----------tolerances

Formed Steel Tube Institute

Forms, printing tions warehouse

concrete joist construction floors--

Foudrinier wire cloth_-__--_-----

Foundry alloys, nonferrous
apprenticeship, minimum standapprenticeship, minimum standclays, testing and grading codes 
Foundry alloys, nonferrous-Con. practices, malleable $---1-0-1$ sands, testing and grading vacuum and float type--

Freight brakes cars, designs of light-weight claim rule book containers

Freon-12 condensers liquid receivers water coolers

Fruit \& Vegetable Brokers' Association

Fruit preserves, standards trees, grades

Fruit, canned

grade specifications

Fryers, hotel and restaurant.....

Fuel and lubricating oils

Fuel equipment, pulverized.research

Fuels

gaseous motor

Fundamental researches in the basic sciences -

Fungicides

Furnace pipe and fittings

Furnaces, sizes_._warm-air, test code.

Furniture, school, colors

Fuses electric

Fusion welding uilding steel

\section{G}

Gage blanks

list of box board and container boards _. -

Gages and tools.-_-

Gages, limit thread plug

Gages of metal on tubular plumbing goods

Gaging, screw thread hot-dipped roofing

roofing -aters, gas.-

Garden hose

walls, concrete

Garment cleaning

Gas appliance seals of approval approval requirements compressed

mask canisters, code for identification -... pipe, mechanical joints

power ranges, domestic

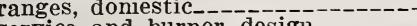
service and burner design tubing, flexible-_-_-_-_-_-_-_---_ welding rods

Gaseous fuels.

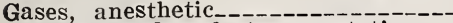
compressed, safe transportation.-electrochemistry hazardous

Gaskets, rubber

Gasoline, natural

Gates, crossing, automatic, railway--

Gear defintions

geometry _._lubrication, industrial_-_. motors, shaft_-_._spur

teeth sizes

Gearing nomenclature

Gears draft inspection tolerances_-_._-_._.-.

Gems - Geographỹ
Page
Glass Coogy t in e r Association of America__._. containers, sizes_.._______ 95, 137, 171

Cutter Manufacturers Association of America packaging_-_- 112

products_-_-_-_-_-_-_-_-_-_-_--- 25

safety safety, specifications and methods
of test.sand test_-_- 15

Glasses, sun _.

Glassware, illuminating

Glazed Brick \& Tile Institute_._-_-- 112 ware

Gloves, la tex, surgeon's_-------- $\quad 38$

$\begin{array}{ll}\text { rubber, surgeon's } & 38 \\ \text { lycerine, crude_- } & \end{array}$

Gold files

filled articles, marking

shell lengths__-___-_ 29

$\begin{array}{lr}\text { Golds, inlay casting } & 28 \\ \text { Golf balls } & 214\end{array}$

Goods, grey_-

Government Research Association_-- 168

Grade-marking of lumber..._..- 184

Grades of paper

Grains -182

Grapes, grade specifications

Graphical symbols and abbreviations for use on drawings Graphic arts Gratings ------- $\quad 38$

Gravel roofing -

Gray-iron castings_-_-_-_-___-_-_ 117

Gray Iron Founders' Society, Inc---- 113

Grease, lubricating

Grey goods_-_-

Grinding code

Wheel Manufacturers Association- 113,127

wheels, dental lathe-_---- 29

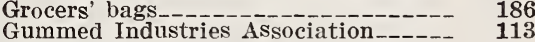

$\begin{array}{lr}\text { Gummed Industries Association_-_-- } & 113 \\ \text { Gymnastics } & 16\end{array}$

Gypsum Association

$\begin{array}{ll}\text { plastering }-1 & 114 \\ \text { reinforced } & \end{array}$

\section{I}

Hacksaw blades _-_-_-_-_-_-_-_- 116

Hack Saw Manufacturers Association of America

Hair dryers, gas__._._._.

Hammer throwing

Hamper act, standard

Hampers -

Hand trucks _...- $\quad \begin{array}{r}114 \\ \text { Hand }\end{array}$

$\begin{array}{ll}\text { Hand trucks } & \\ \text { Handball } & \end{array}$

Handbook of interior wiring design-- 106 Scientific Societies of the United States and Canada________ 172

Society of Automotive Engineers

Standards and Engineering Information. RMA

welded steel tubing

Handbook, metals (ASM)

Handles, hickory

Hardware items

pole-line --.--

Hardwood Dimension Manufacturers
Association, Inc_-_

flooring -

lumber

paneling _. 75

Harvard University

Hay, grades_. 165

Hazardous gases____-__-___-_ 153 
Health, industrial

Page

49

115

eat exchange Institute

transfer

transmission -

Heaters, garage, gas

space, gas

oil burning

test code-co

unit, gas

testing -----

water, electric storage

gas - - - - -

Heating boilers, fire-box

low pressure, rating code

Heating codes district, steam in installation of conversion burners - - standards

Piping and Air Conditioning Contractors National Association - 115 Standards, certified

warm air

Hemlock, northern west coast

Herbs

Hickory Handle Associatioñ

High pressure steam curing bridges, specifications for (book) maintenance

materials, standard specifications for, and methods of sampling and testing (book) planning ( sign posts, steel, zinc-coated

Highways -

Hoists, chain electric

Hoists, derricks, and cranes, safety codes

Home economics

Home Owners' Ioan Corporation

Homeopathic Pharmacopoeia of the United States._.

Hoods, draft, gas

Hoops, coiled elm strip steel.

Hoppers, flour

Horological Institute of America

ose couplings, standardization garden

houses

rubber

water,

Hosiery _lengths and sizes.-.-.standards and tests

women's silk full-fashioned

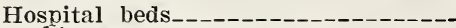
chinaware -equipment and supplies._._._-_. minimum standards plumbing fixtures.-_refrigerators

Hot-dipped zinc-coated products

Hot plates, gas - -

Hot-rolled strip steel

Hot-water tanks.

Hotel chinaware

Household electric ranges, test specifications -

insecticide--.--

House piping, gas

Hurdle-_--standardization

Hydraulic Institute

Hydraulics_-_._-_-_-_-_-_._-_-_

Hydrodynamies

Hypodermic needles, dental

\section{I}

Page

Ice cake sizes_____________ $44,63,144$ compartment sizes for domestic re-

frigerators__.____________ 44,144

cream brick molds and cartons_-- 126 cans, tinned steel___-_-_._-_ 126 cups and cup caps___-___-_-_ 126

hockey -..- 16

industry

latent heat of fusion

manufacturing plants, steam-driven,

test code

refrigerators

Idaho white pine lumber.-.

tag of approval

Illuminating Engineering Society- $\overline{36}, \mathbf{4 6}, 117$

glasses, nomenclature________ 118

glassware

Glassware Standards Institute--_, 118

Impregnated fabrics

Impression compounds--

Incandescent Lamp Manufacturers'

Association _. 118

Incense cedar lumber.- 218

Incinerators, gas

Index of ASTM standards

Indiana Limestone Institute------- 118

Industrial accidents____- 126

control apparatus

gas boilers

health -

Hygiene Foundation of America_-- $\quad 135$

lighting -.-_-_-_-_-_-_-- 117

Management Society.-- 119

medicine, standard for

purchasing-Principles and practices (book ; NAPA)

research laboratories of the United

States (publication) -

Safety Equipment Association

Sand -

Springs --

standardization (magazine)

tires and tubes

Truck Statistical Association

Unit Heater Association__-__-_-

Industries, anthracite-_-_--_-_-

148

172

119

191

210

119

119

153

Ingot brass

Ingot brass and bronze, manual _._-- 183

Ingot bronze

Inlay casting golds ${ }_{\text {investment }}$

investment -

Insecticides

Institute of American Poultry Industries_- 120

Boiler and Radiator Manufacturers_- 74, 120

Book Cloth and Impregnated Fabrics Manufacturers

Cooking and Heating Âppliance Mànufacturers -Leather Cloth and Lacquered Fabrics Manufacturers

Makers of Fxplosives

Paper Chemistry_- 121

Radio Engineers---.-------- 122, 190

Shortening Manufacturers

Insulated Power Cable Engineers Âssociation - 123 wires and cables for other than telephone and telegraph use-_-__-_- 80,88

Insulating board, structural

cork - - - 102

fiberboard -

materials, electrical_-_- $\quad 25$

thermal conductivity

$\begin{array}{ll}\text { Insulation Board Institute-_- } & 123 \\ \text { electrical } & \mathbf{1 7 3}\end{array}$

ozone resistant type, for electric

$\begin{array}{cc}\text { cables }-1-- & 123 \\ \text { thermal } & \end{array}$

Insulators for electric power lines_-_- 80

pin-type

88
23
23
25
35
23
73
23
73
80
06

\section{6
5
0
9
3
7
3
2
8
8
5
0
0}

20

21

.


Interdepartmental Screw Thread Committee

Internal Combustion Engine Institute-

International Acetylene Association-Apple Association - Electrotypers and Stereotypers -

Garment Manufacturers

Government Labor Officials

Ice Cream Manufacturers $-\overline{-}-\overline{-} \bar{d}$ toards and

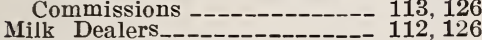

Public Works Officials_-_-_-_- 56

Testing Materials City Managers' Association Commission on Illumination Council of Scientific Unions critical tables of numerical data, physics, chemistry, and technoiogy ( 7 volumes)

Electrotechnical Commission

Fire Chiefs Association --_-_-_--Municipal Signal Association-----

Standards Association

Inter-Society Color Council-- $\overline{8}, \overline{5} \overline{5}, \overline{1} \overline{1} 8,124$

Interstate Commerce Commission

Iowa State College. $46,65,83,132$

Iron and steel

ron zinc-coated

cast, sanitary enamelware gray

pipe nipples.-scrap, classification

Ironers, gas heated.

household

\section{$\mathrm{J}$}

Jack pipe lumber

Janitor supplies, certification of Japanese Raw Silk Intelligence Bureau

Javelin

Jewelers' Vigilance

Committee._-_._-

Jig bushings_-_-_-_-_-_-_-_-_-_-_-

Jigs and fixtures

Joint Committee on Raw Silk Classification

Joist construction, steel, fire resistance ratings for

Joists, steel

Journal of Home Economics

Jute packing, twisted...-.--.--

\section{K}

Keyways for holes in gears_.--_.-Kitchen cabinets, porcelain enamel -steel

tables, porcelain enamel-_-------

Knit underwear.--

\section{I}

Label service of Underwriters' Labo-

Labeling of canned goods

informative the United States (publication) _..-Laces, shoe, braided

Ladders, safety code for the construction, use, and care of

Lamps, electric

electrical for signal purposes, simplification

IES

incandescent, electric-----0portable

Lanterns, electric hand, for trainmen-

Larch, Douglas fir lumber.--.--
Page

Lard cans-_---- 47

cartons -

Latex gloves, surgeon's of ice-..--

Lath, metal, surgen's 136 yarn _-_-_-_-_-_-__-_-_-_- 101

Lathing specifications.- 100

Laundering methods___- 42

Laundry machinery and operation, safety code for.__________- 125, 146

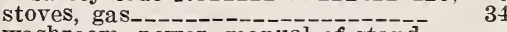
washroom, power, manual of stand-

Laundryowners National Association of the United States and Canada.-

Law, bond. county manager liquor state civil service--

Laws, building

ad for calking purposes_-_-_-_--- 128

Industries Association_-_-_-_--- 128

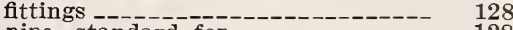

pipe, standard for-- 128

amination _-_-_-_-_-_-_--- 56

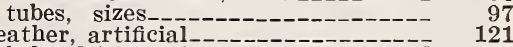

belt drives, short center pivoted motor_-_-_-

belting, vegetable-tanned._-_-_-- 46

measuring -

$\begin{array}{rr}\text { physical tests-- } & 46 \\ \text { thicknesses of } \mathrm{bag}, \mathrm{case} \text {, and strap-- } & 207\end{array}$

upholstery__._. 207

vegetable-tanned, $\mathrm{pH}$ value

Legislation, motor vehicle-------- 20

Lehigh University_-_-_-_-_---- 44, 99

Letter symbols and abbreviations for science and engineering_______ 42, 200

Life preservers, cork Lift trucks

Lighting and signaling equipment, automotive Lighting, aviation basketball courts equipment, specifications_____-_-_fixtures, residence-_._industrial

motor rehicle-natural__._-_._-_-_painting in relation to painting in relation to residence

rural

117
11

school, recommended practice_-_-_- 118 street and highway._-_-_ 117 studio

Lightning arresters, standards code for protection against Rod Manufacturers Association of

Lime United States of America - - 60,128

barrels, standardization.---

plaster.- 166

stucco-_- 166

Limestone -- 118

213 Lime-sulfur solutions

Limit gages

Linoleum and Felt Base Manufacturers Association

Linoleum, battleship

Liquid asphaltic road materials receivers, Freon-12 sulfur dioxide, method of analysis -Tight Paper Container Association_-

Liquids, flammable-_-_--_-_-_-Liquor law----Loaded paper shot shells--.-----
Loading platforms, standard_---

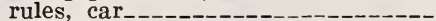
Locomotive construction. tires..-

.

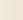

8

6 
Locomotives, coal mine

Logs, mahogany Walnut

Lowell Textile Institute--

Low temperature scales

Lubricating and fuel oils

Lubricating grease.--

Lubrication, gear, industrial

Lumber, aspen

black-walnut

cooling tower

cypress, for freight cars and locomotives

Douglas fir

eastern spruce

Engelmann spruce-grade-marking

hardwood

hardwood dimension, grading rules

hardwood, grading

Idaho white pine-

incense cedar

jack pine

larch, Douglas fir.-

mahogany

northern hemlock

northern white pine

Norway pine

red cedar

red cypress

redwood

sitka spruce

sizes

soft pine

southern hardwood

southern pine

standards, American

sugar pine

tamarack

tank stock

tidewater red cypress

west coast hemiock

western red cedar.

western white spruce

white fir

Lumber and ties, oak, pressure treatment

Lumber and timber, softwood

Luminaires, residential, certified.---

Lye tables

\section{IM}

Machine Screw Nut Bureau__-_-_sclews

tool elements

Machinery, canning

compressed-air, safety codeelectrical

packaging

frigerating

-

forle

Machines, agricultural

Magazine boilers, test code

Mahogany Association Philippine

Malleable Chain Manufacturers' Institute

Founders' Society-

foundry practices

foundry refractories

Malt analysis Research institute standard quality

Management, industrial

Manganese Track Society

Manual of Accident prevention in construction (AGC)

concrete inspection (ACI) engineering

ingot brass and bronze pipe welding, standard

preservative treatment of woo

purchasing and stores department (AAR)

42
129

67

19

173

67

94

218

218

67

114

218

185

94

201

167
218

3,185

201

185

218

73

42

129
Page Manual of Accident prevention in construction-Continued.

104

167
36

185

165

185

165

218

185

130

218

218

218

79
76

201

218

53

214 87 Metallic cartridges recommended practices for railway engineering and maintenance of way

specifications for the purchase of hospital equipment and supplies_ standard practice (CRSI)
standard practice for the power laundry washroom for the power steel construction_-_-_-_-_-_steel products_._-_-_-___-_-_ water works accounting water works practice

Manufacturers Standardization Society of the Valves and Fittings Industry of the United States Maple flooring

Marble, imported and domestic

Marbles, classification

Marine engineering oakum

Marketing program, farm Marking gold filled and rolled gold articles

steel bars

units, - 57

units, concrete

walls, concrete

Matches, safety -

Material classification, standard_-_- $\quad 87$

Materials, building__.___._- 39 handbook_...- 148

highway, standard specifications for, and methods of sampling and testing (book) refractory

Mathematics__-__-_-_-_-____ 172

Mattresses, hospitals and institutions_ 38,139

labeling _-__-_-__-_____- 139

Meal, cottonseed. soybean oil

Meat_-_-_-_-_-_-_-_-_-_-_ 47 coolers - $\quad 98$

Measurements, acoustical

Measurement stanảards__._. 222

Measures and weights

Measuring leather radio noise, methods

Mechanical Engineering (publication)power transmission apparatus, safety code.... power transmission apparatus, saferefrigeration, safety code rubber goods_... saws standards stokers_--

Mechanics, applied_-_-_-_-_-_-_-

Medical remedies, veterinary science standards_. training

Medicine, industrial, standard - search_-

Men's pajamas_-

Mercury arc rectifiers dental _. preparations -

Metal and metal products

Metal cleaning code Cutting Tool Institute Lath Manufacturers Association_-- 136

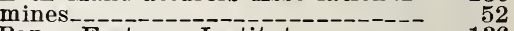
Paper Fastener Institute-_o $\quad 136$

Window Institute__-_-_-_-_-_-_-_- 137 
Metals, fatigue

handbook (ASTM)

nonferrous, classification _...-..--

Meters, electricity, code_..--..--

Methods of sampling aluminum testing hosiery

Michigan State College--

Milk and Ice Cream Can Institute

Milk bottle caps

bottles, standardization--.--

Cap Statistical Bureau

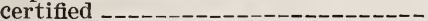
coolers

dry

evaporated

filters skim, dry

Milled rice---

Millinery paper bags._.

Milling cutters

nomenclature, dia meters, and thicknesses

Millwork, toxic preservation----

Mine Inspectors' Institute of America

Mineral aggregates

Mines, coal, drainage-_-_-_-_-coal, safety rules for installing and using electrical equipment.

metal, fire fighting equipment_.--_

Minimum live loads allowable for use in design of buildings

standards for hospitals standards of foundry apprenticeship (book)

Mining

industry standards

Mirror Manufacturers Association

Mirrors, dental cone socket_._-_._-plate-glass

window-glass

Mixer Manufacturers Bureau

Mixers, concrete

dough, high speed.

Mixture, Bordeaux.--

Model traffic ordinances_._._._._.

Molasses feeding, tentative definitions Molded cork pipe covering

Molding, hardwood interior.....-

Molds and dies.

Monolithic concrete sewers

Monorail Manufacturers Association-

Mortars for unit masonry

Mortuary refrigerators

Mosaics

Motion-picture industry standards

Motor and Equipment Association-

Motor carriers explosives and danger-

Fire Apparatus Manufacturers Association -_- - - - - - - - - - - - freight classification, national fuel research fuels

generators, automatic battery-charg-

ing - vehicle legislation.-vehicle lighting
vehicles, inspection requirements vision.

Motorcycle tires and tubes

Motors, alternating-current, for main roll drives

commutating-pole mill-type

railway__._. shaft, gear.-synchronous, for ammonia compressors

Multiple V-Belt Drive Association

Municipal communications systems_-Finance Officers Association_-_._-_ fire-alarm systems

fire apparatus, specifications report, annual, specifications_--

Muslin
173
62

150

88

16
143

143

126

137

112

17,96

63

30

109

30

193
174

135

167

160

137

178

52

52
52

44
26

165

43
52

3

138

29
138

138

78

78
59

15

20

79

102

115

202
27

138

206

98

179
200

200

155

65,66

138

66

199
226

119

20

117

156

210

89

89

42,80

63
138

128

128
69

128

153

127

Nailed wooden boxes_-_.--_-_----

Nails_------

National Academy of Sciences.--- 171

Advisory Commission on Vision for

Motor Drivers

Aircraft Standards Committee

American Wholesale Lumber Association

Automatic Sprinkler Association.--

Basketball Committee of the United States and Canada.

Battery Manufacturers Association

Board of Boiler and Pressure Vessel Inspectors

Board of Fire Underiters

Bureau of Standards-Functions and activities

Canners Association

Canvas Goods Manufacturers Association

Coal Association

Concrete Burial VauIt Âssociation.

Concrete Masonry Association _..-_- 154

Conference on Street and Highway Safety

Conference on Uniform Traffic Accident Statistics --- Conference on Weights and Meas-

ures-----

Consumer Retail Council_- 20, $\mathbf{1 4} \overline{2}, 157,162$

Cottonseed Products Association_- 79, 157

Council of American Shipbuilders_- 25, 158

Council on Compensation Insurance_ 127

Crepe Paper Association of America

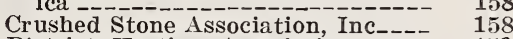

District Heating Association_.._- 159

Door Manufacturers Association, Inc electrical code_- $140,160,164$ Electrical Contractors Association_- 160

Electrical Manufacturers Association_electrical safety code---_-_-_----- 88,106

Elevator Manufacturing industry, Inc-

Fan Manufacturers Association_---

Feldspar Association_-_-

Fertilizer Association

Fire Protection Association-_- 17

$24,69,128,129,151,163$

.

(164

Gas Engine Association__-_-_-_-_- 197

Grease Manufacturers Association-

Hardwood Lumber Association

$75,129,165,201$

Hay Association

Industrial Sand Association_._-_- 166

$\begin{array}{ll}\text { Institute of Health } & 134 \\ \text { League of Commission Merchants-- } & \mathbf{1 2 5}\end{array}$

League of Wholesale Fresh Fruit and Vegetable Distributors _._._. $\quad 166$

Lime Association_. 166

Lubricating Grease Institute-_---- 167

Lumber Manufacturers Association- $\quad 167$

$\begin{array}{lr}\text { Machine Tool Builders Association } & 167 \\ \text { motor freight classification_- } & 66\end{array}$

$\begin{array}{lr}\text { motor freight classification_------ } & 66 \\ \text { Municipal League_--_-_- } & 168\end{array}$

Oak Flooring Manufacturers' Asso-

Paint, Varnish and Lacquer Association-

Paperboard Association--

Paving Brick Association _._._._.--

Petroleum Association

Photographic Dealers Association --

Preservers Association, Inc

Ready Mixed Concrete Association.-

Refrigerator Manufacturers Association. 
National Academy of Sciences-Con. Page Research Council__-_ 8, 118, 155, 170, 171
resins handbook_-

Retail Dry Goods Association.-- 111, 173

Retail Hardware Association_..._ 174

Rivers and Harbors Association.

18

Safety Council_________-_ 127, 175

Sand and Gravel Association

Scale Men's Association -------
School Supplies and Equipment $\mathbf{A S}^{-}$

chool Supplies and Equipment $\mathbf{A}_{\mathbf{S}}-$

Screw Thread Commission.--

Sign Association, Inc

Slag Association

Slate Association

Soybean Processors Association

Supply and Machinery Distributors Association----
ent and Awning Manufacturers

Tent and Awning Manufacturers

Terra Cotta Society.--

Terrazzo and Mosaic Association--

Tuberculosis Association - - - - tioning Association Air Cond

Wholesale Hardware Association of the United States.

176

176

Wooden Box Association

Naticnal Association of Automobile Manufacturers _._.

Bedding Manufacturers

Better Business Bureaus.-.-.--

Bottle Cap Manufacturers_._-_._-

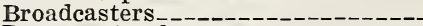

Builders Exchanges-- 139

Building Owners and Managers-- 140, 159

Dyers and Cleaners of United States and Canada

Engine and Boat Manufacturers.-

ran Manufacturers_-_-_-_-_-- 141, 162

Flat Rolled Steel Manufacturers_-- 142

Food Chains_-_-_-_-_-_----- 142

Hosiery Manufacturers

Ice Industries_-_-_-_-_44, 63, 144

Ice Refrigerator Manufacturers-- 14 facturers, Inc-

Marble Dealers

Master Plumbers of the United States

Mutual Botle Cap Manufacturers --- 2,112

Pipe Nipples Manufacturers_-_--- 146

Practical Refrigerating Engineers

Printers' Roller Manufacturers.---

Purchasing Agents Railroads and Utilies Commissioners

180

197

139
36
137

Real Estate Boards

Sheet Metal Distributors

Silo Manufacturers

Taxicab Owners

Waste Material Dealers, Inc

Wool Manufacturers_____-

Natural Gasoline Association of America

lighting

resins _

Naval architecture

Needles, hypodermic, dental_...--

New and nonofficial remedies (book) -

New England Council

New England Manufacturing. Jewelers' and Silversmiths' Association.------

New York Produce Exchange_-_.-_-_

New York University iron, pipe, brass, copper, steel, and 116

Noise, radio, methods of measuring--

Nomenclature, gear.--
illuminating glasses_-

illuminating glasses

Nonferrous foundry alloys_-_-

146

147

69,83

148

149

155

155
149

150

181

117

117
20

114 29
49
Non-Ferrous Hot Water Tank Manufacturers Association

Ingot Metal Institute

metals classification

Nonmedicinal apparatus and device--

Northeastern Lumber Manufacturers Assocition

Northern Hemlock and Hardwood Manufacturers Association_-_-Pine Manufacturers' Association--White Cedar Association_------white cedar poles___-_-_-_.--

white cedar shingles---white pine lumber Northwest Canners Association.- 183, 185 Norway pine lumber Nursery stock Nuts and bolts Nuts, bolts, and rivet proportions Nuts, lock, bearing

Oak flooring, certified

169

Oakum, marine

Oat flour, tentative definitions

Office of Price Administration Production Management

Official and tentative methods of analysis (food products) (book)

Official Classification Committee Railway Equipment Register Ohio State University

Oil Burner Institute, Inc u rners, automatic mechanical draft

circuit breakers-cod liver, fortified country drilling equipment.--heater rating tests, code_.-olive, methods of analysis soybean $-\overline{179}$

Oil-burning appliances, pot-type_---Oils, animal fuel and lubricating refined, methods of analysis sulfated, analysis vegetable Olive, canned, size grades.-oil, methods of analysis Open Steel Flooring Institute, Inc - -(AAR)

Operation of truck mixers and agitators

Ophthalmology

Optical Society of America.

Optics, physical, geometrical, etc----

Orange shellac

Ordinances, building chimney construction-- 153 traffic

Ordnance Department, War Depart-

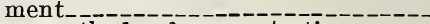
Ores, methods of screen testing Outdoor Advertising Association Ovens, roasting, gas _-_-_-_-_-_-_Overhead track systems._-_-_-_-_Oxygen resistant type insulation for

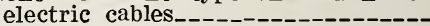

\section{$\mathbf{P}$}

Pacific Coast Building Officials Conference--Packaging of carriage, machine and lag bolts_-_-_-_-_-_-_-_-_---_Institute---

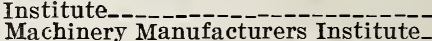
overhead electric railway material_unit first-aid dressings___-_-_-_-_-_ Packing, twisted jute._.
211

236
236

90

23

185

89
79

53

120
53

182

120

182

104
53

46

182

93

185 
Pads, specifications

Paint brushes colors, standardization. specifications

Painting and Decorating Contractors of America

Painting in relation to lighting

Paints

Pajamas, men's---

Panelboards

Paneling, hardwood.-. wall, solid hardwood.-Pan sizes, bread.

Paper, abrasive

Bag Manufacturers Institute bags, millinery boxes

containers

round-nesting

crepedictionary

fasteners, steel

grades

industry--

rolls, corrugated

standardization

Stationery and Tablet Manufacturers Association -_tags

tissue, waxed

waste, classification

paper products

Paper and pulp mills, safety code

Parenteral solutions

Pathology

Patterns, dress

Pavement, cement-bound macadam concrete-

Pavements, brick and concrete

Pavers, concrete

Paving brick, vitrified

Peanut

oil cake

Pears,

- - -

Pecan flooring

Pepper, black---ing occupational footwear standards - - -

Perspiration, fastness to

Petroleum

industry -

Petroleum and petroleum products

Pharmaceuticals

Pharmacopoeia of the United States.Homeopathic, of the United States -

Philippine mahogany

Phonograph amplifiers...-

Phosphated flours

Photochemistry -

Photographic apparatus

Photography

Photometry------------

pH value of vegetable-tanned leather-
Physical standards for railroad employees

therapy apparatus.

Physics

Pig iron

Piling, red cedar

Pillowcases

Pillows, labeling

Pine, jack, lumber

northern white, lumber

Norway, lumber

Norway, lumbe

oil disinfectant_--

ponderosa

sugar, lumber

white, Idaho, lumber-_-_--_-_--

Pipe and pipe fittings_.--

Pipe, cast-iron

cast-iron, pressure

clay

concrete-_-

covering, molded, cork

$-$

Fabrication Institute

69

150

47
210

49
Page | Pipe, cast-iron-Continued.

Page fittingS_-_- 131

24 flanges and fittings

177 furnace -

169 gas, mechanical joints_-_-_-_--- 95

lead, standard _... 128

186 nipples, brass, copper, steel and

117 iron_-_._.

226 sewer, clay-_--_- 97

sewer, concrete.-_-

threads_-_-_-_-_-_-_-_-_-_-_-_-

vitrified, sewer, clay.---.-----water, cast-iron----------
wrought-iron and wrought steel, sizes

Piping, house, gas power, specifications.-pressure, safety code_-_-_.--_-- 61,72

standards

systems, scheme for identiacation- 175

Pistols, testing -

ciatiasher Manufacturers Asso-

clation

lastering --_-_-_-_-_-_-_-_--- 39

gypsum _-_-_-_-_-_-_-_-_- 114

$\begin{array}{rr}\text { specifications } & 100 \\ \text { Plastics, cellulose_- } & \end{array}$

optical properties.--- 173

207

175

125

188

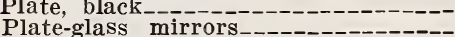

Plates, hot, gas steel _--_-_-_-_-_--_---_---- 45

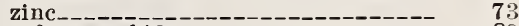

Platforms, skid.-- 89

Plow bolts__- 109

Plumbago crucibles--- 32

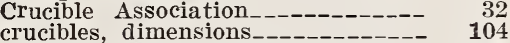

$\begin{array}{rr}\text { crucibles, dimensions } & 104 \\ \text { Plumbing code---_------- } & 63\end{array}$ equipment tests

fixtures, all-clay porcelain_____-_ 146

hospital_____ 38

vitreous china_-

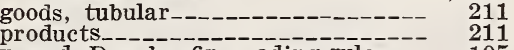

Plywood, Douglas fir, grading rules _-- 105

$\begin{array}{lr}\text { Pole-line hardware- } & 38 \\ \text { Poles, northern white cedar.-- } & 219\end{array}$ western red cedar.- 219

wood_-_-_-_-_-_-_-_-_ 73

Police record system

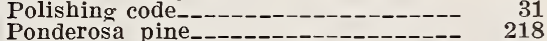

Porcelain, all-clay, plumbing fixtures_ $\quad 146$

Enamel Institute, Inc_-_-_-_-_- 187

$\begin{array}{lr}\text { Porch floors, concrete--- } & 189 \\ \text { Pork trolleys }\end{array}$

Pork trolleys---_-_-_- $\quad 47$

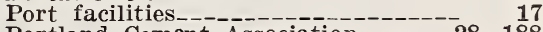

Portland Cement Association_----- 28, 188 $\begin{array}{lr}\text { cement concrete- } & 27\end{array}$

Posts, highway, sign, steel, zinccoated - - - western red cedar-- 219

Potato pulp, sweet, tentative definitions___. 79

Poultry Equipment Association-_.-- 190 items__.

Power-operated radio receiving appliances _-_-_-_-_-_-_-_-_-_-_ Power piping standards---
presses and foot and hand presses, safety code-_._transmission apparatus, mechanical, safety code

$\begin{array}{ll}\text { Practice standards.- } & 127 \\ & \end{array}$

Preferred voltage ratings

Preservations, wood treatment of wood (manual) Preservatives, wood.

Preserves, fruit, standards

Pressure piping, safety code-_treatment of Douglas fir.-treatment of oak ties and lumber--

vessels, laws and rules_._._._._-_- 
Prevention of accidents, railroad-

Printed or dyed silks, standarō methods--
Printed or dyed silks, standard Printed or dyed silks, standard
methods_Printing forms

$$
\text { roller's }
$$

Procurement Division, U. S. Treasury

Department.--_--
Products, abrasive-coated.-clay_-_-_-_-_-_-_-_-_-_-_-_farm, grades and standards..rubber

Propane

Propeller unit heaters

Protection of industrial workers in foundries, safety code for Psychology

Psychrometric chart

Pulp wood

Pulverized fuel equipment.--

Pulverizers, test code-

Pumps, centrifugal

contractors reciprocating

rotaryturbine, deep-well well _.

Purchasing, industrial-principles and practices (book)

Purchasing policies and procedures (book) - Purchasing and stores department manual (AAR)

Putting shot

Pyroxylin coated fabrics.-sheets, rods, and tubes...-

\section{Q}

Quality labels for canned foods__._-_. mark of CRSI _. standards

Quartz-plate standardization.

\section{$\mathbf{R}$}

Racks, storage

Radiator brushes valves

Radiators, cast iron

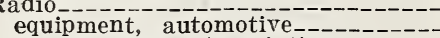
Manufacturers Association...noise, methods of measuring receivers________________-_- 122 receiving appliances, power-operated reception, coordination.-. wave propagation

Radiographic testing

Radiology -

Radiometry

Rags, woolen, -

Railroad cars, electrical equipment on -- Rails employees, physical standards.

Rail Steel Bar Association

Rail-steel concrete reinforcement bars -

Railway and Industrial Spring Asso-

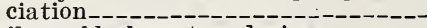

Railway block system devices engineering, manual of recommended practices for

Express Agency Fire Protection Association. materials, electric _-_-_-_-_-_-_-_

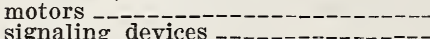
signaling devices _-
springs_-

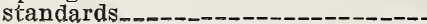

Page

237

13

97

181
193

193

119

165

172
63

207
Railway block system devices-Con. Tie Association_-_._track scales__-

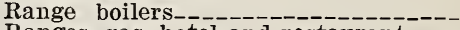
Ranges, gas, hotel and restaurant.-domestic

household electric, test specifications.

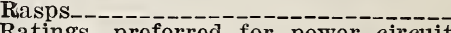
Ratings, preferred for power circuit
breakers

preferred voltage......

Rayons, dyed or printed, standard
methods methods - eady-mixed concrete-_-

Reagent chemicals_._-_._-

Reamers

Receivers, radio

Reciprocating pumps--

Recommended building code-----

tistics, standardization of methods. Records, railway

Record system, police---

Rectifiers, mercury arc

Red cedar lumber piling

Shingle Bureau

western

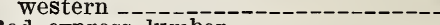
shingles lumber-_-_----------shingles ---

Redwood lumber

Refractories _. cupola__-_---_--_-_-_-_-_-- 58 malleable foundry Refractory material, studies_-_- 133

Refractory materials_-_-_-_-_-_- 58

Refrigerated trucks and buses_----- 63

Refrigerating equipment, commercial, rating of

machinery -

plants, corrosion, specifications.--

Refrigeration, mechanical, s a f e ty code -

plant test code.-.-

standards

Refrigerator coils ice compartments
Refrigerators, standards gas fuel

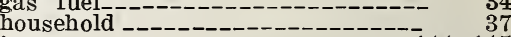
ice_-_._-_-_- 144,145 various kinds _. 98

Registers, sizes_-_-_-_-_-_-_-_--- 180

Regulations for fire apparatus__-_-- 151

Regulators, pressure, gas___-_-- 34

Reinforced concrete-_-_-

Reinforcing bars, plain and deformed- 100 steel, concrete-_- 99

Relief, valves, gas --- -

Requirements for building codes_---- $\quad 93$ $\begin{array}{rr}\text { gas approval } & 34 \\ \text { Rearch, building materials_------ } & 230\end{array}$

$\begin{array}{cc}\text { Research, building materials_------- } & 230 \\ \text { engineering and industrial_------- } & \mathbf{1 7 2}\end{array}$ welding -

Researches, fundamental, in the basic sciences -

Reservoirs

Residence lighting-----lighting fixtures------

Resin, acrylic denture-_.

Resins handbook, national

Resistance Welder Manufacturers Association _-__-__-_-_-_-_-_-_ 192

Restaurant chinaware

guest checks-_-

Retaining walls, concrete--.- 189

Revolvers, testing _..- 203

Rice --_-_-_-__-_-_-__-_- 79 milled

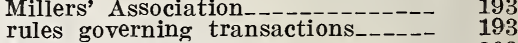

$\begin{array}{ll}\text { Rifles, sporting, testing---- } & \\ \text { Rims, tires and tubes, standardization- } & 210\end{array}$ 
Page

102

Ring buoys, cork

Riserses - hardwood_-

Rivet, bolt, and nut proportions steel, structural _._-_-__-__-_

RMA handbook of standards and en-

gineering information

Road-building equipment construction, specifications graders, tire and rim equipment.-materials, asphaltic, liquid_._-_._--

Roadway, concrete

Roasting ovens, gas

Rock dusting coal mines to prevent coal dust explosions, recommended practice

Rockefeller Foundation

Rods and wire, diameter tolerances

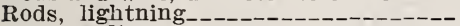
pyroxylin

welding, gas_-_-_-_-_-_-_-_-_ wire

Rolled gold articles, marking

Rolled Gold Platers' Association

Rolled threads for screw shells of electric socket and lamp bases

Roller bearings chains, transmission

Rollers, printing--

年gravel and slide materials

materials, bituminous products, asphalt

Roof insulating board.---

Rope, wire for mines

Ropes

grades

Rotary pumps

Rubber, denture

gloves, surgeon's

goods, mechanical

industry

insulated parkway cables.-...insulated power cables Manufacturers Association. Inc-mill machinery, safety code products scrap classification. sheeting

tires

Rubberized materials

Rural Electrification Administration-8 Rural lighting

Rutgers University --------------

Rye, standard quality

\section{S}

SAE Handbook $---\overline{\text { Manufacturers }}$ National Association----

oper fire insulated

Safes, fire insulated

Safety code(s)

brakes and brake testing

coal mine transportation

compressed air machinery construction, care, and use of ladders.-

conveyors and conveying machinery

elevators, dumbwaiters and escalators

exhaust systems_-_-_._-_._-_._. 126

floor and wall openings, railings, and toe boards_.

forging and hot-metal stamping laundry machinery and operation 1 paratus mechanical refrigeration

paper and pulp mills

power presses and foot and hand presses _.....-.

115
Safety code(s)-Continued.

Page

prevention of dust explosions

rotection of industrial workers in

foundries_-_-_-_-_- 165

the use, care, and protection of

abrasive wheels___-___ 113,127

walkway surfaces.-_-_-_-_-_- 39, 175

window cleaning

59
188 Wood-working plants_-_-_-_-_ 127,156

18 construction industry---------- 175

210 equipment, industrial___-_-_-_ 119

76 Equipment Manufacturers Association, Inc___._._. 194

specifications and methods of test - 156

matches--- -

les for installing and

trical equipment in coal mines_--

Salt packages, sizes_-_-_-_-_-_--- 195

Producers Association-_- 195

Sand, glass_-_-_-_-_-_-_-_-_-_- 176

industrial

$\begin{array}{lr}\text { Sands, foundry, testing and grading-- } & 31 \\ \text { Sanitary Brass Institute } & 195\end{array}$

Cast Iron Enameled Ware Association

Institute of America--_--------- 196

ware, colored... 37

Sash, window, steel zinc-coated_-_-- $\quad 39$

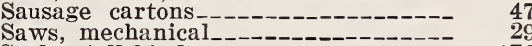

Scales (all kinds- 176

low temperature

Scheme for identification of piping systems _-_-_-_-_-_-_-_-_-_- 175

School buildings, construction-_-- 153 lighting, recommended practice_--- 118 supplies_-_-_-_-_-_-_-_-_-_-_- 176

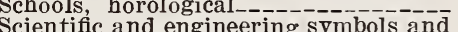
abbreviations. Apparatus Makers of America--- 26, 196

Scrap classification, standard_-_-_- 87

iron classification

iron and steel

rubber classification.-- 150

Rubber Institute..-_- 150

Screen testing of ores, methods_-_-- 43

Screens, wire diameters for mineral aggregate production._-_ 159, 176, 178

Screw fittings_-__-_-_-_-_-_-_-_-_ 131

thread gaging_-_-_-_-_-_-_ 61

threads, fire hose coupling --_---- 153

standards_._. 61

Screws_--_-_--_-_-_-_-_-_---_-- 214

machine-_-_-_-_-_-_-_-_-_--- 129, 214

wood--

Sealing tape-_- 113

Seal of acceptance (foods) - 47

approval, gas appliances_--_---- 34

Seamless Steel Tube Institute_-_---- 197

Secondary aluminum___-_- 15 Metal Institute

Seedlac_-_---_--_-_-_--_-_--_----- 22

Seed, testing

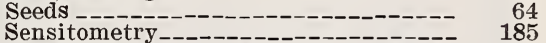

Sewage and water, standard methods of examination of

Sewer pipe, clay concrete-_-_-_-_-_-_-_-_-----

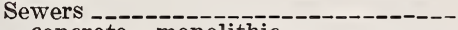
concrete, monolithic - and tool post
openings

Shapes, structural---------------- $\quad 45$

$\begin{array}{rr}\text { Sheet metalware specifications_------ } & 87 \\ \text { steel } & \end{array}$

Sheeting, rubber.--

Sheets, bed $\begin{array}{ll}\text { cork, for ring life buoys } & 37 \\ & \end{array}$ pyroxylin_--- 
Page

Shellac

bleached_-_-

orange

varnish

Shellish, methods of examination

Shells, loaded paper shot_-_-_- 174

Shingles

northern white cedar red cedar

red cypress

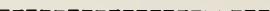

Shipbuilding -

Shipping

tags, paper dress, measurement

work, measurement laces, braided. safety, standards

Shops, railway

concrete

Shortening

Shot, putting

Shotguns, testing of

Shovels

Shrubs, standard

Sidewalks concrete

Sieves for testing purposes

Sifters, flour

Sign, advertising posts, highway, steel, zinc-coated --

Signal and switches, coal mines.

Signal rules, block and interlocking rules, standard code of (AAR) wires and cables

Signaling and lighting equipment, automotive

Signaling devices, railway. systems, automatic block

Signals, railway--

Signs, accident prevention, safety code -

Silicate cements products

Silk, raw color standards

Silks, dyed or printed, standard methods

Silo tile

Silos ----

Silver-plated tableware

Simplification_-

electric lamps for signal purposes sizes of rolled steel wheels for engine trucks

Sitka spruce lumber

Skid platforms

Skim milk, dry__-___-____-_

Slab zinc_-_-_-_-_-_-

Slack barrels

Slack barrel staves..-

Slag-

Slate -- structural

slide roofing

Sluice gates, specifications

Small tools and machine tool elements

Smokestacks

Soap-wrapper tests

Soaps_-

commercial, analysis standard formulas.

Social Science Research Council -

Society for the Promotion of Engineering Education

Society of Automotive Engineers

Motion Picture Engineers neers neers - Engineers

Soft pine lumber

175

173

229

144

19

149

149

27

37
232

87

87

218

89

73

77
77

777
177

178

178

214

167

168

53
228

26

141
127

200

12 ,
Softwood lumber and timber.

Page

Solids, combustible

Solutions, lime-sulfur Southern Cypress Manufacturers Association -- - - - - - - - - - -

Hardwood Producers, Inc--.--

Pine Association

Pine Inspection Bureau

Supply and Machinery Distributors

Association

Soybean

oil_- 179,182

Soybeans, methods of analysis _.._-_- 53

Space heaters, gas___-___-_-_-_ 34

oil burning

test code

Space, rating, standard method of

Special Tool, Die, \& Machine Shop Institute

Specification record (publication) ----

Specifications and codes-- - - - - Specifications for accident-prevention signs ----------clean bituminous coal

Federal, preparation

highway bridges (book)

Procurement Division

equipment (manual)

Spectrophotometry

Spelter specifications

Spice containers

Spirals, steel-reinforcing

Splines, side-bearing involute

Sponge trough sizes

Sponges, specification

Sporting Arms and Ammunition Manu-

facturers' Institute

Sports, athletic

Springs, railway and industrial---steel__-_-_-_-_-_-_--__-_-_--

Sprinklers, automatic and open

Sprinkler systems, automatic Sprockets

1.20
74

140

202

64
234

175

43
238

18

237

38

186

73
64

100

168

59
26

203

16

191

6, 151

pruce, eastern_____________-_ 18

Englemann_-_-_-_-_-_-_-_-_--

sitka -

Spur gear._-_-_-_-_-_-_-_-_-_

Stains, biological_-_--_-_-_-_-_--

Stair treads, hardwood_-_-

Standard barrel for fruits and vegetables

code of block signal rules and interlocking rules (AAR) operating rules (AĀR)

color card of America----------Container Manufacturers Associaoading platforms manual on pipe welding welds

rating code for stoves, coal refrigeration

specifacations for highway materials and methods of sampling and testing (book) interior marble work (publication)

symbols for electrical equipment in buildings_-_-_-_---_-----Standardization

biological products_---_-_---_-carbonated beverage bottles_._-_-commercial

consumer goods

containers

glass containers.--

lime barrels methods of recording and compiling accident statistics paper tires, tubes, and rims 
Standardization-Continued.

welding procedures for pipe welding wheel design tandards, American_.._.......... Anerican lumber

(ASTM)

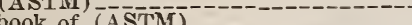
commercial

commercial-----Council (ASA) drawings and drafting-room practice

electrical --

medical shoes

Standpipes

State fertilizer control laws

ures

Stationery paper and items

Staves, barrel, slack and tight concrete

Steam boilers curing, high pressure-_-_--.--heating boilers, stoker-fired code for testing

jet ejector standards

Steam in district heating

Steel

alloy - - articles, zinc-coated._Barrel Manufacturers Council bars, carbon bars, marking

bars, rail

led strip.--.--

construction

construction, manual containers

drums

flat rolled d--

floor gratings

Founders' Society of America...-

Heating Boiler Institute

Joist construction, fire resistauce ratings for

Joist Institute-

Kitchen Cabinet Institute

Package Manufacturers Institute--Pipe nipples

plates

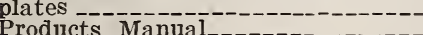

reinforcing, concrete________-_ reinforcing spirals

seamless, tubular products... strip, hot-rolled

structural

structural rivet---0-

Steel and iron scrap

Steel for bridges

buildings

Steels standar

Stockings_._-

Stoddard solvent

Stoker equipment, coal-burning Manufacturers

Stokers, commercial, test code for mechanical

Stone, cast

natural builing

Stoppers, cork-_-

Stoppers, cork racks

Store stocks, standardization

Stoves, coal, standard rating code---cook

laundry, gas

Stratigraphy

Straw, grades

(1)

Strawberries, grades and standards --

Stream tables fire

Street and highway lighting

Street pavement, concrete for

Strip steel, cold-rolled.

hot-rolled

Strip, zine

$201072^{\circ}-41-19$
Page

115

11

10

233

201

42

49
156

156

162

156

187

20

204

142

185
204

204

61

205

204

205

205

146
45

45

99

100

197
45

44

44

150
44
44

45

143

140

206

7

74
22
27

159

40

102

2, 89

87

120
34
34

173

165

75

153

188
45

45

73
Structural Clay Products Institute

Page

112 ,

Engineers' Society of New York_-- 100 insulating board______-___-_ 123 l'ivet steel_._.-.-- 44

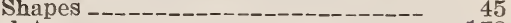

slate_-_-_-_-_-_-_-_-_-_-- 178

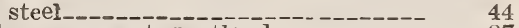

Stucco, cement, portland

Stumps, walnut_-- 67

Sugar

cane-1.- 64

pith, dried, tentative definitions_ 79

pine lumber_-_-_-_-_-_-_--- 218

Sulfated oils, analysis of -

Sulfur dioxide, liquid, method of analy-

sis - - - - - - -

Sun Glass Institute_-_-_-_-_-_-_-- 207

$\begin{array}{ll}\text { Superheaters }-1- & 22 \\ \text { Supplies, hospital } & \end{array}$

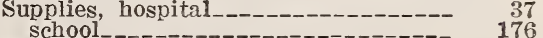

Surgeon's latex gloves_-_- 38

rubber gloves_-__-_- 38

Surgery, traumatic, standard for---- $\quad 26$

Surgical dressings, classification.---- $\quad 26$

$\begin{array}{rr}\text { Sizes--- } & 27 \\ \text { Surveys, fire, of American cities_---- } & 153\end{array}$

Sweeps, fire, of American cities_-_--- 152

Sweeps----_ch ties

Switches and signals, coal mines_-_- 52

Symbols and abbreviations, scientific and engineering

Synchronous motors for ammonia compressors

Tables, kitchen, porcelain enamel_--stream, fire-_Tableware, silver-plated -..$\begin{array}{rr}\text { Tucks - } & 38 \\ \text { cut }-- & \end{array}$

Tag Manufacturers Institute-_-_-- 207

Tags, paper and cloth 207

sizes_-_- 207

Tallow_-

Tamarack lumber. 183

Tank cars____. 84 chlorine-_-_. 96

Tanks_. 38 dip_- 164 hot-water - 182 storage, welding water, steel

Tank-stock lumber Tanners' Council of America_-_-_-- 46, 207 Tape, friction and insulating.-_-_- 80

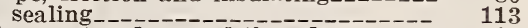

Taps, cut and ground threads_._- 167

Taps and dies_-_._-_._- 135

Tarpaulins _-_-_-_-_-_-_-_-_-_- $\mathbf{1 5 4}$

Technical Association of the Pulp and

Paper Industry_-_-_-_._-_-_ 207

Telegraph equipment specifications, railroad

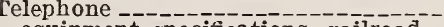
equipment specifications, railroad.-

Television_--_facsimile

Tent, definition of terms

Tents, cotton-fabric_.__. 154

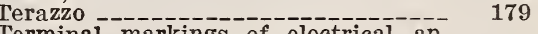

Terminal markings of electrical ap-

paratus - - - - -

Terminals, locomotive, railway _._. 57

Terminology, retail trade_._._.- 174

Terneplate

Terraces, concrete-_-_-_-_-_-n- 189

Terry towels

$\begin{array}{lr}\text { Test code, refrigeration plant_--- } & 63 \\ \end{array}$

Testing machine, brake-lining 
Testing of seed.

vegetable oils

Tests, fire engine

fire, of building construction. plumbing equipment_-_-_-_-__-_-_ soap wrapper

Textile Color Card Association of the United States, Inc

Foundation

$--1-0-1$

Textiles_-_-_-_colored, fastness of cotton, hospital and institutional_-

Thermal conductivity of insulating materials

insulation

Thermostats, gas range, water and space heater

testing code

Thicknesses for bag, case, and strap leather

box board-

Third International Congress of Refrigeration....

Thread, cotton-

Threads, gro pipe Throwsters Research Institute-_-

Thrust bearings

Tidewater red cypress lumber._-_._-_

Tierces, pickled meats_____-_._-_lard.

Ties and lumber, oak, pressure treatment____

Ties, cross and switchrailway

Tile and brick, glazed.----

Tile, clay, structural____-___drain Manufacturers Association, Inc

Tills, wooden

Timber

Timber and lumber, softwood.--

Timken Roller Bearing Company.--

Tin cans, sizes metalware specifications plate--

Tire and Rim Association

Tire chains, welded. tube sizes

Tires, airplane.-. locomotive

rubber - - - solid, truck and trailer solid, truck and trailer truck

Tires, tubes, and rims, standardization tion ---------

Tolerances, diameter of wire and rod forgings gear, inspection round seamless tubes_._-_._._._.

Tool \& Die Institute

Tool holder shanks and tool post openings_.

Tools and gages small small, and machine tool elements_--

Towels, terry_-___-___-_._.

Track-_-_-_-_-_-_-_-_-_-_-_manganese scales, railway̆ systems, overhead

Tracks, coal mine_._._._._._._.

Tractor testing and rating code..--

Tractors, agricultural agricultural, tire and rim equipment industrial, tire and rim equipment industrial, electric

Trade and Professional associations of the United States.....
Page

Traffic control devices, uniform, manual

Traffic ordinances_. signs standards - - -

$\begin{array}{cc}\text { Trailer standards_- } & 198 \\ \text { tires, solid } & \end{array}$ tires, solid

Transformers, distribution, standard-- $\quad 161$

Transformers for resistance welding --_- 192

Transit industry.

Transportation, coal mine, safety code for - - - Traumatic surgery, standard for Trees, deciduous, standard height..-fruits, grades

Trestles, wood

Trim, hardwood interior

Trimmers, wall tile_._. Trolley wire--

Trolleys, beef and pork

Trucking industry, standard code for use in -

Truck mixers, operation.--

Trucks, hand industrial, electric lift - refrigerated

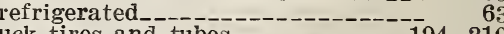

T-slots, their bolts, nuts, tongues, and cutters Tuberculosis, classification.-.-

Tubes, airplane_. pyroxylin -

round seamless, tolerances.-. sizes of tin, lead, and aluminum tires, and rims, standardization.--tire, sizes _..._. vacuum

Tubing and fittings, gas appliance--- $\quad 34$ welded steel

Tubs, wooden

$\begin{array}{ll}\text { Tubular Plumbing Goods Institute---- } & 211\end{array}$ $\begin{array}{ll}\text { products, seamless, steel } & \\ \end{array}$

$\begin{array}{lr}\text { Tungsten blades, standard sizes_----- } & 114 \\ \text { Turnbucleles.-- } & 38\end{array}$

Twine _- 47 hard fiber-- 101

Twines, mixed, classification Twisted Jute Packing and Oakum Institute

\section{U}

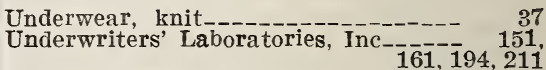

Uniform traficic control devices, manual 20
vehicle code. vehicle code
Union elbows

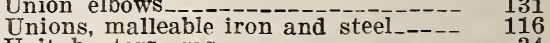

Unit heaters, gas _._._. 34 propeller

United Roofing Contractors Associa-

tion

United States Army color card_... 209 $\begin{array}{ll}\text { Bureau of Mines } & 122 \\ \text { Cap Screw Service Bureau- } & \end{array}$ Department of Agriculture.-- $4 \overline{0}, 142,150$ Department of Commerce......- 45, 156 Department of Labor._-_._- 156 Food \& Drug Administration.--- 90 Golf Association__._._... 214 $\begin{array}{lr}\text { Housing Authority } & 161 \\ \text { Independent Telephone Association_- } & 208,\end{array}$ $\begin{array}{lr}\text { Machine Screw Service Bureau___- } & 214 \\ 214\end{array}$ Maritine Commission__._._._. 18, 30 Pharmacopeial Convention_- 215 Pharmacopoeia Quartermaster Corps Shellac Importers Association_.-_- $\quad 215$ Wood Screw Service Bureau 
Page | Washers-Continued. Page

United Typothetae of America

University of Chattanooga_._._._. Chicago

Delaware

Illinois

Michigan

Pennsylvania

Upholstery leather

Useful Drugs (book)

\section{V}

Vaccines, standardization

Vacuum Cleaner Manufacturers Association.

cooling section standards tubes

Valves, gas-burner.-marine and radiator

refrigerant expansion.-relief, gas -

specifications _-_-_._-_._-_-_-_wrought-iron and wrought-steel, sizes_-

Varnish

brushes shellac

specifications

Varnished cambric insulated cables_--

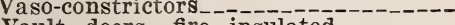

Vault doors, fire insulated._.-_-_-vaults, burial, concrete-_ storage.--

V-belts

Vegetable oils-

Vehicle code

Veneer Association. face and commercial___-_._package industry packages

veneers, hardwood lumber. walnut

Ventilating systems

Ventilation codes

Vessel classification---

Vessels, pressure, laws and rules...unfired pressure, code

Veterans' Administration

Veterinary medical remedies_...--

Vines, standard types_...-..--

Visual acuity standards_...

Vitamin preparations

Vitreous china plumbing fixtures Plumbing Fixtures Association $-195,217$

Vitrified china_. 67 China Manufacturers Association.clay sewer pipe-_._-_._-_._._. paving brickpolley ball

Voltage insulation, high, coordination. ratings, preferred_._._._._._...

Vulcanite files......

\section{W}

Waists, boys

Walkway surfaces, safety code_-_- 39,175

Walks, concrete, specifications _-.--

Wall paneling, hardwood_..-_-_-- 67,165

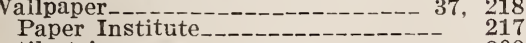
tile trimmers. 209

Walnut $\operatorname{logs}$ stumps

veneers-.-

Walnuts, shelled and unshelled.

War Department__._._._._._._- $32,38,40$

Warehouse forms

Warm-air furnace, testing code heating

heating system, yardstick for evaluation of a forced (booklet)

Washer sizes and tolerances..--

Washers brass and steel, sizes

30

216 Wheel design, standardization

Wheels, abrasive, safety code for the use, care, and protection_______ 113, 127 airplane buifing car, chilled.- 90 chamois - 29 engine trucks, rolled steel, simplififelt cation of sizes_._. grinding, dental lathe grinding, sizes_. steel

wrought steel

White fir lumber

White pine, Idaho

White sprue lumber, northern

180 Window brushes

cleaning, safety code-_. sash steel, zinc-coated

Window-glass mirrors________- 
Windows, metal steel, solid section, sizes.-. Wine Institute

standards

Wiping cloths

Wool, definitions_-_-_-_-_-_-_-_-_ Wire

Cloth Manufacturers Association.-diameter's for mineral aggregate production screens_._.$$
\text { fine }
$$

rods

rope for mines

trolley

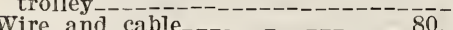

Wire and rods, diameter tolerances

Wires, signal

Wiring design interior, handbo--installations, standards

Wood bridges and trestles industries

poles

es ------1--

preservation

neme

preservative treatment manuai

pulp

screws

Wooden boxes cases
Page

137

137

219

219

196

150
45

219

76,178

110

45

52

88,161

101

128

106

160

57

61

73

160
73
88

216

47,180

180
Page

Woodenware___-__-_-_-_- 47

Wood-working plants, safety code-- 127, 156

Wool, dyed, standard methods

ool and part-wool blankets___._.. 150

fabrics_... 150

Woolen rags classification

Wool standards_-_. 150

Woven dress fabrics

elastic fabrics

Wrappers, bread

Vraps, apple

Wrestling - -

Wrought gold alloys

\section{$\mathrm{Y}$}

Yards, railway

Yardstick for evaluation of a forced warm air heating system (booklet) Yeast

\section{$\mathrm{Z}$}

Zinc-coated, products, hot-dipped-_--steel and iron

Zinc coating

industry -

phosphate cements 


